

\section{Integrated strategy for the assessment of kidney toxicity: the case of aristolochic acids}

Rozaini binti Abdullah 


\section{Thesis committee}

\section{Promotor}

Prof. Dr I.M.C.M. Rietjens

Professor of Toxicology

Wageningen University \& Research

Co-promotors

Dr A. Punt

Food Toxicologist

RIKILT- Wageningen University \& Research

Dr S. Wesseling

Research assistant, Sub-department of Toxicology

Wageningen University \& Research

Dr J. Louisse

Assistant professor, Sub-department of Toxicology

Wageningen University \& Research

\section{Other members}

Prof. Dr S.C. de Vries, Wageningen University \& Research

Prof. Dr B.J Blaauboer, Utrecht University

Dr A.A.C.M Peijnenburg, RIKILT - Wageningen University \& Research

Dr R.A. Ghazali, The National University of Malaysia, Kuala Lumpur

This research was conducted under auspices of the Graduate School VLAG (Advanced studies in Food Technology, Agrobiotechnology, Nutrition and Health Sciences) 


\title{
Integrated strategy for the assessment of kidney toxicity: the case of aristolochic acids
}

\author{
Rozaini binti Abdullah
}

Thesis

submitted in fulfilment of the requirement for the degree of doctor

at Wageningen University

by the authority of the Rector of Magnificus,

Prof. Dr A.P.J. Mol,

in the presence of the

Thesis Committee appointed by the Academic Board

to be defended in public

on Friday 24 March 2017

at 1.30 p.m. in the Aula. 
Rozaini binti Abdullah

Integrated strategy for the assessment of kidney toxicity: the case of aristolochic acids, 208 pages.

$\mathrm{PhD}$ thesis, Wageningen University, Wageningen, the Netherlands (2017)

With references, with summary in English

ISBN 978-94-6343-080-7

DOI http://dx.doi.org/10.18174/403924 


\section{TABLE OF CONTENTS}

$\begin{array}{lll}\text { Chapter } 1 & \text { General introduction } & 7\end{array}$

Chapter 2 Predicting points of departure for risk assessment based on in vitro

cytotoxicity data and physiologically based kinetic (PBK) modeling: the case of kidney toxicity induced by aristolochic acid I

Chapter 3 Defining in vivo dose-response curves for kidney DNA adduct formation of aristolochic acid I in rat, mouse and human by an in vitro and physiologically based kinetic modeling approach

Chapter 4 Prediction of in vivo DNA adduct formation upon exposure to 119 aristolochic acid I and II using a combined in vitro-physiologically based kinetic modeling approach

Chapter 5 Risk assessment of plant food supplements and other herbal products containing aristolochic acids using the Margin of Exposure (MOE) approach

Chapter 6 General discussion and future perspectives

Chapter $7 \quad$ Summary

Appendices Acknowledgements 202

Curriculum Vitae

List of Publications 206

Overview of Completed Training Activities 207 



\section{CHAPTER}

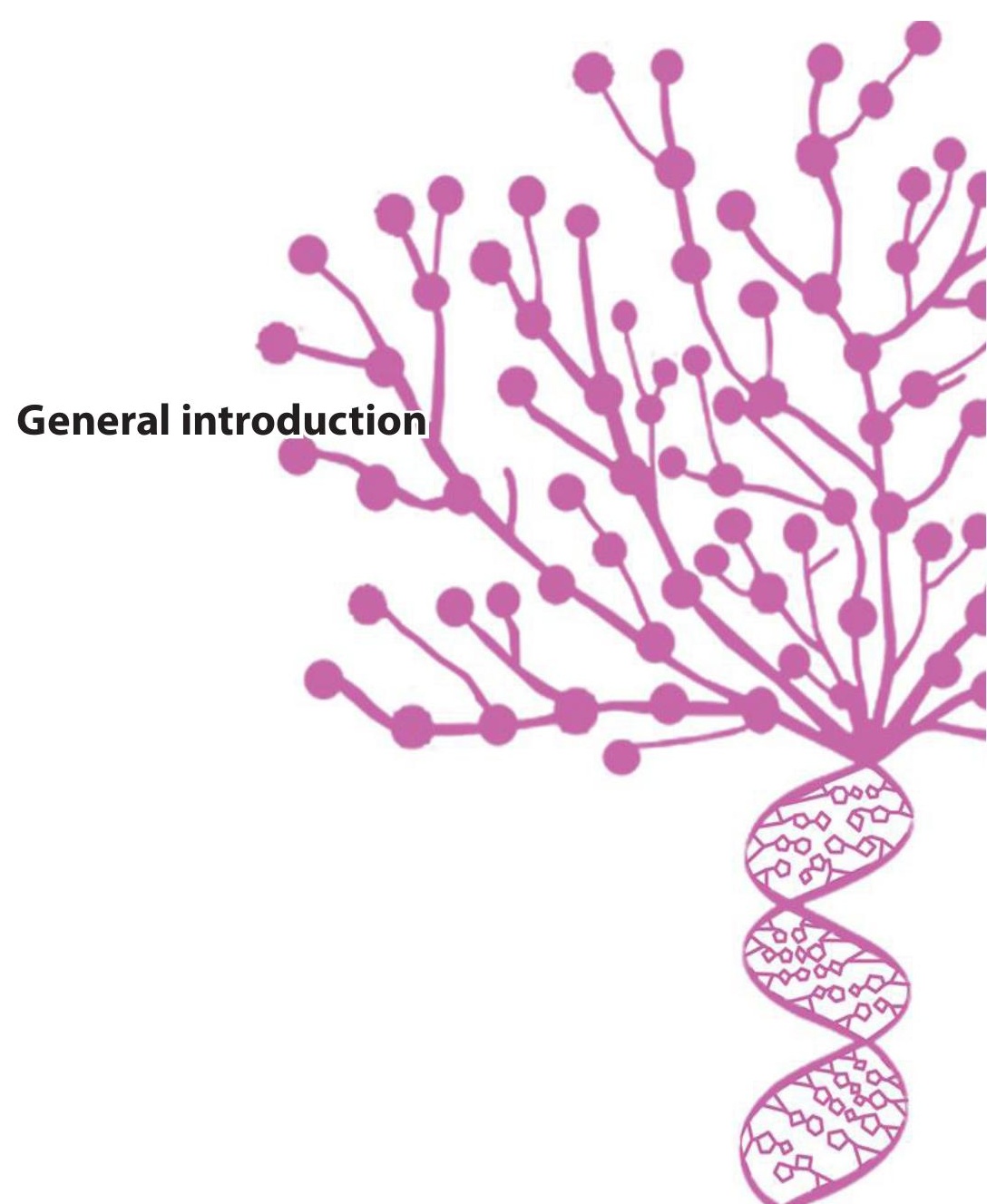




\subsection{THE MODEL COMPOUNDS OF THE PRESENT THESIS:}

\section{ARISTOLOCHIC ACIDS}

The present thesis focusses on the development of a non-animal based approach to predict in vivo kidney toxicity using aristolochic acids (AAs) as model compounds. AAs are important constituents of all Aristolochia species that have been consumed by humans as alternative medicine for more than 2,500 years [1] to treat arthritis, gout, rheumatism and snake bites [2, 3]. AAs are nitrophenanthrene carboxylic acids and the most important congeners are 8-methoxy-6-nitrophenanthro-(3,4-d)-1,3dioxolo-5-carboxylic acid (AAl) and its 8-demethoxylated form (AAll) [4] which differ only in the presence or absence of a methoxy group as shown in Figure 1.1. The amount of AAs present in plants varies depending on the species, season, geographical location and other factors [5]. However, AAI is generally the major component in plant extracts containing AAs [6, 7].

Based on the evidence from epidemiological and experimental animal data, the International Agency for Research on Cancer (IARC) concluded that herbal remedies containing plant species of the genus Aristolochia are carcinogenic in humans and classified these preparations as group 1 carcinogens [8]. Furthermore, AAs are also listed among the most potent 2\% of known carcinogens $[8,9]$.<smiles>COc1cccc2c1cc([N+](=O)[O-])c1c(C(=O)O)cc3c(c12)OCO3</smiles>

aristolochic acid I (AAI)<smiles></smiles>

aristolochic acid II (AAII)

Figure 1.1 Structural formulas of aristolochic acid I (AAI) and aristolochic acid II (AAII).

\subsubsection{Incidents and epidemiological data on aristolochic acids}

As herbal medicine, the ancient Greek used Aristolochia plants to stimulate the process of childbirth and to prevent infections after giving birth [10]. Before 1982, AA-containing preparations were used in pharmaceutical preparations in Germany because of their anti-inflammatory properties [3]. Aristolochia species have also been used in treatment of bites and poisonings, as therapy for gastrointestinal problems and as general health care preparations [10]. However, products containing Page $\mid 8$ 
AAs have been withdrawn from the market in Germany and many other countries [3] after AAs were identified to be carcinogenic in rats in $1982[11,12]$. The risks of exposure to AAs became even more evident in the 1990s when more than 1800 Belgian women were accidently exposed to AAs via the use of weight loss pills [13]. More than 100 of these young women developed chronic renal failure and several of them developed renal and bladder cancer $[13,14]$. These women were exposed to Aristolochia fangchi (containing AAs: $0.65 \pm 0.56 \mathrm{mg} / \mathrm{g}$ of powder) instead of Stephaniae tetrandra because for both herbs the same Chinese nomenclature is used: Fang Ji [13, 14]. AAs have also been associated with chronic progressive renal diseases such as Chinese Herb Nephropathy and Balkan Endemic Nephropathy that became later known as Aristolochic Acid Nephropathy (AAN) [1]. AAN within the Balkan resulted from exposure to flour which was produced from wheat that had been contaminated with seeds of Aristolochia clematitis [15].

\subsubsection{ADME (absorption, distribution, metabolism and excretion)}

To become genotoxic and carcinogenic, AAs need to be metabolized. The principal metabolic pathways for AAs have been established based on studies in rats, mice and humans [16]. Figure 1.2 presents an overview of AA metabolism. AAI is metabolized by oxidative and reductive pathways while AAll is only metabolized by the reductive pathway [17]. Under aerobic conditions, AAI is O-demethylated by cytochrome P450 (CYP) 1A1/2 to a less toxic metabolite, aristolochic acid la (AAla) $[18,19]$. However, under anaerobic conditions, the nitro group is reduced to form aristolactam I, while AAll, which lacks the O-methoxy group, is converted to aristolactam II [3,20]. This reaction is catalyzed by both cytosolic and microsomal enzymes, with $\mathrm{NAD}(\mathrm{P}) \mathrm{H}$ :quinone oxidoreductase (NQO1) being most efficient in nitroreduction $[7,21]$.

The O-demethylation pathway is considered a detoxification reaction to form AAla as a major metabolite which will undergo subsequent conjugation reactions followed by excretion from the body via urine and feces $[16,18,22]$. Nitroreduction is related to bioactivation of AAI and AAll to DNA reactive intermediates that have been suggested to be the linked to the carcinogenicity of these compounds [23-25]. The DNA adducts formed were reported to be 7-(deoxyadenosin- $\left.N^{6}-\mathrm{yl}\right)$ aristolactam I or II (dA-AAI or dA-AAII) and 7-(deoxyguanosin- $N^{2}$-yl)aristolactam I or II (dG-AAl or dGAAII) $[3,22,23,26,27]$ (Figure 1.3). dA-AAl was shown to be the most persistent adduct in the target tissue, i.e. the kidney $[3,28]$.

Although AAs can be bioactivated in other organs such as liver, the kidney has been 
shown to be the major target organ for AA-induced toxicity, including AA-DNA adduct formation and tumor induction [29]. This tissue-specific toxicity has been suggested to be due to the fact that the capacity of the DNA repair processes in the kidney is lower than in other organs [25] and/or to the ability of the proximal tubular cells to take up and concentrate AAs and their metabolites, making the kidney more susceptible to AA-induced toxicity [29].

The conjugation of AAs has not been extensively studied so far, although AA metabolites have been found in the urine and feces in conjugated form either as glucuronides, sulfate or acetate esters $[16,19,30]$. In rats, about $83 \%$ from a total dose of AAl is excreted via urine or feces during 72 hours after a single oral exposure but only $14 \%$ from an equivalent total dose of AAll is excreted via urine or feces [16], which may indicate that AAll circulates longer in the body than AAI. 


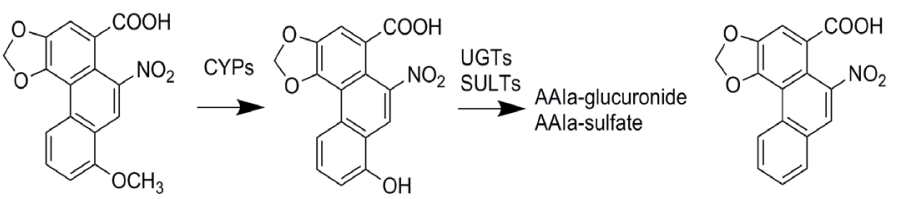

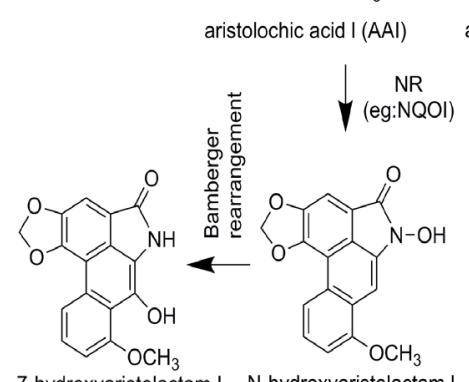

7-hydroxyaristolactam I N-hydroxyaristolactam I

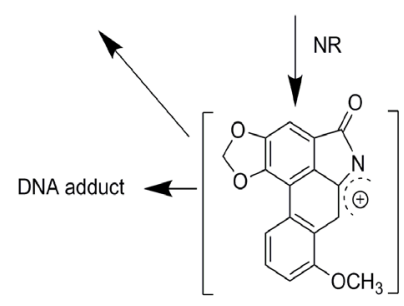

cyclic nitrenium ion<smiles></smiles>

Aristolactam I

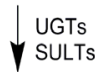

Aristolactam I-glucuronide Aristolactam I-sulfate aristolochic acid la (AAla)

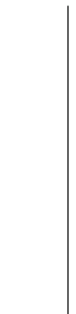<smiles>O=C1Nc2cc3c(O)cccc3c3c4c(cc1c23)OCO4</smiles>

Aristolactam la

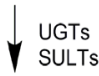

Aristolactam la-glucuronide Aristolactam la-sulfate

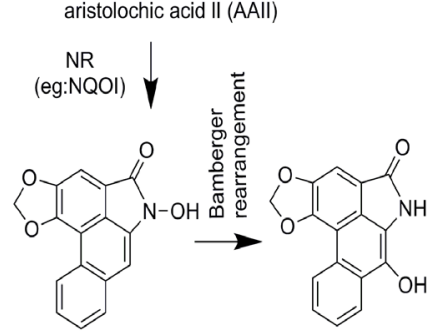

N-hydroxyaristolactam I| 7-hydroxyaristolactam II

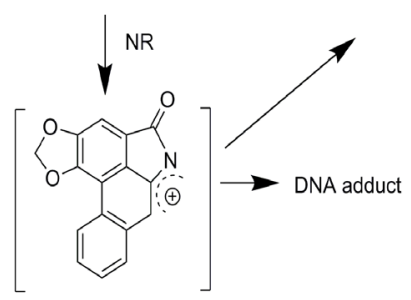

cyclic nitrenium ion

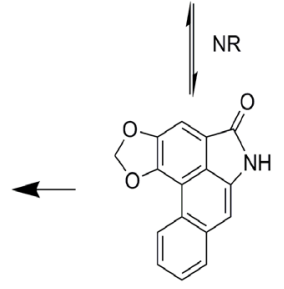

Aristolactam II

$\downarrow$ UGTS

Aristolactam II-glucuronide

Figure 1.2 Metabolic pathways for bioactivation and detoxification of AAs. NR = nitroreduction, $\mathrm{NQOI}=\mathrm{NAD}(\mathrm{P}) \mathrm{H}$ :quinone oxidoreductase, $\mathrm{CYPs}=$ cytochromes $\mathrm{P} 450, \mathrm{UGTs}=$ uridine $5^{\prime}$-diphosphoglucuronosyltransferases, SULTs = sulfotransferases [based on 31, 32-34]. 


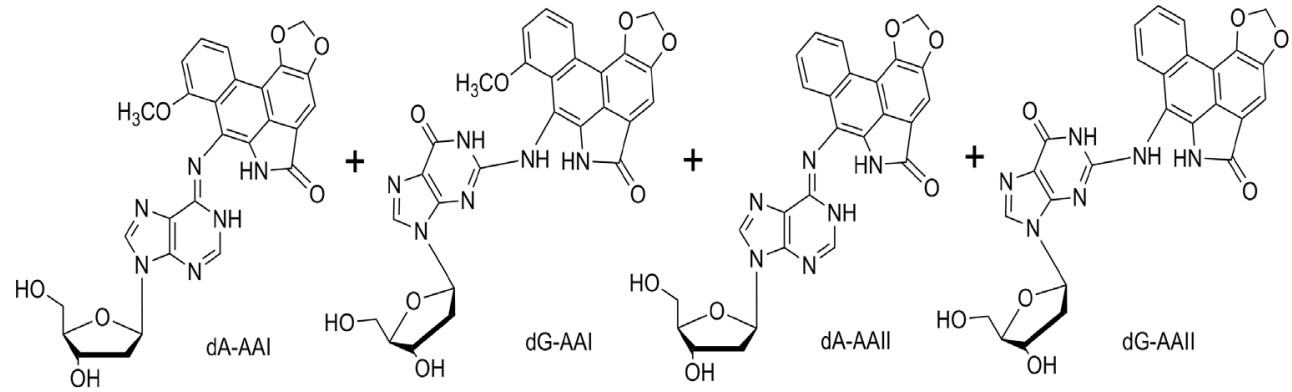

Figure 1.3 Structure of AA DNA adducts; 7-(deoxyadenosin- $N^{6}$-yl)aristolactam I (dA-AAl), 7-(deoxyguanosin- $N^{2}$-yl)aristolactam I (dG-AAI), 7-(deoxyadenosin- $N^{6}$-yl)aristolactam II (dA-AAII) and 7-(deoxyguanosin- $N^{2}$-yl)aristolactam II (dG-AAII) [based on 3, 34].

\subsection{TOXICITY OF ARISTOLOCHIC ACIDS}

\subsubsection{Nephrotoxicity}

The kidney has been shown to be the principal target organ for AA toxicity [35, 36]. The acute toxicity of AAs was first established in rats and mice by Mengs (1987) [36]. Oral and intravenous administration of AAs at high doses led to death due to acute renal failure within 15 days. The predominant feature seen in the animals was severe necrosis of the renal tubules [36]. The blood urea nitrogen (BUN) and serum creatinine concentration are commonly used markers for the estimation of renal function. Upon exposure of rats [35, 37-39] or mice [40-44] to either AAI or to a mixture of AAs, the levels of BUN and serum creatinine increased significantly, reflecting AA-induced kidney toxicity. AAs have also been shown to cause acute hepatotoxicity, however the dose at which AAs cause acute kidney toxicity is much lower than the dose causing acute hepatotoxicity [45].

\subsubsection{Genotoxicity and mutagenicity}

AAs have been shown to be genotoxic mutagens in both in vitro and in vivo assays [3]. AAs are able to induce reverse mutation in Salmonella typhimurium strains TA100 and TA1537 exposed in the absence or presence of a metabolic activation system (S9). However, when nitroreductase deficient strains of bacteria (TA100 NR) were exposed to AAs the compounds tested negative for mutagenic activities indicating that nitroreduction is a crucial step for the bioactivation of AAs to their ultimate mutagenic metabolite(s) [46]. Mutagenicity of AAs also depends on the oxygen tension as under 
low oxygen tension AAI is 19 times more mutagenic than AAll while under standard culture conditions, AAl is only 4 times more mutagenic than AAll [47]. In vivo studies also showed that AAs are both mutagenic and clastogenic inducing both gene mutations and chromosomal aberrations $[48,49]$. It has been found that the mutational frequency in the target tissues (kidney, bladder and forestomach) is significantly higher in AA-exposed lambda/lacZ transgenic mice containing the lacZ gene as a reporter gene for mutations [50] than in the control group and the sequence analysis revealed that AAs induced mainly A:T to T:A transversions [48] in the $p 53$ tumor suppressor gene. Such mutations were also observed in the upper urinary malignancies in Balkan Endemic Nephropathy patients exposed to AAs [51, 52].

A powerful tool for elucidating mechanisms that may underlie chemical-induced carcinogenicity is to characterize and quantify DNA adduct formation, as DNA adducts in humans can serve as an early indicator for cancer risk [53]. Although DNA adducts are generally considered a biomarker of exposure $[54,55]$ rather than a biomarker of effect, it is also well recognized that increased levels of DNA adduct formation reflect a risk factor for cancer development. Both AAI and AAll form DNA adducts in vitro in different cell lines [56-59] and in in vitro incubations using rat liver S9 mix [25], or rat and human liver and kidney fractions (cytosol and microsomes) incubated with calf thymus DNA [7]. DNA adduct formation has also been observed in vivo in rats $[23,29,60]$, mice $[20,32,61]$ and humans $[28,62]$ when exposed to AAs. A frequently used method for detection of AA-DNA adducts is by ${ }^{32}$ P-postlabeling $[20,23,29,62]$. However, this technique does not provide information on the structure of the adducts and may lead to underestimation of the adduct levels due to differences in hydrolysis and labeling efficiencies of normal and adducted nucleotides [63, 64]. Thus, in the present thesis DNA adducts of AAs were identified and quantified using liquid chromatography coupled with electro spray ionization mass spectrometry (LC-ESI-MS/MS). By using this technique, more precise outcomes are obtained $[63,65]$ and the possible underestimation of DNA adduct formation as observed for the ${ }^{32} \mathrm{P}$-postlabeling method is no longer an issue.

\subsubsection{Carcinogenicity}

The carcinogenic properties of AAs are well documented in both humans (see 1.1.1; Incidents and epidemiological data on aristolochic acids) and experimental animals. The carcinogenic properties of AAs were first discovered by Mengs et al. (1982) [11] in studies in which male and female rats that were daily exposed to AAs by gavage at dose levels of $0,0.1,1$ and $10 \mathrm{mg} / \mathrm{kg}$ bw/day showed 
an increase in kidney tumor formation in a dose- and time-dependent manner. Mengs (1988) [66] further studied the tumor formation in mice that were daily exposed to AAs by gavage at dose level of $5 \mathrm{mg} / \mathrm{kg}$ bw/day showing the formation of kidney adenomas within 3 weeks of exposure. Schmeiser et al. (1990) [67] found that not only mixtures of AAs are carcinogenic but that also AAI alone can induce tumors in rats. In contrast, data on tumor induction upon exposure to AAll alone have not been documented.

\subsection{REGULATORY STATUS OF ARISTOLOCHIC ACIDS}

After the Belgian incident, the European Agency for the Evaluation of Medicinal Products issued a position paper in October 2000, warning the European Union Member States 'to take steps to ensure that the public is protected from exposure to aristolochic acids arising from the deliberate use of Aristolochia species or as a result of confusion with other botanical ingredients' [68]. Risk management actions have been taken by the authorities of most EU Member States to prohibit the use of Aristolochia sp. especially in herbal medicine and cosmetic products. The sale of AAcontaining botanical products was significantly limited and also prohibited since 2000 in several other countries such as the USA, Australia, Canada, New Zealand and in many Asian countries (e.g. Japan) $[29,69]$. However, in China not all products containing AAs are banned, for example, Fructus Aristolochiae can be used under prescription of Chinese medicine practitioners [70].

The Belgian incident emphasized the problems related to AAs and raised the question about the safety of plant food supplements (PFS), initiating risk management actions. However, it must be emphasized that the carcinogenic effects of AAs were already known [11, 12] before the Belgian incident. Indeed, the lack of effective surveillance systems for PFS [70] has been the primary cause for the Belgian incident. Despite all the warnings and the regulation, products containing AAs are still found on the market after 2001, for example in traditional medicinal products [69, 71-77] and in products available via online markets $[78,79]$, and are thus available for human consumption. This indicates a need for safety evaluation of PFS that might contain AAs.

\subsection{RISK EVALUATIONS}

There are several approaches for assessing risks of chemicals in foods that are both genotoxic and carcinogenic. For chemicals that are avoidable, a zero tolerance approach is recommended which implies that these compounds cannot enter the market and cannot be used. For chemicals that Page | 14 
are unavoidable, the ALARA principle suggesting to reduce the exposure to as low as reasonably achievable (ALARA) was introduced. This approach provides a qualitative approach to the risk but does not take into account the human exposure $[80,81]$. The threshold of toxicological concern (TTC) approach is useful for chemicals that do not have carcinogenicity data to define the doseresponse relationship. The risk is considered negligible if the exposure is less than $0.15 \mu \mathrm{g} / \mathrm{person}$ per day for less potent carcinogens but it is not applicable to potent carcinogens that belong to one of the excluded chemical categories, such as aflatoxin-like compounds and $\mathrm{N}$-nitroso compounds [80-83].

Another common approach to assess the risks of chemicals that are genotoxic and carcinogenic is by deriving a virtual safe dose (VSD) by extrapolating the animal carcinogenicity data obtained at high dose levels to low dose levels at which the additional lifetime cancer risk would be one in a million upon lifetime exposure. Based on this simple linear extrapolation, usually far outside the experimental dose, the VSD obtained is highly influenced by the shape of doseresponse curve and the model selected. Furthermore, the biological processes underlying cancer formation based on the selected model are unknown and interspecies differences are not taken into account when extrapolating the animal carcinogenicity data to the VSD for human [84]. Therefore, new approaches are needed to overcome these issues.

In order to harmonize the risk assessment of genotoxic carcinogens, the so-called margin of exposure (MOE) approach has been developed, using the ratio between a reference point derived from the dose-response data on tumor formation from an experimental or epidemiology study and the estimated human lifetime exposure [84]. By using this approach, the reference point (also called a point of departure (POD)) is no longer outside the experimental dose range. In order to derive the appropriate POD, the European Food Safety Authority (EFSA) agreed that a benchmark dose (BMD) approach is the most recommended approach [84, 85]. The BMD approach makes use of all the data points in the dose-response curve and better accommodates the uncertainties of fewer amounts of data $[80,84]$. Commonly, the $\mathrm{BMDL}_{10}$ (the lower confidence limit of the BMD causing $10 \%$ extra tumor incidence above background level) is chosen as a POD for calculating the MOE [84]. The MOE is calculated as the ratio between the $\mathrm{BMDL}_{10}$ and the estimated daily intake (EDI) for the relevant study population. EFSA considered that, when the MOE is more than 10,000 , the chemical is considered as a low priority for risk management actions [84]. The threshold value of 10,000 includes i) a factor 100 for interspecies differences and human variability in biokinetics and biodynamics thus dealing with some of the criticism on the VSD approach, ii) a factor 10 for interindividual 
uncertainties in cell cycle control and DNA repair, and iii) a factor 10 for the uncertainties arising from the fact that the used POD (e.g. $\mathrm{BMDL}_{10}$ ) is not equivalent to a no observed adverse effect level (NOAEL) and the effects can occur at lower dose $[80,84]$. The MOE is calculated based on lifetime exposure.

\subsection{PHYSIOLOGICALLY BASED KINETIC (PBK) MODELING-BASED REVERSE DOSIMETRY}

To define the POD in risk assessment using the MOE approach requires animal carcinogenicity data to define the $\mathrm{BMDL}_{10}$. Also evaluation of other toxicological endpoints requires in vivo dose-response data. Therefore, the development of a mode of action-based approach without the use of animal testing is of interest. A novel alternative testing strategy that can potentially be used in quantitative risk assessment without animal testing, consists of translation of in vitro concentration-response curves to in vivo dose-response curves using PBK modeling-based reverse dosimetry [86-89]. By using this integrated in vitro-in silico approach, in vivo dose effect levels and PODs can be defined based on the in vitro effect levels that are assumed to represent the tissue or blood concentrations that would cause toxicity and are translated to in vivo dose levels. Previously, it was shown that PBK modeling-based reverse dosimetry can be used to predict in vivo dose-response curves and PODs for developmental toxicity from results obtained in the in vitro differentiation assay of the embryonic stem cell test [88-90] and also to predict in vivo DNA adduct formation [91-93]. By using the same approach, the present thesis aimed to investigate whether PBK modeling-based reverse dosimetry can convert in vitro concentration response-curves for AA-induced kidney toxicity to in vivo dose response-curves for kidney toxicity, thereby including a novel target tissue and endpoint for evaluation by this alternative testing strategy.

The PBK modeling-based reverse dosimetry approach to predict in vivo dose-response curves and a POD for risk assessment consists of the following steps: (1) establishment of an in vitro concentration-response curve for a selected relevant endpoint using an adequate in vitro model, (2) development of a PBK model describing the in vivo kinetics of the parent compound and relevant metabolites in relevant tissues, (3) evaluation of the PBK model against available literature data, (4) translation of the in vitro concentration-response curve into an in vivo dose-response curve using PBK modeling-based reverse dosimetry, (5) BMD analysis on the predicted in vivo dose-response data to obtain a POD for risk assessment, and (6) evaluation of the predicted POD against available Page | 16 
literature data.

Step 1 involves the selection of an adequate in vitro model that can be used to determine the relevant in vitro concentration-response curves for the compound of interest. For the compounds studied in the present thesis, AAs, kidney toxicity and DNA adduct formation in selected kidney cells provided the models of choice. In the present thesis a selection was made for the LLC-PK1 cell line derived from pig proximal tubular cells. This LLC-PK1 cell line is routinely used to study nephrotoxic effects of chemicals in human because the cells exhibit many of the enzymatic and transport properties of the human proximal tubule cells $[94,95]$ which are the cells that represent the direct target of AAs [39]. The LLC-PK1 cell line also has been proven to be sensitive to AAI exposure [96] and was chosen in the present thesis to model the kidney toxicity and kidney DNA adduct formation of AAs. In addition to LLC-PK1 cells, cells from other kidney cell lines were used as well including the madin-darby canine kidney cell line (MDCK) and a rat proximal tubular cell line (NRK-52E). The comparison of the cytotoxicity of AAI in the LLC-PK1 cells to the AAl cytotoxicity in primary renal human cells and even to other cell types from other species described in the literature [96] reveals that the species differences in dynamics of AAI toxicity may be limited. Therefore, it was concluded that the LLC-PK1 cell line provides an adequate in vitro model for the present studies.

In step 2, PBK models are developed. A PBK model consists of mathematical equations describing the absorption, distribution, metabolism and excretion of a chemical in the body. These models simulate the relationship between the external exposure levels and the internal concentrations of a chemical over time [97]. In a PBK model, target tissues are represented by individual compartments (e.g. liver and kidney) and the non-target tissues are lumped together in either a slowly (e.g. muscle and skin) or a richly (e.g. brain and spleen) perfused tissue compartment. Each compartment has its own physiological and anatomical parameters (e.g. tissue volumes and blood flows), physicochemical parameters (e.g. tissue/plasma partition coefficients) and kinetic parameters (e.g. kinetic constants for relevant biotransformation reactions of the chemical) for which parameter values need to be determined [97-100]. Physiological and anatomical parameter values can be obtained from literature while physicochemical and kinetic parameter values are chemical specific and therefore obtained either using in vivo data, using in silico modeling or using a suitable in vitro technique.

Step 3 includes PBK model evaluation and proceeds by the comparison of PBK modelbased predicted values with the in vivo data available to assess how the developed PBK model performs in predicting the in vivo situation. Once the performance of the model has been evaluated, 
the model can be used to make predictions and translate in vitro concentration-response curves to in vivo dose-response curves using PBK modeling-based reverse dosimetry (step 4).

In step 4 PBK modeling-based reverse dosimetry is applied. In this approach the concentration metric of the in vitro studies is set equal to the concentration in plasma or the relevant tissue in the PBK model, and then the PBK model is used in the reverse order to predict the corresponding dose level. The predictions can be performed using two approaches, including either the use of the maximum concentration $\left(C_{\max }\right)$ or of the area under the concentration-time curve (AUC). In the first approach, each applied concentration in the in vitro experiment is set equal to Cmax in the blood or in a specific tissue as input in the PBK model to calculate the oral dose that results in this concentration. In the second approach, the AUC data are calculated by multiplying the applied concentration with the assay time [101] and the AUC-response curves are translated to the in vivo situation by assessing which oral doses are required to reach these AUC levels in the blood or in a specific tissue.

In step 5, the reference values for risk assessment such as the $\mathrm{BMD}_{10}$ (the benchmark dose causing a $10 \%$ extra risk above background level) or $\mathrm{BMDL}_{10}$ values (the lower confidence limit of the $\mathrm{BMD}_{10}$ ) are obtained from the defined dose-response curves. To evaluate the potential of the PBK modeling-based reverse dosimetry approach to obtain a POD for risk assessment, the predicted PODs based on this approach can be compared with the PODs derived from in vivo literature data (step 6) in order to evaluate the predictive value of this approach.

\subsection{OBJECTIVES AND OUTLINE OF THE THESIS}

The main objective of the present thesis was to investigate whether PBK modeling-based reverse dosimetry can convert in vitro concentration response-curves for AA-induced kidney toxicity to in vivo dose response-curves for kidney toxicity, thereby including a novel target tissue and endpoint for evaluation of this alternative testing strategy. The PBK models were developed based on kinetic parameters derived from in vitro incubations using relevant tissue fractions and/or available literature data. PBK modeling-based reverse dosimetry was used to translate the concentrationresponse curves for cytotoxicity and DNA adduct formation of AAI and AAll in kidney cells in vitro to in vivo dose-response curves in rat, mouse and human. An additional objective was to investigate whether several years after the national restrictions on the presence of AAs in herbal remedies, the risks associated with consumption of AAs via PFS and herbal products is indeed negligible. 
Chapter 1, the current chapter, presents an overview of the basic principles that are of importance for the present thesis, including an introduction to the AAs as model compounds, incidents and epidemiologic data on the AAs, and their ADME characteristics and toxicity profile. Also, the regulatory status, the use of PBK modeling-based reverse dosimetry in risk assessment, and finally the aim and overall objectives of the thesis are introduced.

Chapter 2 presents the development of a PBK model for AAl in rat, mouse and human and the use of these models for the prediction of PODs for evaluation of the nephrotoxicity of AAI.To this end in vitro concentration-response curves for cytotoxicity were translated to in vivo dose-response curves for kidney toxicity using PBK modeling-based reverse dosimetry. The model performance was evaluated by comparison of the predictions to in vivo data available in the literature. Results obtained are expected to provide a possible proof-of-principle for using PBK modeling-based reverse dosimetry of in vitro toxicity data to predict a POD for in vivo nephrotoxicity.

Chapter 3 extends the PBK modeling-based reverse dosimetry approach for predicting kidney toxicity by AAI in chapter 2 to another endpoint, being AAI-DNA adduct formation in the kidney. The predicted levels for in vivo DNA adduct formation in rat, mouse and human kidney were compared to data on in vivo DNA adduct formation available from literature to evaluate the model outcomes. In order to provide insight in the possible implications of DNA adducts for tumor formation induced by $A A I$, the available in vivo tumor data in rats were used to derive the $\mathrm{BMD}_{10}$ values for kidney tumor formation and the PBK model was used to predict the AAI-DNA adduct levels at these $\mathrm{BMD}_{10}$ values.

The relative potency of the major AA congeners in Aristolochia species, AAI and AAll for inducing cytotoxicity and DNA adduct formation in vitro was studied in more detail in Chapter 4. This chapter also describes the development of a new PBK model for AAI and AAll in rat and its use for extrapolating the concentration-response curves to dose-response curves and explaining differences observed between the two AAs.

Chapter 5 investigates whether several years after the banning of AAs in herbal remedies, the risks associated with potential exposure to AAs via PFS is indeed negligible. To this end an MOEbased risk assessment was performed based on AA levels in PFS and herbal products reported in the literature and as detected in newly purchased PFS for this study via internet.

Finally Chapter 6 summarizes the results obtained in the thesis, compiles the overall discussion and presents the future perspectives that follow from the results obtained. 


\section{References}

1. Grollman, A.P., J. Scarborough, and B. Jelakovic, Aristolochic acid nephropathy: an environmental and iatrogenic disease. Advances in Molecular Toxicology, 2009. 3: p. 211-227.

2. Frei, H., F. Würgler, H. Juon, C. Hall, and U. Graf, Aristolochic acid is mutagenic and recombinogenic in Drosophila genotoxicity tests. Archives of Toxicology, 1985. 56(3): p. 158-166.

3. Arlt, V.M., M. Stiborova, and H.H. Schmeiser, Aristolochic acid as a probable human cancer hazard in herbal remedies: a review. Mutagenesis, 2002. 17(4): p. 265-277.

4. Kumar, V., A.K. Prasad, and V.S. Parmar, Naturally occurring aristolactams, aristolochic acids and dioxoaporphines and their biological activities. Natural Products Reports, 2003. 20(6): p. 565-583.

5. NTP, National Toxicology Program. Final report on carcinogens background document for aristolochic acids. Report on carcinogens background document for Aristolochic Acids, 2008(85976).

6. Schmeiser, H.H., C.A. Bieler, M. Wiessler, C.v.Y. de Strihou, and J.-P. Cosyns, Detection of DNA adducts formed by aristolochic acid in renal tissue from patients with Chinese herbs nephropathy. Cancer research, 1996. 56(9): p. 2025-2028.

7. Stiborová, M., E. Frei, B. Sopko, K. Sopková, V. Marková, M. Laňková, T. Kumstýřová, M. Wiessler, and H.H. Schmeiser, Human cytosolic enzymes involved in the metabolic activation of carcinogenic aristolochic acid: evidence for reductive activation by human NAD (P) H: quinone oxidoreductase. Carcinogenesis, 2003. 24(10): p. 1695-1703.

8. IARC, IARC Monographs on the Evaluation of Carcinogenic Risks to Humans. 2002, World Health Organization. p. 68-128.

9. Stiborová, M., E. Frei, V.M. Arlt, and H.H. Schmeiser, The role of biotransformation enzymes in the development of renal injury and urothelial cancer caused by aristolochic acid: urgent questions and difficult answers. Biomedical Papers of the Medical Faculty of the University Palacky Olomouc Czech Republic, 2009. 153(1): p. 5-11.

10. Heinrich, M., J. Chan, S. Wanke, C. Neinhuis, and M.S. Simmonds, Local uses of Aristolochia species and content of nephrotoxic aristolochic acid 1 and 2-a global assessment based on bibliographic sources. Journal of Ethnopharmacology, 2009. 125(1): p. 108-144.

11. Mengs, U., W. Lang, and J.-A. Poch, The carcinogenic action of aristolochic acid in rats. Archives of Toxicology, 1982. 51(2): p. 107-119.

12. Mengs, U., On the histopathogenesis of rat forestomach carcinoma caused by aristolochic acid. Archives of Toxicology, 1983. 52(3): p. 209-220.

13. Vanherweghem, J.-L., C. Tielemans, D. Abramowicz, M. Depierreux, R. Vanhaelen-Fastre, M. Vanhaelen, M. Dratwa, C. Richard, D. Vandervelde, and D. Verbeelen, Rapidly progressive interstitial renal fibrosis in young women: association with slimming regimen including Chinese herbs. The lancet, 1993. 341(8842): p. 387-391.

14. Vanhaelen, M., R. Vanhaelen-Fastre, P. But, and J.-L. Vanherweghem, Identification of aristolochic acid in Chinese herbs. The lancet, 1994. 343(8890): p. 174.

15. Debelle, F.D., J.-L. Vanherweghem, and J.L. Nortier, Aristolochic acid nephropathy: a worldwide problem. Kidney international, 2008. 74(2): p. 158-169.

16. Krumbiegel, G., J. Hallensleben, W. Mennicke, N. Rittmann, and H. Roth, Studies on the metabolism of aristolochic acids I and II. Xenobiotica, 1987. 17(8): p. 981-991.

17. Schmeiser, H., B. Pool, and M. Wiessler, Identification and mutagenicity of metabolites of aristolochic acid formed by rat liver. Carcinogenesis, 1986. 7(1): p. 59-63.

18. Shibutani, S., R.R. Bonala, T. Rosenquist, R. Rieger, N. Suzuki, F. Johnson, F. Miller, and A.P. Grollman, Detoxification of aristolochic acid I by O-demethylation: Less nephrotoxicity and genotoxicity of aristolochic acid la in rodents. Int. J. Cancer, 2010. 127(5): p. 1021-1027.

19. Chan, W., L. Cui, G. Xu, and Z. Cai, Study of the phase I and phase II metabolism of nephrotoxin aristolochic acid by liquid chromatography/tandem mass spectrometry. Rapid Communications in Mass Spectrometry, 2006. 20(11): p. 1755-1760.

20. Shibutani, S., H. Dong, N. Suzuki, S. Ueda, F. Miller, and A.P. Grollman, Selective toxicity of aristolochic acids I and II. Drug Metabolism and Disposition, 2007. 35(7): p. 1217-1222. 
21. Martinek, V., B. Kubickova, V.M. Arlt, E. Frei, H.H. Schmeiser, J. Hudecek, and M. Stiborova, Comparison of activation of aristolochic acid I and II with NADPH: quinone oxidoreductase, sulphotransferases and N-acetyltranferases. Neuro endocrinology letters, 2010. 32: p. 57-70.

22. Luan, Y., G. Xing, J. Ren, and J. Gu, Role of hepatic cytochrome P450 enzymes in the detoxication of aristolochic acid l; effects on DNA adduct, mutation, and tumor formation. Genes and Environment, 2015. 37(1): p. 1.

23. Pfau, W., H.H. Schmeiser, and M. Wiessler, ${ }^{32}$ P-postlabelling analysis of the DNA adducts formed by aristolochic acid I and II. Carcinogenesis, 1990. 11(9): p. 1627-1633.

24. Pfau, W., H.H. Schmeiser, and M. Wiessler, Aristolochic acid binds covalently to the exocyclic amino group of purine nucleotides in DNA. Carcinogenesis, 1990. 11(2): p. 313-319.

25. Schmeiser, H., K.-B. Schoepe, and M. Wiessler, DNA adduct formation of aristolochic acid I and II in vitro and in vivo. Carcinogenesis, 1988. 9(2): p. 297-303.

26. Chan, W., H. Yue, W.T. Poon, Y.-W. Chan, O.J. Schmitz, D.W. Kwong, R.N. Wong, and Z. Cai, Quantification of aristolochic acid-derived DNA adducts in rat kidney and liver by using liquid chromatography-electrospray ionization mass spectrometry. Mutation Research/Fundamental and Molecular Mechanisms of Mutagenesis, 2008. 646(1): p. 17-24.

27. Rietjens, I.M.C.M., M.J. Martena, M.G. Boersma, W. Spiegelenberg, and G.M. Alink, Molecular mechanisms of toxicity of important food borne phytotoxins. Molecular nutrition \& food research, 2005. 49(2): p. 131-158.

28. Bieler, C.A., M. Stiborova, M. Wiessler, J.-P. Cosyns, C.v.Y. de Strihou, and H.H. Schmeiser, ${ }^{32}$ P-post-labelling analysis of DNA adducts formed by aristolochic acid in tissues from patients with Chinese herbs nephropathy. Carcinogenesis, 1997. 18(5): p. 1063-1067.

29. Mei, N., V.M. Arlt, D.H. Phillips, R.H. Heflich, and T. Chen, DNA adduct formation and mutation induction by aristolochic acid in rat kidney and liver. Mutation Research/Fundamental and Molecular Mechanisms of Mutagenesis, 2006. 602(1): p. 83-91.

30. Chan, W., H.B. Luo, Y. Zheng, Y.K. Cheng, and Z. Cai, Investigation of the metabolism and reductive activation of carcinogenic aristolochic acids in rats. Drug Metabolism and Disposition, 2007. 35(6): p. 866-874.

31. Rosenquist, T.A., H.J. Einolf, K.G. Dickman, L. Wang, A. Smith, and A.P. Grollman, Cytochrome P450 1A2 detoxicates aristolochic acid in the mouse. Drug Metabolism and Disposition, 2010. 38(5): $p$. 761-768.

32. Arlt, V.M., K.i. Levová, F.e. Bárta, Z. Shi, J.D. Evans, E. Frei, H.H. Schmeiser, D.W. Nebert, D.H. Phillips, and M. Stiborová, Role of P450 1A1 and P450 1A2 in Bioactivation versus Detoxication of the Renal Carcinogen Aristolochic Acid I: Studies in Cyp1a1 (-/-), Cyp1a2 (-/-), and Cyp1a1/1a2 (-/-) Mice. Chemical Research in Toxicology, 2011. 24(10): p. 1710-1719.

33. Levová, K., M. Moserová, V. Kotrbová, M. Šulc, C.J. Henderson, C.R. Wolf, D.H. Phillips, E. Frei, H.H. Schmeiser, and J. Mareš, Role of cytochromes P450 1A1/2 in detoxication and activation of carcinogenic aristolochic acid I: studies with the hepatic NADPH: cytochrome P450 reductase null (HRN) mouse model. Toxicological Sciences, 2011. 121(1): p. 43-56.

34. Stiborová, M., E. Frei, V.M. Arlt, and H.H. Schmeiser, Metabolic activation of carcinogenic aristolochic acid, a risk factor for Balkan endemic nephropathy. Mutation Research, 2008. 658(1): p. 55-67.

35. Mengs, U. and C. Stotzem, Renal toxicity of aristolochic acid in rats as an example of nephrotoxicity testing in routine toxicology. Archives of Toxicology, 1993. 67(5): p. 307-311.

36. Mengs, U., Acute toxicity of aristolochic acid in rodents. Archives of Toxicology, 1987. 59(5): p. 328-331.

37. Chen, M., M. Su, L. Zhao, J. Jiang, P. Liu, J. Cheng, Y. Lai, Y. Liu, and W. Jia, Metabonomic study of aristolochic acid-induced nephrotoxicity in rats. Journal of proteome research, 2006. 5(4): p. 9951002.

38. Yeh, Y.H., Y.T. Lee, H.S. Hsieh, and D.F. Hwang, Short-term toxicity of aristolochic acid, aristolochic acid-I and aristolochic acid-Il in rats. Food and Chemical Toxicology, 2008. 46(3): p. 11571163. 
39. Lebeau, C., F.D. Debelle, V.M. Arlt, A. Pozdzik, E.G. De Prez, D.H. Phillips, M.M. DeschodtLanckman, J.-L. Vanherweghem, and J.L. Nortier, Early proximal tubule injury in experimental aristolochic acid nephropathy: functional and histological studies. Nephrology Dialysis Transplantation, 2005. 20(11): p. 2321-2332.

40. Xue, X., Y. Xiao, H. Zhu, H. Wang, Y. Liu, T. Xie, and J. Ren, Induction of P450 1A by 3-methylcholanthrene protects mice from aristolochic acid-l-induced acute renal injury. Nephrology Dialysis Transplantation, 2008. 23(10): p. 3074-3081.

41. Xiao, Y., M. Ge, X. Xue, C. Wang, H. Wang, X. Wu, L. Li, L. Liu, X. Qi, and Y. Zhang, Hepatic cytochrome P450s metabolize aristolochic acid and reduce its kidney toxicity. Kidney International, 2008. 73(11): p. 1231-1239.

42. Chen, M., L. Gong, X. Qi, G. Xing, Y. Luan, Y. Wu, Y. Xiao, J. Yao, Y. Li, and X. Xue, Inhibition of renal NQO1 activity by dicoumarol suppresses nitroreduction of aristolochic acid I and attenuates its nephrotoxicity. Toxicological Sciences, 2011. 122(2): p. 288-296.

43. Huang, T., S. Chen, Y. Li, and J. Lee, Urinary d-lactate levels reflect renal function in aristolochic acid-induced nephropathy in mice. Biomedical Chromatography, 2013. 27(9): p. 1100-1106.

44. Yuan, S.Y., C.R. Yang, C.L. Cheng, S.L. Hsu, J.W. Liao, C.C. Lin, Y.Y. Chou, and Y.W. Cheng, Comparative nephrotoxicity of aristolochic acid and tetrandrine in vitro and in vivo. International Journal of Toxicology, 2011. 30(1): p. 35-46.

45. Xiao-shuang, D., Ilang, A.H., W. Jin-hua, X. Yong-qing, W. Zi-lun, U. Chun-ying, L. Li, H. Rong, H. Lian-qiang, and L. Bao-yan, Nephrotoxicity of Aristolochia manshuriensis and aristolochic acids in mice. China Journal of Chinese Materia Medica, 2005. 13: p. 018.

46. Schmeiser, H., B. Pool, and M. Wiessler, Mutagenicity of the two main components of commercially available carcinogenic aristolochic acid in Salmonella typhimurium. Cancer letters, 1984. 23(1): p. 97-101.

47. Maier, P., H. Schawalder, and B. Weibel, Low oxygen tension, as found in tissues in vivo, alters the mutagenic activity of aristolochic acid I and II in primary fibroblast-like rat cells in vitro. Environmental and molecular mutagenesis, 1987. 10(3): p. 275-284.

48. Kohara, A., T. Suzuki, M. Honma, T. Ohwada, and M. Hayashi, Mutagenicity of aristolochic acid in the lambda/lacZ transgenic mouse (Muta ${ }^{\mathrm{TM}}$ Mouse). Mutation Research/Genetic Toxicology and Environmental Mutagenesis, 2002. 515(1): p. 63-72.

49. Chen, L., N. Mei, L. Yao, and T. Chen, Mutations induced by carcinogenic doses of aristolochic acid in kidney of Big Blue transgenic rats. Toxicology Letters, 2006. 165(3): p. 250-256.

50. Gorelick, N.J. and J.C. Mirsalis, Prospects for safety testing: A strategy for the application of transgenic rodent mutagenesis assays. Environmental and molecular mutagenesis, 1996. 28(4): $p$. 434-442.

51. Arlt, V.M., M. Stiborová, J. vom Brocke, M.L. Simoes, G.M. Lord, J.L. Nortier, M. Hollstein, D.H. Phillips, and H.H. Schmeiser, Aristolochic acid mutagenesis: molecular clues to the aetiology of Balkan endemic nephropathy-associated urothelial cancer. Carcinogenesis, 2007. 28(11): p. 2253-2261.

52. Grollman, A.P., S. Shibutani, M. Moriya, F. Miller, L. Wu, U. Moll, N. Suzuki, A. Fernandes, T. Rosenquist, and Z. Medverec, Aristolochic acid and the etiology of endemic (Balkan) nephropathy. Proceedings of the National Academy of Sciences, 2007. 104(29): p. 12129-12134.

53. Poirier, M.C., DNA adducts as exposure biomarkers and indicators of cancer risk. Environmental Health Perspectives, 1997. 105(Suppl 4): p. 907.

54. Swenberg, J.A., E. Fryar-Tita, Y.-C. Jeong, G. Boysen, T. Starr, V.E. Walker, and R.J. Albertini, Biomarkers in toxicology and risk assessment: informing critical dose-response relationships. Chemical Research in Toxicology, 2008. 21(1): p. 253-265.

55. Brink, A., I. Richter, U. Lutz, P. Wanek, H. Stopper, and W.K. Lutz, Biological significance of DNA adducts: comparison of increments over background for various biomarkers of genotoxicity in L5178Y $t k^{+/}$mouse lymphoma cells treated with hydrogen peroxide and cumene hydroperoxide. Mutation Research/Genetic Toxicology and Environmental Mutagenesis, 2009. 678(2): p. 123-128.

56. Romanov, V., V. Sidorenko, T.A. Rosenquist, T. Whyard, and A.P. Grollman, A fluorescencebased analysis of aristolochic acid-derived DNA adducts. Analytical Biochemistry, 2012. 427(1): p. 49- 
51.

57. Nitzsche, D., M.F. Melzig, and V.M. Arlt, Evaluation of the cytotoxicity and genotoxicity of aristolochic acid I-a component of Aristolochiaceae plant extracts used in homeopathy. Environmental Toxicology and Pharmacology, 2013. 35(2): p. 325-334.

58. Arlt, V.M., H.H. Schmeiser, and G.P. Pfeifer, Sequence-specific detection of aristolochic acidDNA adducts in the human p53 gene by terminal transferase-dependent PCR. Carcinogenesis, 2001. 22(1): p. 133-140.

59. Sidorenko, V.S., S. Attaluri, I. Zaitseva, C.R. Iden, K.G. Dickman, F. Johnson, and A.P. Grollman, Bioactivation of the human carcinogen aristolochic acid. Carcinogenesis, 2014. 35(8): p. 1814-1822.

60. Dong, H., N. Suzuki, M.C. Torres, R.R. Bonala, F. Johnson, A.P. Grollman, and S. Shibutani, Quantitative determination of aristolochic Acid-derived DNA adducts in rats using ${ }^{32} p$-postlabeling/ polyacrylamide gel electrophoresis analysis. Drug Metabolism and Disposition, 2006. 34(7): p. 11221127.

61. Yun, B.H., T.A. Rosenquist, V. Sidorenko, C.R. Iden, C.-H. Chen, Y.-S. Pu, R. Bonala, F. Johnson, K.G. Dickman, and A.P. Grollman, Biomonitoring of aristolactam-DNA adducts in human tissues using ultra-performance liquid chromatography/ion-trap mass spectrometry. Chemical Research in Toxicology, 2012. 25(5): p. 1119-1131.

62. Nortier, J.L., M.-C.M. Martinez, H.H. Schmeiser, V.M. Arlt, C.A. Bieler, M. Petein, M.F. Depierreux, L. De Pauw, D. Abramowicz, P. Vereerstraeten, and J.-L. Vanherweghem, Urothelial carcinoma associated with the use of a Chinese herb (Aristolochia fangchi). The new England Journal of Medicine, 2000. 342(23): p. 1686-1692.

63. Beland, F.A., D.R. Doerge, M.I. Churchwell, M.C. Poirier, B. Schoket, and M.M. Marques, Synthesis, characterization, and quantitation of a 4-aminobiphenyl-DNA adduct standard. Chemical Research in Toxicology, 1999. 12(1): p. 68-77.

64. Shields, P., C. Harris, S. Petruzzelli, E. Bowman, and A. Weston, Standardization of the ${ }^{32}$ P-postlabeling assay for polycyclic aromatic hydrocarbon-DNA adducts. Mutagenesis, 1993. 8(2): $\mathrm{p}$. 121-126.

65. Hu, C.-W., M.-R. Chao, and C.-H. Sie, Urinary analysis of 8-oxo-7, 8-dihydroguanine and 8-oxo7, 8-dihydro-2'-deoxyguanosine by isotope-dilution LC-MS/MS with automated solid-phase extraction: study of 8-oxo-7, 8-dihydroguanine stability. Free Radical Biology and Medicine, 2010. 48(1): p. 89-97. 66. Mengs, U., Tumour induction in mice following exposure to aristolochic acid. Archives of Toxicology, 1988. 61(6): p. 504-505.

67. Schmeiser, H.H., J.W. Janssen, J. Lyons, H.R. Scherf, W. Pfau, A. Buchmann, C.R. Bartram, and M. Wiessler, Aristolochic acid activates ras genes in rat tumors at deoxyadenosine residues. Cancer Research, 1990. 50(17): p. 5464-5469.

68. EMEA, The European agency for the evaluation of medicinal products, position paper on the risks associated with the use of herbal products containing Aristolochia species. 2000. p. 1-10.

69. Martena, M.J., J.C. van der Wielen, L.F. van de Laak, E.J. Konings, H.N. de Groot, and I.M.C.M. Rietjens, Enforcement of the ban on aristolochic acids in Chinese traditional herbal preparations on the Dutch market. Analytical and Bioanalytical Chemistry, 2007. 389(1): p. 263-275.

70. Poon, W.-T., C.-K. Lai, and A.Y.-W. Chan, Aristolochic acid nephropathy: the Hong Kong perspective. Hong Kong Journal of Nephrology, 2007. 9(1): p. 7-14.

71. Hashimoto, K., M. Higuchi, B. Makino, I. Sakakibara, M. Kubo, Y. Komatsu, M. Maruno, and M. Okada, Quantitative analysis of aristolochic acids, toxic compounds, contained in some medicinal plants. Journal of Ethnopharmacology, 1999. 64(2): p. 185-189.

72. Lee, T.-Y., M.-L. Wu, J.-F. Deng, and D.-F. Hwang, High-performance liquid chromatographic determination for aristolochic acid in medicinal plants and slimming products. Journal of Chromatography B, 2001. 766(1): p. 169-174.

73. Chan, W., K.C. Lee, N. Liu, and Z. Cai, A sensitivity enhanced high-performance liquid chromatography fluorescence method for the detection of nephrotoxic and carcinogenic aristolochic acid in herbal medicines. Journal of Chromatography A, 2007. 1164(1): p. 113-119.

74. Kuo, C.-H., C.-W. Lee, S.-C. Lin, I.-L. Tsai, S.-S. Lee, Y.J. Tseng, J.-J. Kang, F.-C. Peng, and L. 
Wei-Chu, Rapid determination of aristolochic acids I and II in herbal products and biological samples by ultra-high-pressure liquid chromatography-tandem mass spectrometry. Talanta, 2010. 80(5): p. 16721680.

75. Wei, F., X.L. Cheng, L.Y. Ma, W.T. Jin, B.T. Schaneberg, I.A. Khan, and R.C. Lin, Analysis of aristolochic acids and analogues in medicinal plants and their commercial products by HPLC-PAD-ESI/ MS. Phytochemical Analysis, 2005. 16(3): p. 222-230.

76. loset, J.-R., G. Raoelison, and K. Hostettmann, Detection of aristolochic acid in Chinese phytomedicines and dietary supplements used as slimming regimens. Food and Chemical Toxicology, 2003. 41 (1): p. 29-36.

77. Koh, H., H. Wang, S. Zhou, E. Chan, and S. Woo, Detection of aristolochic acid I, tetrandrine and fangchinoline in medicinal plants by high performance liquid chromatography and liquid chromatography/mass spectrometry. Journal of Pharmaceutical and Biomedical Analysis, 2006. 40(3): p. 653-661.

78. Schaneberg, B. and I. Khan, Analysis of products suspected of containing Aristolochia or Asarum species. Journal of Ethnopharmacology, 2004. 94(2): p. 245-249.

79. Vaclavik, L., A.J. Krynitsky, and J.I. Rader, Quantification of aristolochic acids I and II in herbal dietary supplements by ultra-high-performance liquid chromatography-multistage fragmentation mass spectrometry. Food Additives \& Contaminants: Part A, 2014. 31(5): p. 784-791.

80. Barlow, S., A. Renwick, J. Kleiner, J. Bridges, L. Busk, E. Dybing, L. Edler, G. Eisenbrand, J. Fink-Gremmels, and A. Knaap, Risk assessment of substances that are both genotoxic and carcinogenic: Report of an International Conference organized by EFSA and WHO with support of ILSI Europe. Food and Chemical Toxicology, 2006. 44(10): p. 1636-1650.

81. O'Brien, J., A. Renwick, A. Constable, E. Dybing, D. Müller, J. Schlatter, W. Slob, W. Tueting, J. Van Benthem, and G. Williams, Approaches to the risk assessment of genotoxic carcinogens in food: a critical appraisal. Food and Chemical Toxicology, 2006. 44(10): p. 1613-1635.

82. EFSA and WHO, Review of the Threshold of Toxicological Concern (TTC) approach and development of new TTC decision tree. EFSA supporting publication 2016, 2016. EN-1006: p. 50.

83. van den Berg, S.J., L. Serra-Majem, P. Coppens, and I.M.C.M Rietjens, Safety assessment of plant food supplements (PFS). Food \& Function, 2011. 2(12): p. 760-768.

84. EFSA, European Food Safety Authority. Opinion of the scientific committee on a request from EFSA related to a harmonised approach for risk assessment of substances which are both genotoxic and carcinogenic. EFSA Journal, 2005. 282: p. 1-31.

85. Benford, D., P.M. Bolger, P. Carthew, M. Coulet, M. DiNovi, J.-C. Leblanc, A.G. Renwick, W. Setzer, J. Schlatter, and B. Smith, Application of the margin of exposure (MOE) approach to substances in food that are genotoxic and carcinogenic. Food and Chemical Toxicology, 2010. 48: p. S2-S24.

86. DeJongh, J., M. Nordin-Andersson, B. Ploeger, and A. Forsby, Estimation of systemic toxicity of acrylamide by integration of in vitro toxicity data with kinetic simulations. Toxicology and Applied Pharmacology, 1999. 158(3): p. 261-268.

87. Verwei, M., J.A. van Burgsteden, C.A. Krul, J.J. van de Sandt, and A.P. Freidig, Prediction of in vivo embryotoxic effect levels with a combination of in vitro studies and PBPK modelling. Toxicology Letters, 2006. 165(1): p. 79-87.

88. Louisse, J., E. de Jong, J.J. van de Sandt, B.J. Blaauboer, R.A. Woutersen, A.H. Piersma, I.M.C.M. Rietjens, and M. Verwei, The use of in vitro toxicity data and physiologically based kinetic modeling to predict dose-response curves for in vivo developmental toxicity of glycol ethers in rat and man. Toxicological Sciences, 2010. 118(2): p. 470-484.

89. Strikwold, M., B. Spenkelink, R.A. Woutersen, I.M.C.M. Rietjens, and A. Punt, Combining in vitro embryotoxicity data with physiologically based kinetic (PBK) modelling to define in vivo doseresponse curves for developmental toxicity of phenol in rat and human. Archives of Toxicology, 2013. 87(9): p. 1709-1723.

90. Louisse, J., S. Bosgra, B.J. Blaauboer, I.M.C.M. Rietjens, and M. Verwei, Prediction of in vivo developmental toxicity of all-trans-retinoic acid based on in vitro toxicity data and in silico physiologically based kinetic modeling. Archives of Toxicology, 2015. 89(7): p. 1135-1148. 
91. Punt, A., A. Paini, A. Spenkelink, G. Scholz, B. Schilter, P. van Bladeren, and I.M.C.M. Rietjens, Evaluation of interindividual human variation in bioactivation and DNA adduct formation of estragole in liver predicted by physiologically based kinetic/dynamic (PBK/D) and Monte Carlo modeling. Chemical Research in Toxicology, 2016. 29(4): p. 659-668.

92. Kiwamoto, R., I.M.C.M. Rietjens, and A. Punt, A physiologically based in silico model for trans2-hexenal detoxification and DNA adduct formation in rat. Chemical Research in Toxicology, 2012. 25(12): p. 2630-2641.

93. Kiwamoto, R., A. Spenkelink, I.M.C.M. Rietjens, and A. Punt, A physiologically based in silico model for trans-2-hexenal detoxification and DNA adduct formation in human including interindividual variation indicates efficient detoxification and a negligible genotoxicity risk. Archives of Toxicology, 2013. 87(9): p. 1725-1737.

94. Hull, R., W. Cherry, and G. Weaver, The origin and characteristics of a pig kidney cell strain, LLC-PK1. In vitro, 1976. 12(10): p. 670-677.

95. Gstraunthaler, G., W. Pfaller, and P. Kotanko, Biochemical characterization of renal epithelial cell cultures (LLC-PK1 and MDCK). American Journal of Physiology: Renal Physiology, 1985. 248(4): $p$. F536-F544.

96. Huljic, S., E.I. Bruske, N. Pfitzenmaier, E. O'Brien, and D.R. Dietrich, Species-specific toxicity of aristolochic acid (AA) in vitro. Toxicology in Vitro, 2008. 22(5): p. 1213-1221.

97. Rietjens, I.M.C.M., J. Louisse, and A. Punt, Tutorial on physiologically based kinetic modeling in molecular nutrition and food research. Molecular nutrition \& food research, 2011. 55(6): p. 941-956.

98. Krewski, D., J.R. Withey, L.-f. Ku, and M.E. Andersen, Applications of physiologic pharmacokinetic modeling in carcinogenic risk assessment. Environmental Health Perspectives, 1994. 102(Suppl 11): p. 37.

99. Krishnan, K. and M.E. Andersen, Physiologically based pharmacokinetic modeling in toxicology. Principles and methods of toxicology, 2001. 4: p. 193-241.

100. Clewell, R.A. and H.J. Clewell, Development and specification of physiologically based pharmacokinetic models for use in risk assessment. Regulatory Toxicology and Pharmacology, 2008. 50(1): p. 129-143.

101. Daston, G.P., R.E. Chapin, A.R. Scialli, A.H. Piersma, E.W. Carney, J.M. Rogers, and J.M. Friedman, A different approach to validating screening assays for developmental toxicity. Birth Defects Research Part B: Developmental and Reproductive Toxicology, 2010. 89(6): p. 526-530. 



\section{CHAPTER}

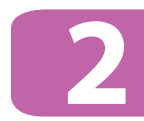

Predicting points of departure for risk assessment based on in vitro cytotoxicity data and physiologically based kinetic (PBK) modeling: the case of kidney toxicity induced by aristolochic acid T

Rozaini Abdullah, Wasma Alhusainy, Jasper Woutersen, Ivonne M. C. M. Rietjens, and Ans Punt

Based on: Food and Chemical Toxicology (2016) 92: 104-116 


\section{ABSTRACT}

Aristolochic acids are naturally occurring nephrotoxins. This study aims to investigate whether physiologically based kinetic (PBK) model-based reverse dosimetry could convert in vitro concentration-response curves of aristolochic acid I (AAI) to in vivo dose response-curves for nephrotoxicity in rat, mouse and human. To achieve this extrapolation, PBK models were developed for AAI in these different species. Subsequently, concentration-response curves obtained from in vitro cytotoxicity models were translated to in vivo dose-response curves using PBK model-based reverse dosimetry. From the predicted in vivo dose-response curves, points of departure (PODs) for risk assessment could be derived. The PBK models elucidated species differences in the kinetics of AAI with the overall catalytic efficiency for metabolic conversion of AAI to aristolochic acid la (AAla) being 2-fold higher by rat and 64-fold higher by mouse than human. Results show that the predicted PODs generally fall within the range of PODs derived from the available in vivo studies. This study provides proof of principle for a new method to predict a POD for in vivo nephrotoxicity by integrating in vitro toxicity testing with in silico PBK model-based reverse dosimetry. 


\subsection{INTRODUCTION}

In theory, in vivo dose-response curves and points of departure (PODs) for defining safe levels of exposure such as acceptable daily intakes (ADIs) or tolerable daily intakes (TDIs) in risk assessment can be obtained by translating in vitro data to in vivo dose-response curves using physiologically based kinetic (PBK) modeling-based reverse dosimetry. In such approaches in vitro effect concentrations are considered as surrogate tissue or blood concentrations that would cause toxicity in the in vivo situation and PBK models are used to calculate the corresponding in vivo dose levels that are needed to reach these surrogate tissue or blood concentrations. From the in vivo doseresponse curves thus predicted, a POD for risk assessment like a benchmark dose (BMD) or lower confidence limit of the BMD (BMDL) can be calculated. Recently we have shown the first proofsof-principle for predicting in vivo dose-response curves for developmental toxicity from in vitro concentration-response curves obtained in the differentiation assay of the embryonic stem cell assay [1-3]. PODs within an order of magnitude of the experimentally determined values could be obtained, indicating accuracy in line with the variation between the PODs derived from different in vivo assays [1-3]. The aim of this study was to investigate whether PBK modeling-based reverse dosimetry could convert concentration-response curves for cytotoxicity in kidney cells in vitro to in vivo dose-response curves for nephrotoxicity in rat, mouse and human, and provide an adequate POD for the evaluation of nephrotoxicity in risk assessment. This was done using the nephrotoxin aristolochic acid I (AAI) as model compound.

Aristolochic acids (AAs) are naturally occurring nephrotoxins derived from Aristolochia species. AA refers to a mixture of structurally related nitrophenanthrene carboxylic acids with the major compounds being 8-methoxy-6-nitrophenanthro-(3,4-d)-1,3-dioxolo-5-carboxylic acid (AAl, Figure 2.1) and its 8-demethoxylated form (AAII) [4]. Aristolochia herbs have been used since ancient times as alternative medicine to treat arthritis, gout, rheumatism, snakebites [5]. However, studies conducted over the years have associated AA with Chinese Herb Nephropathy and Balkan Endemic Nephropathy, later known as Aristolochic Acid Nephropathy (AAN) [6-8]. AA induced nephropathy was first identified in Belgium in 1991, where a group of patients consumed slimming pills containing extracts derived from roots of different Chinese herbs. Due to confusing nomenclature, there was a replacement of the herb Stephania tetranda (called Fang Ji) with Aristolochia fangchi, the latter containing AAs [9]. Over 100 young women suffered from kidney damage and several of them developed kidney and urinary tract cancer $[9,10]$. 


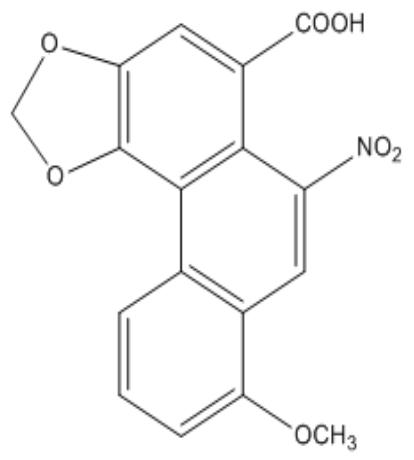

Fig. 2.1 Structural formula of aristolochic acid I.

Based on the Belgian incident, the European Agency for the Evaluation of Medicinal Products issued a position paper in October 2000 [11], warning European Union Member States "to take steps to ensure that the public is protected from exposure to aristolochic acids arising from the deliberate use of Aristolochia species or as a result of confusion with other botanical ingredients". Based on this recommendation, risk management actions have been taken by the authorities of most EU Member States. Despite all the awareness and regulation, products containing AAs were still found to be present on the market for human consumption [12-14] and such products continue to be used as traditional herbal medicine in some countries. AAs are therefore still a public health concern.

Within a natural mixture of AAs, AAI and/or its metabolites have been observed to be mainly responsible for the nephrotoxicity associated with AAN [15-18]. Carcinogenicity of AAI has been related to bioactivation of AAI to a DNA reactive intermediate, aristolactam I-nitrenium, upon nitroreduction [19-21]. This reaction is catalyzed by both cytosolic and microsomal enzymes, with $\mathrm{NAD}(\mathrm{P}) \mathrm{H}$ :quinone oxidoreductase (NQO1) being most efficient in cytosolic nitroreduction [22, 23]. Acute nephrotoxicity induced by AAI has been suggested to be linked to the direct cytotoxic effect of the parent compound. Effects include renal tubular lesions and subsequent cellular interstitial fibrosis [24]. Detoxification of AAI proceeds by demethylation catalyzed by cytochrome P450 (CYP) $1 \mathrm{~A} 1 / 2$ to a less toxic metabolite, AAla [18] (Figure 2.2). The ability to demethylate AAI may determine its toxicity [25].

It is interesting to note that there are evidently certain species differences in the metabolic transformation of AA. Studies have shown that mice display a similar metabolic pattern as rats, but a metabolite pattern that is different from that observed in guinea pigs, rabbits, dogs and humans 
[26]. Mice and rats also have a comparable carcinogenic response when exposed to $A A[27,28]$.

To achieve the aim of this study, PBK models were first developed for AAI in rat, mouse and human. Subsequently, concentration-response curves obtained from in vitro cytotoxicity models were translated to in vivo dose-response curves using PBK model-based reverse dosimetry from which PODs for evaluation of the nephrotoxicity of AAI could be derived. Combining in vitro cytotoxicity studies with PBK models that simulate the absorption, distribution, metabolism, and excretion of AAl in the specific species may thus allow prediction of in vivo dose-response curves, which could be used in the risk assessment to set a POD for evaluation of the nephrotoxicity of AAI. The outcome of this research may provide further support for the use of in vitro-in silico based alternative methods for risk assessment practice.<smiles>COc1cccc2c1cc([N+](=O)[O-])c1c(C(=O)O)cc3c(c12)OCO3</smiles>

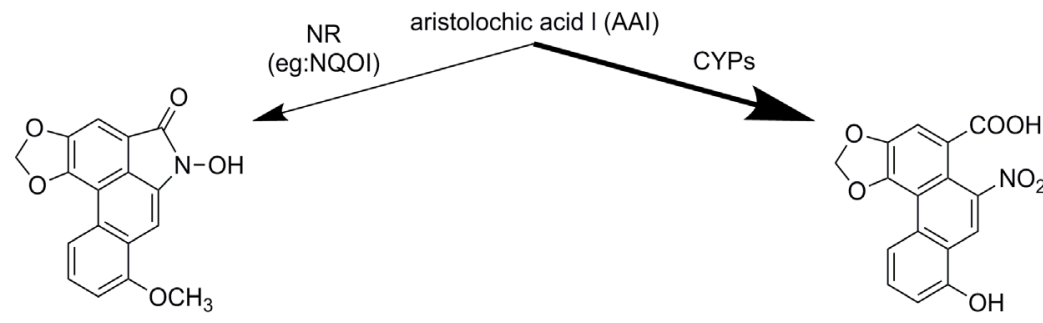

N-hydroxyaristolactam I

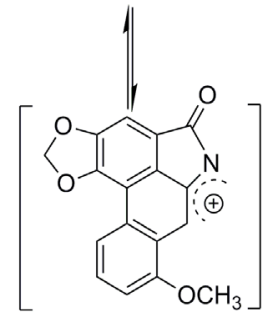

cyclic nitrenium ion

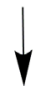

DNA adduct aristolochic acid la (AAla)

UGTs

SULTS

AAla-glucuronide AAla-sulfate

Fig. 2.2 Metabolic pathways for bioactivation and detoxification of aristolochic acid I (AAI), with the bold arrow showing the major metabolic route . NR = nitroreduction, $\mathrm{NQO} 1=\mathrm{NAD}(\mathrm{P}) \mathrm{H}$ :quinone oxidoreductase, CYPs = cytochromes P450, UGTs = uridine 5'-diphospho-glucuronosyltransferases, SULTs $=$ sulfotransferases. 


\subsection{MATERIAL AND METHODS}

\subsubsection{Chemicals}

Aristolochic acid I (AAI) was purchased from Sigma-Aldrich (St. Louis, MO, USA). The LLC-PK1 porcine cell line $\left(\mathrm{ATCC}^{\oplus} \mathrm{CL}-101^{\mathrm{TM}}\right.$ ) and the MDCK canine cell line (ATCC ${ }^{\circledast} \mathrm{CCL}-34^{\mathrm{TM}}$ ) were obtained from the American Type Culture Collection (ATCC). Dulbecco's Modified Eagle Medium (DMEM), Eagle Minimum Essential Medium (MEM), phosphate buffered saline (PBS), and trypsin-EDTA were purchase from Gibco (Paisley, Scotland, UK) and fetal bovine serum from Lonza BioWhittaker (Walkersville, MD, USA). Dimethyl sulfoxide (DMSO) (>99.9\%) was obtained from Acros Organics (Geel, Belgium), acetonitrile (ULC/MS grade) obtained from Biosolve (Valkenswaard, The Netherlands) and trifluoroacetic acid (TFA) (>99.8\%) was purchased from Merck (Darmstadt, Germany). The reduced form of $\beta$-nicotinamide adenine dinucleotide phosphate (NADPH) was obtained from SigmaAldrich. Pooled liver S9 from male Sprague-Dawley rats, male CD-1 mouse and mixed gender human were obtained from Sigma-Aldrich. Pooled intestinal and kidney S9 from Sprague-Dawley rats, CD-1 mouse and mixed gender human were purchased from Xenotech (Lenexa, KS, USA).

\subsubsection{General outline for PBK model-based reverse dosimetry approach}

The in vitro PBK approach to predict in vivo dose-response curves and a POD for risk assessment using in vitro cytotoxicity data consisted of the following steps: (1) establishment of in vitro concentration-response curves of AAI in the LLC-PK1 and MDCK cell lines, (2) development of PBK models describing in vivo kinetic properties of AAI in rat, mouse and human using the kinetic parameters defined in the present study from in vitro assays or literature data, (3) evaluation of the PBK models against available literature data, (4) translation of the in vitro concentration-response curves into in vivo dose-response curves for acute kidney toxicity in rat, mouse and human using the PBK models, (5) BMD analysis on the predicted in vivo dose-response data to obtain a POD for risk assessment, and (6) evaluation of the predictive POD against available literature data.

\subsubsection{In vitro kidney toxicity data}

Two types of kidney cell lines were used as starting point for determining in vitro concentrationresponse curves for cytotoxicity. The LLC-PK1 cell line and the MDCK cell line were cultured in $75 \mathrm{~cm}^{2}$ flasks at $37^{\circ} \mathrm{C}$ in a humidified atmosphere of $5 \% \mathrm{CO}_{2}$ in DMEM (for the LLC-PK1 cell line) or MEM (for 
the MDCK cell line) supplemented with $10 \%(\mathrm{v} / \mathrm{v})$ fetal bovine serum. Cells were subcultured three times a week, using $1 \%(\mathrm{v} / \mathrm{v})$ trypsin-EDTA to detach the cells.

Cytotoxicity was determined with the MTT assay [29] with minor modifications. In brief, $5 \mathrm{x}$ $10^{4} \mathrm{cell} / \mathrm{ml}$ were seeded in 96-well plates. 24 Hours after plating, the cells were exposed to different concentration of $\mathrm{AAl}$ ranging from 0.5 to $250 \mu \mathrm{M}$ (final concentrations), added from 200 times concentrated stock solutions in DMSO. Each concentration was tested in four replicates and three independent experiments were carried out. After 24 hours of treatment, MTT was added and cells were incubated for an additional 3 hours. Cells were lysed and the MTT formazan crystals formed were dissolved by addition of DMSO and the absorbance was measured at $562 \mathrm{~nm}$ using a microplate reader (SpectraMax M2, USA). Relative cell viability (\%) was calculated as (mean absorbance of sample/ mean absorbance of vehicle control) $\times 100 \%$. Cytotoxicity data were analyzed for significant effects compared to the control using a one way analysis of variance (ANOVA) performed using IBM SPSS Statistics software, version 22.

\subsubsection{In vitro incubations of AAI with rat, mouse and human S9 homogenates to derive the kinetic parameters for the PBK model}

Incubations were performed with rat, mouse, and human tissue fractions to measure kinetics of detoxification of AAI by its conversion into AAla by intestine, liver and kidney. In vitro incubation mixtures contained in a final volume of $200 \mu$ (final concentrations): $50 \mathrm{mM}$ Tris- $\mathrm{HCl}$ (pH 7.4) containing $5 \mathrm{mM} \mathrm{MgCl}{ }_{2}, 1 \mathrm{mM} \mathrm{NADPH}$ and pooled liver S9 (1 mg protein/ml), intestine S9 (0.4 $\mathrm{mg}$ protein/ml) or kidney S9 $(0.25 \mathrm{mg}$ protein $/ \mathrm{ml})$ from rat, mouse or human. After $1 \mathrm{~min}$ of preincubation in a shaking water bath at $37^{\circ} \mathrm{C}$, the reactions were started by the addition of AAI (0.5$250 \mu \mathrm{M})$ from 200 times concentrated stock solutions in DMSO. The reactions were carried out for 30 min with all S9 homogenates except for the incubations with mouse intestinal S9, which were carried out for 6 min. Control incubations were performed without (1) S9 homogenate, (2) NADPH, or (3) AAl. The incubations were terminated by the addition of $50 \mu$ ice-cold acetonitrile followed by centrifugation at $16000 \mathrm{~g}$ for $5 \mathrm{~min}$ before analyses of the supernatant by UPLC (Waters Acquity).

From each incubation, $3.5 \mu \mathrm{l}$ of supernatant was injected into the UPLC (Waters Acquity) equipped with a Waters BEH C18 $1.7 \mu \mathrm{m}$ column, 2.1 x 50 mm (Waters, Ireland). A gradient was made with ultra-pure water containing $0.1 \%(\mathrm{v} / \mathrm{v})$ TFA as solvent $\mathrm{A}$ and acetonitrile as solvent $\mathrm{B}$. The flow rate was set to $0.6 \mathrm{ml} / \mathrm{min}$. The starting condition was $80: 20$ (A:B), changing to $75: 25$ from 2 to 6 min, 
then to $20: 80$ from 6 to $6.3 \mathrm{~min}$, then to $0: 100$ from 6.3 to $7.3 \mathrm{~min}$ after which the starting condition were reset from $7.3 \mathrm{~min}$ to $8.0 \mathrm{~min}$ and the column was equilibrated at the starting condition for another 2 min. Detection was carried out with a photodiode array detector (Waters, Milford, MA, USA) at a wavelength of $240 \mathrm{~nm}$.

Due to unavailability of the authentic standard of AAla in the market, the UV/Vis spectrum of the metabolite (AAla) that was formed in S9 incubations with NADPH was compared with the UV/Vis spectrum of AAI revealing the same UV/Vis spectrum. Based on this observation, AAla was quantified using the calibration curve for AAI. A similar procedure was previously applied by others [30]. Quantification of AAla could thus be achieved by comparison of the peak area to the peak areas of the calibration curve of AAl, all at a wavelength of $240 \mathrm{~nm}$. The data for the rate of formation of AAla with increasing AAI concentration were fitted to the standard Michaelis-Menten equation, $v=$ $\mathrm{V}_{\max } \times[S] /\left(\mathrm{K}_{\mathrm{m}}+[\mathrm{S}]\right)$, with $[\mathrm{S}]$ being the substrate concentration, $\mathrm{V}_{\max }$ being the apparent maximum velocity, and $\mathrm{K}_{\mathrm{m}}$ being the apparent Michaelis-Menten constant. This was done with GraphPad Prism, 5.0 software (San Diego, CA, USA).

\subsubsection{PBK models for rat, mouse and human}

A schematic diagram of the structure of the PBK models developed for the different species is shown in Figure 2.3. The final models include separate compartments for liver and intestine (as metabolizing compartments), kidney, fat, arterial blood, venous blood, rapidly perfused and slowly perfused tissue. Kidney toxicity of AAl is known to be due to the parent compound. This implies that the maximum concentration $\left(C_{\max }\right)$ and the area under the curve (AUC) of $A A I$ itself are the parameters that form the basis for the in vitro to in vivo extrapolation. Given this situation, the PBK model should adequately predict the kinetics of disappearance of AAI itself. Because the major metabolic pathway of AAl is its conversion to AAla $[18,31,32]$ and this metabolic conversion dominates the $C_{\max }$ or AUC for AAI, the aim of the present study could be adequately achieved by modeling only this major biotransformation pathway of conversion of AAI to AAla. Minor metabolic routes like the bioactivation by nitroreduction, although playing an important role in the carcinogenicity of AAI and an important challenge for future research, will not significantly affect the predicted $\mathrm{Cmax}$ and AUC for AAI.

AAI was assumed to be taken up from the gastrointestinal tract following first order kinetics and absorbed directly by the liver. An absorption rate constant of $3.27 \mathrm{~h}^{-1}$ as reported by Su et al. 
(2004) [33] for rat, was applied in all three models for rat, mouse and human as no specific absorption rate constants are available for mouse and human. No allometric scaling of the uptake constant was applied as the permeability of compounds across the intestinal barrier has been reported to be relatively constant across species [34]. In case of AAl, this consistency between species is supported by the fact that for beagle dogs, being a larger species than rats, an uptake constant that ranges between 1.9-3.1 $\mathrm{h}^{-1}$ has been reported [35], which is similar to the value obtained for rats.

All physiological parameters were obtained from literature [36]. The tissue/plasma partition coefficients for rat and human were calculated based on the log $\mathrm{K}_{\mathrm{ow}}$ using the method of Berezhkovskiy [37]. The log $\mathrm{K}_{\text {ow }}$ value of AAI has been reported to be $4.45 \pm 0.07$ [38]. The tissue/ plasma partition coefficients for mouse were assumed to be the same as for rat. All physiological parameters and partition coefficients used in the PBK models are presented in Table 2.1.

On the basis of the in vitro kinetic data (see result section), conversion of AAI to AAla was described in the liver (in all species) and intestine (in rat and mouse). The in vitro-derived $V_{\max }$ values ( $\mathrm{nmol} / \mathrm{min} / \mathrm{mg}$ S9 protein) for conversion of AAI by liver S9 fractions were scaled to the liver using the $\mathrm{S} 9$ protein yield of $143 \mathrm{mg} / \mathrm{g}$ liver as scaling factor derived previously based on the cytosolic and microsomal protein yield [39]. The $\mathrm{V}_{\max }$ values for conversion of AAl by intestinal $\mathrm{S} 9$ fractions were scaled accordingly using an estimated S9 protein yield of $11.4 \mathrm{mg} / \mathrm{g}$ small intestine as scaling factor $[2,40]$. The in vivo $K_{m}$ values were assumed to equal the in vitro $K_{m}$ values.

The excretion parameters were determined by fitting the model to the in vivo kinetics data from Ren et al. (2014) [41]. The biliary and urinary excretion rate constants were estimated to be 35 and $0.5 \mathrm{~h}^{-1}$ for the rat. Allometric scaling was used to scale the obtained rate constants from rat to human and mouse. With respect to urinary excretion, the rate constants were scaled based on the differences in glomerular filtration rate (GFR) between the species [42] and for biliary excretion, the rate constants were scaled based on the differences in relative liver weight [43]. The scaled biliary and urinary excretion rate constants were 56.6 and $0.6 \mathrm{~h}^{-1}$ for the mouse model and 26.8 and $0.1 \mathrm{~h}^{-1}$ for the human model. Although AAla was shown to be excreted in the urine [18, $32,44]$, this excretion was not included in the current PBK model since only the formation of AAla and not its excretion will be of influence on the prediction for the disappearance of the parent compound and thus the predicted $C_{\max }$ and AUC for AAI. The set of differential equations describing the mass balance equations including a list of abbreviations used in the equations can be found in supplementary data A. The PBK model equations were solved with Berkeley Madonna (version 8.3.18, UC Berkeley, CA, USA) using Rosenbrock's algorithms for solving stiff systems. 


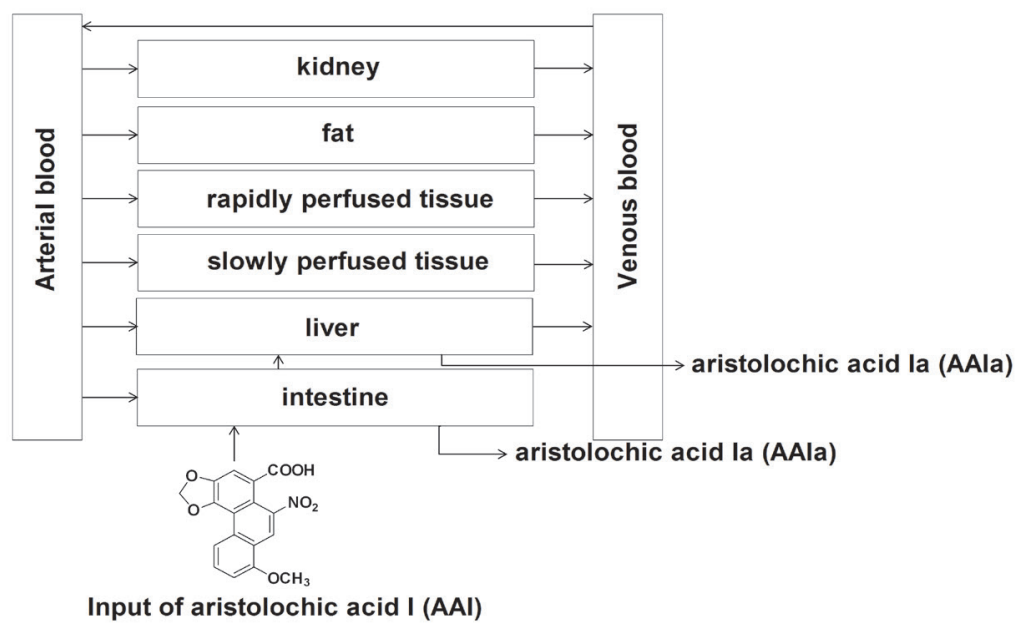

Fig. 2.3 Schematic diagram of the PBK models for aristolochic acid I (AAI) in rat, mouse and human. 
Table 2.1

Parameters used in the PBK models for aristolochic acid I (AAI)

\begin{tabular}{|c|c|c|c|}
\hline \multirow[t]{2}{*}{ Parameters } & \multicolumn{3}{|c|}{ Values } \\
\hline & rat & mouse & human \\
\hline \multicolumn{4}{|l|}{ Physiochemical parameters $^{a}$} \\
\hline \multicolumn{4}{|l|}{ Tissue/plasma partition coefficients } \\
\hline Fat/plasma & 70.3 & $70.3^{b}$ & 54.8 \\
\hline Liver/plasma & 7.3 & $7.3^{b}$ & 7.6 \\
\hline Kidney/plasma & 6.6 & $6.6^{\mathrm{b}}$ & 4.6 \\
\hline Small intestine/plasma & 10.5 & $10.5^{\mathrm{b}}$ & 9.6 \\
\hline Richly perfused tissues/plasma & 7.3 & $7.3^{\mathrm{b}}$ & 7.6 \\
\hline Slowly perfused tissues/plasma & 4.1 & $4.1^{\mathrm{b}}$ & 4.7 \\
\hline \multicolumn{4}{|l|}{ Physiological parameters ${ }^{c}$} \\
\hline Body weight (kg) & 0.25 & 0.025 & 70 \\
\hline \multicolumn{4}{|l|}{ Tissue volumes (\% body weight) } \\
\hline Fat & 7 & 10 & 21.4 \\
\hline Liver & 3.4 & 5.5 & 2.6 \\
\hline Kidney & 0.7 & 1.7 & 0.4 \\
\hline Intestine & 1.4 & 2.5 & 0.9 \\
\hline Arterial blood & 1.9 & 1.2 & 2.0 \\
\hline Venous blood & 5.6 & 3.7 & 5.9 \\
\hline Richly perfused & 3.5 & 0.8 & 5.0 \\
\hline Slowly perfused & 67.6 & 65.1 & 51.7 \\
\hline Cardiac output (1/h/kg bw $\left.{ }^{0.74}\right)$ & 15 & 15 & 15 \\
\hline \multicolumn{4}{|l|}{ Blood flow to tissue (\% cardiac output) } \\
\hline Fat & 7.0 & 9.0 & 5.2 \\
\hline Liver (excluding portal vein fraction) & 13.2 & 6.7 & 4.6 \\
\hline Kidney & 14.1 & 9.1 & 17.5 \\
\hline Intestine & 11.8 & 18.3 & 18.1 \\
\hline Richly perfused & 36.9 & 41.9 & 29.8 \\
\hline Slowly perfused & 17.0 & 15.0 & 24.8 \\
\hline
\end{tabular}

a Berezhkovskiy (2004) [37]

${ }^{b}$ assumed to be the same as for rat

'Brown et al. (1997) [36] 


\subsubsection{PBK model evaluation}

For the model evaluation, a local sensitivity analysis was performed to evaluate the influential parameters on the model output. Normalized sensitivity coefficients (SC) were calculated for the predictions of maximum concentration $\left(C_{\max }\right)$ and the area under the curve (AUC) of AAI in kidney tissue as the model output (C) using the following equation:

$S C=\left(C^{\prime}-C\right) /\left(P^{\prime}-P\right)^{*}(P / C)$

Where $C$ is the initial value of the model output and $C^{\prime}$ is the modified value after changing the parameter value $\mathrm{P}, \mathrm{P}$ is the initial parameter value and $\mathrm{P}^{\prime}$ is the modified parameter value [45]. On the basis of the literature, a $5 \%$ increase in parameter values was chosen, to analyze the effect of a change in a parameter. The sensitivity analysis was conducted for oral exposures to a single doses of 0.1 and $100 \mathrm{mg} / \mathrm{kg}$ bw of AAI. Each parameter was analyzed individually, keeping the other parameters to initial values. The impact of the most sensitive model parameters on the predicted $\mathrm{BMDL}_{10}$ values was subsequently studied by decreasing and increasing all sensitive parameters in the model with 10-fold, as worst case estimate of the uncertainty in the model predictions, and predicting the $\mathrm{BMDL}_{10}$ values based on the altered parameter set. Physiological parameters were kept the same in this analysis.

In order to assess how the PBK models performed in predicting AAI plasma concentrations, the predicted AAI plasma concentrations obtained with the rat model were compared with plasma concentrations from in vivo kinetic studies in rat as reported in the literature [41]. Based on the current model, the full blood concentration of AAI was simulated, not the plasma concentration. Based on the blood to plasma partition ratio (B/P) as predicted with Simcyp software (https:// members.simcyp.com/account/tools/BP/), with the value of the fraction unbound being 0.0225 [32], a log $\mathrm{K}_{\text {ow }}$ of 4.45 [38], a pKa of 2.99 (calculated using Advanced Chemistry Development (ACD/ Labs) Software V11.02 (๑ 1994-2015 ACD/Labs), and the default values for plasma pH of 7.4 and hematocrit of $45 \%$, the predicted B/P is found to be 1.12. Based on this result, the correction from blood to plasma concentration was not considered necessary.

\subsubsection{Translation of the in vitro concentration-response curve to in vivo dose-response curves}

Based on in vitro concentration-response curves from each cell line, the in vivo dose-response curves were predicted by PBK model-based reverse dosimetry. The predictions were done with two Page | 38 
approaches.

In the first approach each applied concentration from the cytotoxicity experiments was set equal to the maximum concentration $\left(C_{\max }\right)$ of $A A I$ in the kidney as input in the PBK model to calculate the oral dose that results in this concentration. In a second approach, the area under the curve (AUC) of AAI was used. To this end the in vitro concentration-response data were translated to AUC-response data, by multiplying the applied concentration with the assay time [46], based on the assumption that the concentration of AAl is constant in the incubations. This assumption underlying the calculation of the AUC was validated by measuring the time-dependent changes in the concentration of $\mathrm{AAl}$ in cell culture medium at two concentrations (10 $\mu \mathrm{M}$ and $200 \mu \mathrm{M})$ with both cell lines, showing no decrease in concentrations of AAI over $24 \mathrm{~h}$ of incubation. For the extrapolation of the in vitro AUC-response curves to the in vivo situation we assessed which oral doses are required in the PBK model to reach these AUC values in the kidney. By performing this exercise for each concentration (or AUC) used in the in vitro assay, the in vitro concentrationresponse curves (or AUC-response curves) could be translated into in vivo dose-response curves.

\subsubsection{BMD analysis of in vitro concentration-response data and of predicted in vivo dose-response data}

$B M D$ modeling was applied on the in vitro concentration-response curves to obtain a $B M C L_{10}$ (lower limit of the $95 \%$ confidence interval of the benchmark concentration at $10 \%$ response) value for cytotoxicity and on the predicted in vivo dose-response data to determine $B M D L_{10}$ values for nephrotoxicity. This BMD modeling was performed using all models for dichotomous data of the Environmental Protection Agency (EPA)'s Benchmark Dose Software (BMDS) version 2.5. Only models that met the requirements for acceptance of the model fit were considered for the determination of $\mathrm{BMDL}_{10}$ values. A similar $\mathrm{BMD}$ analysis was also performed for all predicted in vivo dose-response curves derived upon extrapolation of the concentration-response curves for in vitro cytotoxicity derived from the literature.

\subsubsection{Evaluation of the in vitro PBK approach}

To evaluate the potential of the in vitro-in silico approach to obtain a POD for risk assessment, the POD values predicted by the PBK model-based reverse dosimetry approach based (i.e. $\mathrm{BMDL}_{10}$ values) were compared to PODs derived from in vivo acute kidney toxicity data from literature. 
Chapter 2

Exact numbers on oral bioavailability of AAI and possible AAI metabolism by gut microbiota are not known but it is generally described that upon oral administration, AAI is rapidly absorbed in the gastrointestinal tract and excreted to a large extent in urine [47]. This implies that deviations due to the influence of intestinal metabolism by the microbiota are expected to be limited. If a small amount of orally administered AAI would be metabolized by the microbiome the influence of this pathway on the overall outcome and predictions will depend obviously on the type of metabolites formed and their bioavailability. Therefore, the predictions based on different percentage of AAI bioavailability upon oral exposure were also studied assuming $0 \%, 10 \%$ or $30 \%$ reduction in bioavailability. 


\subsection{RESULTS}

\subsubsection{In vitro cytotoxicity data}

Figure 2.4a shows the concentration-response curve for the cytotoxicity of AAl in vitro as obtained with the LLC-PK1 and the MDCK cell line. The in-vitro BMCL ${ }_{10}$ was $1.4 \mu \mathrm{M}$ for the LLC-PK1 cells and $3.8 \mu \mathrm{M}$ for the MDCK cells respectively $\left({ }^{*} \mathrm{p}<0.05\right)$. Figure $2.4 \mathrm{~b}$ shows that the in vitro concentrationresponse curves obtained in the present study match well with most in vitro concentrationresponse curves reported in the literature for AAI (pure or in a mixture with AAll), except for the data reported by Balachandran et al. (2005) [15] for LLC-PK1 and by Huljic et al. (2008) [48] for one of the experiments with primary porcine cells. These two data sets from literature were excluded from further analyses since they obviously deviate from all other data obtained.

Table 2.2 shows the $\mathrm{BMCL}_{10}$ values derived from the concentration-response curves depicted in Figure 2.4b. The lowest $\mathrm{BMCL}_{10}$ for cytotoxicity was found to be $0.3 \mu \mathrm{M}$ and the highest was $22.5 \mu \mathrm{M}$. This variations may in part be due the mixture effect of AAs [48, 49]. Hsin et al. (2006) [49] and Huljic et al. (2008) [48] exposed cells to a mixture of AAI and AAll while other authors exposed cells to AAI only. This implies that some discrepancy between the data reported in these studies for the concentration dependent effects may be due to the fact that for the mixtures toxicity when expressed as a function of the total AA concentration may be somewhat less because AAll is known to be less cytotoxic than AAI [15, 50]. The outcome from Huljic et al. (2008) [48] for the second concentration-response curve for primary porcine cells was not considered for further analysis because the ratio between the $\mathrm{BMC}$ and the $\mathrm{BMCL}_{10}$ and the value was higher than 10 mainly due to inadequate distribution of the data points over the dose response curve especially in the lower concentration range making the BMD analysis unreliable. 

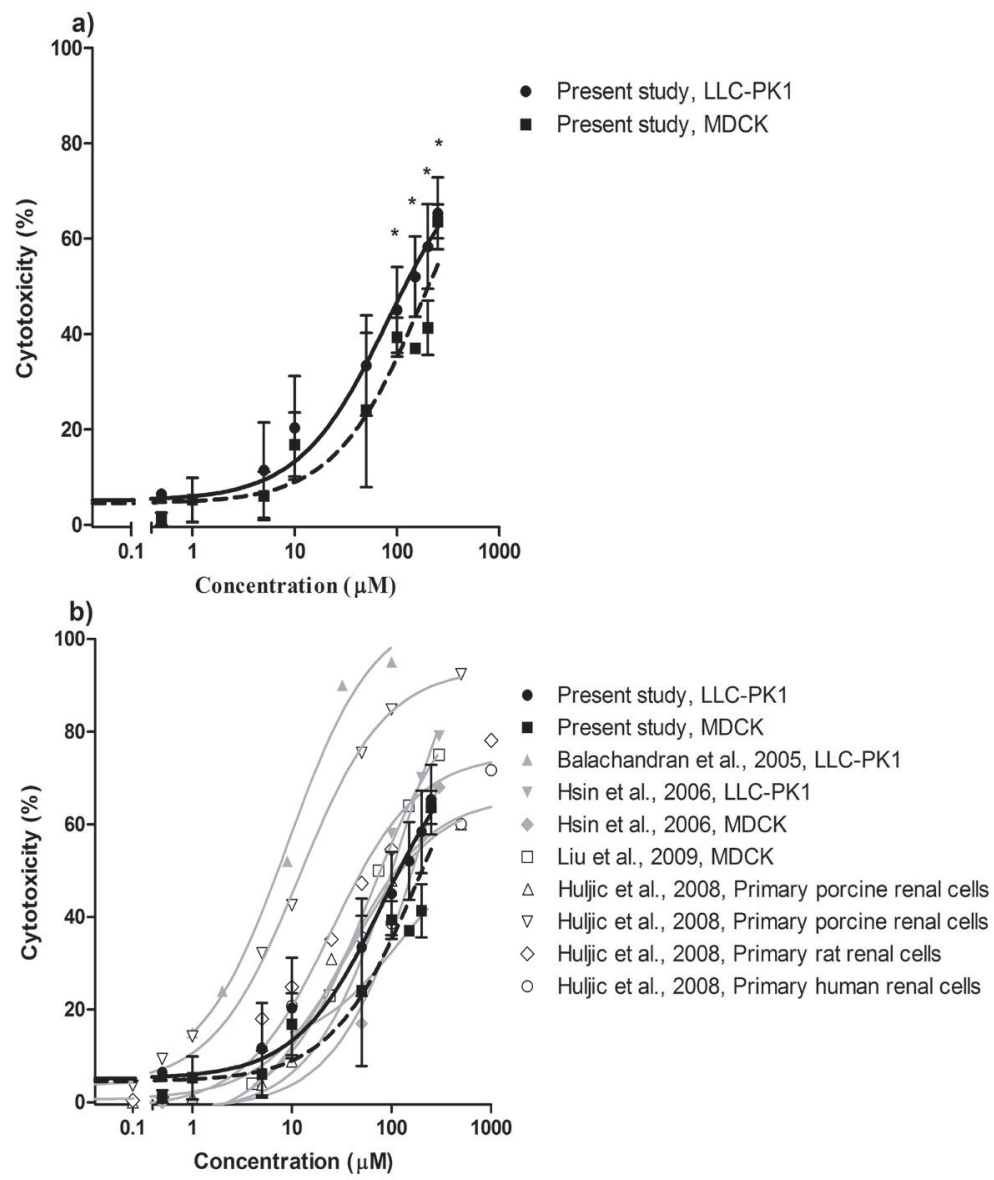

Fig. 2.4 Concentration response-curves for the cytotoxicity of AAI $(\mu \mathrm{M})$ towards the LLC-PK1 (circles) and MDCK (squares) cell line upon 24 hours exposure (mean values \pm SD) (a) and comparison of the data from figure (a) to concentration response-curves reported in literature (b). To allow BMD modeling the individual cytotoxicity data are presented in supplementary data B. One way ANOVA was used to test for significant difference between treatment group versus control group in both cell lines $(* p<0.05)$. 
Table 2.2

$\mathrm{BMCL}_{10}$ values derived from the concentration-response curves depicted in Figure 2.4b. The concentration-response curves that met the criteria for model fit are presented in supplementary data $C$.

\begin{tabular}{lll}
\hline Cell line & $\mathrm{BMCL}_{10}(\mu \mathrm{M})$ & Studies \\
\hline LLC-PK1 & $1.4-1.6$ & Present study \\
MDCK & $3.8-4.2$ & Present study \\
\hline LLC-PK1 & $4.9-15.3$ & Hsin et al. (2006) [49] \\
\hline MDCK & $11.2-22.5$ & Hsin et al. (2006) [49] \\
MDCK & $3.4-8.7$ & Liu et al. (2009) [50] \\
Primary rat renal cells & $1.3-1.4$ & Huljic et al. (2008) [48] \\
Primary human renal cells & $0.3-1.5$ & Huljic et al. (2008) [48] \\
\hline
\end{tabular}

\subsubsection{In vitro kinetic data for rat, mouse and human}

UPLC analysis of the in vitro incubations with AAI performed to derive the kinetic parameters for the PBK models revealed that rat and mouse liver and intestine S9 fractions were capable to convert AAI into AAla. Only one metabolite was found, at a retention time of $5.5 \mathrm{~min}$, which was absent in control incubations. For human samples, only liver 59 was able to form AAla. No conversion of AAI was found in incubations with the kidney 59 fractions of the different species. In each incubation, metabolism followed Michaelis-Menten kinetics (Fig. 2.5). Table 2.3 displays the apparent $\mathrm{V}_{\max }$ and $\mathrm{K}_{\mathrm{m}}$ values obtained from these plots and the (scaled) catalytic efficiency $\left(\mathrm{V}_{\max } / \mathrm{K}_{\mathrm{m}}\right)$ derived from them. The highest conversion of AAI to AAla was observed for mouse. The total catalytic efficiency (sum of liver and intestine) for conversion of AAI by this species was 38-fold higher than for rat and 64-fold higher than for human. This higher catalytic efficiency for mouse was mainly due to a high metabolic conversion of AAI in the intestine, which was only a minor reaction in rat and not observed for human. The overall catalytic efficiency for metabolic conversion of AAI to AAla by rat and human was comparable, being only 2 -fold higher in rat than in human. 


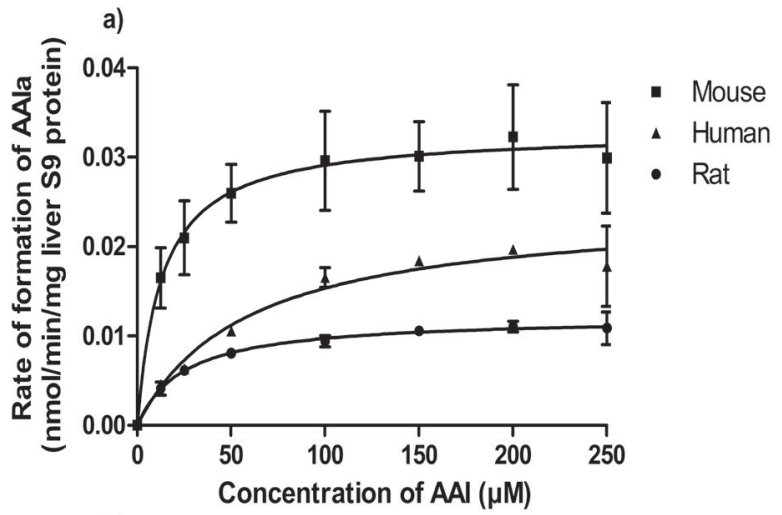

b)

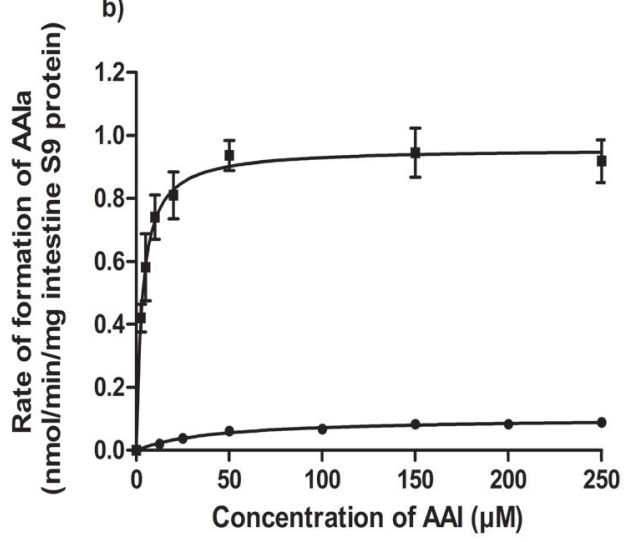

Fig. 2.5 AAI concentration-dependent rate of formation of AAla by liver (a) and intestine (b) in incubations with rat (filled circle), mouse (filled square) and human (filled triangle) S9 fractions and $\mathrm{NADPH}$ as a cofactor. In the plots, each point represents the mean $( \pm S D)$ of $n=3$ measurements. $\mathrm{R}^{2}$ for the fit of the data to the Michaelis-Menten curve was $0.97,0.88$ and 0.94 for data with rat, mouse and human liver S9 and 0,96 and 0.96 for data with rat and mouse intestinal S9. 
Table 2.3

Kinetic parameters for AAla formation from AAI by pooled rat, mouse and human tissue fractions.

\begin{tabular}{|c|c|c|c|c|c|}
\hline $\begin{array}{l}\text { Species } \\
\text { Organ }\end{array}$ & $\begin{array}{l}\mathrm{V}_{\max } \\
(\mathrm{nmol} / \mathrm{min} / \mathrm{mg} \text { protein in } \\
\text { tissue fraction) }\end{array}$ & $\mathrm{K}_{\mathrm{m}}(\mu \mathrm{M})^{\mathrm{a}}$ & $\begin{array}{l}\text { Catalytic efficiency }(\mathrm{mL} / \\
\text { min/mg protein in tissue } \\
\text { fraction) }\end{array}$ & $\begin{array}{l}\text { Scaled } V_{\text {max }}(n m o l / \\
\text { min/g tissue })\end{array}$ & $\begin{array}{l}\text { Scaled catalytic efficiency } \\
\text { (mL/min/g tissue) }\end{array}$ \\
\hline \multicolumn{6}{|l|}{ Rat } \\
\hline Liver & $0.012 \pm 0.0$ & $24.8 \pm 3.0$ & $4.8 \times 10^{-4}$ & 1.7 & 0.07 \\
\hline Intestine & $0.10 \pm 0.0$ & $42.8 \pm 6.4$ & $23 \times 10^{-4}$ & 1.1 & 0.03 \\
\hline $\begin{array}{l}\text { Kidney } \\
\text { Mouse }\end{array}$ & \multicolumn{4}{|c|}{ Mouse } & \\
\hline Liver & $0.03 \pm 0.0$ & $13.1 \pm 3.4$ & $25 \times 10^{-4}$ & 4.7 & 0.36 \\
\hline Intestine & $0.96 \pm 0.0$ & $3.17 \pm 0.3$ & $3030 \times 10^{-4}$ & 10.9 & 3.45 \\
\hline $\begin{array}{l}\text { Kidney } \\
\text { Human }\end{array}$ & n.d. ${ }^{b}$ & n.d. ${ }^{b}$ & - & & \\
\hline Liver & $0.02 \pm 0.0$ & $58.4 \pm 11.1$ & $4.1 \times 10^{-4}$ & 3.4 & 0.06 \\
\hline Intestine & n.d. ${ }^{b}$ & n.d. ${ }^{b}$ & - & & \\
\hline Kidney & n.d. ${ }^{b}$ & n.d. ${ }^{b}$ & - & & \\
\hline
\end{tabular}

a the values are mean \pm SD of three independent determinations.

${ }^{b}$ n.d. non-detected 


\subsubsection{PBK model outcome}

Figure 2.6 shows the plasma concentration-time curve of AAI as predicted by the developed rat PBK model compared to in vivo kinetic data obtained from the literature [41]. By fitting excretion parameters, a model could be obtained that showed no difference (1.1-fold) between the predicted and observed $C_{\max }$ of AAl in plasma at a single oral dose of $25.3 \mathrm{mg} / \mathrm{kg} \mathrm{bw}$. The AUC derived from these data showed a 1.7-fold difference between the AUC predicted with the PBK model and the observed AUC obtained from the literature, being higher for the predicted value. Given these results, it is concluded that the model is fit for its purpose in spite of the fact that some kinetic steps are not included. The predicted $C_{\max }$ and AUC values fall within the generally observed uncertainty in PBK model predictions.

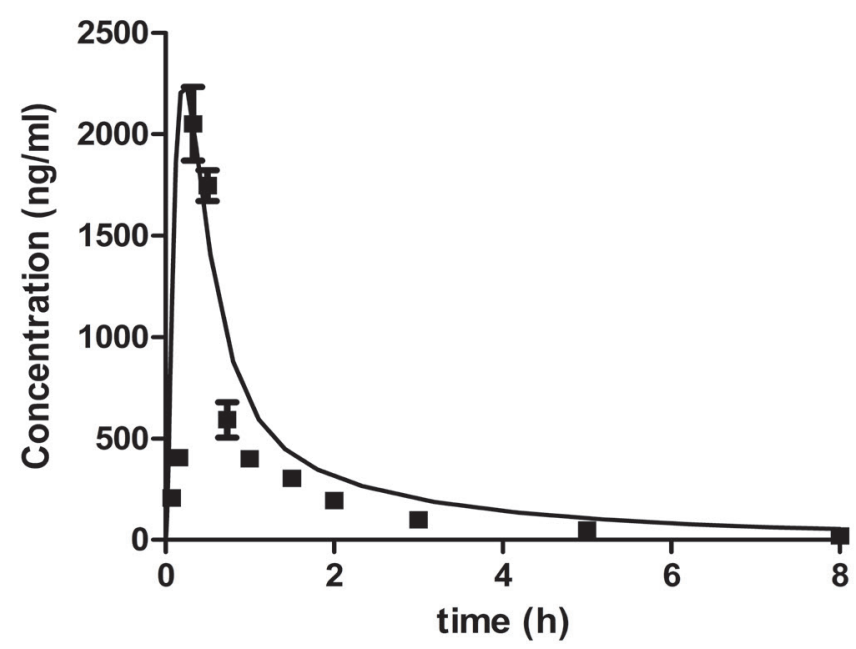

Fig. 2.6 Rat PBK model evaluation by comparison of the PBK model-based predicted concentration time curve (solid line) and literature data (filled square symbols) [41] for AAI maximum plasma concentrations in rat after oral exposure to $25.3 \mathrm{mg} / \mathrm{kg}$ bw of AAl. 


\subsubsection{Sensitivity analysis of the PBK models}

Four sensitivity analyses were performed, based on the maximum concentration $\left(C_{\max }\right)$ or the AUC of AAl in the kidney tissue and exposure to a single oral dose of either 0.1 or $100 \mathrm{mg} / \mathrm{kg}$ bw of AAl. In all sensitivity analyses (supplementary data D) the volume of the liver, biliary excretion, and the partition coefficients for the liver and the kidney were the most influential parameters in all three PBK models, all expressing normalized sensitivity coefficients higher than 0.1 (in absolute value). The partition coefficient for the intestine and the uptake rate constant of AAI were furthermore observed to influence the $C_{\max }$ in all models.

With regard to the different dose levels, the sensitivity analyses revealed that the influence of most PBK model parameters on the model outcomes did not change in a dose dependent manner, except for the parameters related to the intestine which were more influential at low oral dose levels compared to high oral dose levels in the mouse PBK model. Also the normalized sensitivity coefficients of several parameters in the mouse PBK model were dose dependent, namely body weight, volume and blood flow of the kidney. The major difference between the three models was that the parameters for the intestine were more influential in the mouse model than in the rat and human PBK models.

The impact of the most sensitive model parameters on the predicted $B M D L_{10}$ values was subsequently studied by decreasing and increasing all sensitive parameters in the model with 10fold, as worst case estimate of the uncertainty in these parameters, and predicting the $B M D L_{10}$ values based on the altered parameter set. The results of this analysis are provided in supplementary data $\mathrm{E}$ and reveal that the predicted range of $\mathrm{BMDL}_{10}$ values can be about 8.0- to 20.2-fold higher for rat, 3.5- to 26.4-fold higher for mouse and 3.4- to 27.7-fold higher for human. This range is considered acceptable as the $\mathrm{BMDL}_{10}$ predictions generally remain within one order of magnitude from the original predictions or differ maximally 30 -fold.

\subsubsection{Translation of the in vitro concentration-response curves to in vivo dose-response curves}

Figure 2.7 shows the predicted in vivo dose-response curves for kidney toxicity of AAI in rat, mouse and human obtained by converting the in vitro concentrations-response curves from either the LLC-PK1 and the MDCK cell line (Figure 2.4a) by PBK-model based reverse dosimetry. Each plot in Figure 2.7 shows four predicted dose-response curves, derived from the in vitro cytotoxicity 
concentration-response curves obtained with respectively the LLC-PK1 and MDCK cell lines in the present study (Figure 2.4a) using either the $C_{\max }$ or the AUC. Use of the $\mathrm{Cmax}$ resulted in curves that are 15.0- to 23.7-fold lower compared with the curves obtained when using the AUC. The difference in the curves obtained using the LLC-PK1 or MDCK cell data varied by only 1- to 1.4-fold. Table 2.4 presents the $\mathrm{BMDL}_{10}$ values derived from the predicted dose-response curves. The predicted $\mathrm{BMDL}_{10}$ values obtained for the three species were within the same order of magnitude. Based on the $C_{\max }$ approach, the predicted range of $\mathrm{BMDL}_{10}$ values was observed to be on average 1.2-fold higher for human than for rat and 2.3-fold lower for human than for mouse. Based on the AUC, the predicted $\mathrm{BMDL}_{10}$ values derived from the dose-response curves for human were on average 1.0-fold higher for rat and 2.9-fold lower for human than for mouse. These results suggest that the sensitivity of humans for AAl induced kidney toxicity may be more comparable with rat than with mouse, although the difference falls within the 10-fold uncertainty factor generally used to account for interspecies differences [51].

Similar to the PBK-model based predictions defined using the concentration-response curves determined in the present study, predictions were also made using the in vitro concentrationresponse curves for cytotoxicity of AAI as reported in the literature. The results obtained are presented in Table 2.5. The same trends were observed from these analyses, revealing that the range of $\mathrm{BMDL}_{10}$ values for human based on $\mathrm{C}_{\max }$ are about 1.4-fold higher than the range of predicted $\mathrm{BMDL}_{10}$ values for rat and about 1.9-fold lower than the predicted $\mathrm{BMDL}_{10}$ values for mouse. Based on the $A \cup C$, the range of $B_{M D L}$ values derived from the dose-response curves for human were 1.1fold lower than the predicted $\mathrm{BMDL}_{10}$ values for rat and about 2.7-fold lower than predicted $B M D L_{10}$ values for mouse. The predicted $\mathrm{BMDL}_{10}$ values based on the in vitro concentration response-curves from the literature where in the same range as predicted using the cytotoxicity curves of the present study.

\subsubsection{Evaluation of the in vitro-PBK model-based predicted PODs for in vivo and human kidney toxicity}

To evaluate the outcomes of the predicted PODs for in vivo kidney toxicity, the $\mathrm{BMDL}_{10}$ values presented in Table 2.4 and 2.5 were compared to in vivo reported data for acute kidney toxicity of AAI as available in the literature. Table 2.6 and 2.7 present an overview of literature data on the acute kidney toxicity in rat (Table 2.6) and mouse (Table 2.7), measuring for example urinary BUN Page $\mid 48$ 
and creatinine concentrations as a measure of acute toxicity. Table 2.6 and 2.7 also present the PODs that were derived from these studies. BMD analysis of these literature data revealed that the data sets were not suitable for calculation of $\mathrm{BMDL}_{10}$ values due to the limited number of data points and an inadequate distribution of the data points over the dose response curves. As a result, table 2.6 and 2.7 list the NOAEL values or range of estimated NOAEL to LOAEL values that could be derived as POD from these in vivo data. When only a LOAEL was available, the NOAEL was derived using the classical approach, dividing the LOAEL by a factor of 10 .

Figure 2.8 presents a comparison of the predicted median $\mathrm{BMDL}_{10}$ values obtained in the present study to the estimated PODs from the literature data for either rat (Figure 2.8a) or mouse (Figure 2.8b) based on $\mathrm{C}_{\max }$. From this comparison it follows that, given the uncertainty in the PODs derived from the sometimes-limited in vivo data, the PODs derived from the predicted doseresponse curves for the rat and mouse based on $C_{\max }$ fall well within the range of PODs that can be derived from the available in vivo studies. The results presented in Figure 2.8 reveal a 2.3- to 55.6fold difference between the range of experimental PODs and the predicted $B M D L_{10}$ values in the rat model (Figure 2.8a) and 1.5- to 163.8-fold in the mouse model (Figure 2.8b), when performing the extrapolation based on $C_{\max }$. Is it noted that the in vivo data available for mice resulted from studies with ip or iv dosing regimens. This implies high and even up to $100 \%$ bioavailability. In our modelling, AAl was assumed to be $100 \%$ bioavailable upon oral administration allowing comparison to iv or ip administration. In addition, the predictions for the mouse model were also made assuming that $0 \%$ (current data), $10 \%$ or $30 \%$ of the orally administered AAI would not become bioavailable due to for example metabolism by the intestinal microbiota. The predicted PODs at the reduced levels of bioavailability amounted to 1.1- and 1.3-fold higher than the currently predicted values at $10 \%$ and $30 \%$ intestinal microbiome metabolism respectively. Clearly also in this situation the PODs are in line with the in vivo data.

Interestingly, the current human model could also be validated using available human data. The study of Yang et al. (2012) [52] describes 13 patients diagnosed with acute kidney injury (acute AAN) from exposure to AA. The doses that caused acute AAN were reported to range from 0.09 to $4.49 \mathrm{mg} / \mathrm{kg}$ bw/day. The predicted human dose-response curves for kidney toxicity of AAI (Figure 2.7c) predict kidney toxicity in human to occur in the same range with $\mathrm{BMD}_{10}$ values at 1.9$2.1 \mathrm{mg} / \mathrm{kg} \mathrm{bw} /$ day and $4.4-5.3 \mathrm{mg} / \mathrm{kg}$ bw/day when data are predicted based on the $\mathrm{C}_{\max }$ from the LLC-PK1 and MDCK cell line respectively.

The prediction based on the AUC approach, the differences amounted to 1.1- to 111.3-fold 
Chapter 2

for the rat model and more than one order of magnitude for the mouse model different compared with the in vivo PODs (supplementary data F). These results suggest that extrapolation based on $\mathrm{C}_{\max }$ is the most appropriate method to predict acute nephrotoxicity, which may be corroborated by the fact that acute toxicity is generally a result of high exposure resulting from peak concentrations [53]. Altogether the results obtained reveal that our in vitro-in silico PBK model- based reverse dosimetry approach provides data that match the results from in vivo animal experiments well. 


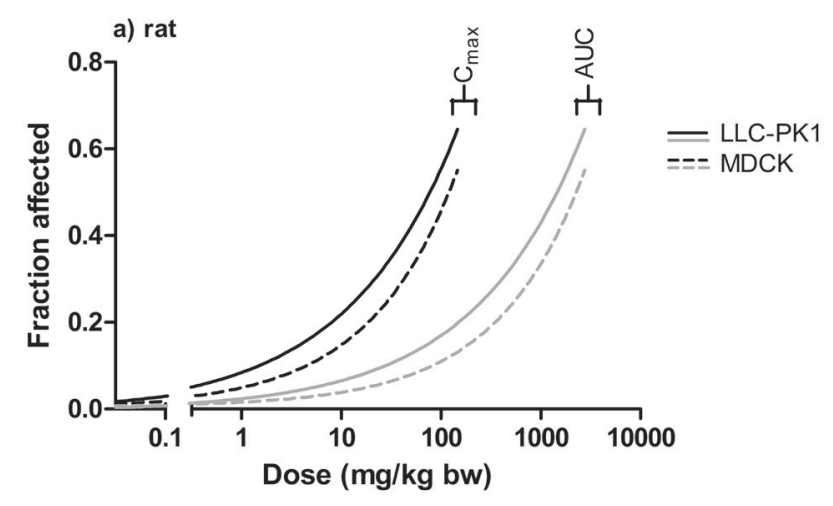

b) mouse
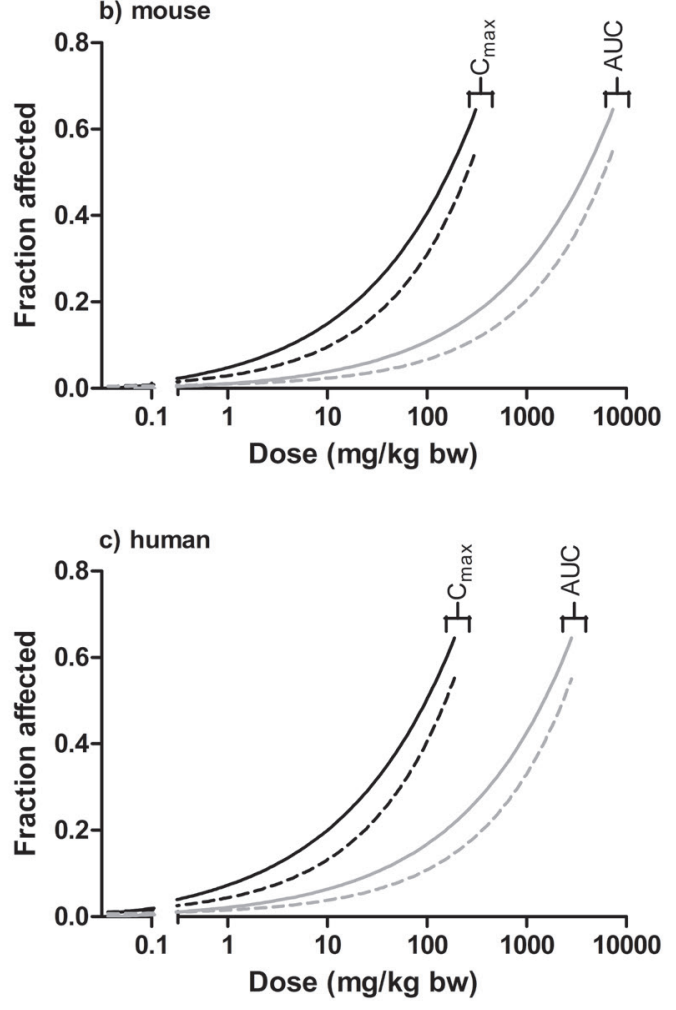

Fig. 2.7 Predicted in vivo dose-response curves for acute kidney toxicity in rat (a), mouse (b) and human (c). The solid lines represent the predicted in vivo dose-response curves based on data from the LLC-PK1 cell line and the dashed lines represent the predicted dose-response curves based on data from the MDCK cell line. The black lines represent the predictions based on the $C_{\max }$ and the grey lines the predictions based on the AUC. 
Chapter 2

Table 2.4

Predicted $\mathrm{BMDL}_{10}$ values derived from dose-response curves predicted using PBK-model based reverse dosimetry, based on either $C_{\max }$ or $A \cup C$, to translate the in vitro concentrations response curves as obtained in the present study to the in vivo situation (Figure 2.4a).

\begin{tabular}{llllll}
\hline Cell line & Approach & \multicolumn{3}{c}{ Predicted $\mathrm{BMDL}_{10}(\mathrm{mg} / \mathrm{kg} \mathrm{bw})$} & Studies \\
\cline { 3 - 5 } & & Rat & Mouse & Human & \\
\hline LLC-PK1 & $\mathrm{C}_{\max }$ & $0.8-1.0$ & $2.5-2.9$ & $1.0-1.2$ & Present study \\
MDCK & $C_{\max }$ & $2.2-2.5$ & $6.3-6.8$ & $2.8-3.1$ & \\
LLC-PK1 & AUC & $15.5-18.4$ & $47--.8-56.7$ & $15.9-18.8$ & \\
MDCK & AUC & $42.3-46.7$ & $126.9-138.5$ & $43.3-47.9$ & \\
\hline
\end{tabular}


Table 2.5

Predicted $\mathrm{BMDL}_{10}$ values derived from dose-response curves predicted using PBK-model based reverse dosimetry, based on either $C_{\max }$ or $A \cup C$, to translate the in vitro concentrations response curves obtained from the literature (Figure 2.4b).

\begin{tabular}{|c|c|c|c|c|c|}
\hline \multirow[t]{2}{*}{ Cell line } & \multirow[t]{2}{*}{ Approach } & \multicolumn{3}{|c|}{ 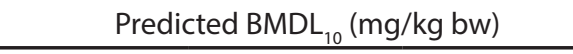 } & \multirow[t]{2}{*}{ Studies } \\
\hline & & Rat & Mouse & Human & \\
\hline LLC-PK1 & $\mathrm{C}_{\max }$ & $3.7-9.0$ & 8.3-19.2 & $4.7-11.5$ & $\begin{array}{l}\text { Hsin et al. } \\
\text { (2006) [49] }\end{array}$ \\
\hline MDCK & $C_{\max }$ & 7.3-13.2 & $16.4-28.1$ & $16.8-22.9$ & $\begin{array}{l}\text { Hsin et al. } \\
\text { (2006) [49] }\end{array}$ \\
\hline MDCK & $\mathrm{C}_{\max }$ & $2.3-5.1$ & $5.8-11.2$ & $2.9-4.3$ & $\begin{array}{l}\text { Liu et al. } \\
\text { (2009) [50] }\end{array}$ \\
\hline $\begin{array}{l}\text { Primary rat renal } \\
\text { cells }\end{array}$ & $C_{\max }$ & $0.4-0.8$ & $2.1-2.3$ & 0.97-1.05 & $\begin{array}{l}\text { Huljic at al. } \\
\text { (2008) [48] }\end{array}$ \\
\hline $\begin{array}{l}\text { Primary human } \\
\text { renal cells }\end{array}$ & $\mathrm{C}_{\max }$ & $0.4-0.9$ & $1.1-2.3$ & $0.5-1.1$ & $\begin{array}{l}\text { Huljic et al. } \\
\text { (2008) [48] }\end{array}$ \\
\hline LLC-PK1 & AUC & 68.9-169 & $189.9-409.9$ & $70.7-153.5$ & $\begin{array}{l}\text { Hsin et al. } \\
\text { (2006) [49] }\end{array}$ \\
\hline MDCK & AUC & $137.5-216.3$ & $377.0-590.9$ & $141.2-255.0$ & $\begin{array}{l}\text { Hsin et al. } \\
\text { (2006) [49] }\end{array}$ \\
\hline MDCK & AUC & $43.5-96.1$ & $123.5-260.1$ & $44.6-98.8$ & $\begin{array}{l}\text { Liu et al. } \\
\text { (2009) [50] }\end{array}$ \\
\hline $\begin{array}{l}\text { Primary rat renal } \\
\text { cells }\end{array}$ & AUC & $14.3-15.6$ & $43.7-48.0$ & $14.6-15.9$ & $\begin{array}{l}\text { Huljic et al. } \\
\text { (2008) [48] }\end{array}$ \\
\hline $\begin{array}{l}\text { Primary human } \\
\text { renal cells }\end{array}$ & AUC & 7.7-16.2 & $22.4-47.0$ & 7.9-16.6 & $\begin{array}{l}\text { Huljic et al. } \\
\text { (2008) [48] }\end{array}$ \\
\hline
\end{tabular}


In vivo rat acute kidney toxicity data of AAl obtained from the literature.

\begin{tabular}{|c|c|c|c|c|c|c|c|c|}
\hline Species & $\begin{array}{l}\text { Exposure } \\
\text { route }\end{array}$ & $\begin{array}{l}\text { Dose }^{a} \\
\text { (mg/kgbw/day) }\end{array}$ & Markers of kidney toxicity & Type of exposure & AA composition & $\begin{array}{l}\text { POD (mg/ } \\
\text { kgbw/day) }\end{array}$ & Figure & Reference \\
\hline Rat & Oral & 0,50 & $\begin{array}{l}\text { BUN \& Creatinine } \\
\text { concentration }\end{array}$ & single & n.a. ${ }^{b}$ & $<50$ & $2.8 a$ & $\begin{array}{l}\text { Chen et al. } \\
\text { (2006) [54] }\end{array}$ \\
\hline Rat & Oral & $0,7.7,38.5,77^{a}$ & $\begin{array}{l}\text { BUN \& Creatinine } \\
\text { concentration }\end{array}$ & single & $\begin{array}{l}78 \% \text { AAI, } 22 \% \\
\text { AAll }\end{array}$ & $38.5 \mathrm{c}$ & $2.8 a$ & $\begin{array}{l}\text { Mengs and } \\
\text { Stotzem (1993) } \\
\text { [28] }\end{array}$ \\
\hline Rat & Oral & 0,10 & $\begin{array}{l}\text { BUN, Creatinine } \\
\text { concentration, AST, ALT \& } \\
\text { ALP activities }\end{array}$ & $\begin{array}{l}\text { repeated ( } 7 \\
\text { times exposed } \\
\text { over } 19 \text { days) }\end{array}$ & AAI only & $<10$ & $2.8 a$ & $\begin{array}{l}\text { Yeh et al. (2008) } \\
\text { [55] }\end{array}$ \\
\hline Rat & SC & $0,4^{\mathrm{a}}$ & $\begin{array}{l}\text { Creatinine concentration } \\
\text { \& urinary protein }\end{array}$ & $\begin{array}{l}\text { repeated (daily } \\
\text { exposed of } 35 \\
\text { days) }\end{array}$ & $\begin{array}{l}40 \% \text { AAl, } 60 \% \\
\text { AAll }\end{array}$ & $<4$ & $2.8 a$ & $\begin{array}{l}\text { Lebeau et al. } \\
\text { (2005) [56] }\end{array}$ \\
\hline
\end{tabular}

a adjusted dose $=$ dose $\mathrm{x}$ percentage of AAI

${ }^{b}$ n.a. non-available

c absolute NOAEL value

$\mathrm{BUN}=$ blood urea nitrogen, $\mathrm{AST}=$ aspartate amino transferase, $\mathrm{ALT}=$ alanine amino transferase, $\mathrm{ALP}=$ alkaline phosphatase 


\section{Table 2.7}

In vivo mouse acute kidney toxicity data of AAl obtained from the literature.

\begin{tabular}{|c|c|c|c|c|c|c|c|c|}
\hline Species & $\begin{array}{l}\text { Exposure } \\
\text { route }\end{array}$ & $\begin{array}{l}\text { Dose }^{a}(\mathrm{mg} / \\
\text { kgbw/day) }\end{array}$ & Markers of kidney toxicity & Type of exposure & AA composition & $\begin{array}{l}\text { POD (mg/ } \\
\text { kgbw/day) }\end{array}$ & Figure & Reference \\
\hline Mouse & IP & 0,10 & $\begin{array}{l}\text { BUN \& Creatinine } \\
\text { concentration }\end{array}$ & single & AAI only & $<10$ & $2.8 \mathrm{~b}$ & $\begin{array}{l}\text { Xue et al. (2008) } \\
\text { [57] }\end{array}$ \\
\hline Mouse & IP & 0,10 & $\begin{array}{l}\text { BUN \& Creatinine } \\
\text { concentration }\end{array}$ & single & AAI only & $<10$ & $2.8 b$ & $\begin{array}{l}\text { Xiao et al. } \\
\text { (2008) [58] }\end{array}$ \\
\hline Mouse & IP & $0,10,20$ & $\begin{array}{l}\text { BUN \& Creatinine } \\
\text { concentration }\end{array}$ & single & AAl only & $<10$ & $2.8 \mathrm{~b}$ & $\begin{array}{l}\text { Chen et al. } \\
\text { (2011) [59] }\end{array}$ \\
\hline Mouse & IV & $0,4.1^{\mathrm{a}}$ & $\begin{array}{l}\text { Creatinine concentration, } \\
\text { urinary protein \& NAG }\end{array}$ & $\begin{array}{l}\text { repeated ( } 5 \text { days } \\
\text { exposed) }\end{array}$ & $\begin{array}{l}41 \% \text { AAl, } 59 \% \\
\text { AAll }\end{array}$ & $<4.1$ & $2.8 \mathrm{~b}$ & $\begin{array}{l}\text { Huang et al. } \\
\text { (2013) [60] }\end{array}$ \\
\hline Mouse & IP & $0,0.6,6^{\mathrm{a}}$ & $\begin{array}{l}\text { BUN \& Creatinine } \\
\text { concentration }\end{array}$ & $\begin{array}{l}\text { repeated ( } 5 \text { times } \\
\text { per week for } 3 \\
\text { months) }\end{array}$ & $\begin{array}{l}60 \% \text { AAl, } 40 \% \\
\text { AAll }\end{array}$ & $<0.6$ & $2.8 \mathrm{~b}$ & $\begin{array}{l}\text { Yuan et al. } \\
\text { (2011) [61] }\end{array}$ \\
\hline
\end{tabular}

a adjusted dose $=$ dose $\mathrm{x}$ percentage of AAI

$\mathrm{BUN}=$ blood urea nitrogen, NAG $=\mathrm{N}-$ Acetyl- $\beta$-D-glucosaminidase . 
a) Rat model

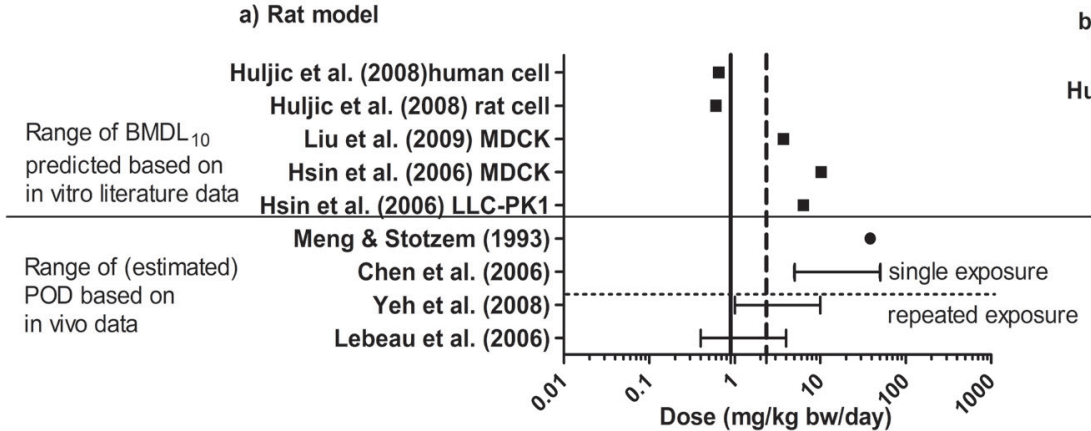

Mouse model

Huljic et al. (2008)human cell Huljic et al. (2008) rat cellLiu et al. (2009) MDCKHsin et al. (2006) MDCK Hsin et al. (2006) LLC-PK1

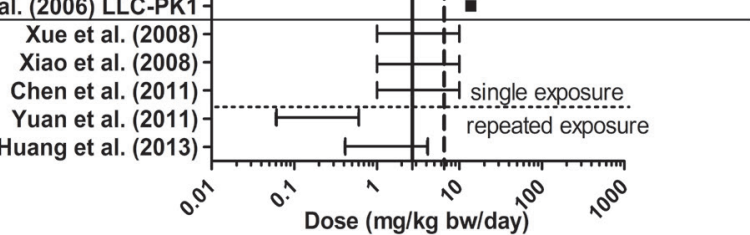

Fig. 2.8 $\mathrm{BMDL}_{10}$ values for acute kidney toxicity of AAl in rat (a) and mouse (b) predicted by the in vitro PBK based-reverse dosimetry approach based on the $C_{\max }$ for LLC-PK1 cell line (vertical solid line), MDCK cell line (vertical dashed line) and predicted based on in vitro literature data (solid squares) as compared to absolute PODs (filled circle) and estimated POD (horizontal capped lines)* values derived from in vivo kidney toxicity studies as shown in Table 2.6 and 2.7 by oral, SC-, IP- or IV- injection exposure.

*range of estimated POD= estimated NOAEL to LOAEL 


\subsection{DISCUSSION}

The aim of the present study was to investigate whether physiologically based kinetic (PBK) modeling-based reverse dosimetry could convert concentration-response curves for cytotoxicity in kidney cells in vitro to in vivo dose-response curves for nephrotoxicity in rat, mouse and human, and provide an adequate POD for the evaluation of nephrotoxicity in risk assessment. This was done using the nephrotoxin aristolochic acid I (AAI) $[5,8,62]$ as model compound.

In a first step, the in vitro cytotoxicity of AAI was determined. The most widely used cell lines to study kidney toxicity in vitro are human kidney-2 (HK-2), madin-darby canine kidney (MDCK) and pig kidney (LLC-PK1) cell lines [15, 49, 50, 58, 63]. It has been reported that the cytotoxic potency of AAI may vary between different cell lines and the most sensitive cell line to study AAI cytotoxicity was reported to be the LLC-PK1 cell line $[15,64]$, which is derived from the proximal tubular epithelial cell line of the pig. It is noted that the target organ of AAI is kidney and more specific the proximal tubular area $[56,65,66]$. However, results of the present study reveal that for the two different kidney cell lines a similar cytotoxic potency was observed. Huljic et al. (2008) [48] suggested the use of primary porcine renal cortex cells to investigate the AA toxicity. Whether the predictive power of the in vitro-in silico approach can be refined to a further extent by using primary kidney cells instead of kidney cell lines remains to be investigated.

In a second step, the present study defined PBK models for AAI in rat, mouse and human. The performance of the rat model could be validated based on data from Ren et al. (2014) [41], comparing the predicted plasma levels of AAl to the reported levels in vivo. Based on this approach, there was no difference in the $C_{\max }$ predicted and actually observed for AAI and an only 1.7-fold difference between the AUC predicted by the PBK model and the AUC actually observed upon a single oral dose of $25.3 \mathrm{mg} / \mathrm{kg}$ bw of AAI. Thus, this model adequately predicts the plasma level of $A A I$ in rat. It is important to note that in the present study, almost all PBK model parameters were either obtained from literature or derived using in vitro techniques, thereby contributing to reduction, refinement and replacement in animal testing. Of course the approach requires further work before it can fully replace the animal studies such as for example studies that demonstrate that by this approach also the target organ and type of adverse effect can be predicted so that it can be applied without upfront knowledge of the target organ or mode of action.

In a final step the PBK models defined were used to translate the in vitro concentrationresponse curves to in vivo dose-response curves for kidney toxicity. From these predicted in vivo 
dose-response curves, $\mathrm{BMDL}_{10}$ values were derived that can be used as $\mathrm{POD}$ that provides a suitable starting point for risk assessment. The outcomes indicate that our predicted $B M D L_{10}$ values based on $C_{\max }$ in the rat model differed about 2.3- to 55.6-fold from the range of experimental PODs derived from available in vivo studies. In the mouse model, the difference was larger, amounting to 1.5to 163.8-fold. However, when comparing the $\mathrm{BMD}_{10}$ values predicted to the dose levels reported to actually cause AAN in human, the predicted values causing human kidney toxicity are within the range of real human data. Close analysis of the differences between the predicted and in vivo reported PODs revealed that especially repeated dose studies seem to result in somewhat lower PODs than the values predicted by our model and observed in the literature for single dose studies. These lower PODs could not be explained by accumulation of AAI in the kidneys, as AAI was observed to be swiftly metabolized and (directly) excreted by all species and inclusion of repeated doses in the PBK models did not lead to higher predicted concentrations of AAI in the kidneys nor lower $\mathrm{BMDL}_{10}$ values (data not shown). Irrespective of the dosing regime, it should be noted that there is already substantial variation in the PODs derived from all in vivo studies, and that the $\mathrm{BMDL}_{10}$ values defined based on our novel in vitro and PBK model-based approach seem to fall within this variation. This conclusion holds especially when taking into account the fact that the quality of the reported in vivo data hampered definition of an accurate POD given that often there was only one dose of AAI being tested while that dose appeared to be an effect level, making estimation of the POD inaccurate.

Taking all these aspects into account it is concluded that the novel in vitro and PBK modelbased approach provides PODs for risk assessment with a similar level of uncertainty as observed in the experimental animal data. Also, combining in vitro cytotoxicity with PBK model-based reverse dosimetry provides a promising approach to predict acute nephrotoxicity in vivo. The PBK modeling approach also has uncertainties as the models rely on various assumptions (e.g. estimation of tissue partition coefficients, interspecies scaling of absorption/excretion rates, unaccounted for metabolic pathways, etc) that may need to be further validated. It remains to be considered whether extra assessment factors may be required to cover these uncertainties once the proposed in vitro-PBK based method would be used for definition of PODs.

In toxicological risk assessment, rodent data could be used as the POD to set the safe level for human consumption. Usually, to accommodate for interspecies differences, a 10-fold uncertainty factor has been used to allow for interspecies differences, with a factor of 4.0 for species differences in kinetics and a factor of 2.5 for species differences in dynamics [67]. The PBK model-based Page $\mid 58$ 
approach allows prediction of dose-response curves for human taking interspecies differences in kinetics already into account. The application of the PBK model based-reverse dosimetry approach may thus reduce the uncertainty factor for species differences from 10 to 2.5 when the POD would be predicted using the human PBK model. The current study demonstrated that our predicted $\mathrm{BMDL}_{10}$ value differed about 1.8-fold between rat and human and about 1.9-fold between mouse and human, corroborating that species differences in kinetics may indeed amount to about 4-fold. Furthermore, when the in vivo dose-response curve would be defined using a human cell model, we can even argue that the factor of 2.5 for the species differences in dynamics is also not needed anymore. Altogether, the uncertainty factor of 10 for interspecies species may then no longer be needed. The current PBK models indicate that rat may be a better model for AAI toxicity in human than mouse because of a higher degree of similarity in the kinetics for its detoxification. It is also important to stress that for the specific case of AAI, the POD for nephrotoxicity could be used to estimate the chances on nephrotoxicity at given levels of exposure (the ratio of the POD and the estimated daily intake should be $>100$ ) but not to define a TDI given that the compound is also a genotoxic carcinogen for which no TDI can be defined. Whether the in vitro-in silico approach could also be used to define a $\mathrm{BMDL}_{10}$ for a genotoxicity/carcinogenicity endpoint and support a risk assessment for the carcinogenicity of AAI based on the so called Margin of Exposure approach [68] remains to be established.

In conclusion, by integrating the in vitro-in silico approach with the reverse dosimetry approach, nephrotoxicity of AAI could be predicted within an order of magnitude accuracy and within the variability also observed between different in vivo studies. The results obtained also indicate that rat may be a better model for studying AAI kidney toxicity than mouse because of a higher degree of similarity in the kinetics for its detoxification.

\section{ACKNOWLEDGEMENTS}

This research was supported by the Ministry of Education of Malaysia (Project number- KPT (BS) 860828565598). 


\section{References}

1. Louisse, J., E. de Jong, J.J. van de Sandt, B.J. Blaauboer, R.A. Woutersen, A.H. Piersma, I.M.C.M. Rietjens, and M. Verwei, The use of in vitro toxicity data and physiologically based kinetic modeling to predict dose-response curves for in vivo developmental toxicity of glycol ethers in rat and man. Toxicological Sciences, 2010. 118(2): p. 470-484.

2. Strikwold, M., B. Spenkelink, R.A. Woutersen, I.M.C.M. Rietjens, and A. Punt, Combining in vitro embryotoxicity data with physiologically based kinetic (PBK) modelling to define in vivo doseresponse curves for developmental toxicity of phenol in rat and human. Archives of Toxicology, 2013. 87(9): p. 1709-1723.

3. Louisse, J., S. Bosgra, B.J. Blaauboer, I.M.C.M. Rietjens, and M. Verwei, Prediction of in vivo developmental toxicity of all-trans-retinoic acid based on in vitro toxicity data and in silico physiologically based kinetic modeling. Archives of Toxicology, 2015. 89(7): p. 1135-1148.

4. Kumar, V., A.K. Prasad, and V.S. Parmar, Naturally occurring aristolactams, aristolochic acids and dioxoaporphines and their biological activities. Natural Products Reports, 2003. 20(6): p. 565-583. 5. Arlt, V.M., M. Stiborova, and H.H. Schmeiser, Aristolochic acid as a probable human cancer hazard in herbal remedies: a review. Mutagenesis, 2002. 17(4): p. 265-277.

6. Grollman, A.P., J. Scarborough, and B. Jelakovic, Aristolochic acid nephropathy: an environmental and iatrogenic disease. Advances in Molecular Toxicology, 2009. 3: p. 211-227.

7. Nortier, J.L., M.-C.M. Martinez, H.H. Schmeiser, V.M. Arlt, C.A. Bieler, M. Petein, M.F. Depierreux, L. De Pauw, D. Abramowicz, P. Vereerstraeten, and J.-L. Vanherweghem, Urothelial carcinoma associated with the use of a Chinese herb (Aristolochia fangchi). The New England Journal of Medicine, 2000. 342(23): p. 1686-1692.

8. $\quad$ Arlt, V.M., H.H. Schmeiser, and G.P. Pfeifer, Sequence-specific detection of aristolochic acidDNA adducts in the human p53 gene by terminal transferase-dependent PCR. Carcinogenesis, 2001. 22(1): p. 133-140.

9. Vanherweghem, J.-L., C. Tielemans, D. Abramowicz, M. Depierreux, R. Vanhaelen-Fastre, M. Vanhaelen, M. Dratwa, C. Richard, D. Vandervelde, and D. Verbeelen, Rapidly progressive interstitial renal fibrosis in young women: association with slimming regimen including Chinese herbs. The lancet, 1993. 341(8842): p. 387-391.

10. Vanhaelen, M., R. Vanhaelen-Fastre, P. But, and J.-L. Vanherweghem, Identification of aristolochic acid in Chinese herbs. The lancet, 1994. 343(8890): p. 174.

11. EMEA, The European agency for the evaluation of medicinal products, position paper on the risks associated with the use of herbal products containing Aristolochia species. 2000. p. 1-10.

12. Martena, M.J., J.C. van der Wielen, L.F. van de Laak, E.J. Konings, H.N. de Groot, and I.M.C.M. Rietjens, Enforcement of the ban on aristolochic acids in Chinese traditional herbal preparations on the Dutch market. Analytical and bioanalytical chemistry, 2007. 389(1): p. 263-275.

13. loset, J.-R., G. Raoelison, and K. Hostettmann, Detection of aristolochic acid in Chinese phytomedicines and dietary supplements used as slimming regimens. Food and Chemical Toxicology, 2003. 41(1): p. 29-36.

14. Schaneberg, B. and I. Khan, Analysis of products suspected of containing Aristolochia or Asarum species. Journal of Ethnopharmacology, 2004. 94(2): p. 245-249.

15. Balachandran, P., F. Wei, R.C. Lin, I.A. Khan, and D.S. Pasco, Structure activity relationships of aristolochic acid analogues: toxicity in cultured renal epithelial cells. Kidney International, 2005. 67(5): p. 1797-1805.

16. Sato, N., D. Takahashi, R. Tsuchiya, T. Mukoyama, S.I. Yamagata, N. Satoh, S. Ueda, S.M. Chen, M. Ogawa, and M. Yoshida, Acute nephrotoxicity of aristolochic acids in mice. Journal of Pharmacy and Pharmacology, 2004. 56(2): p. 221-229.

17. Shibutani, S., H. Dong, N. Suzuki, S. Ueda, F. Miller, and A.P. Grollman, Selective toxicity of aristolochic acids I and II. Drug Metabolism and Disposition, 2007. 35(7): p. 1217-1222.

18. Shibutani, S., R.R. Bonala, T. Rosenquist, R. Rieger, N. Suzuki, F. Johnson, F. Miller, and A.P. Grollman, Detoxification of aristolochic acid I by O-demethylation: Less nephrotoxicity and genotoxicity of aristolochic acid la in rodents. International Journal of Cancer, 2010. 127(5): p. 1021-1027. 
19. Pfau, W., H.H. Schmeiser, and M. Wiessler, Aristolochic acid binds covalently to the exocyclic amino group of purine nucleotides in DNA. Carcinogenesis, 1990. 11(2): p. 313-319.

20. Pfau, W., H.H. Schmeiser, and M. Wiessler, ${ }^{32}$ P-postlabelling analysis of the DNA adducts formed by aristolochic acid I and II. Carcinogenesis, 1990. 11(9): p. 1627-1633.

21. Schmeiser, H., K.-B. Schoepe, and M. Wiessler, DNA adduct formation of aristolochic acid I and II in vitro and in vivo. Carcinogenesis, 1988. 9(2): p. 297-303.

22. Stiborová, M., E. Frei, B. Sopko, K. Sopková, V. Marková, M. Laňková, T. Kumstýřová, M. Wiessler, and H.H. Schmeiser, Human cytosolic enzymes involved in the metabolic activation of carcinogenic aristolochic acid: evidence for reductive activation by human NAD (P) H: quinone oxidoreductase. Carcinogenesis, 2003. 24(10): p. 1695-1703.

23. Martinek, V., B. Kubickova, V.M. Arlt, E. Frei, H.H. Schmeiser, J. Hudecek, and M. Stiborova, Comparison of activation of aristolochic acid I and II with NADPH: quinone oxidoreductase, sulphotransferases and N-acetyltranferases. Neuro Endocrinology Letters, 2010. 32: p. 57-70.

24. Gillerot, G., E. Goffin, P. Moulin, V.M. Arlt, D.H. Phillips, J.P. Cosyns, and O. Devuyst, Aristolochic acid nephropathy and the peritoneum: Functional, structural, and molecular studies. Kidney international, 2003. 64(5): p. 1883-1892.

25. Rosenquist, T.A., H.J. Einolf, K.G. Dickman, L. Wang, A. Smith, and A.P. Grollman, Cytochrome P450 1A2 detoxicates aristolochic acid in the mouse. Drug Metabolism and Disposition, 2010. 38(5): $\mathrm{p}$. 761-768.

26. Krumbiegel, G., J. Hallensleben, W. Mennicke, N. Rittmann, and H. Roth, Studies on the metabolism of aristolochic acids I and II. Xenobiotica, 1987. 17(8): p. 981-991.

27. Mengs, U., Tumour induction in mice following exposure to aristolochic acid. Archives of Toxicology, 1988. 61(6): p. 504-505.

28. Mengs, U. and C. Stotzem, Renal toxicity of aristolochic acid in rats as an example of nephrotoxicity testing in routine toxicology. Archives of Toxicology, 1993. 67(5): p. 307-311.

29. Mosmann, T., Rapid colorimetric assay for cellular growth and survival: application to proliferation and cytotoxicity assays. Journal of immunological methods, 1983. 65(1): p. 55-63.

30. Chan, W., L. Cui, G. Xu, and Z. Cai, Study of the phase I and phase ll metabolism of nephrotoxin aristolochic acid by liquid chromatography/tandem mass spectrometry. Rapid Communications in Mass Spectrometry, 2006. 20(11): p. 1755-1760.

31. Chan, W., H.B. Luo, Y. Zheng, Y.K. Cheng, and Z. Cai, Investigation of the metabolism and reductive activation of carcinogenic aristolochic acids in rats. Drug Metabolism and Disposition, 2007. 35(6): p. 866-874.

32. Priestap, H.A., M.C. Torres, R.A. Rieger, K.G. Dickman, T. Freshwater, D.R. Taft, M.A. Barbieri, and C.R. Iden, Aristolochic acid I metabolism in the isolated perfused rat kidney. Chemical Research in Toxicology, 2011. 25(1): p. 130-139.

33. Su, T., L. Qu, C. Zhang, S. Cai, and X. Li, Studies on pharmacodynamic characteristics of aristolochic acid I in rats. China Journal of Chinese Materia Medica, 2004. 29(7): p. 676-681.

34. Sharma, V. and J.H. McNeill, To scale or not to scale: the principles of dose extrapolation. British journal of pharmacology, 2009. 157(6): p. 907-921.

35. Yang, H., X. Zheng, Y. Du, Z. Chen, D. Zhu, and Y. Lou, Kinetics of aristolochic acid I after oral administration of Radix Aristolochiae or Guanxinsuhe preparation in canines. Journal of Ethnopharmacology, 2011. 135(2): p. 569-574.

36. Brown, R., M. Delp, S. Lindstedt, L. Rhomberg, and R. Beliles, Physiological Parameter Values for Physiologically Based Pharmacokinetic Models. Toxicology and Industrial Health, 1997. 13: p. 407484.

37. Berezhkovskiy, L.M., Volume of distribution at steady state for a linear pharmacokinetic system with peripheral elimination. Journal of Pharmaceutical Sciences, 2004. 93(6): p. 1628-1640.

38. Han, S.Y., J.Q. Qiao, Y.Y. Zhang, H.Z. Lian, and X. Ge, Determination of n-octanol/water partition coefficients of weak ionizable solutes by RP-HPLC with neutral model compounds. Talanta, 2012. 97: p. 355-361.

39. Punt, A., A.P. Freidig, T. Delatour, G. Scholz, M.G. Boersma, B. Schilter, P.J. van Bladeren, 
and I.M.C.M. Rietjens, A physiologically based biokinetic (PBBK) model for estragole bioactivation and detoxification in rat. Toxicology and Applied Pharmacology, 2008. 231(2): p. 248-259.

40. Kiwamoto, R., A. Spenkelink, I.M.C.M. Rietjens, and A. Punt, A physiologically based in silico model for trans-2-hexenal detoxification and DNA adduct formation in human including interindividual variation indicates efficient detoxification and a negligible genotoxicity risk. Archives of Toxicology, 2013. 87(9): p. 1725-1737.

41. Ren, G., Q. Huang, J. Wu, J. Yuan, G. Yang, Z. Yan, and S. Yao, Cloud point extraction-HPLC method for the determination and pharmacokinetic study of aristolochic acids in rat plasma after oral administration of Aristolochiae Fructus. Journal of Chromatography B, 2014. 953: p. 73-79.

42. Lin, J.H., Applications and limitations of interspecies scaling and in vitro extrapolation in pharmacokinetics. Drug Metabolism and Disposition, 1998. 26(12): p. 1202-1212.

43. Yan, G.Z., C.N. Generaux, M. Yoon, R.B. Goldsmith, R.R. Tidwell, J.E. Hall, C.A. Olson, H.J. Clewell, K.L. Brouwer, and M.F. Paine, A semiphysiologically based pharmacokinetic modeling approach to predict the dose-exposure relationship of an antiparasitic prodrug/active metabolite pair. Drug Metabolism and Disposition, 2012. 40(1): p. 6-17.

44. Stiborová, M., K. Levová, F. Bárta, Z. Shi, E. Frei, H.H. Schmeiser, D.W. Nebert, D.H. Phillips, and V.M. Arlt, Bioactivation versus detoxication of the urothelial carcinogen aristolochic acid I by human cytochrome P450 1A1 and 1A2. Toxicological Sciences, 2012. 125(2): p. 345-358.

45. Evans, M.V. and M.E. Andersen, Sensitivity analysis of a physiological model for 2, 3, 7, 8-tetrachlorodibenzo-p-dioxin (TCDD): assessing the impact of specific model parameters on sequestration in liver and fat in the rat. Toxicological Sciences, 2000. 54(1): p. 71-80.

46. Daston, G.P., R.E. Chapin, A.R. Scialli, A.H. Piersma, E.W. Carney, J.M. Rogers, and J.M. Friedman, A different approach to validating screening assays for developmental toxicity. Birth Defects Research Part B: Developmental and Reproductive Toxicology, 2010. 89(6): p. 526-530.

47. NTP, National Toxicology Program. Final report on carcinogens background document for aristolochic acids. Report on Carcinogens Background Document for Aristolochic Acids, 2008(85976).

48. Huljic, S., E.I. Bruske, N. Pfitzenmaier, E. O'Brien, and D.R. Dietrich, Species-specific toxicity of aristolochic acid (AA) in vitro. Toxicology in Vitro, 2008. 22(5): p. 1213-1221.

49. Hsin, Y.H., C.H. Cheng, J.T. Tzen, M.J. Wu, K.H. Shu, and H.C. Chen, Effect of aristolochic acid on intracellular calcium concentration and its links with apoptosis in renal tubular cells. Apoptosis, 2006. 11(12): p. 2167-2177.

50. Liu, Q., Q. Wang, X. Yang, X. Shen, and B. Zhang, Differential cytotoxic effects of denitroaristolochic acid II and aristolochic acids on renal epithelial cells. Toxicology Letters, 2009. 184(1): p. 5-12.

51. IPCS, Guidance document for the use of data in development of chemical-specific adjustment factors (CSAFs) for interspecies differences and human variability in dose/concentration-response assessment. World Health Organization (Geneva), 2001.

52. Yang, L., T. Su, X.M. Li, X. Wang, S.Q. Cai, L.Q. Meng, W.Z. Zou, and H.Y. Wang, Aristolochic acid nephropathy: variation in presentation and prognosis. Nephrology Dialysis Transplantation, 2012. 27(1): p. 292-298.

53. Blaauboer, B.J., J. Hermens, and J. van Eijkeren, Estimating acute toxicity based on in vitro cytotoxicity: role of biokinetic modelling. ALTEX, 2006. 23(suppl): p. 250-253.

54. Chen, M., M. Su, L. Zhao, J. Jiang, P. Liu, J. Cheng, Y. Lai, Y. Liu, and W. Jia, Metabonomic study of aristolochic acid-induced nephrotoxicity in rats. Journal of Proteome Research, 2006. 5(4): p. 9951002.

55. Yeh, Y.H., Y.T. Lee, H.S. Hsieh, and D.F. Hwang, Short-term toxicity of aristolochic acid, aristolochic acid-I and aristolochic acid-II in rats. Food and Chemical Toxicology, 2008. 46(3): p. 11571163.

56. Lebeau, C., F.D. Debelle, V.M. Arlt, A. Pozdzik, E.G. De Prez, D.H. Phillips, M.M. DeschodtLanckman, J.-L. Vanherweghem, and J.L. Nortier, Early proximal tubule injury in experimental aristolochic acid nephropathy: functional and histological studies. Nephrology Dialysis Transplantation, 
2005. 20(11): p. 2321-2332.

57. Xue, X., Y. Xiao, H. Zhu, H. Wang, Y. Liu, T. Xie, and J. Ren, Induction of P450 1A by 3-methylcholanthrene protects mice from aristolochic acid-l-induced acute renal injury. Nephrology Dialysis Transplantation, 2008. 23(10): p. 3074-3081.

58. Xiao, Y., M. Ge, X. Xue, C. Wang, H. Wang, X. Wu, L. Li, L. Liu, X. Qi, and Y. Zhang, Hepatic cytochrome P450s metabolize aristolochic acid and reduce its kidney toxicity. Kidney International, 2008. 73(11): p. 1231-1239.

59. Chen, M., L. Gong, X. Qi, G. Xing, Y. Luan, Y. Wu, Y. Xiao, J. Yao, Y. Li, and X. Xue, Inhibition of renal NQO1 activity by dicoumarol suppresses nitroreduction of aristolochic acid I and attenuates its nephrotoxicity. Toxicological Sciences, 2011. 122(2): p. 288-296.

60. Huang, T., S. Chen, Y. Li, and J. Lee, Urinary d-lactate levels reflect renal function in aristolochic acid-induced nephropathy in mice. Biomedical Chromatography, 2013. 27(9): p. 1100-1106.

61. Yuan, S.Y., C.R. Yang, C.L. Cheng, S.L. Hsu, J.W. Liao, C.C. Lin, Y.Y. Chou, and Y.W. Cheng, Comparative nephrotoxicity of aristolochic acid and tetrandrine in vitro and in vivo. International Journal of Toxicology, 2011. 30(1): p. 35-46.

62. Mengs, U., W. Lang, and J.-A. Poch, The carcinogenic action of aristolochic acid in rats. Archives of Toxicology, 1982. 51(2): p. 107-119.

63. Li, J., L. Zhang, Z. Jiang, B. Shu, F. Li, Q. Bao, and L. Zhang, Toxicities of aristolochic acid I and aristololactam I in cultured renal epithelial cells. Toxicology in Vitro, 2010. 24(4): p. 1092-1097.

64. Cai, Y. and T.G. Cai, Two new aristolochic acid derivatives from the roots of Aristolochia fangchi and their cytotoxicities. Chemical and Pharmaceutical Bulletin, 2010. 58(8): p. 1093-1095.

65. Lebeau, C., V.M. Arlt, H.H. Schmeiser, A. Boom, P.J. Verroust, O. Devuyst, and R. Beauwens, Aristolochic acid impedes endocytosis and induces DNA adducts in proximal tubule cells. Kidney International, 2001.60(4): p. 1332-1342.

66. Mengs, U., Acute toxicity of aristolochic acid in rodents. Archives of Toxicology, 1987. 59(5): p. 328-331.

67. Renwick, A., Data-derived safety factors for the evaluation of food additives and environmental contaminants. Food additives \& contaminants, 1993. 10(3): p. 275-305.

68. EFSA, European Food Safety Authority. Opinion of the scientific committee on a request from EFSA related to a harmonised approach for risk assessment of substances which are both genotoxic and carcinogenic. EFSA Journal, 2005. 282: p. 1-31. 
Supplementary data A. Mass balance equation and parameter specifications of PBK model for aristolochic acid I in the rat

\section{Compound}

Aristolochic acid I

Aristolochic acid la

Compartment (Tissue (T))

Small intestine

Liver

Kidney

Slowly perfused tissue

Richly perfused tissue

Fat compartment

Arterial

Venous

\section{abbreviation}

AAI

AAla

\section{abbreviation}

।

L

K

$\mathrm{S}$

$\mathrm{R}$

$\mathrm{F}$

A

V

\section{Variable}

Blood flow rate to tissue

Cardiac output

Concentration of AAI in tissue or blood

Partitioning coefficient tissue:blood AAI

Volume of tissue or blood

Amount AAl in tissue or blood

Maximum rate of formation metabolite, AAla in tissue

Michaelis-Menten constant for formation metabolite, AAla in tissue $\mu \mathrm{M}$

Uptake rate $\mathrm{AAl}$ in intestine

Excretion rate in bile

Excretion rate in urine

\section{Unit}

$\mathrm{Ih}^{-1}$

$\mathrm{Ih}^{-1}$

$\mu \mathrm{M}$

$-$

I

umol

$\mu \mathrm{mol} \mathrm{h}^{-1}$ abbreviation

$\mathrm{Q}(\mathrm{T})$

QC

$\mathrm{C}(\mathrm{T})_{\mathrm{AAl}}$

$\mathrm{P}(\mathrm{T})_{\text {AAI }}$

$\mathrm{V}(\mathrm{T})$

$A(T)_{\text {AAI }}$

$\operatorname{Vmax}(\mathrm{T})_{\text {AAla }}$

$\mathrm{Km}(\mathrm{T})_{\text {AAla }}$

Ka

Kbile

Kurine

\section{Small intestine}

$\mathrm{dAl}_{\mathrm{AAl}} / \mathrm{dt}=\mathrm{dUptake} \mathrm{AAl} / \mathrm{dt}+\mathrm{QI}^{*}\left(\mathrm{CA}_{\mathrm{AAl}}-\mathrm{Cl}_{\mathrm{AAl}} / \mathrm{PI}_{\mathrm{AAl}}\right)-\left[\left(\mathrm{Vmaxl}_{\mathrm{AAla}}{ }^{*} \mathrm{Cl}_{\mathrm{AAl}} / \mathrm{PI}_{\mathrm{AAl}}\right) /\left(\mathrm{Kml}_{\mathrm{AAla}}+\mathrm{Cl}_{\mathrm{AAl}} / \mathrm{PI}_{\mathrm{AAl}}\right)\right]$

Page | 64 


\section{Uptake of AAI from GI tract}

dUptake $_{A A I} / d t=-d A G I_{A A I} / d t=k a * A G I_{A A I}$

$\mathrm{AGI}_{\mathrm{AAl}}(0)=$ Oral dose

$\mathrm{Cl}_{\mathrm{AAI}}=\mathrm{Al}_{\mathrm{AAI}} / \mathrm{VI}$

\section{Liver compartment}

$$
\begin{aligned}
& \mathrm{dAL}_{\mathrm{AAl}} / \mathrm{dt}=\mathrm{QL} * \mathrm{CA}+\mathrm{QI}^{*} \mathrm{Cl}_{\mathrm{AAl}} / \mathrm{PI}_{\mathrm{AAI}}-(\mathrm{QL}+\mathrm{QI}){ }^{*} \mathrm{CL}_{\mathrm{AAl}} / \mathrm{PL}_{\mathrm{AAI}}-\left(\mathrm{VmaxL}_{\mathrm{AAla}}{ }^{*} \mathrm{CL}_{\mathrm{AAl}} / \mathrm{PL}_{\mathrm{AAl}}\right) /\left(\mathrm{Km}_{\mathrm{AAla}}+\mathrm{CL}_{\mathrm{AAl}} / \mathrm{PL}_{\mathrm{AAl}}\right)- \\
& \mathrm{dEb}_{\mathrm{AAl}} / \mathrm{dt} \\
& \mathrm{CL}_{\mathrm{AAI}}=\mathrm{AL}_{\mathrm{AAl}} / \mathrm{VL}
\end{aligned}
$$

\section{Excretion rate in bile}

$\mathrm{dEb}_{\mathrm{AAl}} / \mathrm{dt}=\mathrm{Kbile}^{*} \mathrm{AL}$

$\mathrm{Eb}(0)=0$

\section{Kidney compartment}

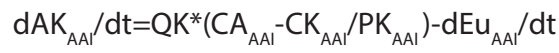

$\mathrm{CK}_{\mathrm{AAI}}=\mathrm{AK}_{\mathrm{AAI}} / \mathrm{VK}$

\section{Excretion rate in urine}

$\mathrm{dEu}_{\mathrm{AAI}} / \mathrm{dt}=$ Kurine*AK

$\mathrm{Eu}(0)=0$

\section{Slowly perfused tissue}

$$
\begin{aligned}
& \mathrm{dAS}_{\mathrm{AAl}} / \mathrm{dt}=\mathrm{QS} *\left(\mathrm{CA}_{\mathrm{AAl}}-\mathrm{CS}_{\mathrm{AAl}} / \mathrm{PS}_{\mathrm{AAl}}\right) \\
& \mathrm{CS}_{\mathrm{AAl}}=\mathrm{AS}_{\mathrm{AAl}} / \mathrm{VS}
\end{aligned}
$$

\section{Richly perfused tissue}

$$
\begin{aligned}
& \mathrm{dAR}_{\mathrm{AAl}} / \mathrm{dt}=\mathrm{QR}^{*}\left(\mathrm{CA}_{\mathrm{AAl}}-\mathrm{CR}_{\mathrm{AAl}} / \mathrm{PR}_{\mathrm{AAl}}\right) \\
& \mathrm{CR}_{\mathrm{AAl}}=\mathrm{AR}_{\mathrm{AAl}} / \mathrm{VR}
\end{aligned}
$$

\section{Fat compartment}

$\mathrm{dAF}_{\mathrm{AAl}} / \mathrm{dt}=\mathrm{QF}^{*}\left(\mathrm{CA}_{\mathrm{AAl}}-\mathrm{CF}_{\mathrm{AAl}} / \mathrm{PF}_{\mathrm{AAl}}\right)$ 
Chapter 2

$\mathrm{CF}_{\mathrm{AAI}}=\mathrm{AF}_{\mathrm{AAl}} / \mathrm{VF}$

Arterial blood compartment

$\mathrm{CA}_{\mathrm{AAl}}=\mathrm{CV}_{\mathrm{AAl}}$

\section{Venous blood compartment}

$\mathrm{dAV} \mathrm{AAI}_{\mathrm{AA}} / \mathrm{dt}=\left(\mathrm{QF}^{*} \mathrm{CF}_{\mathrm{AAl}} / \mathrm{PF}_{\mathrm{AAI}}\right)+\left(\mathrm{QK}^{*} \mathrm{CK}_{\mathrm{AAl}} / \mathrm{PK}_{\mathrm{AAI}}\right)+\left(\mathrm{QR}^{*} \mathrm{CR}_{\mathrm{AAl}} / \mathrm{PR}_{\mathrm{AAl}}\right)+\left(\mathrm{QS}^{*} \mathrm{CS}_{\mathrm{AAl}} / \mathrm{PS}_{\mathrm{AAI}}\right)+(\mathrm{QL}+\mathrm{QI})^{*} \mathrm{CL}_{\mathrm{AAI}} / \mathrm{PL}_{\mathrm{AAl}}$ $-\mathrm{QC}^{*} \mathrm{CV}_{\mathrm{AAI}}$

$\mathrm{CV}_{\mathrm{AAl}}=\mathrm{AV}_{\mathrm{AAl}} / \mathrm{VV}$ 
Supplementary data B. In vitro cytotoxicity data of AAI based on the experiments of the present study and literature studies. For the in vitro literature data, the results from the graphs were extracted with Plotdigitizer software (Boston, MA)

\begin{tabular}{|c|c|c|c|c|c|}
\hline Cell line & Method & Exposure time (hr) & Concentrations of AAI $(\mu \mathrm{M})$ & Mean of cytotoxicity (\%) & Studies \\
\hline LLC-PK1 & MTT assay & 24 & $\begin{array}{l}0,0.5,1,5,10,50,100,150 \\
200,250\end{array}$ & $\begin{array}{l}0,6.5,5.2,11.5,20.3,33.5,45.0,52.0,58.4 \\
65.3\end{array}$ & Present study \\
\hline MDCK & MTT assay & 24 & $\begin{array}{l}0,0.5,1,5,10,50,100,150 \\
200,250\end{array}$ & $\begin{array}{l}0,1.2,5.3,6.0,16.8,24.1,39.3,37.0,41.3 \\
63.6\end{array}$ & Present study \\
\hline LLC-PK1 & $\begin{array}{l}\text { Neutral red } \\
\text { assay }\end{array}$ & 48 & $1,2,9,32,100$ & $15,24,52,90,95$ & $\begin{array}{l}\text { Balachandran et al. } \\
\text { (2005) [15] }\end{array}$ \\
\hline LLC-PK1 & MTT assay & 24 & $0,50,100,200,300$ & $0,23,58,70,79$ & $\begin{array}{l}\text { Hsin et al. (2006) } \\
\text { [49] }\end{array}$ \\
\hline MDCK & MTT assay & 24 & $0,50,100,200,300$ & $0,17,39,57,68$ & $\begin{array}{l}\text { Hsin et al. (2006) } \\
\text { [49] }\end{array}$ \\
\hline MDCK & MTT assay & 24 & $5,25,75,150,300$ & $4,23,50,64,75$ & Liu et al. (2009) [50] \\
\hline $\begin{array}{l}\text { Primary renal } \\
\text { cells of porcine }\end{array}$ & MTT assay & 24 & $\begin{array}{l}0.01,0.05,0.1,0.5,1,5,10 \\
50,100,500\end{array}$ & $6,2,0,1.1,1,3.8,8.9,30.9,47.9,60$ & $\begin{array}{l}\text { Huljic et al. (2008) } \\
{[48]}\end{array}$ \\
\hline $\begin{array}{l}\text { Primary renal } \\
\text { cells of porcine }\end{array}$ & $\begin{array}{l}\text { Cell number } \\
\text { counting }\end{array}$ & 24 & $\begin{array}{l}0.01,0.05,0.1,0.5,1,5,10 \\
25,100,500\end{array}$ & $\begin{array}{l}-1,4.1,3.5,9.4,14.2,32.2,42.5,75.4,84.8 \\
92.4\end{array}$ & $\begin{array}{l}\text { Huljic et al. (2008) } \\
{[48]}\end{array}$ \\
\hline $\begin{array}{l}\text { Primary renal } \\
\text { cells of rat }\end{array}$ & $\begin{array}{l}\text { Cell number } \\
\text { counting }\end{array}$ & 24 & $\begin{array}{l}0.01,0.1,0.5,5,10,25,50 \\
100,1000\end{array}$ & $-9,0.4,1.1,18,24.9,35.1,47.3,54.6,78.1$ & $\begin{array}{l}\text { Huljic et al. (2008) } \\
{[48]}\end{array}$ \\
\hline $\begin{array}{l}\text { Primary renal } \\
\text { cell of human }\end{array}$ & $\begin{array}{l}\text { Cell number } \\
\text { counting }\end{array}$ & 24 & $\begin{array}{l}0.01,0.1,1,5,10,50,100 \\
500,1000\end{array}$ & $\begin{array}{l}-9.2,-8.3,-3.2,11.6,20.8,35.6,38.6,60 \\
71.7\end{array}$ & $\begin{array}{l}\text { Huljic et al. (2008) } \\
{[48]}\end{array}$ \\
\hline
\end{tabular}


Supplementary data C. Table 1-Results from a BMC analysis for in vitro cytotoxicity of AAI towards LLC-PK1 cell line upon for 24 hours exposure by MTT assay (present study) using BMDS software version 2.5, a BMD of $10 \%$ and default settings. The data used as input for the BMC analysis are presented in Figure 2.4b.

\begin{tabular}{|c|c|c|c|c|c|c|c|}
\hline Model & Restriction & $\begin{array}{l}\text { No. of } \\
\text { parameters }\end{array}$ & Log Likelihood & p-value & Accepted $^{a}$ & $\mathrm{BMC}_{10}(\mu \mathrm{M})$ & $\mathrm{BMCL}_{10}(\mu \mathrm{M})$ \\
\hline Full & & 10 & -464.687 & - & - & - & - \\
\hline Gamma & none & 2 & -465.583 & 1.0 & Yes & 2.6 & 1.4 \\
\hline LogLogistic & none & 2 & -466.682 & 0.8 & Yes & 2.8 & 1.6 \\
\hline LogProbit & none & 2 & -467.663 & 0.6 & Yes & 2.5 & 1.6 \\
\hline Multistage & none & 3 & -474.421 & 0.0 & No & & \\
\hline Probit & $n a^{b}$ & 2 & -493.941 & 0.0 & No & & \\
\hline
\end{tabular}

a Fitted model not significantly different than the full model at $p<0.05$.

${ }^{\mathrm{b}}$ not applicable 
Supplementary data C. Table 2-Results from a BMC analysis for in vitro cytotoxicity of AAl towards MDCK cell line upon for 24 hours exposure by MTT assay (present study) using BMDS software version 2.5, a BMD of 10\% and default settings. The data used as input for the BMC analysis are presented in Figure 2.4b.

\begin{tabular}{|c|c|c|c|c|c|c|c|}
\hline Model & Restriction & $\begin{array}{l}\text { No. of } \\
\text { parameters }\end{array}$ & Log Likelihood & $\mathrm{p}$-value & Accepted $^{a}$ & $\mathrm{BMC}_{10}(\mu \mathrm{M})$ & $\mathrm{BMCL}_{10}(\mu \mathrm{M})$ \\
\hline Reduced & & 1 & -544.921 & - & - & - & - \\
\hline Full & & 10 & -416.919 & - & - & - & - \\
\hline Gamma & none & 2 & -423.438 & 0.1 & Yes & 7.1 & 4.1 \\
\hline Logistic & $n a^{b}$ & 2 & -446.132 & 0.0 & No & & \\
\hline LogLogistic & none & 2 & -426.433 & 0.05 & Yes & 6.4 & 3.9 \\
\hline LogProbit & none & 2 & -424.641 & 0.05 & Yes & 5.9 & 3.8 \\
\hline Multistage & none & 3 & -431.04 & 0.0 & No & & \\
\hline Probit & $n a^{b}$ & 2 & -444.247 & 0.0 & No & & \\
\hline Weibull & none & 2 & -423.636 & 0.1 & Yes & 6.9 & 4.2 \\
\hline Quantal-Linear & $n a^{b}$ & 2 & -432.852 & 0.0 & No & & \\
\hline
\end{tabular}

${ }^{a}$ Fitted model not significantly different than the full model at $p<0.05$.

${ }^{\mathrm{b}}$ not applicable 
Supplementary data C. Table 3- Results from a BMC analysis for in vitro cytotoxicity of AA towards LLC-PK1 cell line upon for 24 hours exposure by MTT assay (Hsin et al., 2006) using BMDS software version 2.5, a BMD of $10 \%$ and default settings. The data used as input for the BMC analysis are presented in Figure 2.4b.

\begin{tabular}{|c|c|c|c|c|c|c|c|}
\hline Model & Restriction & $\begin{array}{l}\text { No. of } \\
\text { parameters }\end{array}$ & Log Likelihood & $p$-value & Accepted $^{\mathrm{a}}$ & $\mathrm{BMC}_{10}(\mu \mathrm{M})$ & $\mathrm{BMCL}_{10}(\mu \mathrm{M})$ \\
\hline Reduced & & 1 & -344.972 & - & - & - & - \\
\hline Full & & 5 & -234.439 & - & - & - & - \\
\hline Gamma & none & 2 & -238.096 & 0.06 & Yes & 11.9 & 4.9 \\
\hline Logistic & $n a^{b}$ & 2 & -262.246 & 0.0 & No & & \\
\hline LogLogistic & none & 2 & -236.682 & 0.2 & Yes & 19.8 & 12.1 \\
\hline LogProbit & none & 2 & -236.744 & 0.2 & Yes & 21.5 & 13.5 \\
\hline Multistage & none & 2 & -237.22 & 0.1 & Yes & 13.9 & 11.2 \\
\hline Probit & nab & 2 & -261.959 & 0.0 & No & & \\
\hline Weibull & none & 2 & -237.944 & 0.07 & Yes & 12.2 & 6.2 \\
\hline Quantal-Linear & $n a^{b}$ & 1 & -238.629 & 0.08 & Yes & 17.2 & 15.3 \\
\hline
\end{tabular}

${ }^{a}$ Fitted model not significantly different than the full model at $\mathrm{p}<0.05$.

${ }^{\mathrm{b}}$ not applicable 
Supplementary data C. Table 4-Results from a BMC analysis for in vitro cytotoxicity of AA towards MDCK cell line upon for 24 hours exposure by MTT assay (Hsin et al., 2006) using BMDS software version 2.5, a BMD of 10\% and default settings. The data used as input for the BMC analysis are presented in Figure 2.4b.

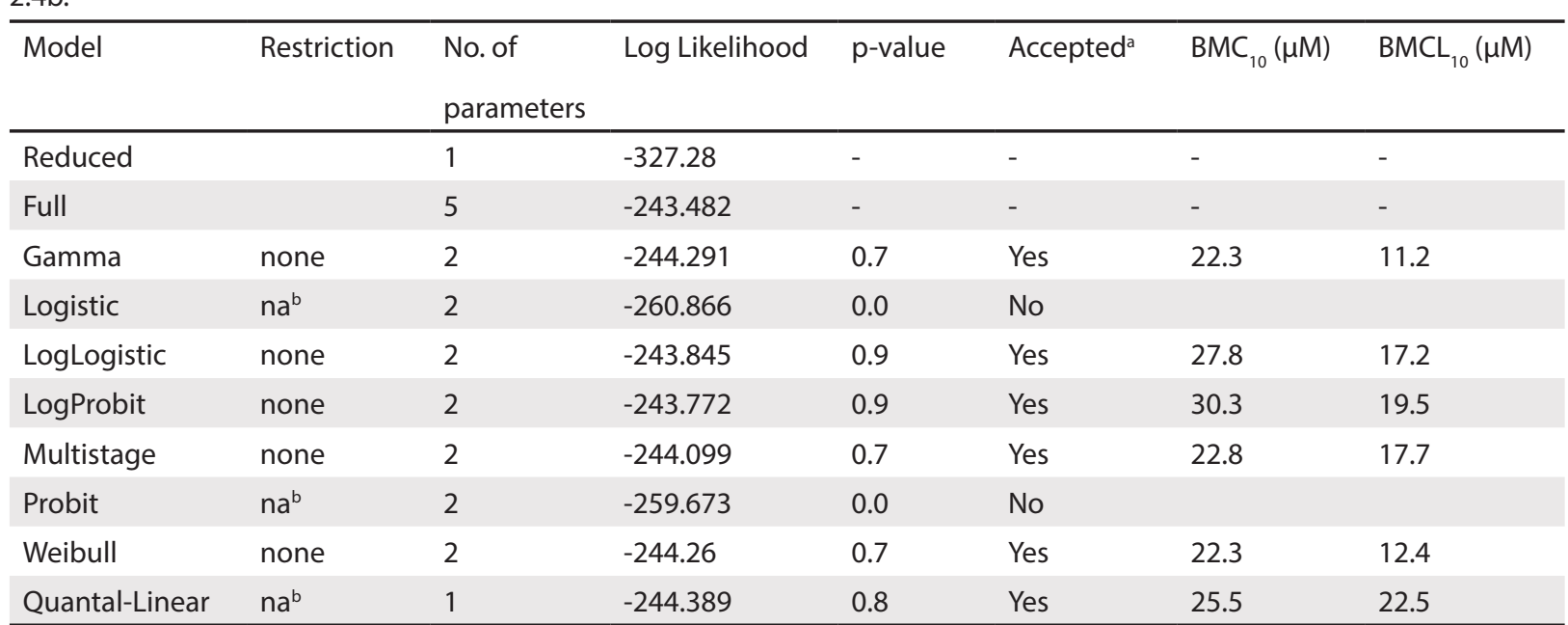

${ }^{a}$ Fitted model not significantly different than the full model at $p<0.05$.

${ }^{\mathrm{b}}$ not applicable 
Supplementary data C. Table 5-Results from a BMC analysis for in vitro cytotoxicity of AAI towards MDCK cell line upon for 24 hours exposure by MTT assay (Liu et al., 2009) using BMDS software version 2.5, a BMD of $10 \%$ and default settings. The data used as input for the BMC analysis are presented in Figure 2.4b.

\begin{tabular}{|c|c|c|c|c|c|c|c|}
\hline Model & Restriction & $\begin{array}{l}\text { No. of } \\
\text { parameters }\end{array}$ & Log Likelihood & p-value & Accepted $^{a}$ & $\mathrm{BMC}_{10}(\mu \mathrm{M})$ & $\mathrm{BMCL}_{10}(\mu \mathrm{M})$ \\
\hline Reduced & & 1 & -341.935 & - & - & - & - \\
\hline Full & & 5 & -261.612 & - & - & - & - \\
\hline Gamma & none & 2 & -264.59 & 0.1 & Yes & 6.4 & 3.4 \\
\hline Logistic & $n a^{b}$ & 2 & -283.314 & 0.0 & No & & \\
\hline LogLogistic & none & 2 & -262.071 & 0.8 & Yes & 8.6 & 5.5 \\
\hline LogProbit & none & 2 & -261.881 & 0.9 & Yes & 8.7 & 5.8 \\
\hline Multistage & none & 3 & -261.986 & 0.7 & Yes & 10.4 & 8.7 \\
\hline Probit & nab & 2 & -283.299 & 0.0 & No & & \\
\hline Weibull & none & 2 & -263.777 & 0.2 & Yes & 6.7 & 3.9 \\
\hline Quantal-Linear & $n a^{b}$ & 2 & -268.828 & 0.0 & No & & \\
\hline
\end{tabular}

${ }^{a}$ Fitted model not significantly different than the full model at $p<0.05$.

${ }^{\mathrm{b}}$ not applicable 
Supplementary data C. Table 6-Results from a BMC analysis for in vitro cytotoxicity of AA towards primary rat kidney cortex cell upon for 24 hours exposure by cell number counting (Huljic et al., 2008) using BMDS software version 2.5, a BMC of 10\% and default settings. The data used as input for the BMD analysis are presented in Figure 2.4b.

\begin{tabular}{|c|c|c|c|c|c|c|c|}
\hline Model & Restriction & $\begin{array}{l}\text { No. of } \\
\text { parameters }\end{array}$ & Log Likelihood & $\mathrm{p}$-value & Accepted $^{a}$ & $\mathrm{BMC}_{10}(\mu \mathrm{M})$ & $\mathrm{BMCL}_{10}(\mu \mathrm{M})$ \\
\hline Reduced & & 1 & -504.03 & - & - & - & - \\
\hline Full & & 8 & -367.216 & - & - & - & - \\
\hline Gamma & none & 2 & -382.504 & 0.0 & No & & \\
\hline Logistic & $n a^{b}$ & 2 & -443.136 & 0.0 & No & & \\
\hline LogLogistic & none & 2 & -371.231 & 0.2 & Yes & 2.1 & 1.3 \\
\hline LogProbit & none & 2 & -369.54 & 0.6 & Yes & 2.2 & 1.4 \\
\hline Multistage & none & 3 & -383.886 & 0.0 & No & & \\
\hline Probit & $n a^{b}$ & 2 & -442.885 & 0.0 & No & & \\
\hline Weibull & none & 2 & -376.732 & 0.0 & No & & \\
\hline Quantal-Linear & $n a^{b}$ & 2 & -431.176 & 0.0 & No & & \\
\hline
\end{tabular}

${ }^{a}$ Fitted model not significantly different than the full model at $p<0.05$.

${ }^{\mathrm{b}}$ not applicable 
Supplementary data C. Table 7- Results from a BMC analysis for in vitro cytotoxicity of AA towards primary human cell upon for 24 hours exposure by cell number counting (Huljic et al., 2008) using BMDS software version 2.5, a BMD of $10 \%$ and default settings. The data used as input for the BMC analysis are presented in Figure 2.4b.

\begin{tabular}{|c|c|c|c|c|c|c|c|}
\hline Model & Restriction & $\begin{array}{l}\text { No. of } \\
\text { parameters }\end{array}$ & Log Likelihood & $p$-value & Accepted $^{\mathrm{a}}$ & $\mathrm{BMC}_{10}(\mu \mathrm{M})$ & $\mathrm{BMCL}_{10}(\mu \mathrm{M})$ \\
\hline Reduced & & 1 & -403.135 & - & - & - & - \\
\hline Full & & 6 & -345.659 & - & - & - & - \\
\hline Gamma & none & 2 & -346.849 & 0.7 & Yes & 1.1 & 0.3 \\
\hline Logistic & $n a^{b}$ & 2 & -357.805 & 0.0 & No & & \\
\hline LogLogistic & none & 2 & -346.497 & 0.8 & Yes & 2.5 & 1.2 \\
\hline LogProbit & none & 3 & -346.456 & 0.7 & Yes & 3.2 & 1.5 \\
\hline Multistage & none & 3 & -350.346 & 0.0 & No & & \\
\hline Probit & $n a^{b}$ & 2 & -357.774 & 0.0 & No & & \\
\hline Weibull & none & 2 & -346.521 & 0.8 & Yes & 1.8 & 0.7 \\
\hline Quantal-Linear & $n a^{b}$ & 2 & -353.831 & 0.0 & No & & \\
\hline
\end{tabular}

${ }^{a}$ Fitted model not significantly different than the full model at $p<0.05$.

${ }^{\mathrm{b}}$ not applicable 

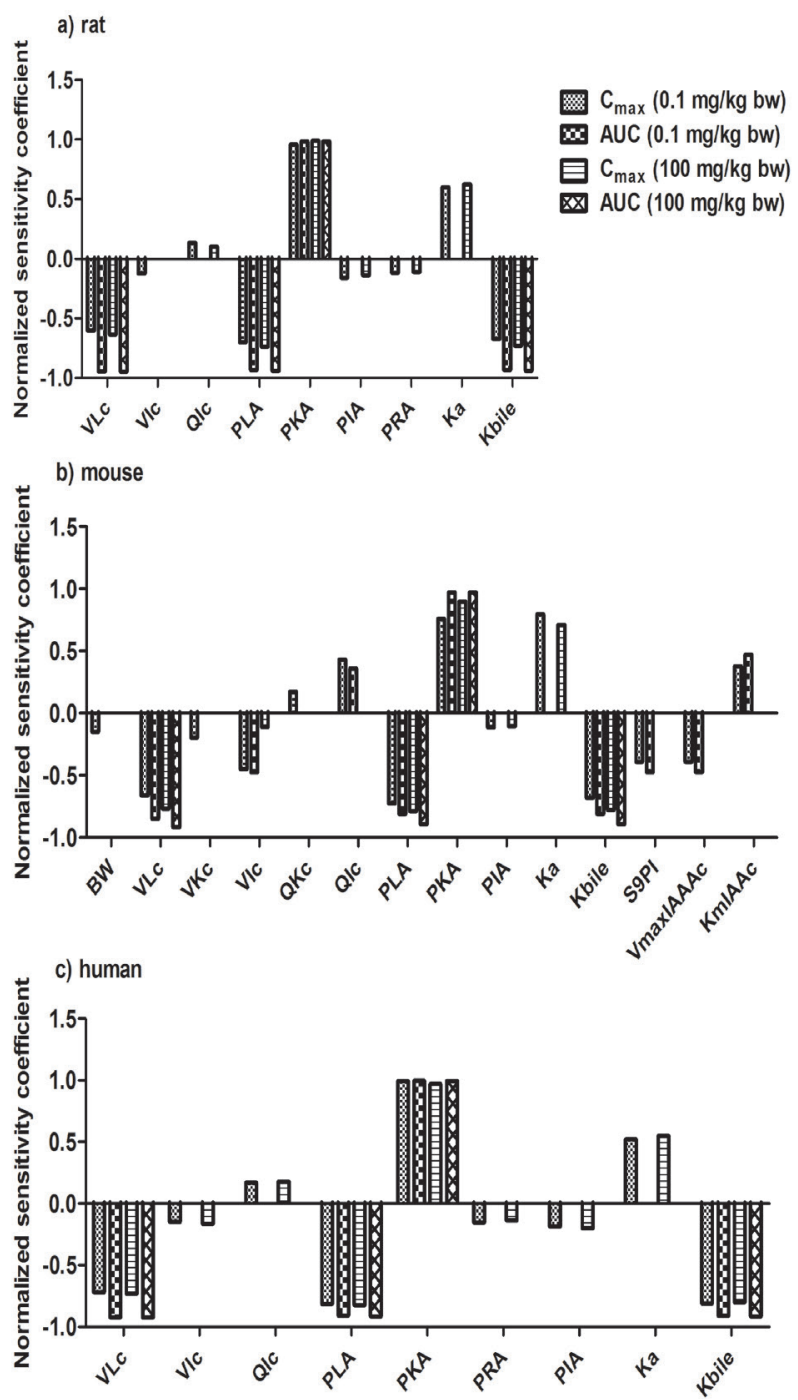

Supplementary data D. Normalized sensitivity coefficients for parameters of the PBK model for rat (a), mouse (b) and human (c) on $\mathrm{C}_{\max }$ and AUC values in kidney tissue from single oral dose of $0.1 \mathrm{mg} /$ $\mathrm{kg}$ bw and $100 \mathrm{mg} / \mathrm{kg}$ bw. Normalized sensitivity coefficients $\geq 0.1$ are presented. BW= bodyweight, $\mathrm{VLC}=$ volume of liver, $\mathrm{VKc}=$ volume of kidney, $\mathrm{Vlc}=$ volume of intestine, $\mathrm{QKc}=$ blood flow to kidney, $\mathrm{QIC}=$ blood flow to intestine, PLA = partition coefficient of liver, PKA = partition coefficient of kidney, PRA = partition coefficient of richly perfused tissue, PIA = partition coefficient of intestine, $\mathrm{Ka}=$ uptake rate constant from gastrointestinal tract, $\mathrm{Kbile}=$ excretion rate via bile constant, S9PI $=$ intestinal $\mathrm{S} 9$ protein yield, VmaxIAAAc and $\mathrm{KmIAAc}=$ the maximum rate of formation and the Michaelis-Menten constant for formation of AAla in intestine. 


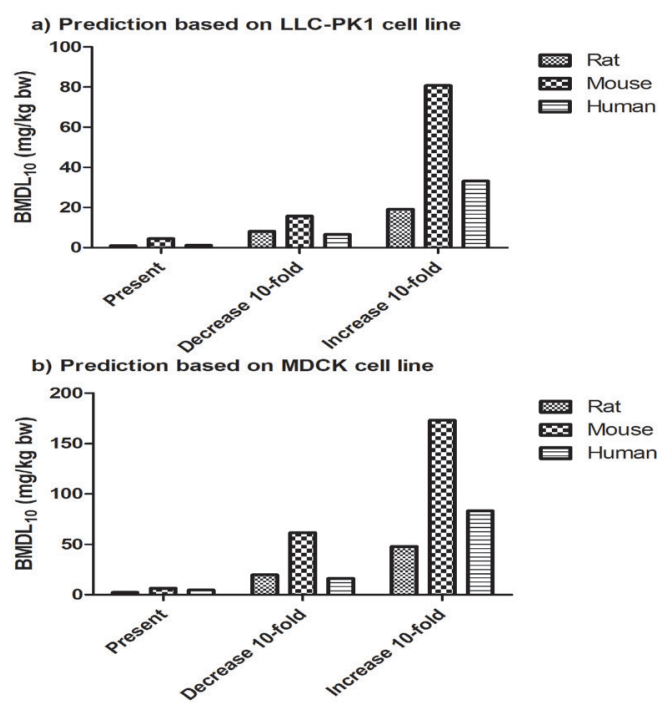

Supplementary data E. Influence of the most sensitive parameters in the PBK model on the predictions of the $\mathrm{BMDL}_{10}$ for rat, mouse and human as predicted based on LLC-PK1 (a) and MDCK (b) cell lines based on reverse dosimetry. The analysis was performed by increasing and decreasing the most sensitive parameters (with the exception of physiological parameters) 10-fold, representing a worst-case estimate of the uncertainty in the model parameters. The sensitive parameters for rat and human models changed were partition coefficients of liver, kidney, intestine and richly perfused tissue, uptake rate constant from gastrointestinal tract and excretion rate via bile constant. In case of mouse models, all the sensitive parameters changed were similar with rat and human models except for the partition coefficient of richly perfused tissue that were not included. However, the intestinal S9 protein yield and intestinal kinetics parameters were included in mouse model. Both increasing and decreasing the most sensitive parameters resulted in higher $\mathrm{BMDL}_{10}$ values. In case of increasing the most sensitive parameters with 10-fold, the kidney concentration of AAI went down as AAI was faster excreted by urinary and biliary excretion and retained longer in different tissues (due to higher partition coefficients). Therefore higher dose levels needed to be simulated in order to match the peak kidney concentrations with the in vitro effect concentrations within the reverse dosimetry approach, resulting in higher predicted $\mathrm{BMDL}_{10}$ values. When decreasing the most sensitive parameters, the predicted $\mathrm{BMDL}_{10}$ values also increased as a result of lower predicted kidney concentrations of AAI. In this case the lower kidney concentrations were a result of lowering the partition coefficients, resulting in a higher fraction of AAI that is available for metabolic conversion. 
a) Rat model

Huljic et al. (2008)human cell

Huljic et al. (2008) rat cell

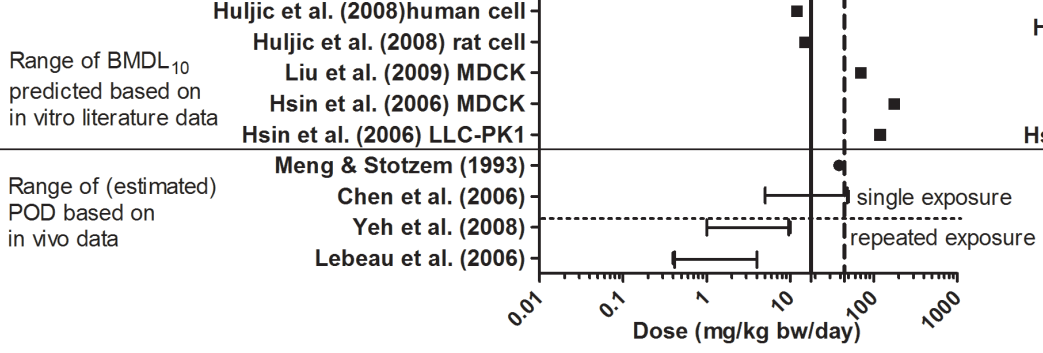

b) Mouse model

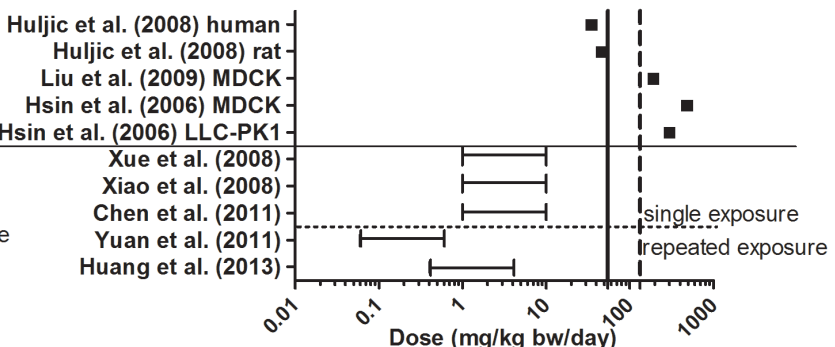

Supplementary data $\mathrm{F} . \mathrm{BMDL}_{10}$ values for acute kidney toxicity of AAI in rat (a) and mouse (b) predicted by the in vitro PBK based-reverse dosimetry approach based on the AUC for LLC-PK1 cell line (vertical solid line), MDCK cell line (vertical dashed line) and predicted based on in vitro literature data (solid squares) as compared to absolute PODs (filled circle) and estimated POD (horizontal capped lines)* values derived from in vivo kidney toxicity studies as shown in Table 2.6 and 2.7 by oral or IP exposure.

${ }^{*}$ range of estimated POD= estimated NOAEL to LOAEL 



\section{CHAPTER}

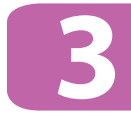

Defining in vivo dose-response curves for kidney DNA adduct formation of aristolochic acid I in rat, mouse and human by an in vitro and physiologically based kinetic modeling approach

Rozaini Abdullah, Sebastiaan Wesseling, Bert Spenkelink, Jochem Louisse, Ans Punt; and

Ivonne M. C. M. Rietjens

Submitted 


\section{ABSTRACT}

Aristolochic acid I (AAl) is a well-known genotoxic kidney carcinogen. Metabolic conversion of AAI into the DNA reactive aristolactam-nitrenium ion is involved in the mode of action of tumor formation. This study aims to predict in vivo AAI-DNA adduct formation in the kidney of rat, mouse and human by translating the in vitro concentration-response curves for AAI-DNA adduct formation to the in vivo situation using physiologically based kinetic (PBK) modeling-based reverse dosimetry. DNA adduct formation in kidney proximal tubular LLC-PK1 cells exposed to AAI was quantified by LC-ESI-MS/MS. Subsequently, the in vitro concentration-response curves were converted to predicted in vivo dose-response curves in rat, mouse and human kidney using PBK models. Results obtained revealed a dose-dependent increase in AAI-DNA adduct formation in the rat, mouse and human kidney and the predicted DNA adduct levels were generally within an order of magnitude compared to values reported in the literature. Then, in vivo tumor data in rats were used to derive $\mathrm{a} \mathrm{BMD}_{10}$ (benchmark dose producing a defined 10\% extra risk, above background level) value for kidney tumor formation and the PBK model was used to predict the AAI-DNA adduct levels at these $B M D_{10}$ values. Levels of DNA adducts predicted at the $B_{10}$ value for kidney tumor formation in rats amounted to 4-11 adducts in $10^{8}$ nucleotides. Predicted DNA adduct levels are within the range of variation observed when analyzing different animal studies. Therefore, the combined in vitro-PBK modeling approach contributes to the reduction, refinement and replacement of animal testing. 


\subsection{INTRODUCTION}

The development of science-based non-animal testing strategies in human safety assessment of chemicals is an important challenge. Current efforts in this area focus on the development and use of in vitro alternative testing strategies using cells in culture resulting in concentration-response curves. However, concentration-response curves from in vitro models are of limited use for human risk and safety assessment, because risk assessment requires in vivo dose-response curves from which points of departure can be derived. A novel alternative testing strategy that can be used to solve this discrepancy between in vitro and in vivo data involves the translation of in vitro concentration-response curves to in vivo dose-response curves using physiologically based kinetic (PBK) modeling-based reverse dosimetry [1-6]. By using this integrated in vitro-in silico approach, in vivo dose-response levels and points of departure for risk assessment can be defined based on in vitro concentration-response curves. Previously, we reported proofs of principle for this approach, including the prediction of in vivo DNA adduct formation of alkenylbenzenes [7] or a, $\beta$-unsaturated aldehydes $[8,9]$ and the prediction of in vivo developmental toxicity of glycol ethers [4], phenol [5] and retinoic acid [6]. In a recent study, we translated in vitro concentration-response curves for cytotoxicity of aristolochic acid I (AAI) in LLC-PK1 or MDCK cells to in vivo dose-response curves for kidney toxicity from which we derived $\mathrm{BMDL}_{10}$ values (benchmark dose $10 \%$ lower confidence limit) that can be used as points of departure for risk assessment [1]. Given that the ultimate critical effect of AAI toxicity is not only kidney toxicity but also DNA adduct formation resulting in AAI-induced mutagenesis and carcinogenesis, the aim of the present study was to translate in vitro concentrationresponse curves for DNA adduct formation in a kidney cell line to in vivo dose response-curves for DNA adduct formation in the kidney of rat, mouse and human. Over the past years, a number of in vivo studies has been carried out to evaluate the dose-dependent DNA adduct formation in the kidney of rats [10-14] and mice [15-17] exposed to AAl or a mixture of aristolochic acids (AAs). Also human studies on AA kidney DNA adduct formation in patients with Aristolochic Acid Nephropathy (AAN) are available $[13,18]$, enabling validation of the predictions made.

AAs are main components in all Aristolochia species that have been used as a traditional medicine to treat arthritis, gout, rheumatism and snake bites $[19,20]$. However, products containing AAs were prohibited after Mengs and colleagues discovered the carcinogenic effects of AAs in rats $[21,22]$. The risks of exposure to AAs became even more evident in 1993 when more than 1800 Belgian women were accidentally exposed to AAs via slimming pills [23] and later, more than 100 
of these young women developed chronic kidney failure, developing into cancer of the kidneys and the urinary tract in several patients $[23,24]$. These medical disorders were associated with the presence of kidney AA-DNA adducts [25]. A large body of evidence suggests that AA-induced DNA adduct formation, followed by cellular proliferation and fixation of mutations, is responsible for cancer development in AA-treated animals $[20,26]$ and humans $[20,27]$.

AAs are nitrophenanthrene carboxylic acids and the most studied congeners are 8-methoxy-6-nitrophenanthro-(3,4-d)-1,3-dioxolo-5-carboxylic acid (AAl, Figure 3.1) and its 8-demethoxylated form (AAII) [28]. It was found by Schmeiser and coworkers, that not only mixtures of AAs were found to be carcinogenic but that AAI alone could induce tumors in rat [29]. AAI is the major component in the mixtures of AAs $[25,30]$. Formation of the $\mathrm{N}$-hydroxyaristolactam metabolite of AAI is considered to lead to DNA adduct formation, whereas formation of aristolochic acid la (AAla) is considered as a detoxification reaction (Figure 3.2) [31]. Nitroreduction of AAI leads to formation of $\mathrm{N}$-hydroxyaristolactams, which is catalyzed by both cytosolic and microsomal enzymes of which $\mathrm{NAD}(\mathrm{P}) \mathrm{H}$ : quinone oxidoreductase (NQOI) is the most important enzyme [30, 32-34]. This reaction generates a reactive nitrenium intermediate, which can bind to DNA, and results in the formation of AAI-DNA adducts [14, 35] (Figure 3.2). The major adduct formed is 7-(deoxyadenosin$N^{6}$-yl)aristolactam I (dA-AAl), which has also been found to be the most persistent adduct in the kidney tissue $[13,20]$. Although AAl may be bioactivated in other organs such as the liver, the kidney has been shown to be the major target organ for AAI-induced toxicity including AAI-DNA adduct formation and tumor induction [10]. This tissue specific toxicity has been suggested to be due to the fact that the capacity of the DNA repair processes in the kidney is lower than in other organs [36] and/or to the ability of the proximal tubule cells to take up and concentrate AAs and their metabolites, making the kidney more susceptible to AA-induced toxicity [10]. 


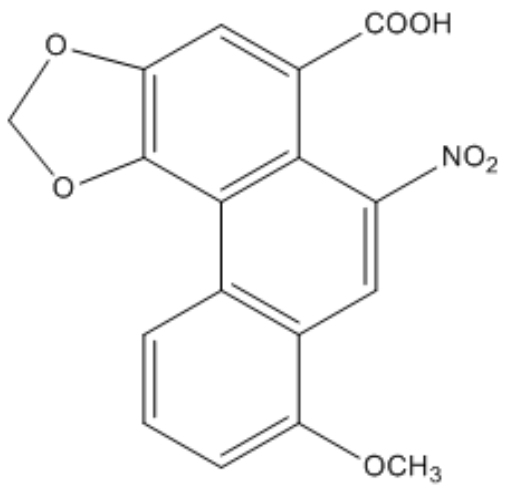

Fig. 3.1 Structural formula of aristolochic acid I (AAI).

As indicated, the aim of the present study was to predict in vivo AAI-DNA adduct formation in the kidney of rat, mouse and human by extrapolation of in vitro concentration-response curves for AAI-DNA adduct formation to the in vivo situation using PBK modeling-based reverse dosimetry. By defining dose-response curves for rat, mouse and human, using only in vitro and in silico methods, the outcome of this study may provide new insights in alternative methods for human risk assessment, especially with respect to possible species-dependent differences in dose-dependent DNA adduct formation and related carcinogenicity. 


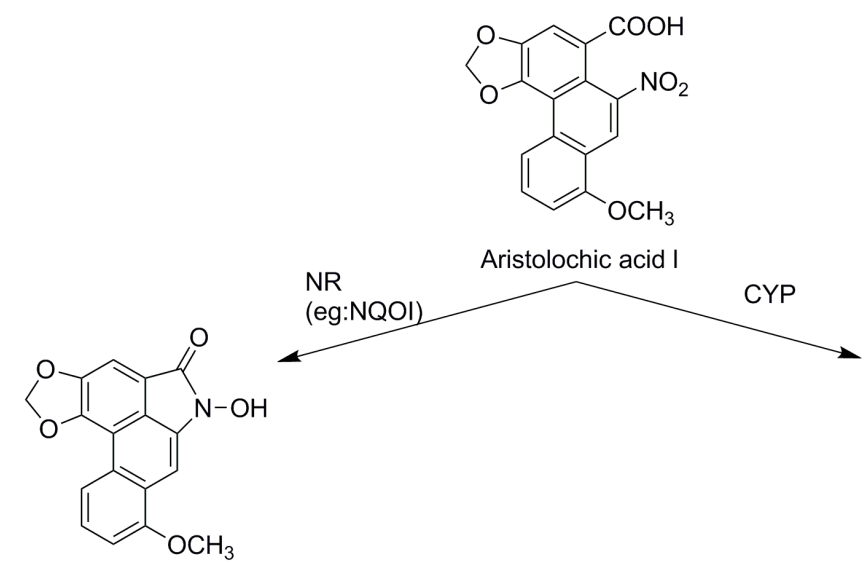

N-hydroxyaristolactam I<smiles></smiles>

cyclic nitrenium ion

DNA

$\checkmark$<smiles>COc1cccc2c1c(N=c1[nH]cnc3c1ncn3[C@H](OCCO)[C@H](O)CO)c1c3c(cc4c(c32)OCO4)C(=O)N1</smiles>

HO<smiles>COc1cccc2c1c(N=c1[nH]cnc3c1ncn3[C@H](OCCO)[C@H](O)CO)c1c3c(cc4c(c32)OCO4)C(=O)N1</smiles><smiles></smiles>

dG-AAI<smiles>O=C(O)c1cc2c(c3c([N+](=O)[O-])cc(O)cc13)OCO2</smiles>

Aristolochic acid la (Aala)

UGT

SULT

Aala-glucuronide Aala-sulfate

Fig. 3.2 Metabolic pathways for detoxification, bioactivation and DNA adduct formation of aristolochic acid I (AAI). NR = nitroreduction, $\mathrm{NQOI}=\mathrm{NAD}(\mathrm{P}) \mathrm{H}$ :quinone oxidoreductase, $\mathrm{dA}-\mathrm{AAI}=$ deoxyadenosine AAl, dG-AAI = deoxyguanosine AAI, CYPs = cytochromes P450, UGTs = uridine 5'-diphospho-glucuronosyltransferases, SULTs = sulfotransferases. 


\subsection{MATERIAL AND METHODS}

\subsubsection{Chemicals}

Aristolochic acid I (AAI) was purchased from Sigma-Aldrich (Zwijndrecht, NL). The LLC-PK1 porcine cell line $\left(\mathrm{ATCC}^{\otimes} \mathrm{CL}-101^{\mathrm{TM}}\right.$ ) was obtained from the American Type Culture Collection (ATCC). Dulbecco's Modified Eagle Medium (DMEM), phosphate buffered saline (PBS) and trypsin-EDTA were purchased from Gibco (Paisley, Scotland, UK) and fetal calf serum (FCS) from Lonza BioWhittaker (Walkersville, MD, USA). Deoxyadenosine (dA), deoxyguanosine (dG), N,N-dimethylformamide (DMF), zinc powder, phosphodiesterase I from Crotalus adamanteus (venom phosphodiesterase), phosphodiesterase II from bovine spleen (spleen phosphodiesterase), nucleus PI and alkaline phosphatase were purchased from Sigma-Aldrich. Dimethyl sulfoxide (DMSO) (>99.9\%) was obtained from Acros Organics (Geel, Belgium). Acetonitrile (ACN; ULC/MS grade) was obtained from Biosolve BV (Valkenswaard, The Netherlands). Formic acid and ethanol were obtained from VWR Merck (Darmstadt, Germany).

\subsubsection{General outline for PBK model-based reverse dosimetry approach}

Development of the in vitro-PBK approach to predict in vivo dose-response curves for DNA adduct formation consisted of the following steps: (1) establishment of in vitro concentration-response curves for AAI-dependent DNA adduct formation in the LLC-PK1 cell line, (2) translation of the in vitro concentration-response curves into in vivo dose-response curves for DNA adduct formation in rat, mouse and human using established PBK models [1] describing in vivo kinetics of AAl in rat, mouse and human, and (3) evaluation of the predictions against available in vivo data.

\subsubsection{In vitro DNA adduct formation in LLC-PK1 cells}

The LLC-PK1 cell line was cultured in $75 \mathrm{~cm}^{2}$ flasks at $37^{\circ} \mathrm{C}$ in a humidified atmosphere of $5 \% \mathrm{CO}_{2}$ in DMEM supplemented with fetal calf serum (10\% v/v). Cells were subcultured three times a week, using $1 \%(\mathrm{v} / \mathrm{v})$ trypsin-EDTA to detach the cells. Cytotoxicity was evaluated using the MTT assay as previously described [1].

A total of approximately $1 \times 10^{6}$ cells/flask were seeded. At confluency of $80-90 \%$, the cells were exposed for $24 \mathrm{~h}$ to AAl at different concentrations ranging from 0.5 to $20 \mu \mathrm{M}$ (final concentration in the DMEM without serum) added from 200 times concentrated stock solutions in 
DMSO. In line with previous studies [37, 38], exposure of cells to AAI was performed in serum-free medium to prevent binding of AAI to serum proteins, which would decrease the free concentration of AAI to which the cells were exposed [39].

To obtain a sufficient amount of DNA, all concentrations of AAI were tested in duplicate and the duplicate samples were pooled. After the exposure to AAl, cells were scraped in $5 \mathrm{~mL} P B S$, collected in a $10 \mathrm{~mL}$ tube and centrifuged at $1500 \mathrm{rpm}$ for $5 \mathrm{~min}$. The pellets were stored at $-20^{\circ} \mathrm{C}$ until DNA isolation. For DNA isolation, a QIAamp DNA Mini Kit from Qiagen (Hilden, Germany) was applied according to the procedure as recommended by the supplier. The yield and purity of the extracted DNA were determined using Nanodrop 1000 technology by measuring the absorbance ratio A260/280 $\mathrm{nm}$. DNA samples with an absorbance ratio of 1.8-2.0 were considered pure. Digestion of DNA was performed as previously described [40] with minor modifications. In short, 40 $\mu \mathrm{L}$ P1 buffer (300 mM sodium acetate, $1 \mathrm{mM} \mathrm{ZnSO}_{4^{\prime}} \mathrm{pH}$ 5.3), $20 \mu \mathrm{L}$ SPDE (spleen phosphodiesterase) solution $(0.001 \mathrm{U} / \mu \mathrm{L})$, and $10 \mu \mathrm{L}$ nuclease $\mathrm{PI}(0.5 \mathrm{U} / \mu \mathrm{L}$ in water) were added to $50 \mu \mathrm{g}$ DNA and incubated for $4 \mathrm{~h}$ at $37^{\circ} \mathrm{C}$. Then, $40 \mu \mathrm{L}$ PA buffer (500 mM Tris, $1 \mathrm{mM}$ EDTA, pH 8.0), $20 \mu \mathrm{L}$ VPDE (venom phosphodiesterase) solution $(0.0002 \mathrm{U} / \mu \mathrm{L}$ in water), and $15 \mu \mathrm{L}$ alkaline phosphatase $(0.27$ $\mathrm{U} / \mu \mathrm{L}$ ) were added and the sample was incubated for another $2 \mathrm{~h}$ at $37^{\circ} \mathrm{C}$. The hydrolyzed samples were evaporated to dryness and reconstituted in $50 \mu \mathrm{L}$ water. The samples were kept at $-80^{\circ} \mathrm{C}$ until analysis using Liquid Chromatography-Electrospray lonization-Tandem Mass Spectrometry (LC-ESIMS/MS).

\subsubsection{Synthesis of dA-AAI and dG-AAI adducts}

The synthesis of the dA-AAI and dG-AAl adducts was performed by reaction of AAI with dA or dG using a modification of the protocol described previously [15]. In short, $100 \mu \mathrm{L}$ of AAI in DMF (10 $\mathrm{mM}$ ) was mixed with $80 \mathrm{mg}$ of preactivated zinc dust ( $<150 \mu \mathrm{m}, 99.95 \%)$. Then, $1000 \mu \mathrm{L}$ of dA or dG dissolved in potassium phosphate $(50 \mathrm{mM}, \mathrm{pH} 5.8)$ were added to the AAI / zinc dust mixture to give a final concentration range that varied from 0 to $100 \mu \mathrm{M}$. After incubation in the dark at $37^{\circ} \mathrm{C}$ for 16 $\mathrm{h}$, the samples were put on ice for $30 \mathrm{~min}$ and centrifuged at $15000 \mathrm{rpm}$ for $10 \mathrm{~min}$. The efficiency of the synthesis (\% of dA or dG that reacted) was determined by analysis of the supernatant by HPLC on a Waters Alliance system with PDA-detection ( $260 \mathrm{~nm}$ ) and a Grace Alltima C18 150 x $4.6 \mathrm{~mm}$ column measuring the unreacted $d A$ or $d G$. Elution of $d A$ was performed isocratically with $90 \%$ ammonium formate $(10 \mathrm{mM})$ and $10 \%$ acetonitrile, and elution of $\mathrm{dG}$ with $95 \%$ and $5 \%$ of the same solutions 
respectively, at a flow of $0.8 \mathrm{ml} / \mathrm{min}$. The methods included a washing step with $100 \%$ acetonitrile before the new injection. The final amount of dA-AAI and dG-AAI in the calibration curve samples were assumed to be $2 \%$ of the starting material as previously reported [15]. The synthesized adduct samples obtained were used in LC-ESI-MS/MS to define a calibration curve for the quantification of dA-AAI and dG-AAl adducts in the cell studies.

\subsubsection{LC-ESI-MS/MS method for detection and quantification of dA-}

\section{AAl and dG-AAI}

The LC-ESI-MS/MS method for detection and quantification of dA-AAI and dG-AAI was adapted from Yun et al. (2012) [15] LC-ESI-MS/MS was performed on a Perkin Elmer 200 series HPLC System (Perkin Elmer, Waltham, MA) coupled to an API 3000 system (Applied Biosystem, Foster city, CA) as previously described [41, 42]. In brief, $10 \mu \mathrm{L}$ of sample was injected on an Agilent Zorbax Extend-C18 column, 2.1 x $50 \mathrm{~nm}$, 3.5 Micron 80 A (Basel, Switzerland), with a Zorbax guard column. A gradient was made with ultra-pure water containing $0.1 \%$ formic acid as solvent $A$ and $100 \%$ acetonitrile as solvent B. The flow rate was set to $0.3 \mathrm{~mL} / \mathrm{min}$. In a total run of $15.5 \mathrm{~min}$, the starting condition was 90:10 (A:B) for $1 \mathrm{~min}$ followed by changing to $50: 50$ in $2.5 \mathrm{~min}$, then to 0:100 in $1 \mathrm{~min}$ and remaining at 0:100 for another $2 \mathrm{~min}$ before returning to the starting condition over $1 \mathrm{~min}$ and keeping these conditions for $8 \mathrm{~min}$ to allow the column to re-equilibrate at room temperature.

The mass spectrometric analysis in the positive ion mode was optimized with the following settings: nebulizer gas (air) at $10 \mathrm{psi}$, curtain gas (nitrogen) at $10 \mathrm{psi}$, ion spray voltage at $4000 \mathrm{~V}$, collision energy (CE) at $28 \mathrm{eV}$, ion source temperature at $400^{\circ} \mathrm{C}$, declustering potential set at $69 \mathrm{~V}$, focusing potential at $175 \mathrm{~V}$, entrance potential at $13 \mathrm{~V}$, and collision cell exit at $15 \mathrm{~V}$. Nitrogen was used as sheath gas turbo, ion spray, with a pressure of $7000 \mathrm{~L} / \mathrm{h}$. The dwell time per transition was $0.05 \mathrm{sec}$. A divert valve was used in order to discard the gradient after elution of the peak. The mass spectrometer was operated in MRM mode with the following $\mathrm{m} / \mathrm{z}$ transitions; $543 \rightarrow 427$ for $\mathrm{dA}-\mathrm{AAI}$ and $559 \rightarrow 443$ for dG-AAI.

Data analysis of the calibration series and the samples was performed using the Analyst software version 1.5 (Applied Biosystem, Foster city, CA). Calibration curves were derived by plotting the peak area of synthesized dA-AAI or dG-AAl against the concentration of dA-AAI or dG-AAI and were used to determine the amount of DNA adducts in the samples of AAI-exposed cells. The amount of $\mathrm{dA}-\mathrm{AAI}$ or dG-AAl detected in the samples was related to the total amount of digested 
DNA detected in each sample and adjusted for the mass conversion of double strands DNA per 1000 nucleotides (nts) that correspond to $607.6 \mathrm{~g} / \mathrm{mol}$, in order to quantify the number of adducts per $10^{8}$ nts.

\subsubsection{PBK models for rat, mouse and human}

In our previous work [1], PBK models were developed that describe the toxicokinetics of AAI in rat, mouse and human. In the present work, the same PBK models were used to convert concentrations to dose levels that would induce the DNA adducts levels observed in vitro. To this purpose an equation describing the AAI concentration dependent DNA adduct formation in LLC-PK1 kidney cells in vitro was added to the kidney compartment of the PBK model. In this way, the kinetic parameters for bioactivation of AAI to its DNA adduct forming metabolite were implicitly included in the combined in vitro-in silico model, since this takes place in the LLC-PK1 cells in vitro.

The set of differential equations describing the mass balance equations can be found in supplementary data A. The PBK model equations were solved with Berkeley Madonna (version 8.3.18, UC Berkeley, CA, USA) using Rosenbrock's algorithms for solving stiff systems. A sensitivity analysis was performed to evaluate the influential parameters on the model output. Normalized sensitivity coefficients (SC) were calculated for the area under the curve (AUC) of the AAI venous blood concentration in the kidney as the model output (C) using the following equation:

$\mathrm{SC}=\left(\mathrm{C}^{\prime}-\mathrm{C}\right) /\left(\mathrm{P}^{\prime}-\mathrm{P}\right)^{*}(\mathrm{P} / \mathrm{C})$

where $C$ is the initial value of the model output, $C^{\prime}$ is the modified value after changing parameter value $P, P$ is the initial parameter value and $P^{\prime}$ is the modified parameter value [43]. A 5\% increase in parameter values was chosen to analyze the effect of a change in a parameter. The sensitivity analysis was conducted for oral exposure to single doses of 0.1 and $100 \mathrm{mg} / \mathrm{kg}$ bw of AAl to simulate the influential of low and high dose levels to the model output.

\subsubsection{Translation of in vitro concentration-response curves to in vivo dose-response curves}

Based on the in vitro concentration-response curve for AAI-DNA adduct formation in LLC-PK1 kidney cells, the in vivo dose-response curves for DNA adduct formation in the kidney of rat, mouse and human were predicted by PBK modeling-based reverse dosimetry. To this end, the concentrationresponse data from the in vitro DNA adduct formation experiment, were translated to AUCPage $\mid 88$ 
response data by multiplying the concentration with the exposure time $(24 \mathrm{~h})$. The extrapolation of the in vitro free AUC-response curve to the in vivo situation was done by assessing which oral doses are required in the PBK model to reach equivalent free AUC values of the AAI venous blood in the kidney as conventional marker of the biological active concentration in a tissue that can be linked to toxicodynamic data $[44,45]$.

Since AAI has a high binding affinity to protein [39], this leads to the differences in the free fraction of AAl in vitro, where medium without serum was used, as compared to the in vivo situation, where high protein levels are present $[46,47]$. We have also measured the DNA adduct formation in cells exposed in the presence of FCS and the results confirm that protein binding significantly decreases the DNA adduct formation (data not shown) and should thus be taken into account. A correction for difference in free fraction between the in vitro and in vivo situation was included by multiplying the in vitro concentrations, obtained in absence of proteins, with a correction factor that amounted to 4.6. This factor was taken from Dickman et al. (2011), who showed that the free fraction of AAI in conditions resembling plasma is about 4.6 times lower than the free fraction in vitro in culture conditions where no proteins are added [39].

Based on these assumptions the following equation was used to describe the formation of dA-AAI and dG-AAI adducts as a function of the AUC of the AAI venous blood concentration in the kidney in the PBK model:

$\mathrm{DNA}=\mathrm{A}^{*} \mathrm{AUCVK}_{\mathrm{AAI}}$

'DNA' is the amount of DNA adducts (number of adducts $/ 10^{8} \mathrm{nts}$ ) formed, ' $A$ ' is the slope, calculated based on the data from the in vitro experiments in which the in vitro AUC values were plotted against the amounts of DNA adducts that are formed within the in vitro experiment, measured in absence of albumin (see Results section). The in vitro AUC values were multiplied by 4.6 to account for the differences in free fraction between the in vitro an in vivo situation. 'AUCVK ${ }_{A A 1}$ ' represents the AUC of the AAI venous blood concentration in the kidney (CVK), defined as the total kidney concentration $(C K)$ divided by the kidney:plasma partition coefficient $\left(\mathrm{P}_{\mathrm{k:p}}\right)$.

The PBK model allows estimation of the DNA adduct formation with different oral doses of AAI. The prediction of DNA adduct formation based on the AUC approach has been done before in other PBK or dynamic modeling-based predictions [40]. Based on the current state-of-the-art, predictions on DNA adduct formation were made for the kidney as a whole. Yet, for some of the in vivo data used for evaluations DNA adduct levels were reported for specific regions of the kidney and species differences region specific occurrence of DNA adducts might occur. This may lead to a 
source of uncertainty in the model predictions as indicated in the discussion section.

\subsubsection{Evaluation of the PBK modeling-based reverse dosimetry approach to predict in vivo DNA adduct formation}

To evaluate the potential of the in vitro-in silico approach to obtain a dose-response curve for in vivo DNA adduct formation of AAI, the DNA adduct formation predicted by the PBK modeling-basedreverse dosimetry approach were compared to data on in vivo DNA adduct formation in rat $[10,11$, 14], mouse [15-17] and human kidney [13, 18] available from literature.

\subsubsection{Prediction of AAI-DNA adduct formation at the $\mathrm{BMD}_{10}$ for kidney tumor formation}

In order to relate the predicted formation of DNA adducts with tumor formation induced by AAI, the $\mathrm{BMD}_{10}$ (the benchmark dose resulting in a 10\% extra risk, above background level) calculated based on kidney tumor incidence data [21] was used in further analysis. Supplementary data B present the results from the $B M D$ analysis and reveal a $B M D_{10}$ value of $0.05-0.15 \mathrm{mg} / \mathrm{kg}$ bw/day. The PBK models were used to predict the number of adducts formed in $10^{8} \mathrm{nts}$ at these $\mathrm{BMD}_{10}$ values. The dose level in human that would result in the adduct level at the $\mathrm{BMD}_{10}$ in a carcinogenicity study in rats [21] was calculated and compared with the estimated intake levels and related tumor incidences in Belgian patients. 


\subsection{RESULTS}

\subsubsection{In vitro DNA adduct formation data}

Figure 3.3a shows the concentration response-curve for AAI-DNA adduct formation upon exposure of the LLC-PK1 cells to increasing concentrations of AAI. The LC-ESI-MS/MS chromatogram for $543 \rightarrow 427$ and $559 \rightarrow 443$ transitions of hydrolyzed DNA isolated from LLC-PK1 cells exposed to AAI shows that the $\mathrm{dA}$ - and dG-AAl adducts eluted at $3.5 \mathrm{~min}$ and $3.1 \mathrm{~min}$ respectively. These experimental data show a concentration-dependent increase in both dA-AAI and dG-AAI DNA adduct formation at increasing concentrations of AAl up to $20 \mu \mathrm{M}$ (the highest concentration tested). At $20 \mu \mathrm{M}$ of AAl, the level of dA-AAI DNA adducts formed after $24 \mathrm{~h}$ of incubation amounted to $530000 \pm 180000$ adducts $/ 10^{8}$ nts (average $\pm S D$ of three independent experiments). Formation of dG-AAl adducts was 66 -fold lower than the formation of dA-AAl adducts $\left(8000 \pm 2000\right.$ adducts $/ 10^{8}$ nts at $20 \mu \mathrm{M}$ AAI). The results obtained reveal a linear relationship between the concentration and the level of adduct formation observed; dA-AAI $=24875^{*}[\mathrm{AAI}]\left(\mathrm{r}^{2}=0.98\right)$ and $\mathrm{dG}-\mathrm{AAI}=385^{*}[\mathrm{AAI}]\left(\mathrm{r}^{2}=0.96\right)$. As the formation of dG-AAl adducts was low and almost negligible compared to dA-AAI adduct formation, only formation of dA-AAl adducts was used for further analyses.

Figure $3.3 \mathrm{~b}$ shows the in vitro concentration-response curve obtained in the present study for AAI concentration dependent dA-AAI DNA adduct formation in the LLC-PK1 cells as compared to in vitro concentration-response curves reported in the literature. This comparison reveals higher dA-AAI DNA adduct levels detected in the present study than dA-AAI DNA adduct levels detected before as reported in the studies available in literature. It is also of interest to note that the results presented in Figure 3.3b indicate that DNA adduct formation reported so far is higher in kidney cell lines as compared to non-kidney cell lines. 
a)

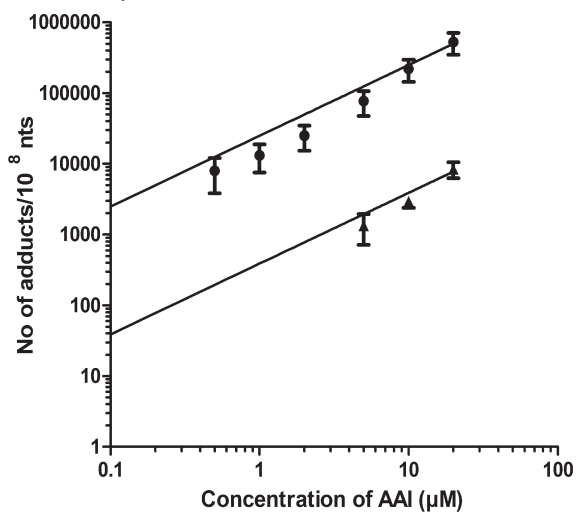

- Present study, dA-AAl

$\mp$ Present study, dG-AAI

b)

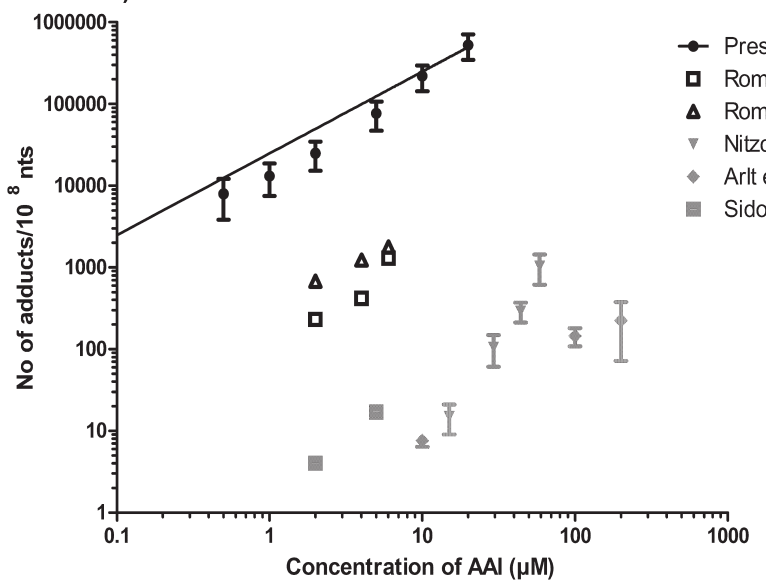

Fig. 3.3 Concentration response-curves for dA-AAI (circle) and dG-AAl adduct formation (triangle) in LLC-PK1 cells upon 24 hours exposure to increasing concentrations of $A A I(\mu M)$, expressed in no of adducts $/ 10^{8}$ nts as quantified by LC-ESI-MS/MS (mean values \pm SD) (a) and comparison to concentration response-curves reported in literature quantified by ${ }^{32} \mathrm{P}$-postlabeling (b). The black symbols show data from kidney cell lines and the grey symbols show data from non-kidney cell lines. The linear equation was fit through the origin. 


\subsubsection{Sensitivity analysis of the PBK models}

Sensitivity analyses were performed at a low and high dose level ( 0.1 and $100 \mathrm{mg} / \mathrm{kg}$ bw of AAl) to identify the key parameters that influence the model outcome (AUC of the AAI venous blood concentration in the kidney). In both sensitivity analyses (supplementary data $C$ ) the volume of the liver, biliary excretion and the partition coefficient of the liver were the most influential parameters in the PBK models for all three species, all expressing normalized sensitivity coefficients higher than 0.1 (in absolute value). The sensitivity analyses also revealed that parameters related to the intestine (volume of the intestine, blood flow to intestine, 59 protein yield, the maximum rate of formation of aristolochic acid la metabolite and the Michaelis-Menten constant for formation of aristolochic acid la metabolite) had a large influence on the model output only in the mouse PBK model, which were more influential at low oral dose levels compared to high dose levels. Also the body weight in the mouse PBK model was the sensitive parameter at low oral dose levels.

\subsubsection{Translation of the in vitro concentration-response curve to in vivo dose-response curves}

We assumed that the AUC and not the $C_{\max }$ is the most appropriate dose metric related to AAIinduced DNA adduct formation because DNA adduct formation will depend more on cumulative exposure than on the maximum exposure concentration in the tissue of interest [48]. Therefore, the concentration-response curve of dA-AAl adduct formation (Figure 3.3a), was converted to an $A U C_{\text {AAl(in vitro) }}$ response curve (Figure 3.4) by multiplying the concentration by the time of incubation (24 h). The AUC $C_{\text {All(in vitro) }}$ response curve presented in Figure 3.4 can be described by a linear equation through the origin by:

$\mathrm{DNA}_{\mathrm{dA}}=1036.5 * \mathrm{AUC}_{\mathrm{AAl}}$

in which DNA $A_{d A}$ represents the amount of dA-AAI DNA adducts (no of adducts/ $10^{8} \mathrm{nts}$ ) formed in the kidney cells at a certain $A U C_{A A I}\left(h^{*} \mu \mathrm{mol} / L\right)$ of AAI. A correction factor for protein binding was applied to this in vitro concentration-response equation (see materials and methods section) to account for the differences in free fraction between the in vitro and in vivo situation. When including this correction, the following equation was obtained:

$D_{\mathrm{DNA}}=225^{*} \mathrm{AUC}_{\mathrm{AAl}}$

This equation was incorporated in the PBK models, by defining that the corrected AUC of AAI in vitro should equal the AUC of the AAl venous blood in the kidney in the PBK model (see equation [2] of 
the Materials and Methods section), thus providing a link between the PBK model and the equation for DNA adduct formation in vitro and defining a PBK model that can predict DNA adduct formation as a function of the AAI dose. Given the fact that cells of the LLC-PK1 cell line are able to repair the DNA adduct formation $[49,50]$, the current equation implicitly represent not only the formation of DNA adducts but also repair.

Figure 3.5 shows the predicted in vivo dose-response curves for DNA binding of AAI in rat, mouse and human obtained by converting the in vitro AUC-response curve for DNA adduct formation in LLC-PK1 cells (Figure 3.4) by PBK modeling-based reverse dosimetry. The predicted DNA adduct formation reveals that the species differences in kinetics result in DNA adduct formation being 1.4-fold lower in rat kidney compared with human kidney and 3.7-fold lower in mouse kidney than in human kidney at similar dose levels per kg body wt. These results indicate that the sensitivity of human for AAl-induced DNA adduct formation may be more comparable to rat than to mouse.

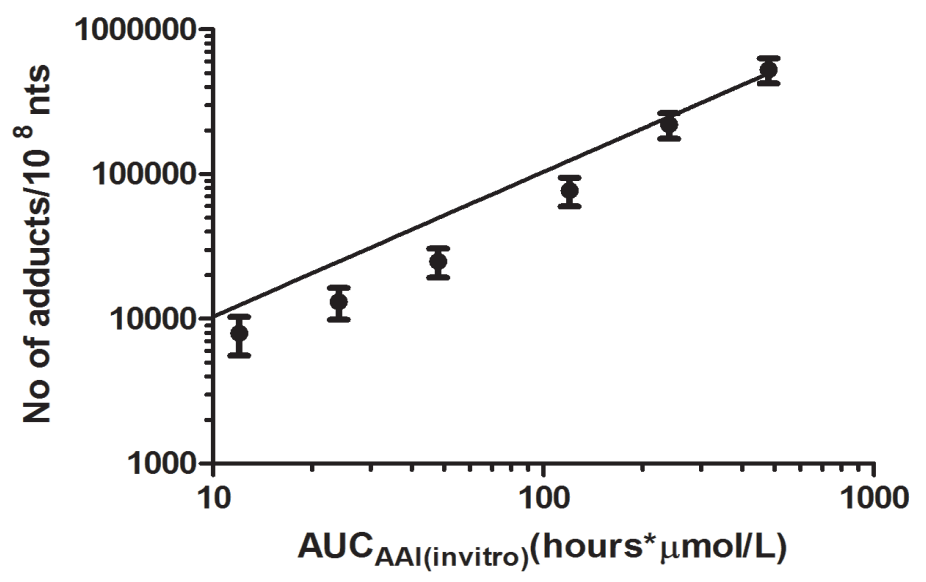

Fig. 3.4 dA-AAl adduct formation in LLC-PK1 kidney cell line expressed in no of adducts $/ 10^{8}$ nts as a function of $A U C_{\text {AAl(in vitro) }}$ (hours* $\mu \mathrm{mol} / \mathrm{L}$ ), and quantified by LC-ESI-MS/MS (mean values $\pm S D$ ). The linear equation was fit through the origin 


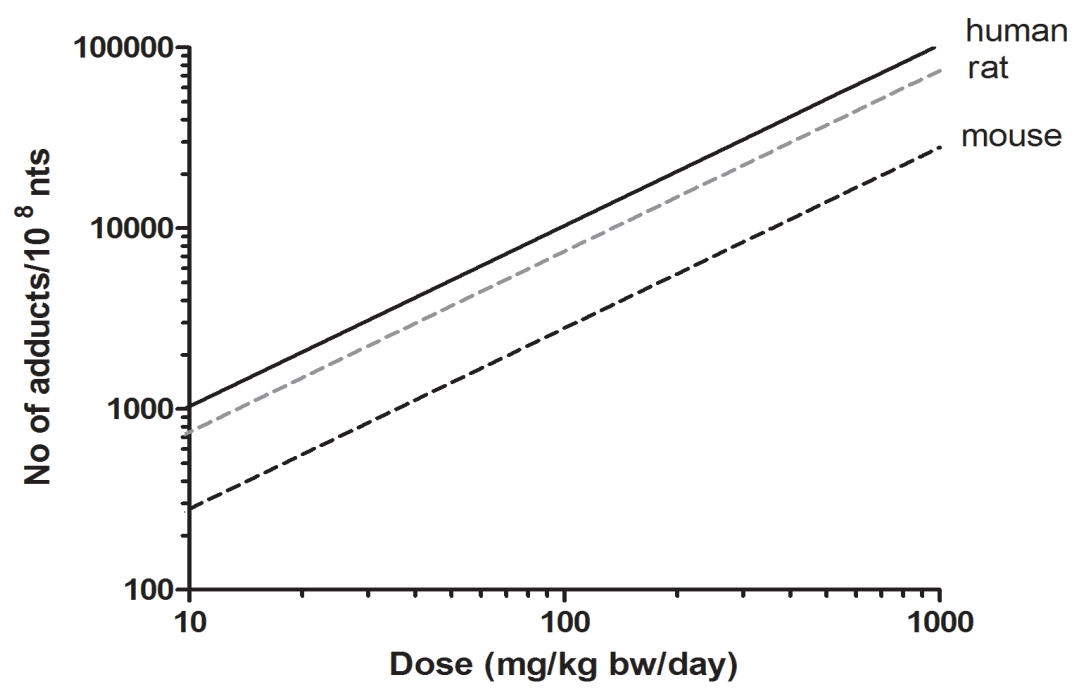

Fig. 3.5 PBK model-based reverse dosimetry predicted in vivo dose-response curves for DNA adduct formation in the kidney of rat (grey dashed line), mouse (black dashed line) and human (black solid line)

\subsubsection{Evaluation of the in vitro-PBK model-based predictions of in vivo DNA adduct formation by AAI in the kidney}

To evaluate the outcomes of the in vitro-PBK model based predictions for dose dependent AAIDNA adduct formation in the kidney, the predicted dose-response curves for DNA adduct formation were compared to dose dependent DNA adduct formation in the kidney of rat, mouse and human as reported in the literature. Table 3.1, 3.2 and 3.3 and Figure 3.6, 3.7 and 3.8 present an overview of in vivo literature data on DNA adduct formation in rat (Table 3.1, Figure 3.6), mouse (Table 3.2, Figure 3.7) and human (Table 3.3, Figure 3.8) expressed as number of adducts per $10^{8} \mathrm{nts}$. From the overview of all in vivo data, it appears that the reported literature data on in vivo DNA adduct formation vary significantly. Data for rats show 3 orders of magnitude difference in the levels of DNA adducts detected at similar dose levels between the different studies and relatively low levels of AAI-DNA adduct levels in especially the studies reported by Bieler et al. (1997) [13] and Chan et al. (2008) [12]. This difference cannot be ascribed to the generally lower levels obtained with 
${ }^{32}$ P-postlabeling than with LC-MS/MS methods since the data reported by Chan et al. (2008) [12] were obtained using LC-MS/MS. The differences may be due to the duration of exposure given that both the Bieler et al. (1997) [13] and Chan et al. (2008) [12] studies measured DNA adduct formation after a single exposure as compared to repeated longer exposure for the other studies. However, the fact that the levels in the mouse studies by Yun et al. (2012) [15] and Arlt et al. (2011) [17] that were both obtained after single exposure and detection by ${ }^{32}$ P-postlabeling differed also 2 orders of magnitude seems to contradict this explanation. Given that the reasons underlying this unusually large discrepancy between different in vivo studies for the rats remain unclear and the fact that data reported by Bieler et al. (1997) [13] and Chan et al. (2008) [12] seem out of line with all other in vivo data (Figure 3.6) we decided to exclude these data from further evaluation of our predictions.

Figure 3.6 presents a comparison of the predicted dose-dependent DNA adduct formation by the rat model as compared to the remaining rat literature data. Our predicted values were 1.7- to 3.1-fold lower than data from the studies from Mei et al. (2006) [10] and Dong et al. (2006) [11] and 17.7-fold higher than data from Pfau et al. (1990) [14] in which DNA adduct formation was quantified by ${ }^{32} \mathrm{P}$-postlabeling. Figure 3.7 presents a similar comparison for data from mice and reveals that our predicted DNA adduct levels were 15.7- to 36.4-fold lower as compared to mouse literature data from Yun et al. (2012) [15] and Shibutani et al. (2007) [16] while the predicted DNA adduct level was 11.1-fold higher than data reported by Arlt et al. (2011) [17].

Data reported for Belgian patients were used to evaluate the human model, although it should be kept in mind that there might be large uncertainty in the estimated dose levels. The uncertainties in intake estimates are often a reality in human data derived from intoxication incidents. Nonetheless, such intoxication incidents provide a valuable source of human data as experiments with defined dose levels and exposure regimes are, for ethical reasons, not allowed for a compound like AAI. As AA-DNA adducts in human tissues show a long term persistence with after 89 months after the discontinuation of exposure, levels of AA-DNA adducts still being elevated above background [27], a direct link with exposure might still be made. Figure 3.8 presents the dose dependent AAI-DNA adduct formation predicted for human kidney and reveals that the predicted DNA adduct formation was 2.3- to 85.1-fold lower as compared to the levels of AAI-DNA adducts detected in kidney tissue of patients with AAN. From this comparison it follows that the in vitroin silico based prediction provides data that match relatively well with the DNA adduct results presented in available in vivo studies. 


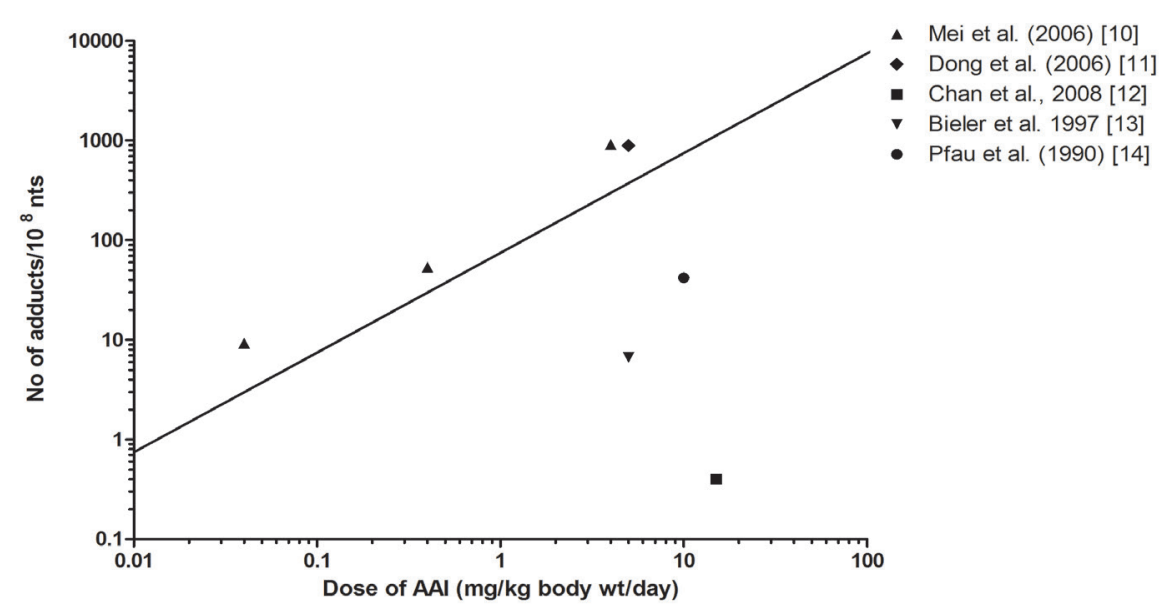

Fig. 3.6 Comparison of PBK model-based reverse dosimetry predicted dose dependent DNA adduct formation (straight line) in the kidney of rats exposed orally to AAI to data on in vivo AAI-DNA adduct formation in the kidney of rats as taken from literature. See Table 3.1 for specifications of the experimental conditions for the in vivo studies 


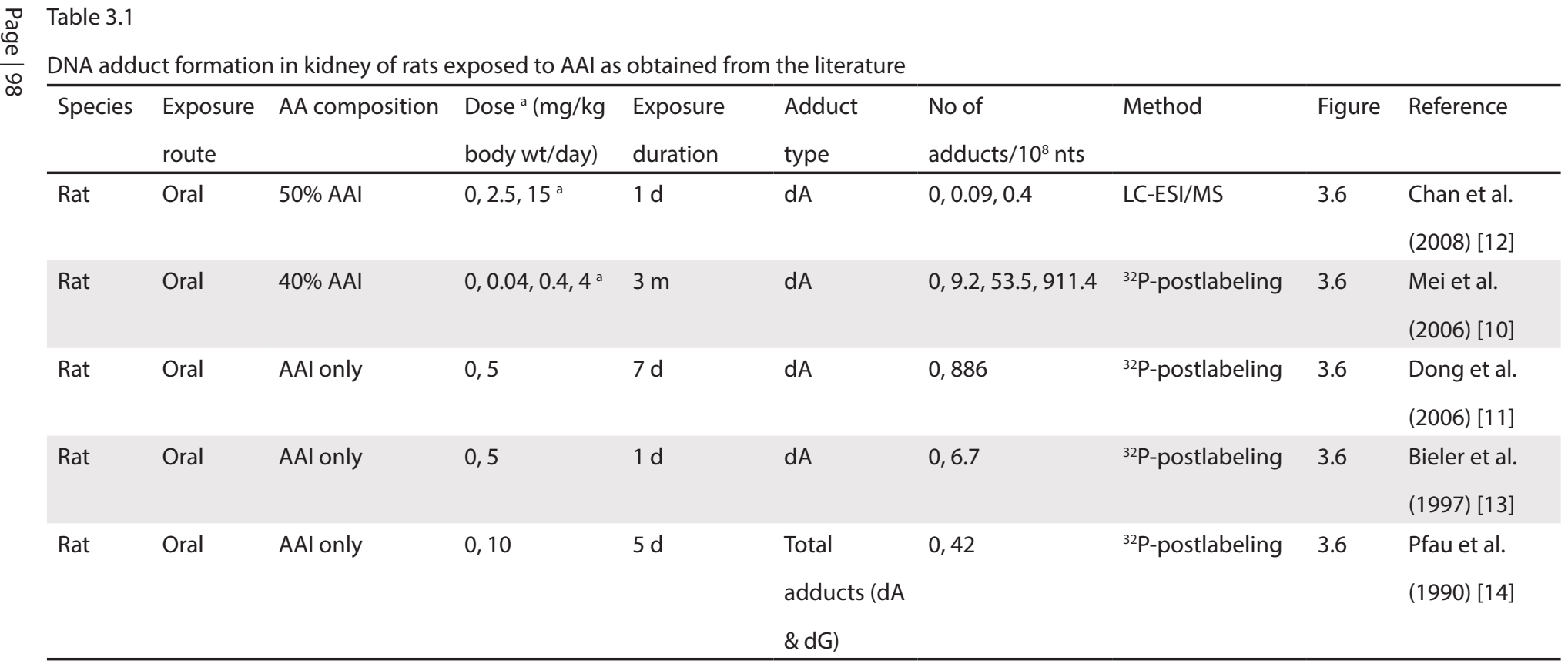

${ }^{\text {a }}$ adjusted dose $=$ dose $\mathrm{x}$ percentage of AAI 


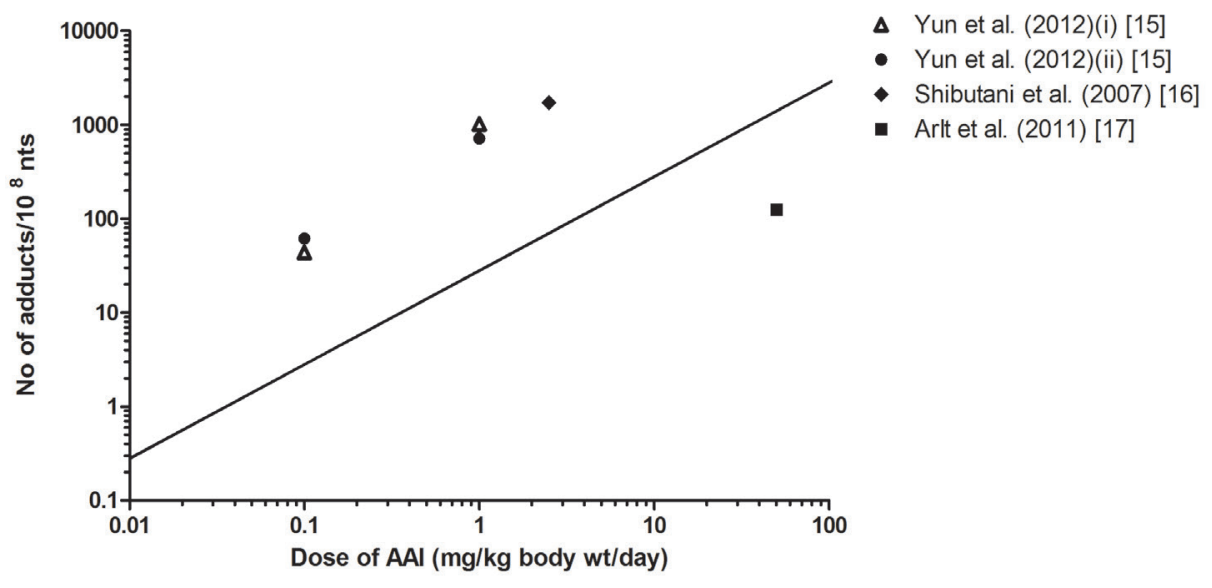

Fig. 3.7 Comparison of PBK model-based reverse dosimetry predicted dose dependent AAI-DNA adduct formation (straight line) in the kidney of mice exposed orally to AAI to data on in vivo AAIDNA adduct formation in the kidney of mice as taken from literature. See Table 3.2 for specifications of the experimental conditions for the in vivo studies 


\begin{tabular}{|c|c|c|c|c|c|c|c|c|c|}
\hline Species & $\begin{array}{l}\text { Exposure } \\
\text { route }\end{array}$ & $\begin{array}{l}\text { AA } \\
\text { composition }\end{array}$ & $\begin{array}{l}\text { Dose(mg/ } \\
\text { kg body } \\
\text { wt/day) }\end{array}$ & $\begin{array}{l}\text { Exposure } \\
\text { duration }\end{array}$ & $\begin{array}{l}\text { Adduct } \\
\text { type }\end{array}$ & $\begin{array}{l}\text { No of } \\
\text { adducts } / 10^{8} \text { nts }\end{array}$ & Method & Figure & Reference \\
\hline Mouse & IP & AAI only & $0,0.1,1$ & $1 \mathrm{~d}$ & $d A$ & $\begin{array}{l}0,43.9,1020 \text { (i) } \\
0,61.6,717 \text { (ii) }\end{array}$ & $\begin{array}{l}\text { UPLC-ESI/MS (i) \& } \\
\text { 32P-postlabeling (ii) }\end{array}$ & 3.7 & $\begin{array}{l}\text { Yun et al. } \\
\text { (2012) [15] }\end{array}$ \\
\hline Mouse & Oral & AAI only & $0,2.5$ & $9 d$ & $\mathrm{dA}$ & 0,1720 & ${ }^{32} \mathrm{P}$-postlabeling & 3.7 & $\begin{array}{l}\text { Shibutani } \\
\text { et al. (2007) } \\
{[16]}\end{array}$ \\
\hline Mouse & Oral & AAI only & 0,50 & $1 \mathrm{~d}$ & $\begin{array}{l}\text { Total } \\
\text { adducts } \\
\text { (dA\&dG) }\end{array}$ & $0,125.7$ & ${ }^{32} \mathrm{P}$-postlabeling & 3.7 & $\begin{array}{l}\text { Arlt et al. } \\
\text { (2011) [17] }\end{array}$ \\
\hline
\end{tabular}




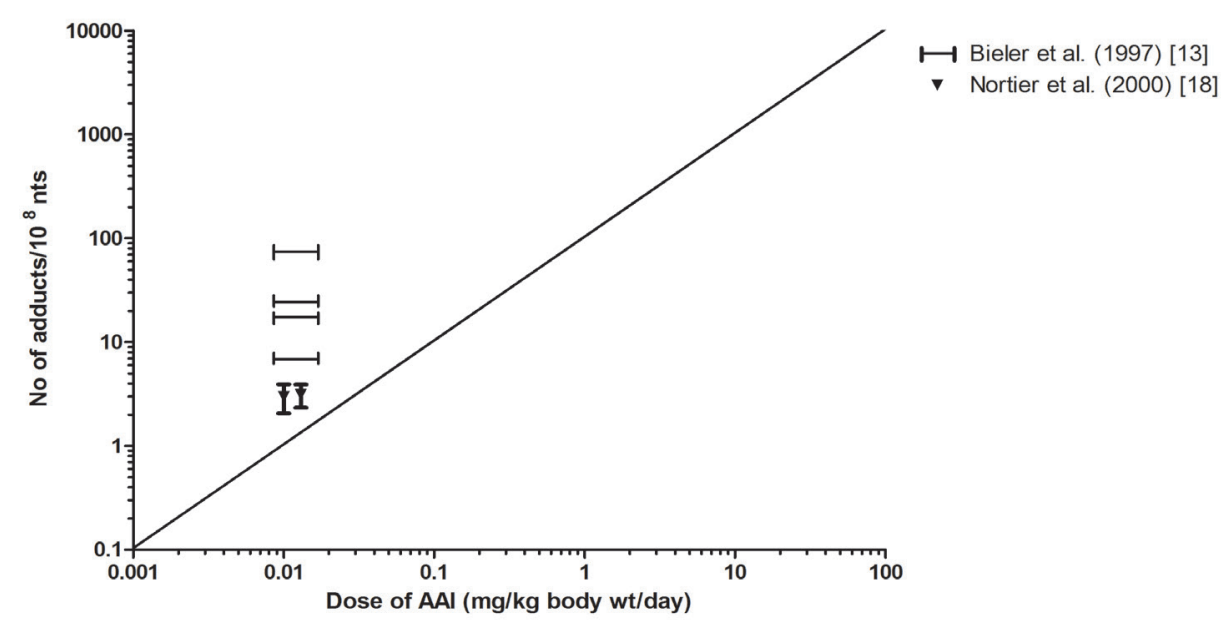

Fig. 3.8 Comparison of PBK model-based reverse dosimetry predicted dose dependent AAI-DNA adduct formation in the kidney of humans (straight line) exposed orally to AAI to data on AAI-DNA adduct formation in AAN patients as taken from the literature. See Table 3.3 for specifications for the human studies where study from Bieler et al. [13] presents data based on the estimated range of exposure from different individuals 


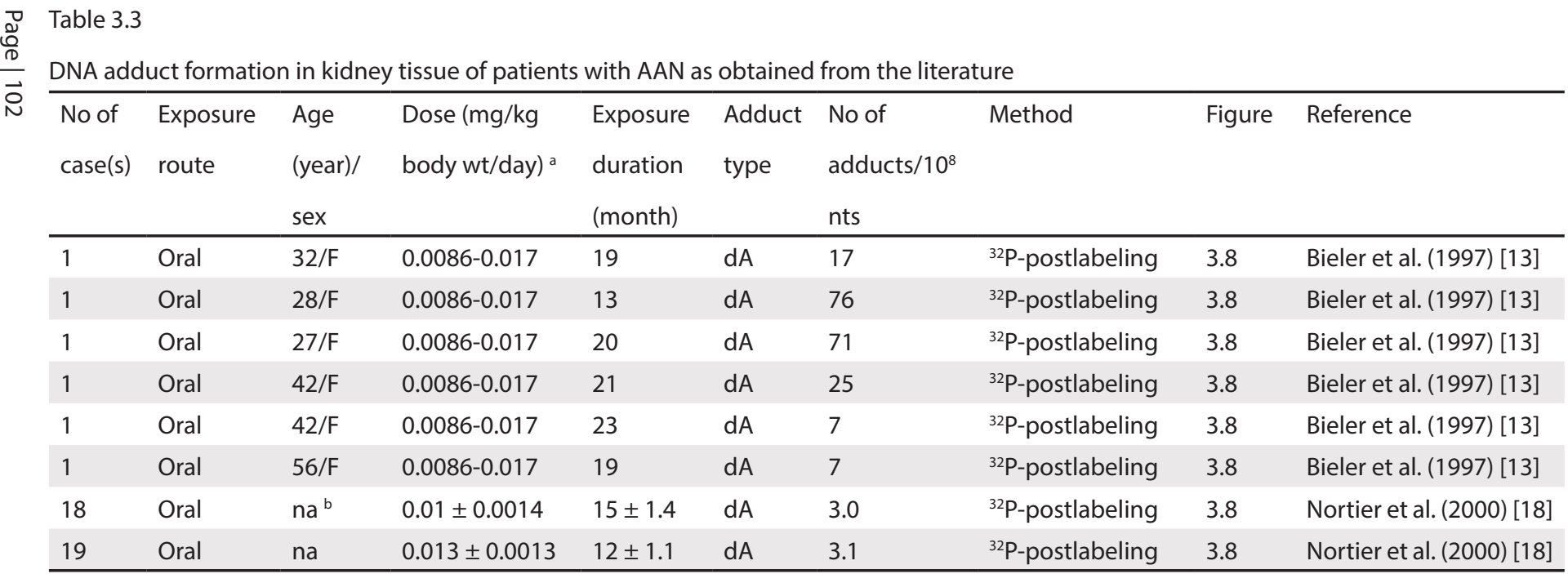

a Dose is estimated based on the consumption of AAl by patients who took formula II, estimated to contain $2 \mathrm{mg} / \mathrm{g}$ of AAl from Stefania tetranda powder [23], 3 times a day and $70 \mathrm{~kg}$ body wt

${ }^{\mathrm{b}}$ n.a. non-available 


\subsubsection{Predicted AAI-DNA adduct formation at the BMD10 for tumor formation}

The PBK models now available allow quantification of AAI-DNA adduct formation at any dose level of interest. In a next step the models were used to predict the level of AAI-DNA adducts formed at dose levels causing a significant increase in kidney tumor incidence above background levels. To achieve this, data from Meng et al. (1982) [21] on kidney tumor formation in rats exposed to AAs were used to calculate the $\mathrm{BMD}_{10}$ value for tumor formation (supplementary data $\mathrm{B}$ ). Due to unavailability of kidney tumor data from mice and humans that allow dose response modeling by $B M D$ analysis, only a $B M D_{10}$ based on the rat study could be used in this analysis. The $B M D_{10}$ values of the accepted dose-response curves were used individually as input in the rat PBK model to predict DNA adduct formation at these dose levels. The predicted levels of AAI-DNA adduct formation at the $\mathrm{BMD}_{10}$ values for tumor formation thus obtained ranged from 4-11 adducts in $10^{8}$ nts (supplementary data B). The human PBK model predicts that this level of kidney DNA adducts that may result in $10 \%$ tumor incidence would be reached at dose levels of $0.04-0.11 \mathrm{mg} / \mathrm{kg} \mathrm{bw} /$ day, which is in line with the fact that at dose levels that are about 4-fold lower (0.01-0.03 mg/kg bw/day) $5 \%$ of Belgian patients exposed to AAs suffered from end stage nephropathy [51] with 50\% ( 2.5\% of patients) developing cancer in the urinary tract [18, 52]. 


\subsection{DISCUSSION}

The objective of the present study was to demonstrate whether PBK modeling-based reverse dosimetry of in vitro concentration-response curves for DNA adduct formation upon exposure to AAI could accurately predict in vivo dose-response curves for AAI-DNA adduct formation in the kidney of rat, mouse and human. The current study demonstrated that combining in vitro DNA adduct formation data with a PBK model for AAI kinetics is a promising approach to predict the DNA adduct formation in vivo. Given that PBK models can be developed for different species including human, the approach even allows prediction of dose response curves for AAI-dependent DNA adduct formation in the kidney of humans.

In vitro DNA adduct formation was determined using LLC-PK1 cells, which are proximal tubular cells from pig kidney that have been frequently used to assess in vitro AAl-induced- toxicity $[37,53,54]$. Although AAI-DNA adduct formation in pig cells may differ from AAI-DNA adduct formation in kidney cells of rat, mouse and human, we reasonably predicted the DNA adduct levels for these three using this cell line. The LLC-PK1 cell line is routinely used to study nephrotoxic effects of chemicals in humans because the cells exhibit many of the enzymatic and transport properties of human proximal tubule cells $[55,56]$ which are the cells that represent the direct target of AAI [57]. Furthermore, comparison of the cytotoxicity of AAI in the LLC-PK1 cells to the AAI cytotoxicity in primary renal human cells and even to the cytotoxicity in other cell types from other species described in the literature $[1,58]$ reveals that species differences in dynamics of AAI toxicity may be limited. In addition, in our previous study, in vitro toxicity data on AAI in LLC-PK1 cells provided adequate input for PBK model-based prediction of in vivo kidney toxicity of AAI [1]. Therefore, in the approach taken in the present study, species differences in AAI dynamics were assumed to be limited and species differences in kinetics were taken care of by using species-specific PBK models.

The present study revealed dA-AAI to be the major adduct formed in vitro after exposure of LLC-PK1 cells to AAI, which is in line with the major AAl-induced DNA adduct formed in rat [13, 59], mouse [15, 16] and human [13]. An overview of literature data revealed that the AAI DNA adduct formation in the LLC-PK1 kidney cells was higher than that in HepG2 (human hepatoma) [60], MCF7 (human mammary carcinoma) [61] or GM00637 (human fibroblast) [38] cells exposed at similar concentrations. It is interesting to note this clear difference in adduct levels when comparing cells from different organs (i.e. kidney versus non-kidney) since these in vitro results are in line with kidney being the target organ for AAl-induced tumor formation [20,62]. 
In order to translate the in vitro concentration-response curve to in vivo dose-response curves, PBK model-based reverse dosimetry was used. To this end the previously developed PBK models for AAI kinetics in rat, mouse and human [1] were combined with in vitro data obtained in the present study for the AAI concentration dependent formation of the AAI-DNA adducts in LLCPK1 cells. The in vivo dose-response curves thus obtained for rat, mouse and human were compared to available data in the literature to evaluate the predictions. These literature data revealed large differences between different studies in the levels of kidney AAI-DNA adduct formation at comparable dose levels. Rat data reported in literature varied over three orders of magnitude, a difference that is hard to explain. This observation however illustrates the variation that can be obtained between different in vivo studies reporting dose-response behavior for the same endpoint. For the rat, mouse and human models, the PBK model-based predictions for DNA adduct formation, were at best 1.7-fold lower, 11.1-fold higher and 2.3-fold lower than the rat, mouse and human literature data respectively. It is important to note that for the in vivo studies that reported lower values than the levels predicted by the PBK model-based approach the AAI-DNA adducts were quantified by a ${ }^{32} \mathrm{P}$-postlabeling technique. This comparison reveals that the levels of dA-AAI DNA adducts detected by LC-ESI-MS/MS in the present study were higher than the levels detected by ${ }^{32} \mathrm{P}$-postlabeling in the studies available so far in literature indicating that LC-ESI-MS/MS method is more efficient than post-labeling, an observation that is in line with studies on DNA adduct formation by other compounds detected by LC-MS or ${ }^{32} \mathrm{P}$-postlabeling techniques [63-65]. ${ }^{32} \mathrm{P}$-postlabeling may lead to underestimation of the adduct levels due to differences in hydrolysis and labeling efficiencies of normal and adducted nucleotides $[63,66]$. In addition, when standard compounds are not available, quantification in the ${ }^{32} \mathrm{P}$-postlabeling method is less accurate, unless the compounds are chemically synthesized which can be quite labor intensive [67]. In recent years the development of LC coupled to MS as alternative to detect and quantify the DNA adduct levels is well documented $[67,68]$. By using this method more accurate and precise outcomes are obtained [63, 64, 69]. The use of LC-MS in the current study and the possible underestimation of ${ }^{32}$ P-postlabeling method for DNA adduct levels might be an important factor for the apparent lower levels detected in vivo as compared to the PBK model-based predictions when using ${ }^{32}$ P-postlabeling to quantify the number of DNA adducts.

The application of quantification of DNA adducts in humans has been proposed to serve as an early indicator of cancer risks and can be used to better evaluate species differences in risk assessment. It is important to note that the presence of DNA adducts is considered a biomarker of 
exposure rather than a biomarker of effect [70]. This is due to the fact that a majority of the DNA adducts may be non-mutagenic and/or may be repaired by repair mechanisms. In our PBK modelbased predictions this DNA repair was taken into account at least to some extent given that it is implicitly included in the concentration-response curves generated in the LLC-PK1 cells that will have supported repair of the AAI-DNA adduct while exposed in vitro. In spite of the fact that DNA adduct formation is not a biomarker of effect, an increase in the level of DNA adducts is generally considered to be related to an increase in the risk on developing cancer [71]. The PBK models were therefore used to predict the levels of AAI-DNA adducts at the $\mathrm{BMD}_{10}$ for actual tumor formation to link doses that cause cancer in animal studies to in vivo human DNA adduct formation. Levels of DNA adducts predicted at the $\mathrm{BMD}_{10}$ for kidney tumor formation in rats amounted to 4-11 adducts in $10^{8} \mathrm{nts}$. Using the human PBK model, we predicted that the level of kidney DNA adducts that may result in $10 \%$ tumor incidence would be reached at dose levels of $0.04-0.11 \mathrm{mg} / \mathrm{kg} \mathrm{bw} /$ day. This is about 4-fold higher than the estimated dose to which Belgian patients were exposed (0.01-0.03 mg/ $\mathrm{kg} \mathrm{bw/day)} \mathrm{of} \mathrm{which} \mathrm{5 \%} \mathrm{suffered} \mathrm{from} \mathrm{end} \mathrm{stage} \mathrm{nephropathy} \mathrm{[51]} \mathrm{with} \mathrm{50 \%} \mathrm{(} \mathrm{2.5 \%} \mathrm{of} \mathrm{patients)}$ developed cancer in the urinary tract $[18,52]$.

Although the in vitro-PBK modeling approach presented in the present study has uncertainties in its predictions due to many assumptions in the parameters used in the model [1] and possible differences in toxicodynamics between the in vitro and the in vivo situation, the results of the present study show that these effects are likely to be limited since predictions made for the various species using the data from the LLC-PK1 cells already quite adequately match the in vivo data for the different species. The results reveal that the variation between different experimental studies reporting DNA adduct formation in kidney in the same species appear to vary three orders of magnitude. The predicted level of AAI-adduct formation in the kidney falls within this range and the difference between the predictions and the actual in vivo data is smaller than this variation between studies. Deviations observed between predicted and actually observed values may be due to several factors. These include the fact that at the present state-of-the-art DNA adduct levels as well as the predictions made are directed at whole kidney tissue, while the actual formation of DNA adducts and tumors may vary between species in the different regions of the tissue [72]. Another factor causing the deviations may be due to possible species differences in bioactivation of AAI to N-hydroxyaristolactam I and in DNA repair mechanisms, which were not covered in the in vitro DNA-binding studies. Finally of course experimental variations in DNA adduct level measurements, quantification techniques and uncertainties in exposure scenarios as observed to occur may also Page | 106 
explain part of these deviations.

Based on the results obtained it can be concluded that the novel in vitro-PBK approach predicts DNA adduct formation with a similar or even lower level of variation than observed when comparing different experimental animal studies, thereby contributing to the reduction, refinement and replacement in animal testing.

\section{ACKNOWLEDGEMENTS}

This research was supported by the Ministry of Education of Malaysia (Project number- KPT (BS) 860828565598). 


\section{References}

1. Abdullah, R., W. Alhusainy, J. Woutersen, I.M.C.M. Rietjens, and A. Punt, Predicting points of departure for risk assessment based on in vitro cytotoxicity data and physiologically based kinetic (PBK) modeling: the case of kidney toxicity induced by aristolochic acid I. Food and Chemical Toxicology, 2016. 92: p. 104-116.

2. DeJongh, J., M. Nordin-Andersson, B. Ploeger, and A. Forsby, Estimation of systemic toxicity of acrylamide by integration of in vitro toxicity data with kinetic simulations. Toxicology and Applied Pharmacology, 1999. 158(3): p. 261-268.

3. Verwei, M., J.A. van Burgsteden, C.A. Krul, J.J. van de Sandt, and A.P. Freidig, Prediction of in vivo embryotoxic effect levels with a combination of in vitro studies and PBPK modelling. Toxicology Letters, 2006. 165(1): p. 79-87.

4. Louisse, J., E. de Jong, J.J. van de Sandt, B.J. Blaauboer, R.A. Woutersen, A.H. Piersma, I.M.C.M. Rietjens, and M. Verwei, The use of in vitro toxicity data and physiologically based kinetic modeling to predict dose-response curves for in vivo developmental toxicity of glycol ethers in rat and man. Toxicological Sciences, 2010. 118(2): p. 470-484.

5. Strikwold, M., B. Spenkelink, R.A. Woutersen, I.M.C.M. Rietjens, and A. Punt, Combining in vitro embryotoxicity data with physiologically based kinetic (PBK) modelling to define in vivo doseresponse curves for developmental toxicity of phenol in rat and human. Archives of Toxicology, 2013. 87(9): p. 1709-1723.

6. Louisse, J., S. Bosgra, B.J. Blaauboer, I.M.C.M. Rietjens, and M. Verwei, Prediction of in vivo developmental toxicity of all-trans-retinoic acid based on in vitro toxicity data and in silico physiologically based kinetic modeling. Archives of Toxicology, 2015. 89(7): p. 1135-1148.

7. Punt, A., A. Paini, A. Spenkelink, G. Scholz, B. Schilter, P. van Bladeren, and I.M.C.M. Rietjens, Evaluation of interindividual human variation in bioactivation and DNA adduct formation of estragole in liver predicted by physiologically based kinetic/dynamic (PBK/D) and Monte Carlo modeling. Chemical Research in Toxicology, 2016. 29(4): p. 659-668.

8. Kiwamoto, R., I.M.C.M. Rietjens, and A. Punt, A physiologically based in silico model for trans2-hexenal detoxification and DNA adduct formation in rat. Chemical Research in Toxicology, 2012. 25(12): p. 2630-2641.

9. Kiwamoto, R., A. Spenkelink, I.M.C.M. Rietjens, and A. Punt, A physiologically based in silico model for trans-2-hexenal detoxification and DNA adduct formation in human including interindividual variation indicates efficient detoxification and a negligible genotoxicity risk. Archives of Toxicology, 2013. 87(9): p. 1725-1737.

10. Mei, N., V.M. Arlt, D.H. Phillips, R.H. Heflich, and T. Chen, DNA adduct formation and mutation induction by aristolochic acid in rat kidney and liver. Mutation Research/Fundamental and Molecular Mechanisms of Mutagenesis, 2006. 602(1): p. 83-91.

11. Dong, H., N. Suzuki, M.C. Torres, R.R. Bonala, F. Johnson, A.P. Grollman, and S. Shibutani, Quantitative determination of aristolochic Acid-derived DNA adducts in rats using ${ }^{32} p$-postlabeling/ polyacrylamide gel electrophoresis analysis. Drug Metabolism and Disposition, 2006. 34(7): p. 11221127.

12. Chan, W., H. Yue, W.T. Poon, Y.-W. Chan, O.J. Schmitz, D.W. Kwong, R.N. Wong, and Z. Cai, Quantification of aristolochic acid-derived DNA adducts in rat kidney and liver by using liquid chromatography-electrospray ionization mass spectrometry. Mutation Research/Fundamental and Molecular Mechanisms of Mutagenesis, 2008. 646(1): p. 17-24.

13. Bieler, C.A., M. Stiborova, M. Wiessler, J.-P. Cosyns, C.v.Y. de Strihou, and H.H. Schmeiser, ${ }^{32}$ P-post-labelling analysis of DNA adducts formed by aristolochic acid in tissues from patients with Chinese herbs nephropathy. Carcinogenesis, 1997. 18(5): p. 1063-1067.

14. Pfau, W., H.H. Schmeiser, and M. Wiessler, ${ }^{32}$ P-postlabelling analysis of the DNA adducts formed by aristolochic acid I and II. Carcinogenesis, 1990. 11(9): p. 1627-1633.

15. Yun, B.H., T.A. Rosenquist, V. Sidorenko, C.R. Iden, C.-H. Chen, Y.-S. Pu, R. Bonala, F. Johnson, K.G. Dickman, and A.P. Grollman, Biomonitoring of aristolactam-DNA adducts in human tissues using ultra-performance liquid chromatography/ion-trap mass spectrometry. Chemical Research in 
Toxicology, 2012. 25(5): p. 1119-1131.

16. Shibutani, S., H. Dong, N. Suzuki, S. Ueda, F. Miller, and A.P. Grollman, Selective toxicity of aristolochic acids I and II. Drug Metabolism and Disposition, 2007. 35(7): p. 1217-1222.

17. Arlt, V.M., K.i. Levová, F.e. Bárta, Z. Shi, J.D. Evans, E. Frei, H.H. Schmeiser, D.W. Nebert, D.H. Phillips, and M. Stiborová, Role of P450 1A1 and P450 1A2 in Bioactivation versus Detoxication of the Renal Carcinogen Aristolochic Acid I: Studies in Cyp1a1 (-/-), Cyp1a2 (-/-), and Cyp1a1/1a2 (-/-) Mice. Chemical Research in Toxicology, 2011. 24(10): p. 1710-1719.

18. Nortier, J.L., M.-C.M. Martinez, H.H. Schmeiser, V.M. Arlt, C.A. Bieler, M. Petein, M.F. Depierreux, L. De Pauw, D. Abramowicz, P. Vereerstraeten, and J.-L. Vanherweghem, Urothelial carcinoma associated with the use of a Chinese herb (Aristolochia fangchi). The New England Journal of Medicine, 2000. 342(23): p. 1686-1692.

19. Frei, H., F. Würgler, H. Juon, C. Hall, and U. Graf, Aristolochic acid is mutagenic and recombinogenic in Drosophila genotoxicity tests. Archives of Toxicology, 1985. 56(3): p. 158-166.

20. Arlt, V.M., M. Stiborova, and H.H. Schmeiser, Aristolochic acid as a probable human cancer hazard in herbal remedies: a review. Mutagenesis, 2002. 17(4): p. 265-277.

21. Mengs, U., W. Lang, and J.-A. Poch, The carcinogenic action of aristolochic acid in rats. Archives of Toxicology, 1982. 51(2): p. 107-119.

22. Mengs, U., On the histopathogenesis of rat forestomach carcinoma caused by aristolochic acid. Archives of Toxicology, 1983. 52(3): p. 209-220.

23. Vanherweghem, J.-L., C. Tielemans, D. Abramowicz, M. Depierreux, R. Vanhaelen-Fastre, M. Vanhaelen, M. Dratwa, C. Richard, D. Vandervelde, and D. Verbeelen, Rapidly progressive interstitial renal fibrosis in young women: association with slimming regimen including Chinese herbs. The lancet, 1993. 341(8842): p. 387-391.

24. Vanhaelen, M., R. Vanhaelen-Fastre, P. But, and J.-L. Vanherweghem, Identification of aristolochic acid in Chinese herbs. The lancet, 1994. 343(8890): p. 174.

25. Schmeiser, H.H., C.A. Bieler, M. Wiessler, C.v.Y. de Strihou, and J.-P. Cosyns, Detection of DNA adducts formed by aristolochic acid in renal tissue from patients with Chinese herbs nephropathy. Cancer research, 1996. 56(9): p. 2025-2028.

26. Arlt, V.M., M. Stiborová, J. vom Brocke, M.L. Simoes, G.M. Lord, J.L. Nortier, M. Hollstein, D.H. Phillips, and H.H. Schmeiser, Aristolochic acid mutagenesis: molecular clues to the aetiology of Balkan endemic nephropathy-associated urothelial cancer. Carcinogenesis, 2007. 28(11): p. 2253-2261.

27. Nortier, J. and J.-L. Vanherweghem, Renal interstitial fibrosis and urothelial carcinoma associated with the use of a Chinese herb (Aristolochia fangchi). Toxicology, 2002. 181: p. 577-580.

28. Kumar, V., A.K. Prasad, and V.S. Parmar, Naturally occurring aristolactams, aristolochic acids and dioxoaporphines and their biological activities. Natural Products Reports, 2003. 20(6): p. 565-583. 29. Schmeiser, H.H., J.W. Janssen, J. Lyons, H.R. Scherf, W. Pfau, A. Buchmann, C.R. Bartram, and M. Wiessler, Aristolochic acid activates ras genes in rat tumors at deoxyadenosine residues. Cancer Research, 1990.50(17): p. 5464-5469.

30. Stiborová, M., E. Frei, B. Sopko, K. Sopková, V. Marková, M. Laňková, T. Kumstýřová, M. Wiessler, and H.H. Schmeiser, Human cytosolic enzymes involved in the metabolic activation of carcinogenic aristolochic acid: evidence for reductive activation by human NAD (P) H: quinone oxidoreductase. Carcinogenesis, 2003. 24(10): p. 1695-1703.

31. Shibutani, S., R.R. Bonala, T. Rosenquist, R. Rieger, N. Suzuki, F. Johnson, F. Miller, and A.P. Grollman, Detoxification of aristolochic acid I by O-demethylation: Less nephrotoxicity and genotoxicity of aristolochic acid la in rodents. International Journal of Cancer, 2010. 127(5): p. 1021-1027.

32. Stiborová, M., J. Mareîs, E. Frei, V.M. Arlt, V. Martínek, and H.H. Schmeiser, The human carcinogen aristolochic acid I is activated to form DNA adducts by human NAD (P) H: quinone oxidoreductase without the contribution of acetyltransferases or sulfotransferases. Environmental Molecular and Mutagenesis, 2011. 52(6): p. 448-459.

33. Stiborová, M., E. Frei, V.M. Arlt, and H.H. Schmeiser, Metabolic activation of carcinogenic aristolochic acid, a risk factor for Balkan endemic nephropathy. Mutation Research, 2008. 658(1): p. 55-67. 
34. Chen, M., L. Gong, X. Qi, G. Xing, Y. Luan, Y. Wu, Y. Xiao, J. Yao, Y. Li, and X. Xue, Inhibition of renal NQO1 activity by dicoumarol suppresses nitroreduction of aristolochic acid I and attenuates its nephrotoxicity. Toxicological Sciences, 2011. 122(2): p. 288-296.

35. Pfau, W., H.H. Schmeiser, and M. Wiessler, Aristolochic acid binds covalently to the exocyclic amino group of purine nucleotides in DNA. Carcinogenesis, 1990. 11(2): p. 313-319.

36. Schmeiser, H., K.-B. Schoepe, and M. Wiessler, DNA adduct formation of aristolochic acid I and II in vitro and in vivo. Carcinogenesis, 1988. 9(2): p. 297-303.

37. Romanov, V., V. Sidorenko, T.A. Rosenquist, T. Whyard, and A.P. Grollman, A fluorescencebased analysis of aristolochic acid-derived DNA adducts. Analytical Biochemistry, 2012. 427(1): p. 4951.

38. Sidorenko, V.S., S. Attaluri, I. Zaitseva, C.R. Iden, K.G. Dickman, F. Johnson, and A.P. Grollman, Bioactivation of the human carcinogen aristolochic acid. Carcinogenesis, 2014. 35(8): p. 1814-1822.

39. Dickman, K.G., D.H. Sweet, R. Bonala, T. Ray, and A. Wu, Physiological and molecular characterization of aristolochic acid transport by the kidney. Journal of Pharmacology and Experimental Therapeutics, 2011. 338(2): p. 588-597.

40. Paini, A., A. Punt, F. Viton, G. Scholz, T. Delatour, M. Marin-Kuan, B. Schilter, P.J. van Bladeren, and I.M.C.M. Rietjens, A physiologically based biodynamic (PBBD) model for estragole DNA binding in rat liver based on in vitro kinetic data and estragole DNA adduct formation in primary hepatocytes. Toxicology and Applied Pharmacology, 2010. 245(1): p. 57-66.

41. Paini, A., A. Punt, G. Scholz, E. Gremaud, B. Spenkelink, G. Alink, B. Schilter, P.J. van Bladeren, and I.M.C.M. Rietjens, In vivo validation of DNA adduct formation by estragole in rats predicted by physiologically based biodynamic modelling. Mutagenesis, 2012. 27(6): p. 653-663.

42. Punt, A., T. Delatour, G. Scholz, B. Schilter, P.J. van Bladeren, and I.M.C.M. Rietjens, Tandem mass spectrometry analysis of N 2-(trans-Isoestragol-3'-yl)-2'-deoxyguanosine as a strategy to study species differences in sulfotransferase conversion of the proximate carcinogen $1^{\prime}$-hydroxyestragole. Chemical Research in Toxicology, 2007. 20(7): p. 991-998.

43. Evans, M.V. and M.E. Andersen, Sensitivity analysis of a physiological model for 2, 3, 7, 8-tetrachlorodibenzo-p-dioxin (TCDD): assessing the impact of specific model parameters on sequestration in liver and fat in the rat. Toxicological Sciences, 2000. 54(1): p. 71-80.

44. Peters, S.A., Physiological model for distribution, in Physiologically-based pharmacokinetic (PBPK) modeling and simulations: principles, methods, and applications in the pharmaceutical industry. 2012, John Wiley \& Sons: Hoboken, NJ, USA. p. 89-117.

45. Jones, H. and K. Rowland-Yeo, Basic concepts in physiologically based pharmacokinetic modeling in drug discovery and development. CPT: pharmacometrics \& systems pharmacology, 2013. 2(8): p. 1-12.

46. Gülden, M., P. Dierickx, and H. Seibert, Validation of a prediction model for estimating serum concentrations of chemicals which are equivalent to toxic concentrations in vitro. Toxicology In Vitro, 2006. 20(7): p. 1114-1124.

47. Blaauboer, B.J., Biokinetic modeling and in vitro-in vivo extrapolations. Journal of Toxicology and Environmental Health, Part B, 2010. 13(2-4): p. 242-252.

48. Turteltaub, K.W. and K.H. Dingley, Application of accelerated mass spectrometry (AMS) in DNA adduct quantification and identification. Toxicology Letters, 1998. 102: p. 435-439.

49. Vamvakas, S., W. Dekant, and D. Henschler, Assessment of unscheduled DNA synthesis in a cultured line of renal epithelial cells exposed to cysteine S-conjugates of haloalkenes and haloalkanes. Mutation Research, 1989. 222(4): p. 329-335.

50. Li, Y., Z. Liu, X. Guo, J. Shu, Z. Chen, and L. Li, Aristolochic acid I-induced DNA damage and cell cycle arrest in renal tubular epithelial cells in vitro. Archives of Toxicology, 2006. 80(8): p. 524-532.

51. Vanherweghem, J.-L., Misuse of herbal remedies: the case of an outbreak of terminal renal failure in Belgium (Chinese herbs nephropathy). The Journal of Alternative and Complementary Medicine, 1998. 4(1): p. 9-13.

52. Cosyns, J.-P., M. Jadoul, J.-P. Squifflet, F.-X. Wese, and C.v.Y. de Strihou, Urothelial lesions in Chinese-herb nephropathy. Amercan Journal of Kidney Diseases, 1999. 33(6): p. 1011-1017. 
53. Hsin, Y.H., C.H. Cheng, J.T. Tzen, M.J. Wu, K.H. Shu, and H.C. Chen, Effect of aristolochic acid on intracellular calcium concentration and its links with apoptosis in renal tubular cells. Apoptosis, 2006. 11(12): p. 2167-2177.

54. Balachandran, P., F. Wei, R.C. Lin, I.A. Khan, and D.S. Pasco, Structure activity relationships of aristolochic acid analogues: toxicity in cultured renal epithelial cells. Kidney International, 2005. 67(5): p. 1797-1805.

55. Hull, R., W. Cherry, and G. Weaver, The origin and characteristics of a pig kidney cell strain, LLC-PK1. In vitro, 1976. 12(10): p. 670-677.

56. Gstraunthaler, G., W. Pfaller, and P. Kotanko, Biochemical characterization of renal epithelial cell cultures (LLC-PK1 and MDCK). American Journal of Physiology: Renal Pgysiology, 1985. 248(4): p. F536-F544.

57. Lebeau, C., F.D. Debelle, V.M. Arlt, A. Pozdzik, E.G. De Prez, D.H. Phillips, M.M. DeschodtLanckman, J.-L. Vanherweghem, and J.L. Nortier, Early proximal tubule injury in experimental aristolochic acid nephropathy: functional and histological studies. Nephrology Dialysis Transplantation, 2005. 20(11): p. 2321-2332.

58. Huljic, S., E.I. Bruske, N. Pfitzenmaier, E. O'Brien, and D.R. Dietrich, Species-specific toxicity of aristolochic acid $(A A)$ in vitro. Toxicology in Vitro, 2008. 22(5): p. 1213-1221.

59. Stiborová, M., R.C. Fernando, H.H. Schmeiser, E. Frei, W. Pafau, and M. Wiessler, Characterization of DNA adducts formed by aristolochic acids in the target organ (forestomach) of rats by ${ }^{32}$ P-postlabelling analysis using different chromatographic procedures. Carcinogenesis, 1994. 15(6): p. 1187-1192.

60. Nitzsche, D., M.F. Melzig, and V.M. Arlt, Evaluation of the cytotoxicity and genotoxicity of aristolochic acid I-a component of Aristolochiaceae plant extracts used in homeopathy. Environmental Toxicology and Pharmacology, 2013. 35(2): p. 325-334.

61. Arlt, V.M., H.H. Schmeiser, and G.P. Pfeifer, Sequence-specific detection of aristolochic acidDNA adducts in the human p53 gene by terminal transferase-dependent PCR. Carcinogenesis, 2001. 22(1): p. 133-140.

62. Mengs, U. and C. Stotzem, Renal toxicity of aristolochic acid in rats as an example of nephrotoxicity testing in routine toxicology. Archives of Toxicology, 1993. 67(5): p. 307-311.

63. Beland, F.A., D.R. Doerge, M.I. Churchwell, M.C. Poirier, B. Schoket, and M.M. Marques, Synthesis, characterization, and quantitation of a 4-aminobiphenyl-DNA adduct standard. Chemical Research in Toxicology, 1999. 12(1): p. 68-77.

64. Doerge, D.R., M.I. Churchwell, M.M. Marques, and F.A. Beland, Quantitative analysis of 4-aminobiphenyl-C8-deoxyguanosyl DNA adducts produced in vitro and in vivo using HPLC-ES-MS. Carcinogenesis, 1999. 20(6): p. 1055-1061.

65. Soglia, J.R., R.J. Turesky, A. Paehler, and P. Vouros, Quantification of the heterocyclic aromatic amine DNA adduct N-(deoxyguanosin-8-yl)-2-amino-3-methylimidazo [4,5-f] quinoline in livers of rats using capillary liquid chromatography/microelectrospray mass spectrometry: a dose-response study. Analytical Chemistry, 2001. 73(13): p. 2819-2827.

66. Shields, P., C. Harris, S. Petruzzelli, E. Bowman, and A. Weston, Standardization of the ${ }^{32}$ P-postlabeling assay for polycyclic aromatic hydrocarbon-DNA adducts. Mutagenesis, 1993. 8(2): $\mathrm{p}$. 121-126.

67. Singh, R. and P.B. Farmer, Liquid chromatography-electrospray ionization-mass spectrometry: the future of DNA adduct detection. Carcinogenesis, 2006. 27(2): p. 178-196.

68. Yun, B.H., T.A. Rosenquist, J. Nikolić, D. Dragičević, K. Tomić, B. Jelaković, K.G. Dickman, A.P. Grollman, and R.J. Turesky, Human Formalin-Fixed Paraffin-Embedded Tissues: An Untapped Specimen for Biomonitoring of Carcinogen DNA Adducts by Mass Spectrometry. Analytical Chemistry, 2013. 85(9): p. 4251-4258.

69. Hu, C.-W., M.-R. Chao, and C.-H. Sie, Urinary analysis of 8-oxo-7, 8-dihydroguanine and 8-oxo7, 8-dihydro-2'-deoxyguanosine by isotope-dilution LC-MS/MS with automated solid-phase extraction: study of 8-oxo-7, 8-dihydroguanine stability. Free Radical Biology and Medicine, 2010. 48(1): p. 89-97. 70. Neumann, H.-G., The role of DNA damage in chemical carcinogenesis of aromatic amines. 
Journal of Cancer Research and Clinical Oncology, 1986. 112(2): p. 100-106.

71. Paini, A., G. Scholz, M. Marin-Kuan, B. Schilter, J. O'Brien, P.J. van Bladeren, and I.M.C.M. Rietjens, Quantitative comparison between in vivo DNA adduct formation from exposure to selected DNA-reactive carcinogens, natural background levels of DNA adduct formation and tumour incidence in rodent bioassays. Mutagenesis, 2011. 26(5): p. 605-618.

72. Cosyns, J.-P., R.-M. Goebbels, V. Liberton, H.H. Schmeiser, C.A. Bieler, and A.M. Bernard, Chinese herbs nephropathy-associated slimming regimen induces tumours in the forestomach but no interstitial nephropathy in rats. Archives of Toxicology, 1998. 72(11): p. 738-743. 
Supplementary data A. Mass balance equation and parameter specifications of PBK model for aristolochic acid I in the rat

\section{Compound}

Aristolochic acid I

Aristolochic acid la

Compartment (Tissue (T))

Small intestine

Liver

Kidney

Slowly perfused tissue

Richly perfused tissue

Fat compartment

Arterial

Venous

\section{abbreviation}

AAI

AAla

\section{abbreviation}

।

L

$\mathrm{K}$

$\mathrm{S}$

$\mathrm{R}$

$\mathrm{F}$

A

V

\section{Variable}

Blood flow rate to tissue

Cardiac output

Concentration of AAI in tissue or blood

Partitioning coefficient tissue:blood AAI

Volume of tissue or blood

Amount AAl in tissue or blood

Maximum rate of formation metabolite, AAla in tissue

Michaelis-Menten constant for formation metabolite, AAla in tissue $\mu \mathrm{M}$

Uptake rate $\mathrm{AAl}$ in intestine

Excretion rate in bile

Excretion rate in urine

\section{Unit}

$\mathrm{Ih}^{-1}$

$\mathrm{Ih}^{-1}$

$\mu \mathrm{M}$

$-$

I

$\mu \mathrm{mol}$

$\mu \mathrm{mol} \mathrm{h}{ }^{-1}$ abbreviation

$\mathrm{Q}(\mathrm{T})$

QC

$\mathrm{C}(\mathrm{T})_{\mathrm{AAl}}$

$\mathrm{P}(\mathrm{T})_{\text {AAI }}$

$\mathrm{V}(\mathrm{T})$

$A(T)_{\text {AAI }}$

$\operatorname{Vmax}(\mathrm{T})_{\text {AAla }}$

$\mathrm{Km}(\mathrm{T})_{\text {AAla }}$

Ka

Kbile

Kurine

\section{Small intestine}

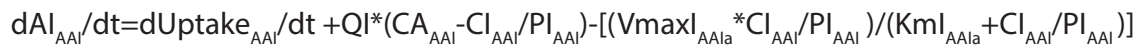




\section{Uptake of AAI from GI tract}

dUptake $_{\text {AAI }} / d t=-d A G I_{A A I} / d t=k a * A G I_{A A I}$

$\mathrm{AGI}_{\mathrm{AAI}}(0)=$ Oral dose

$\mathrm{Cl}_{\mathrm{AAI}}=\mathrm{Al}_{\mathrm{AAI}} / \mathrm{VI}$

\section{Liver compartment}

$$
\begin{aligned}
& \mathrm{dAL} \mathrm{AAl}_{\mathrm{AA}} / \mathrm{dt}=\mathrm{QL}{ }^{*} \mathrm{CA}+\mathrm{QI}^{*} \mathrm{Cl}_{\mathrm{AAl}} / \mathrm{PI}_{\mathrm{AAI}}-(\mathrm{QL}+\mathrm{QI}){ }^{*} \mathrm{CL}_{\mathrm{AAl}} / \mathrm{PL}_{\mathrm{AAI}}-\left(\mathrm{VmaxL}_{\mathrm{AAla}}{ }^{*} \mathrm{CL}_{\mathrm{AAl}} / \mathrm{PL}_{\mathrm{AAl}}\right) /\left(\mathrm{Km}_{\mathrm{AAla}}+\mathrm{CL}_{\mathrm{AAl}} / \mathrm{PL}_{\mathrm{AAl}}\right)- \\
& \mathrm{dEb}_{\mathrm{AAl}} / \mathrm{dt} \\
& \mathrm{CL}_{\mathrm{AAI}}=\mathrm{AL} \mathrm{AAI}_{\mathrm{AA}} / \mathrm{VL}
\end{aligned}
$$

\section{Excretion rate in bile}

$\mathrm{dEb}_{\mathrm{AAl}} / \mathrm{dt}=\mathrm{Kbile}^{*} \mathrm{AL}$

$\mathrm{Eb}(0)=0$

\section{Kidney compartment}

$\mathrm{dAK}_{\mathrm{AAl}} / \mathrm{dt}=\mathrm{QK}^{*}\left(\mathrm{CA}_{\mathrm{AAI}}-\mathrm{CK}_{\mathrm{AAI}} / \mathrm{PK}_{\mathrm{AAl}}\right)-\mathrm{dEu}_{\mathrm{AAl}} / \mathrm{dt}$

$\mathrm{CK}_{\mathrm{AAI}}=\mathrm{AK}_{\mathrm{AAI}} / \mathrm{VK}$

$\mathrm{CVK}_{\mathrm{AAI}}=\mathrm{CK}_{\mathrm{AAl}} / \mathrm{PK}_{\mathrm{AAI}}$

$\mathrm{dAUCVK} \mathrm{AAI}_{\mathrm{A}} / \mathrm{dt}=\mathrm{CVK}_{\mathrm{AAI}}$

\section{Excretion rate in urine}

$\mathrm{dEu}_{\mathrm{AAl}} / \mathrm{dt}=$ Kurine* $\mathrm{AK}$

$\mathrm{Eu}(0)=0$

\section{DNA adduct formation}

$D N A=A^{*} A U C_{\text {AAI }}$

'DNA' is the amount of DNA adducts (number of adducts $/ 10^{8} \mathrm{nts}$ ) formed due to specific binding of AAI to either deoxyadenosine nucleosides or deoxyguanosine nucleosides at a certain 'AUC ${ }_{A A I}$ ' (hours* $\mu \mathrm{mol} / \mathrm{L}$ ) of $\mathrm{AAl}$, and 'A' is the slope, respectively, calculated based on the data from the in vitro experiments. 


\section{Slowly perfused tissue}

$$
\begin{aligned}
& \mathrm{dAS}_{\mathrm{AAl}} / \mathrm{dt}=\mathrm{QS} *\left(\mathrm{CA}_{\mathrm{AAl}}-\mathrm{CS}_{\mathrm{AAl}} / \mathrm{PS}_{\mathrm{AAl}}\right) \\
& \mathrm{CS}_{\mathrm{AAl}}=\mathrm{AS}_{\mathrm{AAl}} / \mathrm{VS}
\end{aligned}
$$

\section{Richly perfused tissue}

$\mathrm{dAR}_{\mathrm{AAl}} / \mathrm{dt}=\mathrm{QR}^{*}\left(\mathrm{CA}_{\mathrm{AAI}}-\mathrm{CR}_{\mathrm{AAl}} / \mathrm{PR}_{\mathrm{AAI}}\right)$

$\mathrm{CR}_{\mathrm{AAI}}=\mathrm{AR}_{\mathrm{AAI}} / \mathrm{VR}$

\section{Fat compartment}

$$
\begin{aligned}
& \mathrm{dAF}_{\mathrm{AAl}} / \mathrm{dt}=\mathrm{QF} \mathrm{F}^{*}\left(\mathrm{CA}_{\mathrm{AAl}}-\mathrm{CF}_{\mathrm{AAl}} / \mathrm{PF}_{\mathrm{AAl}}\right) \\
& \mathrm{CF}_{\mathrm{AAl}}=\mathrm{AF}_{\mathrm{AAl}} / \mathrm{VF}
\end{aligned}
$$

\section{Arterial blood compartment}

$$
\mathrm{CA}_{\mathrm{AAI}}=\mathrm{CV}_{\mathrm{AAI}}
$$

\section{Venous blood compartment}

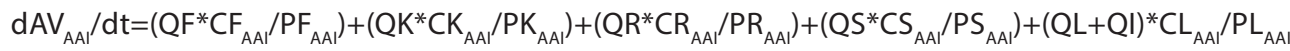

$$
\begin{aligned}
& -\mathrm{QC}^{*} \mathrm{CV}_{\mathrm{AAl}} \\
& \mathrm{CV}_{\mathrm{AAl}}=\mathrm{AV}_{\mathrm{AAl}} / \mathrm{NV}
\end{aligned}
$$


ڤั Supplementary data B.

Results from a BMD analysis of the data for kidney tumor formation in rats [21] exposed to AA using BMDS software version 2.5, a BMD of 10\% and default

$\vec{\sigma}$ settings. BMD10 values were used as a dose to calculate the amount of DNA adducts formed, predicted by PBK model-based reverse dosimetry

\begin{tabular}{|c|c|c|c|c|c|c|c|c|}
\hline Model & Restriction & $\begin{array}{l}\text { No of } \\
\text { parameters }\end{array}$ & Log Likelihood & $\mathrm{p}$-value & Accepted $^{a}$ & $\begin{array}{l}\mathrm{BMD}_{10}(\mathrm{mg} / \mathrm{kg} \\
\text { body wt/day) }\end{array}$ & $\begin{array}{l}\mathrm{BMDL}_{10}(\mathrm{mg} / \\
\mathrm{kg} \text { body wt/ } \\
\text { day) }\end{array}$ & $\begin{array}{l}\text { PBK-Predicted } \\
\text { number of adducts } \\
\text { in } 10^{8} \text { nts at } \mathrm{BMD}_{10}\end{array}$ \\
\hline Reduced & & 1 & -22.2921 & - & - & - & - & \\
\hline Full & & 4 & -15.5048 & - & - & - & - & \\
\hline Gamma & none & 4 & -15.6056 & 0.9042 & No & 0.06 & 0.003 & \\
\hline Logistic & $n a^{b}$ & 2 & -16.3038 & 0.5144 & Yes & 0.15 & 0.10 & 11 \\
\hline LogLogistic & none & 2 & -15.5861 & 0.9528 & No & 0.05 & 0.004 & \\
\hline LogProbit & none & 2 & -15.5422 & 0.9781 & No & 0.05 & 0.005 & \\
\hline Multistage & none & 2 & -15.6008 & 0.9499 & Yes & 0.05 & 0.01 & 4 \\
\hline Probit & $n a^{b}$ & 2 & -16.2417 & 0.9888 & Yes & 0.13 & 0.09 & 10 \\
\hline Weibull & none & 2 & -15.6055 & 0.5387 & No & 0.05 & 0.003 & \\
\hline Quantal-Linear & $n a^{b}$ & 1 & -15.6056 & 0.9409 & Yes & 0.05 & 0.03 & 4 \\
\hline
\end{tabular}

${ }^{a}$ Criteria for acceptance included $p$-value $>0.05$ and the ratio between $\mathrm{BMD}_{10}$ and $\mathrm{BMDL}_{10}<10$

${ }^{\mathrm{b}}$ not applicable 


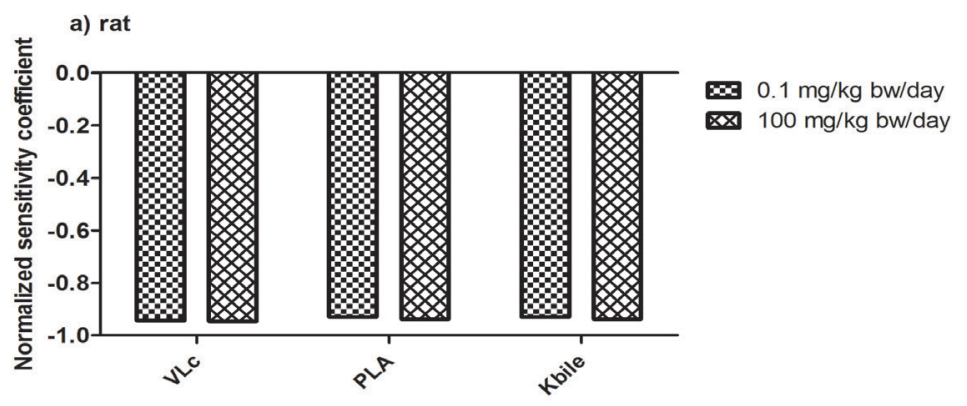

b) mouse
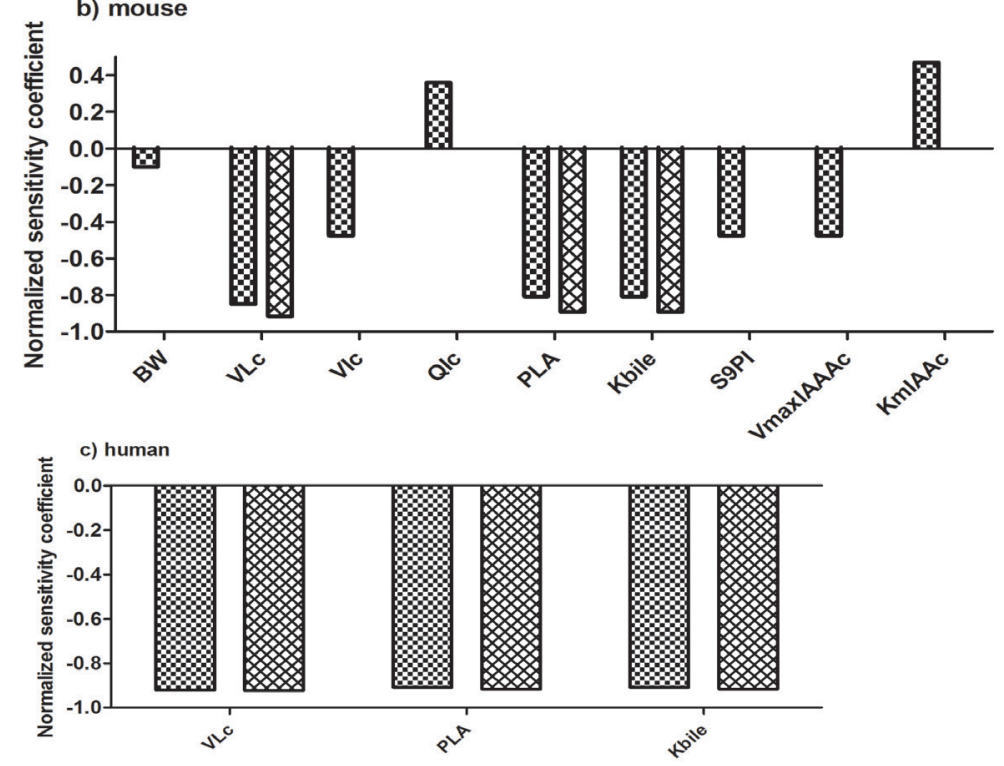

Supplementary data C. Normalized sensitivity coefficients for parameters of the PBK model for rat (a), mouse (b) and human (c) on AUC values in blood from single oral dose of $0.1 \mathrm{mg} / \mathrm{kg}$ bw and $100 \mathrm{mg} / \mathrm{kg}$ bw. Normalized sensitivity coefficients $\geq 0.1$ are presented. VLc= volume of liver, Vlc $=$ volume of intestine, BW = body weight, $\mathrm{QIC}=$ blood flow to intestine, PLA = partition coefficient of liver, Kbile = excretion rate via bile constant, S9PI = intestinal S9 protein yield, VmaxIAAAc and $\mathrm{KmIAAC}=$ the maximum rate of formation and the Michaelis-Menten constant for formation of AAla in intestine. 



\section{CHAPTER}

4

Prediction of in vivo DNA adduct formation upon exposure to aristolochic acid I land II using a combined in vitro-physiologically based kinetic modeling approach

Rozaini Abdullah, Sebastiaan Wesseling, Bert Spenkelink, Ivonne M. C. M. Rietjens, and

Jochem Louisse

In preparation 


\section{ABSTRACT}

Aristolochic acids (AAs) are chemicals present in Aristolochia species, which have been reported to cause kidney cancer in rats, mice and humans, via the formation of AA-DNA adducts. The aim of this study was to assess whether in vivo DNA adduct formation upon AA exposure can be predicted without the use of animal experiments. To achieve this aim, the kidney proximal tubular cell lines LLC-PK1 and NRK-52E were exposed to increasing concentrations of a mixture of AAI and AAll (1:1) for 24 hours, after which DNA adducts were quantified by LC-MS/MS. Subsequently, the in vitro concentration-response curves were converted to predicted in vivo dose-response curves for AAIand AAll-DNA adduct formation in the rat kidney using a PBK model describing AAI and AAll kinetics in rats. The results obtained showed a concentration-dependent linear increase in AAI- and AAllDNA adduct levels in both cell lines, showing slightly higher DNA adduct levels in LLC-PK1 cells compared to NRK-52E cells. The predicted in vivo DNA adduct levels obtained using PBK modelingbased reverse dosimetry of the in vitro data were compared to data on AA-DNA adduct formation in rats in vivo. This analysis revealed that the predicted DNA adduct levels fell within the range of DNA adduct levels reported in vivo, though the in vivo studies showed remarkably large differences. The ratio between dA-AAI and dA-AAll adducts detected in vitro was 355-fold higher than reported in the in vivo rat studies (ratio in vitro $=213$, ratio in rats in vivo $=0.6$ ). The $\mathrm{dA}-\mathrm{AAI} / \mathrm{dA}-\mathrm{AAll}$ ratio predicted using PBK modeling-based reverse dosimetry (ratio $=75$ ) was lower than observed in vitro but still on average 125-fold higher than the ratio observed in vivo in rats. Interestingly, human data show 18- to 70-fold higher levels of dA-AAI adducts than dA-AAll adducts in aristolochic acid nephropathy patients, indicating larger differences in $\mathrm{dA}-\mathrm{AAl} / \mathrm{dA}-\mathrm{AAll}$ ratios in humans compared to rats. This indicates that the difference between in vitro and in vivo AAI- and AAll-DNA adduct ratios can only in part be explained by differences in in vivo kinetics, and that other -as yet unidentifiedfactors may contribute as well, but also that the discrepancy between the difference in DNA adduct formation of AAI and AAll in the in vitro and the in vivo situation is still an unresolved issue that needs further investigation. It is concluded that PBK model-based conversion of in vitro data to in vivo data for AA-derived DNA adduct formation is feasible but needs further refinement to also adequately predict the relative differences between the two AAs, while also the discrepancy between the values reported in vivo needs to be resolved. 


\subsection{INTRODUCTION}

Aristolochic acids (AAs) are nitrophenanthrene carboxylic acids of which the most studied congeners are 8-methoxy-6-nitrophenanthro-(3,4-d)-1,3-dioxolo-5-carboxylic acid (AAI) and 6-nitrophenanthro-(3,4-d)-1,3-dioxolo-5-carboxylic acid (AAII) [1] which differ only by the methoxy group that is present in AAI but not in AAll as shown in Figure 4.1. AAl is metabolized by oxidative and reductive pathways while AAll, because of the lack of the methoxy group, only by reductive pathways [2]. An overview of the metabolic pathways of AAI and AAll is presented in Figure 4.2. Under aerobic conditions, AAl is O-demethylated by cytochrome P450 1A1/2 to aristolochic acid la (AAla) which is considered a detoxification route given that the hydroxyl moiety introduced in the molecule provides a reaction center for effective conjugation and urinary elimination [3-5]. Under anaerobic conditions, the nitro groups in AAI and AAll are reduced to form respectively aristolactam I and aristolactam II [6, 7]. This reaction is catalyzed by both cytosolic and microsomal enzymes, with $\mathrm{NAD}(\mathrm{P}) \mathrm{H}$ :quinone oxidoreductase (NQO1) being most efficient in cytosolic nitroreduction [8, 9]. Nitroreduction is accompanied by bioactivation of the AAs to cyclic nitrenium ions that are able to form covalent DNA adducts (Figure 4.2) [10, 11].

Several in vitro studies report that AAI is more cytotoxic than AAll [12-15] and a similar difference in toxicity has been reported in in vivo studies $[7,16]$. The relative difference in potential of AAI and AAll for formation of DNA adducts and induction of mutations and kidney tumors is less well established. Also the relative potential for in vitro DNA adduct formation of AAI as compared to that of AAll is not well documented yet. The single literature reference available reported a study of DNA adduct formation of a mixture of AAs (the ratio of AAI and AAll not specified) in OK cells, which are kidney cells derived from opossum, exposed in vitro showing that 10-fold higher DNA-AAI adducts than DNA-AAll adducts were found [17]. In vivo studies showed equal formation of DNA adducts at similar oral dose levels of AAI and AAll in mice [7] or higher (2- to 5-fold) AAll-DNA adduct levels than AAI-DNA adduct levels in rats and mice [18-20]. For human aristolochic acid nephropathy (AAN) patients, 18- to 70-fold higher levels of dA-AAI than dA-AAll adducts were reported [21, 22]. Factors that may contribute to the discrepancy between the in vitro and in vivo situation in relative AAI-DNA and AAll-DNA adduct levels may relate to differences in toxicokinetics and toxicodynamics in the in vitro compared to the in vivo situation.

In a previous study, we translated the in vitro concentration-response curve for AAI-DNA adduct formation in LLC-PK1 cells to in vivo dose-response curves for DNA adduct formation in the 
kidney of rat, mouse and human using physiologically based kinetic (PBK) modeling-based reverse dosimetry [23]. The predicted in vivo AAI-DNA adduct levels fell within the (large) range of in vivo AAI-DNA adduct levels reported in the literature, showing the proof-of-principle that DNA adduct levels may be predicted using PBK modeling-based reverse dosimetry. However, real-life exposure to AAs is often to a mixture of AAI and AAll, rather than to AAI alone, and both AAI- and AAll-DNA adducts may play a role in the development of cancer. Therefore, the aim of the present study was to determine the DNA adduct formation of AAI and AAll in kidney cells in vitro and to translate the obtained in vitro concentration-dependent DNA adduct formation to the in vivo situation using PBK modeling-based reverse dosimetry, in order to assess whether in vivo DNA adduct formation upon AA exposure can be predicted without the use of animal experiments. To achieve this aim, the kidney proximal tubular cell lines LLC-PK1 and NRK-52E were exposed to increasing concentrations of a mixture of AAI and AAll (1:1) for 24 hours, after which DNA adducts were quantified by LC-MS/ MS. Subsequently, the in vitro concentration-response curves were converted to predicted in vivo dose-response curves for AAI- and AAll-DNA adduct formation in the rat kidney using a PBK model describing AAI and AAll kinetics in rat, and predicted DNA adduct levels were compared to DNA adduct levels in vivo as reported in the literature.<smiles>COc1cccc2c1cc([N+](=O)[O-])c1c(C(=O)O)cc3c(c12)OCO3</smiles>

aristolochic acid I (AAI)<smiles>O=C(O)c1cc2c(c3c1c([N+](=O)[O-])cc1ccccc13)OCO2</smiles>

aristolochic acid II (AAII)

Fig. 4.1 Structural formula of aristolochic acid I (AAI) and aristolochic acid II (AAII). 


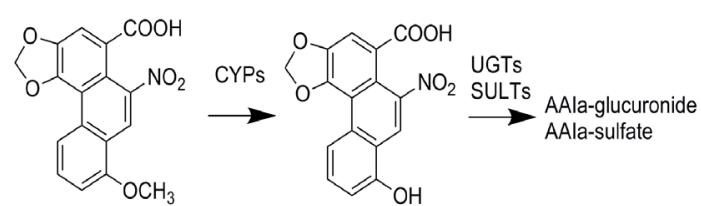

aristolochic acid I (AAI) aristolochic acid la (AAla)

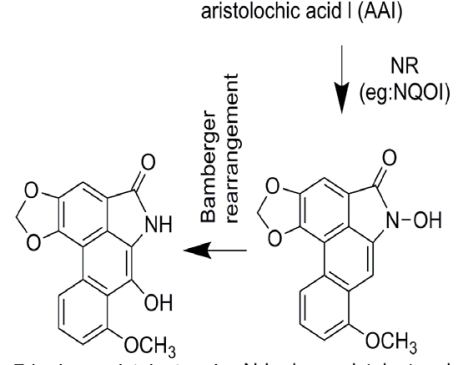

7-hydroxyaristolactam I N-hydroxyaristolactam I

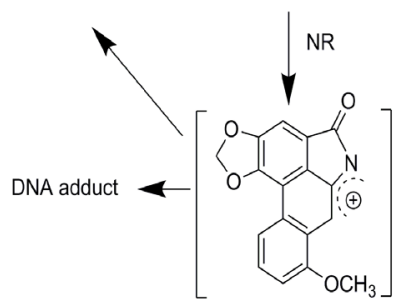

cyclic nitrenium ion

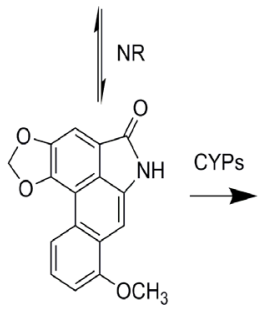

Aristolactam I

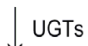

$\uparrow$ SULTS

Aristolactam I-glucuronide Aristolactam I-sulfate

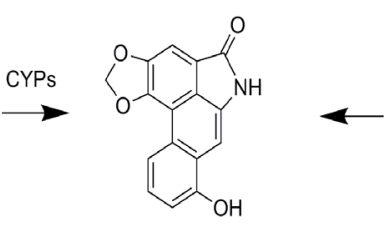

Aristolactam la

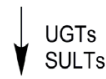

Aristolactam la-glucuronide Aristolactam la-sulfate<smiles></smiles>

aristolochic acid II (AAII)

NR

(eg:NQOI)

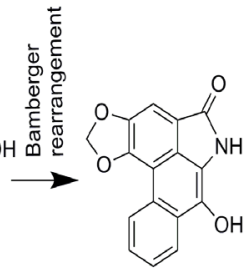

N-hydroxyaristolactam II 7-hydroxyaristolactam II

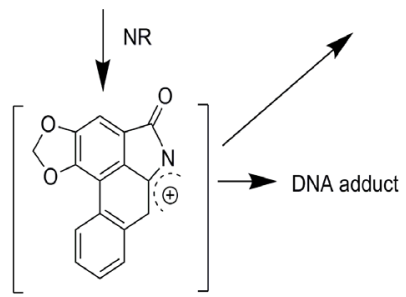

cyclic nitrenium ion

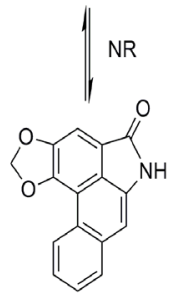

Aristolactam II

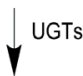

Aristolactam Il-glucuronide

Fig. 4.2 Metabolic pathways for detoxification, bioactivation and DNA adduct formation of aristolochic acid I (AAI) and aristolochic acid II (AAII). NR = nitroreduction, NQOI = NAD(P) $\mathrm{H}$ :quinone oxidoreductase, $\mathrm{dA}-\mathrm{AAI}=$ deoxyadenosine $\mathrm{AAI}, \mathrm{dG}-\mathrm{AAI}=$ deoxyguanosine $\mathrm{AAI}, \mathrm{dA}-\mathrm{AAll}$ = deoxyadenosine AAll, dG-AAll = deoxyguanosine AAll, CYPs = cytochromes P450, UGTs = uridine 5'-diphospho-glucuronosyltransferases, SULTs = sulfotransferases [based on 24, 25-27] 


\subsection{MATERIAL AND METHODS}

\subsubsection{Chemicals}

AAI or AAll were obtained from Sigma-Aldrich (Zwijndrecht, NL) and a mixture of AAs (50\% AAI and 50\% AAII) was purchased from Enzo Life Sciences (Farmingdale, NY, USA). The LLC-PK1 porcine kidney cell line (ATCC ${ }^{\circledR}$ CL-101 ${ }^{\mathrm{TM}}$ ) and NRK-52E rat kidney cell line (ATCC ${ }^{\circledR}$ CRL-1571 ${ }^{\mathrm{TM}}$ ) were obtained from the American Type Culture Collection (ATCC). Dulbecco's Modified Eagle Medium (DMEM), phosphate buffered saline (PBS) and trypsin-EDTA were purchased from Gibco (Paisley, Scotland, UK) and fetal calf serum (FCS) from Lonza BioWhittaker (Walkersville, MD, USA). 2'-Deoxyadenosine (dA), 2'-deoxyguanosine (dG), N,N-dimethylformamide (DMF), zinc powder, phosphodiesterase I from Crotalus adamanteus (venom phosphodiesterase), phosphodiesterase II from bovine spleen (spleen phosphodiesterase), nucleus PI and alkaline phosphatase were purchased from SigmaAldrich. Dimethyl sulfoxide (DMSO) (>99.9\%) was obtained from Acros Organics (Geel, Belgium). Acetonitrile (ACN; ULC/MS grade) was obtained from Biosolve BV (Valkenswaard, The Netherlands). Formic acid and ethanol were obtained from VWR Merck (Darmstadt, Germany).

\subsubsection{In vitro DNA adduct formation}

DNA adduct formation was determined using a method as previously described [23]. In brief, a total of approximately $1 \times 10^{6}$ cells/ $75 \mathrm{~cm}^{2}$ culture flask were seeded. When reaching a confluency of $80-90 \%$, the cells were exposed for 24 hours to the AA mixture at different concentrations ranging from 0.5 to $20 \mu \mathrm{M}$ AAs (final concentration of total AAs) added from 200 times concentrated stock solutions in DMSO to DMEM without serum. To obtain a sufficient amount of DNA, for all AA concentrations, two samples were pooled. After the exposure to AAs, cells were scraped in $5 \mathrm{~mL}$ PBS, collected in a $10 \mathrm{~mL}$ tube and centrifuged at $1500 \mathrm{rpm}$ for $5 \mathrm{~min}$. The pellets were stored at $-20^{\circ} \mathrm{C}$ until DNA isolation. For DNA isolation, a QIAamp DNA Mini Kit from Qiagen (Hilden, Germany) was applied according to the procedure as recommended by the supplier. The yield and purity of the extracted DNA were determined using Nanodrop 1000 technology by measuring the absorbance ratio of 260/280. DNA samples with an absorbance ratio of 1.8-2.0 were considered pure and were used for further analysis. Digestion of DNA was performed as previously described [23]. The samples were kept at $-80^{\circ} \mathrm{C}$ until Triple Quadrupole Liquid Chromatography Mass Spectrometer (LC-MS/MS) analysis. 


\subsubsection{Synthesis of dA-AAI, dG-AAI, dA-AAII and dG-AAll adducts}

The synthesis of the DNA adduct standards dA-AAI, dG-AAl, dA-AAll and dG-AAll was performed via a reaction of AAI or AAll with $\mathrm{dA}$ or $\mathrm{dG}$ using a modification of the protocol described previously $[23,28]$. In short, $100 \mu \mathrm{L}$ of AAI or AAll in DMF $(10 \mathrm{mM})$ was mixed with $80 \mathrm{mg}$ of preactivated zinc powder ( $<150 \mu \mathrm{m}, 99.99 \%)$. Then, $1 \mathrm{~mL}$ of dA or dG dissolved in potassium phosphate (50 mM, $\mathrm{pH}$ 5.8) were added to the AAI- or AAll-zinc dust mixture to give a final concentration range that varied from 0 to $100 \mu \mathrm{M}$. After incubation in the dark at $37^{\circ} \mathrm{C}$ for 16 hours, the samples were put on ice for $30 \mathrm{~min}$ and centrifuged at $15000 \mathrm{rpm}$ for $10 \mathrm{~min}$. The approximate overall yields of adducts were assumed to be $2 \%$ of the starting material as previously reported [28]. The synthesized adduct samples obtained were used in LC-MS to define a calibration curve for the quantification of dA-AAI, dG-AAI, dA-AAll and dG-AAll adducts in the cell studies.

\subsubsection{LC-MS/MS method for detection and quantification of dA-AAI and dG-AAI}

The LC-MS/MS method for detection and quantification of dA-AAI, dG-AAI, dA-AAll and dG-AAll was adapted from Abdullah et al. [23]. LC-MS/MS analysis was performed on a Nexera X2 Ultra High Performance Liquid Chromatography (UHPLC) system coupled to an LC-MS/MS (LC-MS-8040; Shimadzu Benelux, 's Hertogenbosch, the Netherlands). In brief, $5 \mu \mathrm{L}$ of sample was injected on a Phenomenex Kinetex-C18 column, $50 \times 2.1 \mathrm{~mm}, 1.7 \mu \mathrm{m}$ (Utrecht, the Netherlands), with a Phenomenex Security Guard ULTRA pre-column. A gradient was made with ultra-pure water containing $0.1 \%(\mathrm{v} / \mathrm{v})$ formic acid as solvent $\mathrm{A}$ and $100 \%$ acetonitrile containing $0.1 \%(\mathrm{v} / \mathrm{v})$ formic acid as solvent $B$. The flow rate was set to $0.3 \mathrm{~mL} / \mathrm{min}$. In a total run of $12.0 \mathrm{~min}$, the starting condition was 95:5 (A:B) for 1 min followed by changing to 0:100 in $6 \mathrm{~min}$ and remaining at 0:100 for another $0.5 \mathrm{~min}$ before returning to the starting condition over $0.1 \mathrm{~min}$ and keeping these conditions for 4.4 min to allow the column to re-equilibrate at room temperature.

The mass spectrometric analysis in the positive ion mode was optimized with the following settings: nebulizer gas flow at $2 \mathrm{~L} / \mathrm{min}$, drying gas flow at $15 \mathrm{~L} / \mathrm{min}, \mathrm{DL}$ temperature at $250^{\circ} \mathrm{C}$, heat block temperature at $400^{\circ} \mathrm{C}$ and $\mathrm{CID}$ gas at $230 \mathrm{kPa}$. The dwell time per transition was $33 \mathrm{msec}$. A divert valve was used in order to discard the eluate in the first minute (e.g. removal of salts) and after finishing MS measurement. The mass spectrometer was operated in MRM mode with the following $\mathrm{m} / \mathrm{z}$ transitions; $543 \rightarrow 427$ for dA-AAl, $559 \rightarrow 443$ for dG-AAl, $513 \rightarrow 397$ for dA-AAll and $529 \rightarrow 413$ for 
dG-AAll. The collision energy used to obtain the daughter fragments was $20 \mathrm{eV}$ for dA-AAl and dAAAll, $28 \mathrm{eV}$ for dG-AAI and $11 \mathrm{eV}$ for dG-AAll.

Data analysis of the calibration series and the samples was performed using the LabSolutions software version 5.8 (Shimadzu Corporation, Kyoto, Japan). Calibration curves were derived by plotting the peak area of respective synthesized adducts against the concentration of dA-AAl, dG-AAI, dA-AAll or dG-AAll and were used to determine the amount of DNA adducts in the samples of AA-exposed cells. The amount of dA-AAl, dG-AAI, dA-AAll or dG-AAll detected in the samples was related to the total amount of digested DNA detected in each sample and adjusted for the mass conversion of double strands DNA per 1000 nucleotides (nts) that correspond to $607.6 \mathrm{~g} /$ mol, in order to quantify the number of adducts per $10^{8} \mathrm{nts}$.

\subsubsection{PBK models for AAI and AAll in rat}

In our previous work [29], PBK models were developed that describe the toxicokinetics of AAI in rat, mouse and human. In the present study, the developed rat PBK model was used as a starting point to establish a new PBK model for AAI and AAll in rat with some modifications. The schematic representation of the PBK model structure is shown in Figure 4.3. Both AAI and AAll were assumed to be taken up from the gastrointestinal tract following first order kinetics and directly transported to the liver. The same absorption rate constant of AAI of 3.27/h [30] was applied to the AAll model. All physiological parameters were kept similar as previously described [29]. The tissue/plasma partition coefficients of rat were calculated based on the log $\mathrm{K}_{\text {ow }}$ values reported to be $4.45 \pm 0.07$ for AAl and $3.99 \pm 0.06$ for AAll [31] using the method of Berezkhovskiy (2004) [32]. The tissue/plasma partition coefficients used in the PBK models for both compounds are presented in Table 4.1. The metabolic clearance rates of AAI and AAll was described in the liver compartment by fitting a first order rate constant for hepatic clearance to correctly predict the in vivo blood levels of AAI and AAll, respectively, as reported by Ren et al. (2014) [33]. The metabolic clearance rates were estimated to be 3.9 L/h for AAI and 1.5 L/hr for AAll. In the study of Ren et al. (2014) rats were exposed to a mixture of AAI and AAll via dosing to Aristolochiae Fructus of which AAll levels were assumed to be 13-fold lower than AAI levels based on the ratio of AAs observed in the commercial samples of Aristolochiae Fructus [34].

To enable the models to predict DNA adduct formation in the kidney an equation describing the AAI and AAll concentration-dependent DNA adduct formation in LLC-PK1 and NRK- 
52E kidney cells in vitro was added to kidney compartment of the PBK model, as described in the next section. In this way, the kinetic parameters for bioactivation of AAI and AAll to its DNA adduct forming metabolite in the kidney were implicitly included in the model.

A set of differential equations describing the mass balance equations of the model is included in the Supplementary data A. The PBK model equations were solved with Berkeley Madonna (version 8.3.18, UC Berkeley, CS, USA) using Rosenbrock's algorithms for solving stiff systems. A local sensitivity analysis was performed to identify influential parameters for the model output. To this purpose, normalized sensitivity coefficients (SC) were calculated with respect to the area under the curve (AUC) of AAl and AAll in the plasma as the model output (C) using the following equation:

$\mathrm{SC}=\left(\mathrm{C}^{\prime}-\mathrm{C}\right) /\left(\mathrm{P}^{\prime}-\mathrm{P}\right)^{*}(\mathrm{P} / \mathrm{C})$

where $C$ is the initial output of the model output and $C^{\prime}$ is the modified output after changing the parameter value P. $\mathrm{P}$ is the initial parameter value and $\mathrm{P}^{\prime}$ is the modified parameter value $(5 \%$ increase). The sensitivity analysis was conducted for an oral exposure to single dose of 0.1 and 100 $\mathrm{mg} / \mathrm{kg}$ bw of AAl and AAll representing a low and a high dose of AA. 


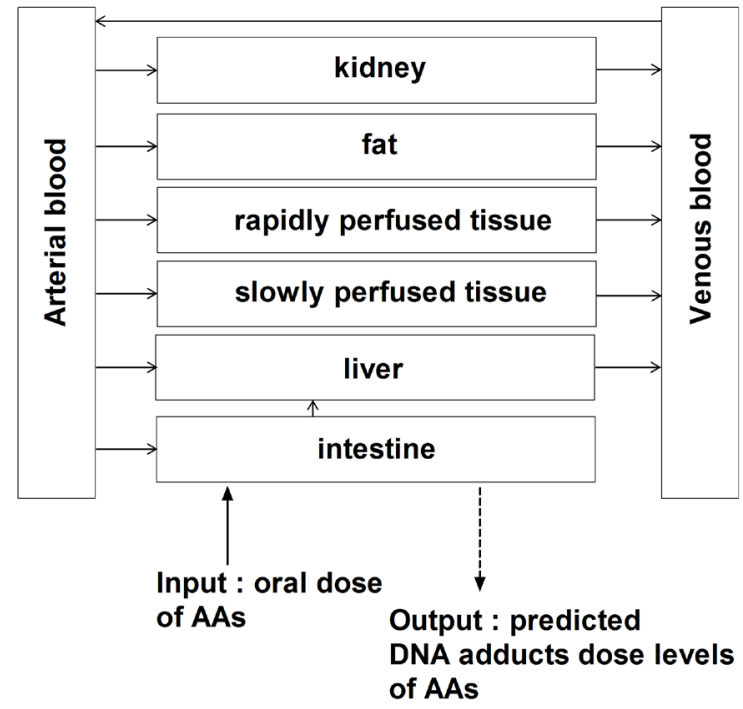

Fig. 4.3 Schematic representation of the PBK models for aristolochic acid I and II in rat.

Table 4.1

Tissue/plasma partition coefficients used in the PBK model for AAI and AAlla

\begin{tabular}{lll}
\hline & AAl & AAll \\
\hline Fat/plasma & 70.3 & 24.0 \\
\hline Liver/plasma & 7.3 & 4.0 \\
Kidney/plasma & 6.6 & 3.7 \\
Small intestine/plasma & 10.5 & 5.8 \\
Richly perfused tissues/plasma & 7.3 & 4.0 \\
\hline Slowly perfused tissue/plasma & 4.1 & 2.4 \\
\hline
\end{tabular}

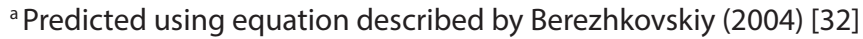




\subsubsection{PBK modeling-based reverse dosimetry of in vitro data to the in vivo situation}

The in vitro concentration-response curve for AAI- and AAll-DNA adduct formation in both kidney cell lines were translated into in vivo dose-response curves for DNA adduct formation in the kidney of rat using PBK modeling-based reverse dosimetry. The following equation was used to describe the formation of either dA-AAl, dG-AAI, dA-AAll or dG-AAll adducts as a function of the AUC for AAI or AAll in the blood concentration in the kidney in the PBK model:

$D N A=A^{*} A \cup C_{\text {AAl or AAll }}$

With DNA being the amount of DNA adducts (number of adducts $/ 10^{8} \mathrm{nts}$ ) formed due to specific binding of AAI or AAll to either deoxyadenosine nucleosides or deoxyguanosine nucleosides dependent on the AUC of AAI or AAll (hours* $\mu \mathrm{mol} / \mathrm{L}$ ) in the kidney blood and A is the slope, which was calculated based on AUC-dependent DNA adduct formation data from the in vitro experiments. The description of dA-AAI, dG-AAI, dA-AAll and dG-AAll adduct formation in the kidney in the PBK model was made assuming that the relation between the AUC and the DNA adduct level of AAI or AAll in vitro is equal to the AUC and the DNA adduct level of AAI or AAll in vivo. The in vitro AUC values were multiplied by 4.6 to account for the differences in free fraction between in vitro and in vivo situation as previously described [23]. The PBK model allows estimation of the DNA adduct formation with different oral doses of AAI or AAll.

\subsubsection{Evaluation of the PBK modeling-based reverse dosimetry approach to predict in vivo DNA adduct formation}

To evaluate the potential of the in vitro-in silico approach to predict a dose-response curve for in vivo DNA adduct formation of AAI and AAll, the DNA adduct formation predicted by the PBK modelingbased reverse dosimetry approach was compared to data on in vivo DNA adduct formation in rats available from the literature $[18,35,36]$. 


\subsection{RESULTS}

\subsubsection{In vitro DNA adduct formation of AAI and AAll in kidney cells}

To obtain concentration-response curves for DNA adduct formation of AAI and AAll in kidney cells, LLC-PK1 and NRK-52E cells were exposed to a mixture (1:1) of AAI and AAll. By exposing the cells to the AA-mixture in the same incubation the best comparison between the relative DNA binding potency may be obtained. At the concentrations used AAI and AAll were shown to not influence each other in the formation of DNA adducts when assessing data on DNA adducts formed upon exposure to a mixture of AAs as compared to data on DNA adducts formed upon exposure to either AAI or AAll alone (data not shown). The LC-MS/MS chromatogram for $543 \rightarrow 427,559 \rightarrow 443$, $513 \rightarrow 397$ and $529 \rightarrow 413$ transitions of the synthesized reference compounds show that the $\mathrm{dA}$ - and dG-AAl adducts eluted at $6.02 \mathrm{~min}$ and $5.56 \mathrm{~min}$, respectively, and that the dA- and dG-AAll adducts eluted at $5.75 \mathrm{~min}$ and $5.46 \mathrm{~min}$, respectively. The hydrolyzed DNA isolated from LLC-PK1 and NRK$52 \mathrm{E}$ cells exposed to the same concentration of AAs reveals formation of all four adducts at different levels (Figure 4.4). Figure 4.5 shows the concentration response-curves for AAI- and AAll-DNA adduct formation upon exposure of the LLC-PK1 and NRK-52E cells to increasing concentrations of AAs. These experimental data show an increased formation of all four DNA adducts at increasing concentrations of AA-mixture up to $20 \mu \mathrm{M}$ (the highest concentration tested). The results obtained reveal a linear relationship between the AA concentration applied and the level of adduct formation observed which can be described by the linear equations presented in Table 4.2. Results obtained reveal that DNA adduct levels were higher in LLC-PK1 cells than in NRK-52E cells. The data also show that dA-AAI levels were 112-fold higher than dA-AAll levels and dG-AAI levels were 75-fold higher than dG-AAll levels in LLC-PK1 cells. In NRK-52E cells, dA-AAI levels were 314-fold higher than dAAAll levels and dG-AAI levels were 125-fold higher than dG-AAll levels. 


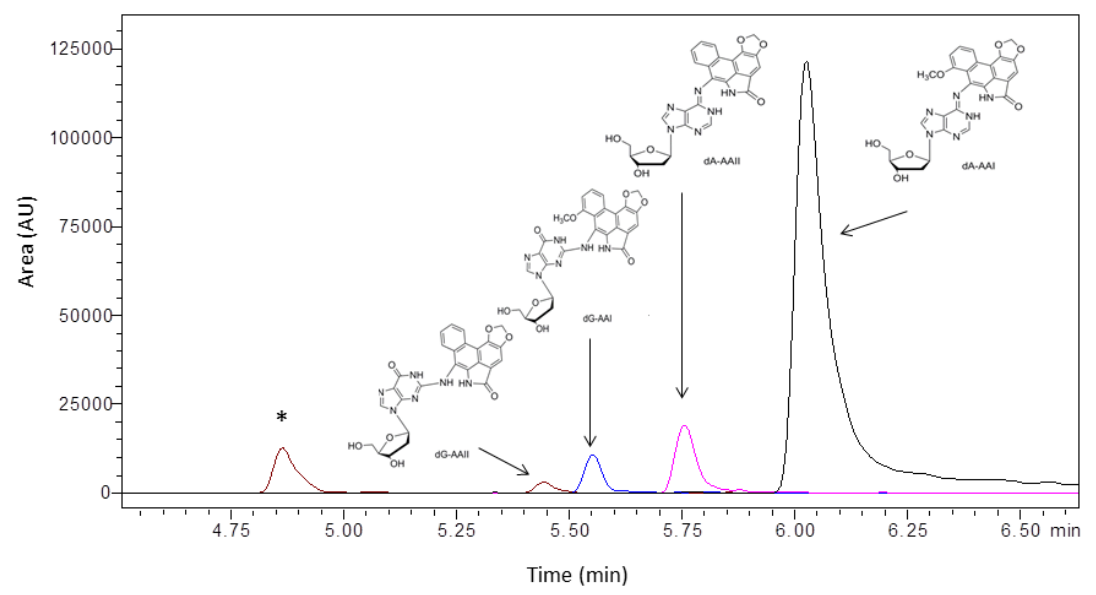

Fig. 4.4 LC-MS/MS chromatogram of AA-DNA adducts in LLC-PK1 cells exposed to $20 \mu \mathrm{M}$ AAs (50\% AAI and 50\% AAII). The peak marked with an asterisk was present in all samples at a similar level. 


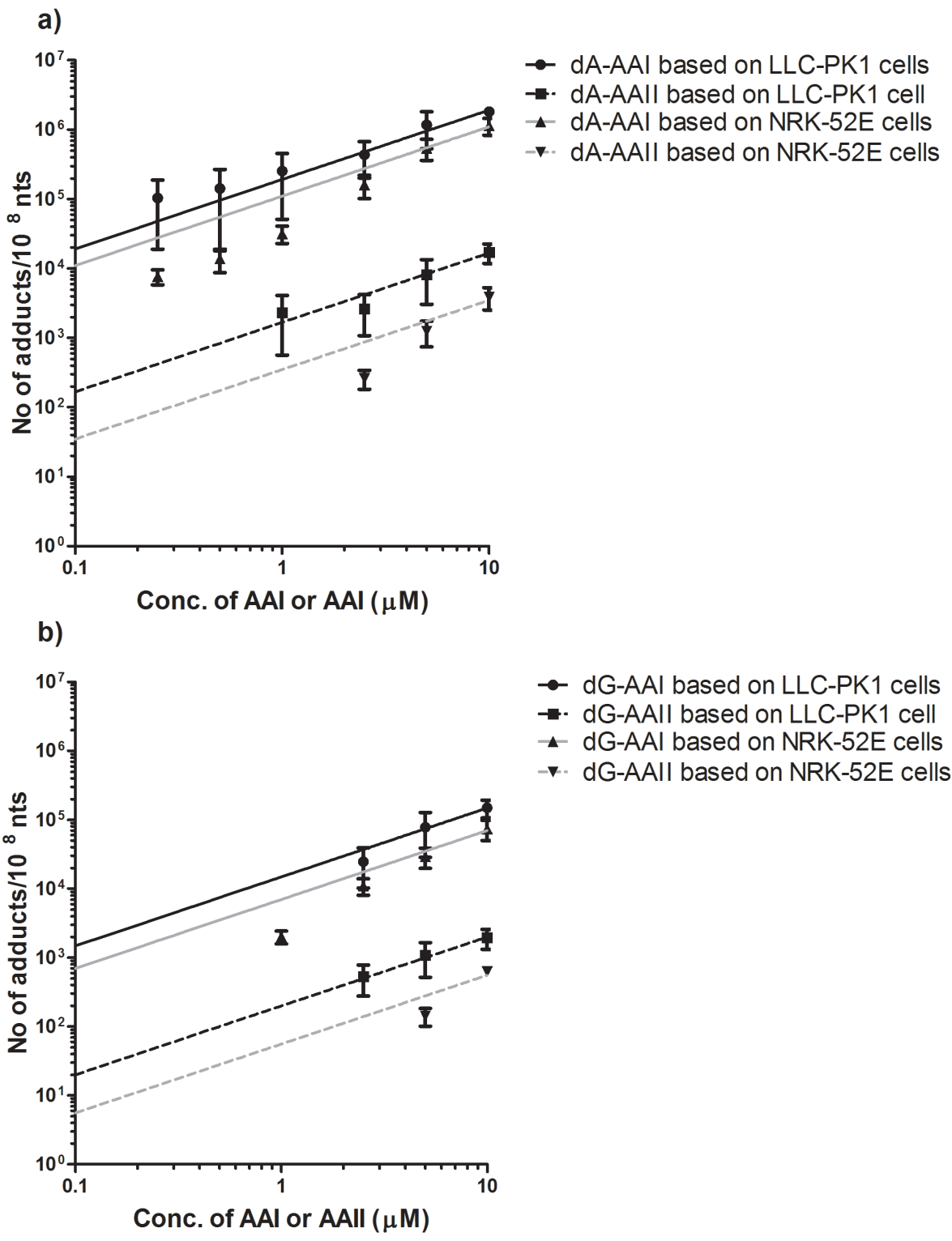

Fig. 4.5 Concentration response-curves for dA-AAI/AAll adducts (a) and dG-AAI/AAll adducts (b) in LLC-PK1cells (black lines) and NRK-52E cells (grey lines) upon 24 hours exposure to increasing concentration of $A A s(\mu M)$, expressed in no of adducts $/ 10^{8}$ nts as quantified by LC-MS/MS (mean values \pm SEM). The linear regression line was fit through the origin. 
Table 4.2

Linear equations describing the formation of DNA adducts in LLC-PK1 cells and NRK-52E cells as a function of AA concentration.

\begin{tabular}{lll}
\hline DNA adduct & \multicolumn{2}{c}{ Linear equations $^{\text {a }}$} \\
\cline { 2 - 3 } & LLC-PK1 & NRK-52E \\
\hline dA-AAI & DNA $=1.9 \times 10^{5 *}[\mathrm{AAI}]\left(\mathrm{r}^{2}=0.97\right) \mathrm{a}$ & DNA $=1.1 \times 10^{5 *}[\mathrm{AAI}]\left(\mathrm{r}^{2}=0.98\right)$ \\
$\mathrm{dG}-\mathrm{AAI}$ & $\mathrm{DNA}=1.5 \times 10^{4 *}[\mathrm{AAI}]\left(\mathrm{r}^{2}=0.99\right)$ & DNA $=7.0 \times 10^{3 *}[\mathrm{AAI}]\left(\mathrm{r}^{2}=0.94\right)$ \\
dA-AAll & DNA $=1.7 \times 10^{3 *}[\mathrm{AAII}]\left(\mathrm{r}^{2}=0.99\right)$ & DNA $=3.5 \times 10^{2 *}[\mathrm{AAII}]\left(\mathrm{r}^{2}=0.89\right)$ \\
dG-AAll & DNA $=2.0 \times 10^{2 *}[\mathrm{AAII}]\left(\mathrm{r}^{2}=0.98\right)$ & DNA $=5.6 \times 10^{1 *}[\mathrm{AAII}]\left(\mathrm{r}^{2}=0.80\right)$ \\
\hline
\end{tabular}

a DNA represents the amount of dA- or dG-AAI or AAll DNA adducts (no of adducts/ $10^{8} \mathrm{nts}$ ) formed in the kidney cells at a defined concentration of AAI or AAll $(\mu M)$.

\subsubsection{PBK model evaluation}

Figure 4.6 shows the plasma concentration-time curves of AAI and AAll as predicted by the developed rat PBK model compared to in vivo kinetic data obtained from literature [33]. It must be noted that PBK model values for hepatic clearance of AAI and AAll were chosen to fit these in vivo data and the model could not be evaluated against other in vivo kinetic data, because these are not available. A sensitivity analysis was performed at a low and a high dose level $(0.1$ and $100 \mathrm{mg} / \mathrm{kg}$ bw/day of AAI and AAll) to identify the key parameters that influence the model outcome of interest (AUC of AAI and AAll blood concentration in the kidney). In both sensitivity analyses (supplementary data B) the body weight and clearance rate constant of AAI and AAll in the liver were the most influential parameters in the PBK models, all expressing normalized sensitivity coefficients higher than 0.1 (in absolute value). The sensitivity analyses also revealed that the sensitivity of the model parameters was the same at low and at high dose levels. 


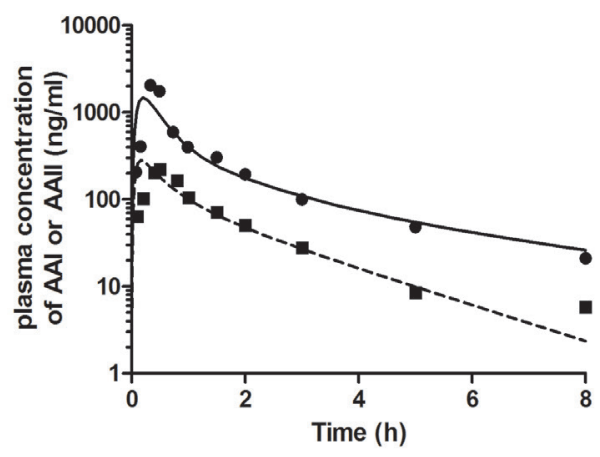

Fig. 4.6 PBK model-based prediction of AAI and AAll plasma levels (AAI-solid line; AAll-dashed line) and the literature data [33] on AAI and AAll plasma levels (AAI-filled circle symbols; AAll-filled square symbols) in rats after oral exposure to $25.3 \mathrm{mg} / \mathrm{kg}$ bw of AAl and $2.0 \mathrm{mg} / \mathrm{kg}$ bw of AAll.

\subsubsection{Translation of the in vitro concentration-response curve to in vivo dose-response curves}

The concentration-response curves of DNA adduct formation (Figure 4.5), were converted to AUC $\mathrm{AAI}_{\mathrm{Al}}$ or AAll (in vitro) response curves by multiplying the concentration by the time of incubation ( 24 hours). Subsequently the AUC values were corrected for the differences in protein levels in the in vitro and in vivo situation, since the in vitro studies have been performed in the absence of serum, whereas in the in vivo situation (kidney blood) plasma proteins are present. For this correction, it was assumed that the free fraction of $A A I$ and AAll in the in vitro situation is 4.6-fold higher than their free fraction in plasma, as previously described in our previous study [23]. The AUCAAI or AAll response curves thus obtained are presented in Figure 4.7 and can be described by linear regression lines through the origin of which the equation are presented in Table 4.3.

These equations were incorporated in the PBK models to predict in vivo DNA adduct formation. To this end, it was assumed that a certain AUCAAI or AAll in the kidney blood in vivo equals a certain AUCAAI or AAll in vitro. This approach provides a link between the PBK model and the equation for DNA adduct formation in vitro and defines a PBK model that can predict DNA adduct formation as a function of the AAI or AAll dose. Figure 4.8 shows the predicted in vivo doseresponse curves for DNA adduct formation of AAI and AAll in rat obtained by converting the in vitro AUC-response curve for DNA adduct formation in LLC-PK1 and NRK-52E cells (Figure 4.7) to the in vivo situation by PBK modeling-based reverse dosimetry. 


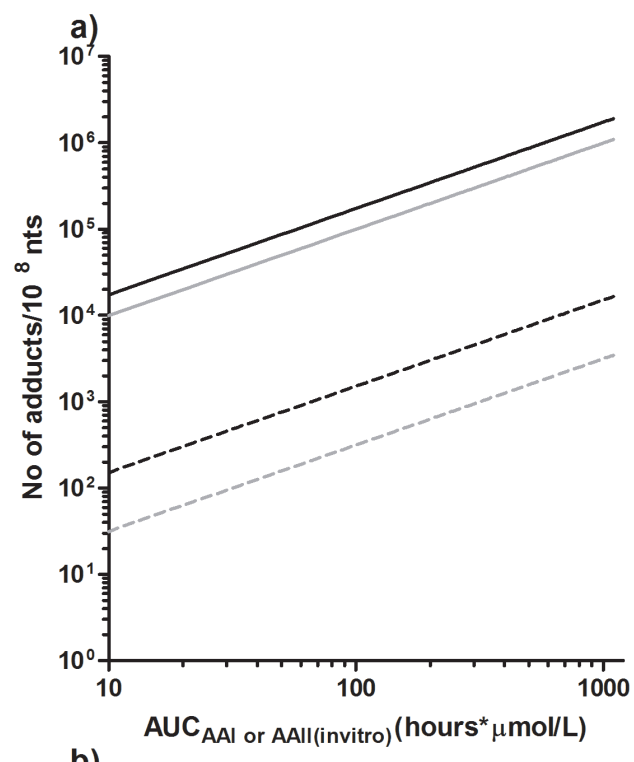

- dA-AAI based on LLC-PK1 cells

--. dA-AAIl based on LLC-PK1 cell

- dA-AAI based on NRK-52E cells

--. dA-AAll based on NRK-52E cells

b)

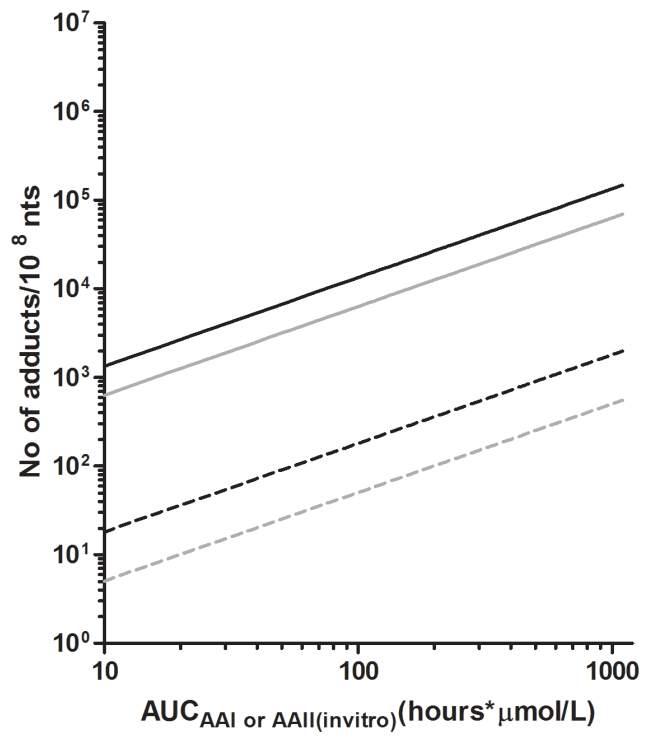

Fig. 4.7 AUC-dependent dA-AAI/AAll adduct (a) and dG-AAI/AAll adduct (b) levels in the rat kidney based on in vitro data from LLC-PK1 cells (black lines) and NRK-52E cells (grey lines) expressed in no of adducts $/ 10^{8} \mathrm{nts}$. The linear equation was fit through the origin. 
Chapter 4

\section{Table 4.3}

Linear equations describing the formation of DNA adducts as a function of AUC based on the AUCresponse curves after correction for differences in free fraction in vitro compared to in vivo.

\begin{tabular}{lll}
\hline DNA adducts & Cell line & Linear equations ${ }^{a}$ \\
\hline dA-AAI & LLC-PK1 & DNA $=1.7 \times 10^{3 *} \mathrm{AUC}_{\text {AAl }}$ \\
& NRK-52E & DNA $=9.9 \times 10^{2 *} \mathrm{AUC}_{\text {AAl }}$ \\
\hline dG-AAI & LLC-PK1 & DNA $=1.3 \times 10^{2 *} \mathrm{AUC}_{\text {AAl }}$ \\
& NRK-52E & DNA $=6.3 \times 10^{1 *} \mathrm{AUC}_{\text {AAl }}$ \\
\hline dA-AAll & LLC-PK1 & DNA $=1.5 \times 10^{1 *} \mathrm{AUC}_{\text {AAll }}$ \\
& NRK-52E & DNA $=3.1^{*} A U C_{\text {AAll }}$ \\
\hline dG-AAIl & LLC-PK1 & DNA $=1.8^{*} A U C_{\text {AAll }}$ \\
& NRK-52E & DNA $=0.5^{*} A U C_{\text {AAll }}$ \\
\hline
\end{tabular}

${ }^{\text {a }}$ DNA represents the amount of dA- or dG-AAI or AAll DNA adducts (no of adducts/ $10^{8} \mathrm{nts}$ ) formed in the kidney cells at a certain AUC AAl $_{\text {(hour }}^{*} \mu \mathrm{mol} / \mathrm{L}$ ) of AAI or AAll. 


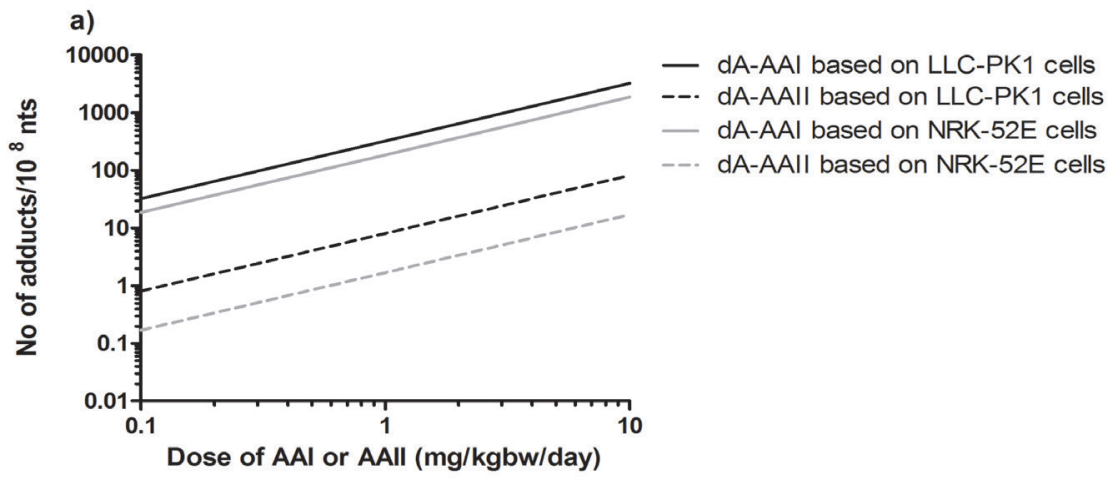

b)

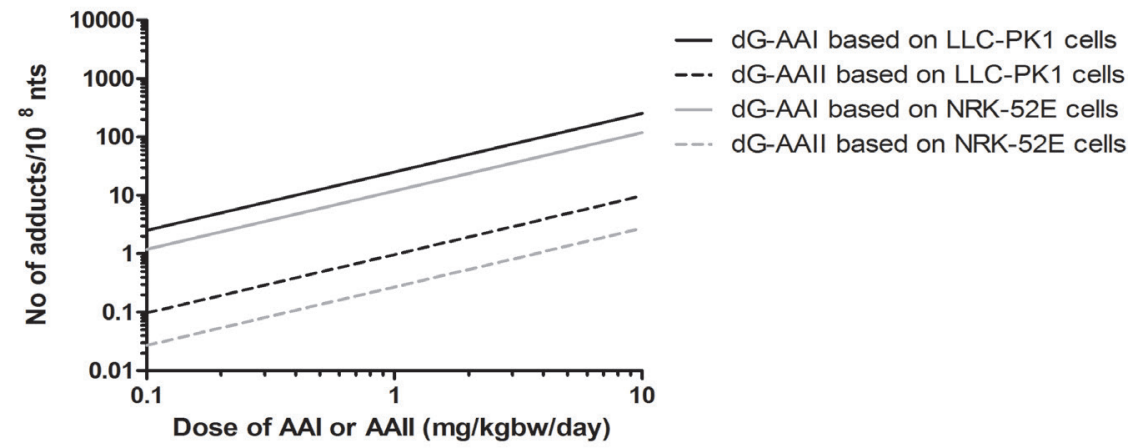

Fig. 4.8 PBK modeling-based reverse dosimetry predicted in vivo dose-response curves for DNA adduct formation of AAI and AAll in the kidney of rats.

\subsubsection{Evaluation of the PBK modeling-based predictions of in vivo DNA adduct formation of AAI and AAll in the rat kidney}

To evaluate the predictions for AA dose-dependent AAI- and AAll-DNA adduct formation in the kidney in vivo, the predicted dose-response curves for DNA adduct formation were compared to in vivo data on AA dose-dependent DNA adduct formation in the kidney of rats as reported in the literature. Table 4.4 presents an overview of in vivo literature data on DNA adduct formation in rats and humans expressed as number of adducts per $10^{8}$ nucleotides. From the overview of all in vivo data reported in rat studies, it appears that the reported literature data on in vivo AA-DNA adduct formation in rat kidney vary up to 3 orders of magnitude at similar exposure. Figure 4.9 presents a comparison of the predicted DNA adduct formation based on translation of in vitro data from LLCPK1 and NRK-52E cells as compared to the in vivo data from the literature. Especially the data from Chan et al. (2008) [36], who only measured dA adducts, seem out of line with other in vivo data. 
The predicted dA-AAI adduct levels match the DNA adduct levels reported in vivo by Mei et al. (2006) [35] and Dong et al. (2006) [18], but were more than 3 orders of magnitude higher than the data reported by Chan et al. (2008) [36] (Figure 4.9a). The predicted dG-AAl adduct levels match the data of Dong et al. (2006) [18], but were 17- to 75-fold lower than the levels reported by Mei et al. (2006) [35] (Figure 4.9b). The predicted dA-AAll adduct levels did not match any of the three in vivo datasets, but fell within the available in vivo data: predicted dA-AAll levels were 44- to 512-fold lower than the data of Mei et al. (2006) [35] and Dong et al. (2006) [18], and 26- to 196-fold higher than the data of Chan et al. (2008) [36] (Figure 4.9c). Levels of predicted dG-AAll adducts did not match the single in vivo dataset available [18], but were 165- to 593-fold lower (Figure 4.9d).

\subsubsection{Comparison of relative dA-AAI/dA-AAll levels in vitro compared to in vivo and predicted in vivo}

In our in vitro studies, the level of AAI-DNA adduct formation was higher than AAll-DNA adduct formation at similar concentrations, which was also observed in AAN patients, whereas such differences have not been reported for the rat in vivo situation. To further analyze these differences, Figure 4.10 shows an overview of the ratio between the dA-AAl-adducts and the dA-AAll-adducts obtained in our in vitro studies, in the in vivo studies as reported in the literature and also as predicted using the in vitro-PBK modeling-based reverse dosimetry approach. $\mathrm{dA}$-adducts were chosen for this analysis, because they were shown to be the major adducts formed in vivo [6, 22]. Figure 4.10 shows that the ratio between dA-AAI adducts and dA-AAll adducts in vitro was 112 for the LLC-PK1 cells and 314 for the NRK-52E cells, whereas the average ratio amounts to 0.6 in rat in vivo, resulting in an on average 355-fold higher ratio in vitro compared to rat in vivo. The ratio predicted using PBK modeling-based reverse dosimetry was lower than observed in vitro amounting to 40 based on the LLC-PK1 data and 110 based on the NRK-52E data, but was still on average 125-fold higher than the ratio for rat in vivo. This indicates that the difference between in vitro dA-AAI- and dA-AAll adduct formation compared to in vivo AAI- and AAll-DNA adduct formation, can only in part be explained by differences in in vivo kinetics, and that other -as yet unidentified-factors may contribute as well. It is of interest to note, however, that the PBK model-based predicted ratios of 40 (based on the LLCPK1 data) and of 110 (based on the NRK-52E) for the level of dA-AAI to dA-AAll adducts is better in line with the ratio of 18 to 70 reported for AAN patients who took the herbal remedy containing AAs (Table 4.4) (Figure 4.10) [21, 22]. 
Table 4.4

Data on DNA adduct formation in kidney of rats and humans exposed to either AAl, AAll or a mixture of AAs, as obtained from the literature.

\begin{tabular}{|c|c|c|c|c|c|c|c|c|c|}
\hline Species & $\begin{array}{l}\text { Exposure } \\
\text { route }\end{array}$ & $\begin{array}{l}\text { AA } \\
\text { composition }\end{array}$ & $\begin{array}{l}\text { Dose a (mg/kg } \\
\text { body wt/day) }\end{array}$ & $\begin{array}{l}\text { Exposure } \\
\text { duration }\end{array}$ & $\begin{array}{l}\text { Adduct } \\
\text { type }\end{array}$ & $\begin{array}{l}\text { No of adducts } / 10^{8} \\
\text { nts }\end{array}$ & Method & Figure & Reference \\
\hline \multirow[t]{2}{*}{ Rat } & Oral & $50 \%$ AAI \& & $0,2.5,15^{\text {a }}$ & $1 \mathrm{~d}$ & dA-AAl & $0,0.09,0.4$ & LC-ESI/MS & 4.9 & Chan et al. (2008) [36] \\
\hline & & $50 \%$ AAll & & & dA-AAll & $0,0.16,0.62$ & & 4.10 & \\
\hline \multirow[t]{3}{*}{ Rat } & Oral & $40 \%$ AAI \& & $0,0.04,0.4,4^{a}$ & $3 \mathrm{~m}$ & dA-AAl & $0,9.2,53.5,911.4$ & ${ }^{32} \mathrm{p} \mathrm{b}^{\mathrm{b}}$ & 4.9, & Mei et al. (2006) [35] \\
\hline & & $56 \%$ AAll & $0,0.056,0.56,5.6^{a}$ & & dG-AAI & $0,35.6,266.5,1676.6$ & & 4.10 & \\
\hline & & & & & dA-AAll & $0,49.1,384.6,2010.3$ & & & \\
\hline \multirow[t]{4}{*}{ Rat } & Oral & AAI or AAll & 0,5 & $7 d$ & dA-AAI & 0,886 & ${ }^{32} \mathrm{P} \mathrm{b}$ & 4.9, & Dong et al. (2006) [18] \\
\hline & & & & & dG-AAI & 0,98 & & 4.10 & \\
\hline & & & & & dA-AAll & 0,3380 & & & \\
\hline & & & & & dG-AAll & 0,800 & & & \\
\hline \multirow[t]{2}{*}{ Human } & Oral & AAl and AAll & $n a^{c}$ & na & dA-AAl & $n a^{d}$ & LC-ESI/MS & 4.10 & Grollman et al. (2007) \\
\hline & & & & & dA-AAll & $n a^{d}$ & & & {$[21]$} \\
\hline \multirow[t]{2}{*}{ Human } & Oral & AAl and AAll & $0.0086-0.017$ & $19-21 \mathrm{~m}$ & dA-AAl & $7-76^{e}$ & ${ }^{32} \mathrm{p} \mathrm{b}$ & 4.10 & Bieler et al. (1997) [22] \\
\hline & & & & & dA-AAll & $0.6-3.1^{\mathrm{e}}$ & & & \\
\hline
\end{tabular}

a adjusted dose $=$ dose $\mathrm{x}$ percentage of AAI or AAll

${ }^{\text {b }}{ }^{32}$-postlabeling

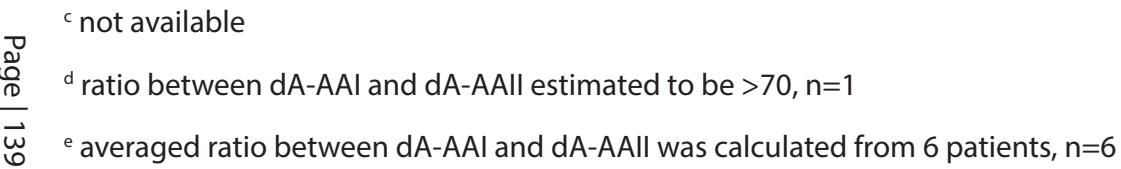




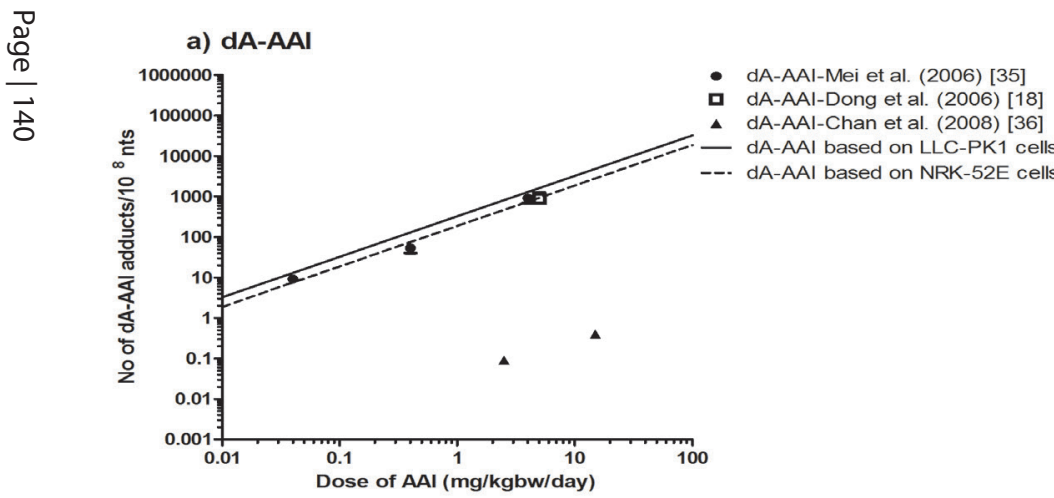
c) dA-AAll

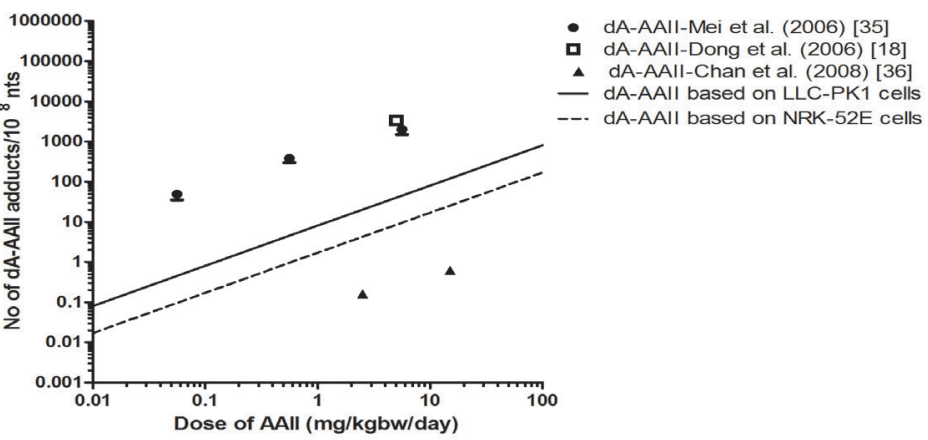

d) dG-AAll

b) dG-AAI
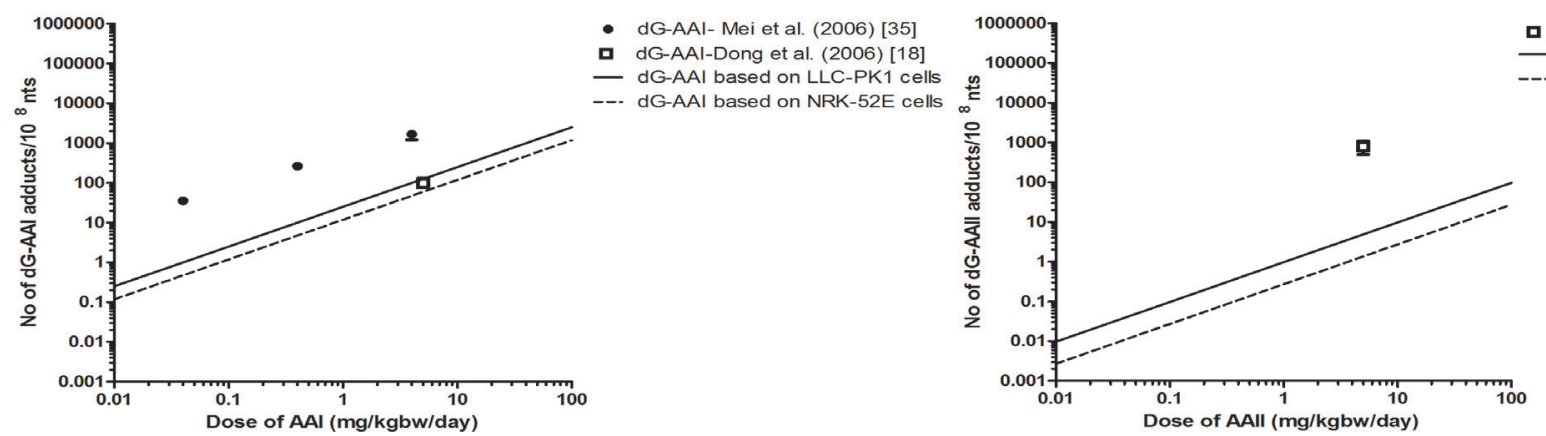

Fig. 4.9 Comparison of PBK model-based reverse dosimetry predicted dose dependent formation of dA-AAI (a), dG-AAI (b), dA-AAll (c) and dG-AAll (d) adducts (straight lines) in the kidney of rats exposed orally to AAI or AAll to data on in vivo AA-DNA adduct formation in the kidney of rats as reported in the literature. See Table 4.4 for specifications of the experimental conditions for the in vivo studies. 


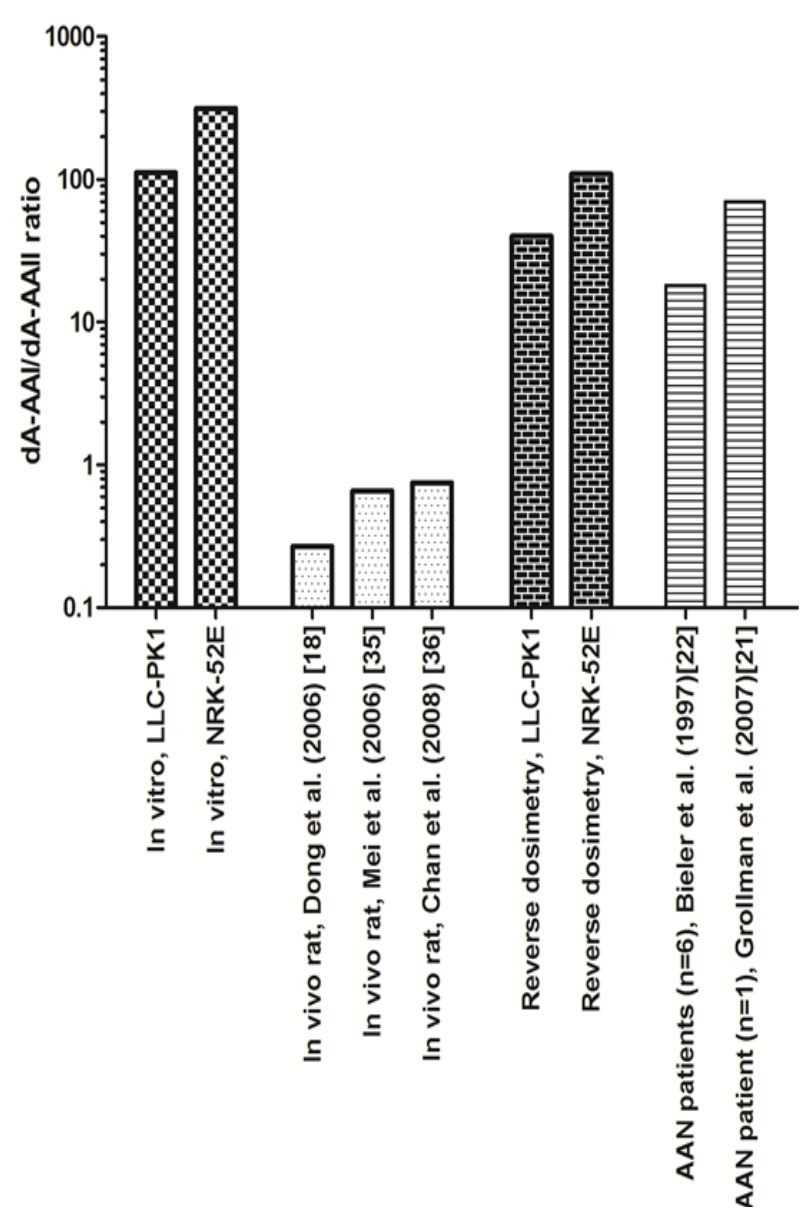

Fig. 4.10 Relative dA-AAl levels compared to dA-AAll levels (dA-AAl/dA-AAll ratio) in the in vitro situation, the in vivo situation, predicted using PBK modeling-based reverse dosimetry and in AAN patients. 


\subsection{DISCUSSION}

Over the past decades, there is increasing interest in the development of methods that allow in vitro-in vivo extrapolation. PBK modeling-based reverse dosimetry has been shown to successfully relate in vitro concentrations to in vivo doses [29, 37-39]. The present study aimed to assess the DNA adduct formation of AAI and AAll in kidney cells in vitro and the possibility of predicting in vivo DNA adduct formation of AAI and AAll in the kidney in vivo without the use of animals. To this end, in vitro concentration response curves of dA-AAI, dG-AAl, dA-AAll and dG-AAll adducts were obtained in kidney cells in vitro, and subsequently translated to predicted in vivo dose-response curves for AA-induced DNA adduct formation in rats using PBK modeling-based reverse dosimetry. These predicted DNA adduct levels were compared to in vivo DNA adduct levels as reported in the literature in order to evaluate the approach. The analysis of the in vivo data revealed a large discrepancy between the different values reported in vivo, thereby hampering the evaluation of the predictions made. The results of this study also show that AAI-DNA adduct levels are about 100-fold higher than AAll-DNA adduct levels in vitro, whereas levels of AAI- and AAll-DNA adducts have been reported to be quite similar in rats in vivo. This discrepancy between the in vitro and in vivo situation could be partly resolved by taking possible differences in in vivo toxicokinetics into account, although a difference in the predicted AAI/AAll DNA adduct ratio versus the AAI/AAll DNA adduct ratio observed in in vivo rat studies remained. This indicates that other factors may be responsible for causing the discrepancies between the in vitro and in vivo situation.

For AAI-DNA adducts, the predicted DNA adduct levels match the data of dA-AAI from Mei et al. (2006) [35] and Dong et al. (2006) [18] and the data of dG-AAl from Dong et al. (2008) [18]. For AAll-DNA adducts, the predicted DNA adduct levels did not match any in vivo dataset, but fell within the range of data reported for dA-AAll adducts, while the values for dG-AAll adducts were underpredicted compared to the single dataset available. In general, the evaluation of the predictions appeared to be hampered by the fact that the DNA adduct levels as reported in vivo in rats deviate by more than 3 orders of magnitude at similar AA exposure levels (Table 4.4 and Figure 4.9). The factors that may contribute to these large differences may be differences in techniques used for analysis ( ${ }^{32} \mathrm{P}$-postlabeling vs LC-MS), the use of AAI and AAll in mixtures vs pure AAI or AAll, the exposure duration, and differences in methods used for AA-adduct quantification and definition of calibration curves, the latter possibly caused by the fact that the respective DNA adducts have to be chemically synthesized by a method with only limited yield [28]. 
Comparing the DNA adduct formation of AAI and AAll in vitro shows that AAI-DNA adducts are 112- and 314-fold higher than AAll-DNA adducts in cell lines derived from the pig and rat kidney, respectively. A higher formation of AAI-DNA adducts has also been found before in opossum kidney cells in which AAI-DNA adducts were 10-fold higher than AAll-DNA adducts [17]. AAI has also been reported to induce an 11-fold higher number of $d A$-adducts than AAll in in vitro enzymatic incubations of calf thymus DNA using xanthine oxidase, which is involved in catalyzing the reductive reaction that leads to the formation of reactive intermediates that binds to DNA [40]. However, as shown in Table 4.4 and Figure 4.9, DNA adduct levels of AAI and AAll in the kidney of exposed rats are very similar. On the other hand, it was demonstrated that the level of dA-AAl adducts was about 18- and 70-fold higher than dA-AAll adducts in AAN patients who took herbal remedy containing AAs [21, 22]. These data indicate differences between the in vitro and the in vivo situation, but also possible interspecies differences. Differences between the in vitro and in vivo ratio may be due to possible differences in ADME processes of AAI compared to AAll in vivo [20]. Possible differences in clearance was taken into account in the present study when predicting DNA adduct levels in rats using PBK modeling-based reverse dosimetry. Using this approach, the discrepancy between the in vitro and in vivo situation was reduced 3-fold but still remained substantial, indicating that other -as yet unidentified- factors may be responsible for causing the discrepancies between the in vitro and in vivo situation. It is likely that the presence of the O-methoxy group in AAl, which is absent in AAll, may play a key role in the differences between AAI and AAll, resulting in a higher clearance of AAI. The half-life of DNA adducts depends on the chemical stability of the adduct, but also on repair processes and the absence or presence of cell death upon exposure to the chemical. To date, there is no information regarding the stability and biological consequences of dA-AAI versus dA-AAll adducts in vivo $[35,41]$. Also, possible differences in oxygen tension could play a role in differences in relative numbers of AAl- and AAll-DNA adducts in the in vitro compared to the in vivo situation [42]. Especially the level of bioactivation to a DNA reactive intermediate via nitroreduction of these two chemicals has been reported to be different under aerobic and anaerobic conditions [11, 40]. This points at the need to further study the potential differences between different in vitro models to be used for the combined in vitro-PBK modeling approach.

In the present study, LLC-PK1 cells and NRK-52E cells were used to measure in vitro DNA adduct formation. The LLC-PK1 cell line is a porcine cells line that is routinely used to study nephrotoxic effects of chemicals in humans because the cells exhibit many of the enzymatic and transport properties of the human proximal tubule cells $[43,44]$ which are the cells that represent 
the direct target of AAI [45]. The NRK-52E cell line is a rat cell line and may therefore be a better model to predict DNA adduct levels in rats. However, although we found differences in DNA adduct levels in LLC-PK1 cells compared to NRK-52E cells, it cannot be concluded that predictions based on one of these cell lines is better, given the large variation in the DNA adduct levels reported in vivo. Interestingly, AA-DNA adduct levels formed upon AA exposure in different in vitro models, including non-kidney cells, have been reported to differ up to 3 orders of magnitude [23], indicating the large variation in the results also obtained in in vitro models. More understanding of the mechanisms underlying these differences is required in order to select a model that best resembles the in vivo situation. Furthermore the ratio of AAI- and AAll-DNA adducts may also vary with the in vitro model used, which is an interesting topic for further studies.

Altogether, it is concluded that PBK model-based conversion of in vitro data to in vivo data for AA derived DNA adduct formation is feasible but needs further refinement to also adequately predict the relative differences between the two AAs, while also the discrepancy between the different values reported in vivo needs to be resolved.

\section{ACKNOWLEDGEMENTS}

This research was supported by the Ministry of Education of Malaysia (Project number- KPT (BS) 860828565598). 


\section{References}

1. Kumar, V., A.K. Prasad, and V.S. Parmar, Naturally occurring aristolactams, aristolochic acids and dioxoaporphines and their biological activities. Natural Products Reports, 2003. 20(6): p. 565-583.

2. Schmeiser, H., B. Pool, and M. Wiessler, Identification and mutagenicity of metabolites of aristolochic acid formed by rat liver. Carcinogenesis, 1986. 7(1): p. 59-63.

3. Chan, W., L. Cui, G. Xu, and Z. Cai, Study of the phase I and phase II metabolism of nephrotoxin aristolochic acid by liquid chromatography/tandem mass spectrometry. Rapid Communications in Mass Spectrometry, 2006. 20(11): p. 1755-1760.

4. Shibutani, S., R.R. Bonala, T. Rosenquist, R. Rieger, N. Suzuki, F. Johnson, F. Miller, and A.P. Grollman, Detoxification of aristolochic acid I by O-demethylation: Less nephrotoxicity and genotoxicity of aristolochic acid la in rodents. International Journal of Cancer, 2010. 127(5): p. 1021-1027.

5. Luan, Y., G. Xing, J. Ren, and J. Gu, Role of hepatic cytochrome P450 enzymes in the detoxication of aristolochic acid l; effects on DNA adduct, mutation, and tumor formation. Genes and Environment, 2015. 37(1): p. 1.

6. Arlt, V.M., M. Stiborova, and H.H. Schmeiser, Aristolochic acid as a probable human cancer hazard in herbal remedies: a review. Mutagenesis, 2002. 17(4): p. 265-277.

7. Shibutani, S., H. Dong, N. Suzuki, S. Ueda, F. Miller, and A.P. Grollman, Selective toxicity of aristolochic acids I and II. Drug Metabolism and Disposition, 2007. 35(7): p. 1217-1222.

8. Martinek, V., B. Kubickova, V.M. Arlt, E. Frei, H.H. Schmeiser, J. Hudecek, and M. Stiborova, Comparison of activation of aristolochic acid I and II with NADPH: quinone oxidoreductase, sulphotransferases and N-acetyltranferases. Neuro endocrinology letters, 2010. 32: p. 57-70.

9. Stiborová, M., E. Frei, B. Sopko, K. Sopková, V. Marková, M. Laňková, T. Kumstýřová, M. Wiessler, and H.H. Schmeiser, Human cytosolic enzymes involved in the metabolic activation of carcinogenic aristolochic acid: evidence for reductive activation by human NAD (P) H: quinone oxidoreductase. Carcinogenesis, 2003. 24(10): p. 1695-1703.

10. Pfau, W., H.H. Schmeiser, and M. Wiessler, ${ }^{32}$ P-postlabelling analysis of the DNA adducts formed by aristolochic acid I and II. Carcinogenesis, 1990. 11(9): p. 1627-1633.

11. Schmeiser, H., K.-B. Schoepe, and M. Wiessler, DNA adduct formation of aristolochic acid I and II in vitro and in vivo. Carcinogenesis, 1988. 9(2): p. 297-303.

12. Zhang, C.-Y., X. Wang, T. Su, C.-M. Ma, Y.-J. Wen, M.-Y. Shang, X.-M. Li, G.-X. Liu, and S.-Q. Cai, New aristolochic acid, aristololactam and renal cytotoxic constituents from the stem and leaves of Aristolochia contorta. Die Pharmazie-An International Journal of Pharmaceutical Sciences, 2005. 60(10): p. 785-788.

13. Balachandran, P., F. Wei, R.C. Lin, I.A. Khan, and D.S. Pasco, Structure activity relationships of aristolochic acid analogues: toxicity in cultured renal epithelial cells. Kidney International, 2005. 67(5): p. 1797-1805.

14. Cai, Y. and T.G. Cai, Two new aristolochic acid derivatives from the roots of Aristolochia fangchi and their cytotoxicities. Chemical and Pharmaceutical Bulletin, 2010. 58(8): p. 1093-1095.

15. Liu, Q., Q. Wang, X. Yang, X. Shen, and B. Zhang, Differential cytotoxic effects of denitroaristolochic acid II and aristolochic acids on renal epithelial cells. Toxicology Letters, 2009. 184(1): p. 5-12.

16. Sato, N., D. Takahashi, R. Tsuchiya, T. Mukoyama, S.I. Yamagata, N. Satoh, S. Ueda, S.M. Chen, M. Ogawa, and M. Yoshida, Acute nephrotoxicity of aristolochic acids in mice. Journal of Pharmacy and Pharmacology, 2004. 56(2): p. 221-229.

17. Lebeau, C., V.M. Arlt, H.H. Schmeiser, A. Boom, P.J. Verroust, O. Devuyst, and R. Beauwens, Aristolochic acid impedes endocytosis and induces DNA adducts in proximal tubule cells. Kidney International, 2001.60(4): p. 1332-1342.

18. Dong, H., N. Suzuki, M.C. Torres, R.R. Bonala, F. Johnson, A.P. Grollman, and S. Shibutani, Quantitative determination of aristolochic Acid-derived DNA adducts in rats using ${ }^{32} p$-postlabeling/ polyacrylamide gel electrophoresis analysis. Drug Metabolism and Disposition, 2006. 34(7): p. 11221127.

19. Leung, E.M. and W. Chan, Noninvasive measurement of aristolochic acid-DNA adducts 
in urine samples from aristolochic acid-treated rats by liquid chromatography coupled tandem mass spectrometry: Evidence for DNA repair by nucleotide-excision repair mechanisms. Mutation Research/ Fundamental and Molecular Mechanisms of Mutagenesis, 2014. 766: p. 1-6.

20. Xing, G., X. Qi, M. Chen, Y. Wu, J. Yao, L. Gong, T. Nohmi, Y. Luan, and J. Ren, Comparison of the mutagenicity of aristolochic acid I and aristolochic acid II in the gpt delta transgenic mouse kidney. Mutation Research/Genetic Toxicology and Environmental Mutagenesis, 2012. 743(1): p. 52-58.

21. Grollman, A.P., S. Shibutani, M. Moriya, F. Miller, L. Wu, U. Moll, N. Suzuki, A. Fernandes, T. Rosenquist, and Z. Medverec, Aristolochic acid and the etiology of endemic (Balkan) nephropathy. Proceeding of the National Academy of Sciences of the United States of America, 2007. 104(29): p. 12129-12134.

22. Bieler, C.A., M. Stiborova, M. Wiessler, J.-P. Cosyns, C.v.Y. de Strihou, and H.H. Schmeiser, ${ }^{32}$ P-post-labelling analysis of DNA adducts formed by aristolochic acid in tissues from patients with Chinese herbs nephropathy. Carcinogenesis, 1997. 18(5): p. 1063-1067.

23. Abdullah, R., S. Wesseling, B. Spenkelink, J. Louisse, A. Punt, and I.M.C.M. Rietjens, Defining in vivo dose-response curves for kidney DNA adduct formation of aristolochic acid I in rat, mouse and human by an in vitro and physiologically based kinetic modeling approach. Submitted.

24. Rosenquist, T.A., H.J. Einolf, K.G. Dickman, L. Wang, A. Smith, and A.P. Grollman, Cytochrome P450 1A2 detoxicates aristolochic acid in the mouse. Drug Metabolism and Disposition, 2010. 38(5): $\mathrm{p}$. 761-768.

25. Arlt, V.M., K.i. Levová, F.e. Bárta, Z. Shi, J.D. Evans, E. Frei, H.H. Schmeiser, D.W. Nebert, D.H. Phillips, and M. Stiborová, Role of P450 1A1 and P450 1A2 in Bioactivation versus Detoxication of the Renal Carcinogen Aristolochic Acid I: Studies in Cyp1a1 (-/-), Cyp1a2 (-/-), and Cyp1a1/1a2 (-/-) Mice. Chemical Research in Toxicology, 2011. 24(10): p. 1710-1719.

26. Levová, K., M. Moserová, V. Kotrbová, M. Šulc, C.J. Henderson, C.R. Wolf, D.H. Phillips, E. Frei, H.H. Schmeiser, and J. Mareš, Role of cytochromes P450 1A1/2 in detoxication and activation of carcinogenic aristolochic acid I: studies with the hepatic NADPH: cytochrome P450 reductase null (HRN) mouse model. Toxicological Sciences, 2011. 121(1): p. 43-56.

27. Stiborová, M., E. Frei, V.M. Arlt, and H.H. Schmeiser, Metabolic activation of carcinogenic aristolochic acid, a risk factor for Balkan endemic nephropathy. Mutation Research, 2008. 658(1): p. 55-67.

28. Yun, B.H., T.A. Rosenquist, V. Sidorenko, C.R. Iden, C.-H. Chen, Y.-S. Pu, R. Bonala, F. Johnson, K.G. Dickman, and A.P. Grollman, Biomonitoring of aristolactam-DNA adducts in human tissues using ultra-performance liquid chromatography/ion-trap mass spectrometry. Chemical Research in Toxicology, 2012. 25(5): p. 1119-1131.

29. Abdullah, R., W. Alhusainy, J. Woutersen, I.M.C.M. Rietjens, and A. Punt, Predicting points of departure for risk assessment based on in vitro cytotoxicity data and physiologically based kinetic (PBK) modeling: the case of kidney toxicity induced by aristolochic acid I. Food and Chemical Toxicology, 2016. 92: p. 104-116.

30. Su, T., L. Qu, C. Zhang, S. Cai, and X. Li, Studies on pharmacodynamic characteristics of aristolochic acid I in rats. China Journal of Chinese Materia Medica, 2004. 29(7): p. 676-681.

31. Han, S.Y., J.Q. Qiao, Y.Y. Zhang, H.Z. Lian, and X. Ge, Determination of n-octanol/water partition coefficients of weak ionizable solutes by RP-HPLC with neutral model compounds. Talanta, 2012. 97: p. 355-361.

32. Berezhkovskiy, L.M., Volume of distribution at steady state for a linear pharmacokinetic system with peripheral elimination. Journal of Pharmaceutical Sciences, 2004. 93(6): p. 1628-1640.

33. Ren, G., Q. Huang, J. Wu, J. Yuan, G. Yang, Z. Yan, and S. Yao, Cloud point extraction-HPLC method for the determination and pharmacokinetic study of aristolochic acids in rat plasma after oral administration of Aristolochiae Fructus. Journal of Chromatography B, 2014. 953: p. 73-79.

34. Xu, Y.-Q., X.-W. Li, G.-X. Liu, X. Wang, M.-Y. Shang, X.-M. Li, and S.-Q. Cai, Comparative study of the contents of analogues of aristolochic acid in two kinds of Aristolochiae Fructus by high-performance liquid chromatography. Journal of natural medicines, 2013. 67(1): p. 113-122.

35. Mei, N., V.M. Arlt, D.H. Phillips, R.H. Heflich, and T. Chen, DNA adduct formation and mutation 
induction by aristolochic acid in rat kidney and liver. Mutation Research/Fundamental and Molecular Mechanisms of Mutagenesis, 2006. 602(1): p. 83-91.

36. Chan, W., H. Yue, W.T. Poon, Y.-W. Chan, O.J. Schmitz, D.W. Kwong, R.N. Wong, and Z. Cai, Quantification of aristolochic acid-derived DNA adducts in rat kidney and liver by using liquid chromatography-electrospray ionization mass spectrometry. Mutation Research/Fundamental and Molecular Mechanisms of Mutagenesis, 2008. 646(1): p. 17-24.

37. DeJongh, J., M. Nordin-Andersson, B. Ploeger, and A. Forsby, Estimation of systemic toxicity of acrylamide by integration of in vitro toxicity data with kinetic simulations. Toxicology and Applied Pharmacology, 1999. 158(3): p. 261-268.

38. Verwei, M., J.A. van Burgsteden, C.A. Krul, J.J. van de Sandt, and A.P. Freidig, Prediction of in vivo embryotoxic effect levels with a combination of in vitro studies and PBPK modelling. Toxicology Letters, 2006. 165(1): p. 79-87.

39. Louisse, J., E. de Jong, J.J. van de Sandt, B.J. Blaauboer, R.A. Woutersen, A.H. Piersma, I.M.C.M. Rietjens, and M. Verwei, The use of in vitro toxicity data and physiologically based kinetic modeling to predict dose-response curves for in vivo developmental toxicity of glycol ethers in rat and man. Toxicological Sciences, 2010. 118(2): p. 470-484.

40. Schmeiser, H., E. Frei, M. Wiessler, and M. Stiborova, Comparison of DNA adduct formation by aristolochic acids in various in vitro activation systems by ${ }^{32} P$-post-labelling: evidence for reductive activation by peroxidases. Carcinogenesis, 1997. 18(5): p. 1055-1062.

41. Kathuria, P., P. Sharma, and S.D. Wetmore, Effect of base sequence context on the conformational heterogeneity of aristolactam-I adducted DNA: structural and energetic insights into sequence-dependent repair and mutagenicity. Toxicology Research, 2016. 5(1): p. 197-209.

42. Maier, P., H. Schawalder, and B. Weibel, Low oxygen tension, as found in tissues in vivo, alters the mutagenic activity of aristolochic acid I and II in primary fibroblast-like rat cells in vitro. Environmental and molecular mutagenesis, 1987. 10(3): p. 275-284.

43. Hull, R., W. Cherry, and G. Weaver, The origin and characteristics of a pig kidney cell strain, LLC-PK1. In vitro, 1976. 12(10): p. 670-677.

44. Gstraunthaler, G., W. Pfaller, and P. Kotanko, Biochemical characterization of renal epithelial cell cultures (LLC-PK1 and MDCK). American Journal of Physiology: Renal Pgysiology, 1985. 248(4): $p$. F536-F544.

45. Lebeau, C., F.D. Debelle, V.M. Arlt, A. Pozdzik, E.G. De Prez, D.H. Phillips, M.M. DeschodtLanckman, J.-L. Vanherweghem, and J.L. Nortier, Early proximal tubule injury in experimental aristolochic acid nephropathy: functional and histological studies. Nephrology Dialysis Transplantation, 2005. 20(11): p. 2321-2332. 
Supplementary data A. Mass balance equation and parameter specifications of PBK model for aristolochic acid I or II in the rat

\section{Compound}

Aristolochic acid I or II

Compartment (Tissue (T))

Small intestine

Liver

Kidney

Slowly perfused tissue

Richly perfused tissue

Fat compartment

Arterial

Venous

\section{abbreviation}

AA

\section{abbreviation}

।

L

K

$\mathrm{S}$

$\mathrm{R}$

$\mathrm{F}$

A

V

\section{Variable}

Blood flow rate to tissue

Cardiac output

Concentration of AAI in tissue or blood

Partitioning coefficient tissue:blood AAl or II

Volume of tissue or blood

Amount AAI or II in tissue or blood

Uptake rate AAI or II in intestine

Clearance of AAI or II in liver

\section{Unit}

$\mathrm{Ih}^{-1}$

$\mathrm{Ih}^{-1}$

$\mu \mathrm{M}$

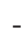

I

$\mu \mathrm{mol}$

$h^{-1}$

$\mathrm{Ih}^{-1}$

\section{abbreviation}

$\mathrm{Q}(\mathrm{T})$

QC

$\mathrm{C}(\mathrm{T}) \mathrm{AA}$

$\mathrm{P}(\mathrm{T}) \mathrm{AA}$

$\mathrm{V}(\mathrm{T})$

$A(T) A A$

$\mathrm{Ka}$

CAAL

\section{Small intestine}

$\mathrm{dAl}_{\mathrm{AA}} / \mathrm{dt}=\mathrm{dUptake}{ }_{\mathrm{AA}} / \mathrm{dt}+\mathrm{QI}{ }^{*}\left(\mathrm{CA}_{\mathrm{AA}}-\mathrm{Cl}_{\mathrm{AA}} / \mathrm{PI}_{\mathrm{AA}}\right)$

\section{Uptake of AAI from GI tract}

dUptake $_{\mathrm{AA}} / \mathrm{dt}=-\mathrm{dAGl}{ }_{\mathrm{AA}} / \mathrm{dt}=\mathrm{ka}^{*} \mathrm{AGI}_{\mathrm{AA}}$

$\mathrm{AGI}_{\mathrm{AA}}(0)=$ Oral dose

Page | 148 
$\mathrm{Cl}_{\mathrm{AA}}=\mathrm{Al}_{\mathrm{AA}} \mathrm{NI}$

\section{Liver compartment}

$\mathrm{dAL}_{\mathrm{AA}} / \mathrm{dt}=\mathrm{QL}{ }^{*} \mathrm{CA}+\mathrm{QI}{ }^{*} \mathrm{Cl}_{\mathrm{AA}} / \mathrm{PI}_{\mathrm{AA}}-(\mathrm{QL}+\mathrm{QI})^{*} \mathrm{CL}_{\mathrm{AA}} / \mathrm{PL}_{\mathrm{AA}}-\mathrm{dClearance}{ }_{\mathrm{AA}} / \mathrm{dt}$

$\mathrm{CL}_{\mathrm{AA}}=\mathrm{AL}_{\mathrm{AA}} / \mathrm{VL}$

\section{Clearance of AAI or II}

dClearance $_{A A} / d t=C A A L^{*} C_{A A} / P_{A A}$

$\operatorname{CAAL}(0)=0$

\section{Kidney compartment}

$\mathrm{dAK}_{\mathrm{AA}} / \mathrm{dt}=\mathrm{QK} *\left(\mathrm{CA}_{\mathrm{AA}}-\mathrm{CK}_{\mathrm{AA}} / \mathrm{PK}_{\mathrm{AA}}\right)$

$\mathrm{CK}_{\mathrm{AA}}=\mathrm{AK}_{\mathrm{AA}} / \mathrm{VK}$

$\mathrm{CVK}_{\mathrm{AA}}=\mathrm{CK}_{\mathrm{AA}} / \mathrm{PK}_{\mathrm{AA}}$

$\mathrm{dAUCVK} \mathrm{AA}_{\mathrm{AA}} / \mathrm{dt}=\mathrm{CVK}_{\mathrm{AA}}$

\section{DNA adduct formation}

$D N A=A^{*} A \cup C_{A A}$

'DNA' is the amount of DNA adducts (number of adducts $/ 10^{8} \mathrm{nts}$ ) formed due to specific binding of AAI or AAll to either deoxyadenosine nucleosides or deoxyguanosine nucleosides at a certain 'AUC ${ }_{\mathrm{AA}}$ ' (hours* $\mu \mathrm{mol} / \mathrm{L}$ ) of AAl or AAll, and 'A' is the slope, respectively, calculated based on the data from the in vitro experiments.

\section{Slowly perfused tissue}

$$
\begin{aligned}
& \mathrm{dAS}_{\mathrm{AA}} / \mathrm{dt}=\mathrm{QS} *\left(\mathrm{CA}_{\mathrm{AA}}-\mathrm{CS}_{\mathrm{AA}} / \mathrm{PS}_{\mathrm{AA}}\right) \\
& \mathrm{CS}_{\mathrm{AA}}=\mathrm{AS}_{\mathrm{AA}} / \mathrm{VS}
\end{aligned}
$$

\section{Richly perfused tissue}

$$
\begin{aligned}
& \mathrm{dAR}_{\mathrm{AA}} / \mathrm{dt}=\mathrm{QR} \mathrm{R}^{*}\left(\mathrm{CA}_{\mathrm{AA}}-\mathrm{CR}_{\mathrm{AA}} / \mathrm{PR}_{\mathrm{AA}}\right) \\
& \mathrm{CR}_{\mathrm{AA}}=\mathrm{AR}_{\mathrm{AA}} / \mathrm{VR}
\end{aligned}
$$


Chapter 4

\section{Fat compartment}

$\mathrm{dAF}_{\mathrm{AA}} / \mathrm{dt}=\mathrm{QF} *\left(\mathrm{CA}_{\mathrm{AA}}-\mathrm{CF}_{\mathrm{AA}} / \mathrm{PF}_{\mathrm{AA}}\right)$

$\mathrm{CF}_{\mathrm{AA}}=\mathrm{AF}_{\mathrm{AA}} / \mathrm{VF}$

\section{Arterial blood compartment}

$\mathrm{CA}_{\mathrm{AA}}=\mathrm{CV}_{\mathrm{AA}}$

\section{Venous blood compartment}

$d A V_{A A} / d t=\left(Q F^{*} C F_{A A} / P F_{A A}\right)+\left(Q^{*} C^{*} K_{A A} / P K_{A A}\right)+\left(Q^{*} C R_{A A} / P R_{A A}\right)+\left(Q^{*} C_{A A} / P S_{A A}\right)+(Q L+Q I)^{*} C L_{A A} / P_{A A}{ }^{-}$ $\mathrm{QC}^{*} \mathrm{CV}_{\mathrm{AA}}$

$\mathrm{CV}_{\mathrm{AA}}=\mathrm{AV}_{\mathrm{AA}} / \mathrm{VV}$ 

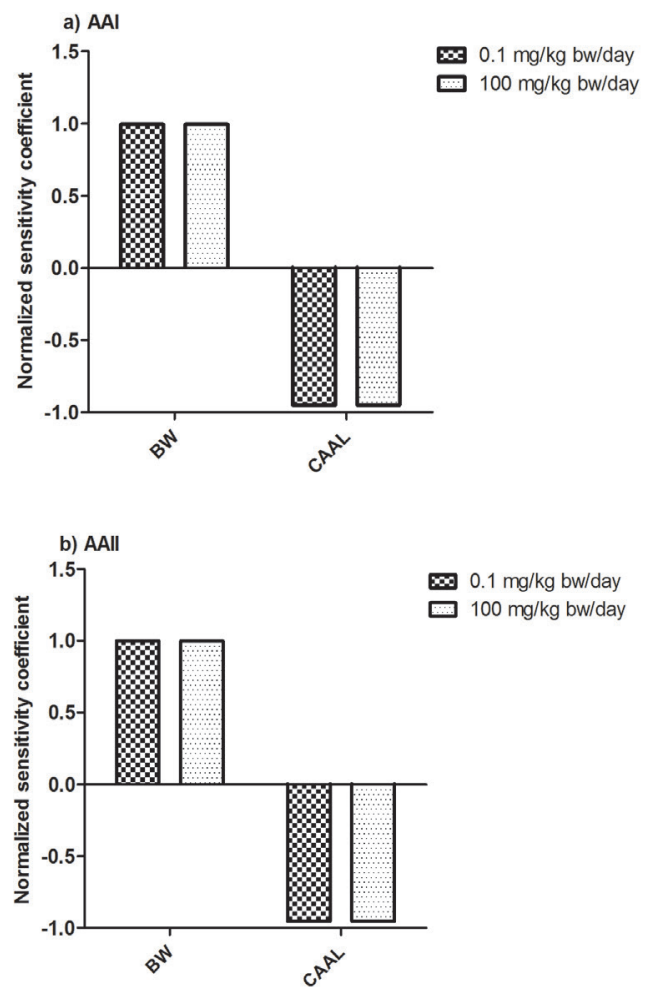

Supplementary data B. Normalized sensitivity coefficients for parameters of the PBK model for rat exposed to AAI (a) and AAll (b) on AUC values in the kidney blood from single oral dose of $0.1 \mathrm{mg} /$ $\mathrm{kg}$ bw and $100 \mathrm{mg} / \mathrm{kg}$ bw. Normalized sensitivity coefficients $\geq 0.1$ are presented. BW= bodyweight, $\mathrm{CAAL}=$ clearance of $\mathrm{AA}$ in liver. 



\section{CHAPTER}

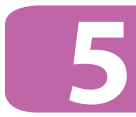

Risk assessment of plant food supplements and other herbal products containing aristolochicacids using the Margin of Exposure (MOE) approach

Rozaini Abdullah, Leolean Nyle Diaz,

Sebastiaan Wesseling, and Ivonne M.C.M. Rietjens

Based on: Food Additives and Contaminants: Part A (2017) 34(2): 135-144 


\section{ABSTRACT}

After the incidences with induction of Aristolochic Acid Nephropathy upon use of herbal weight loss preparations that accidentally contained aristolochic acids (AAs), several countries defined national restrictions on the presence of AAs in food, including plant food supplements (PFS) and herbal products. This study investigates whether the risks associated with exposure to AAs via PFS and herbal products are at present indeed negligible. Data reported in literature on AA levels in PFS and other herbal products and obtained from a new series of PFS in the present study were used to calculate the estimated daily intakes (EDIs) and corresponding margin of exposure (MOEs). Available literature data revealed that 206 out of 573 samples were found to contain aristolochic acid I (AAI) and/or aristolochic acid II (AAIl). The results obtained from recently collected PFS revealed that both AAI and AAll were detected in three out of 18 analysed PFS at levels up to 594.8 and $235.3 \mu \mathrm{g} / \mathrm{g}$, respectively, being in line with the levels reported in literature. The EDIs resulting from intake of these PFS resulted in MOEs that were generally below 10,000 corroborating the priority for risk management. Although these results refer to PFS collected by targeted sampling strategies, the data reveal that AA-containing PFS are still freely available. When considering that the use of these samples may be limited to shorter periods of time, the EDls might be lower, but MOE values would still be lower than 10,000 for more than $50 \%$ of the AA-containing PFS and herbal products. In conclusion, the presence of AAs in PFS and herbal products even several years after instalment of the legal restrictions still raises concern especially for people who frequently use the respective PFS and herbal products. 


\subsection{INTRODUCTION}

Plant food supplements (PFS) and other herbal products are widely distributed for their perceived health benefits. It is important to note that most of these traditional botanical products have never been the subject of thorough pre-marketing toxicological safety assessment as required for example for modern pharmaceuticals or food additives [1, 2]. Based on their traditional use for long periods of time, these botanical preparations are often assumed to be safe. However, this is not always the case. A recent inventory on the possible presence of botanical ingredients that may be a safety concern because they are genotoxic and carcinogenic revealed concerns over especially alkenylbenzenes, pyrrolizidine alkaloids and aristolochic acids (AAs) [3], the latter group being the topic of the present study. AAs have been proven to cause nephrotoxicity, genotoxicity and carcinogenicity and have been classified by the IARC in Group 1 meaning that there is sufficient evidence that they cause tumours in humans [4].

AAs are found in plants from the Aristolochiaceae family which are also known to be one of the oldest traditional remedy systems used worldwide [5]. AAs derived from Aristolochia species occur as a mixture of two structurally related nitrophenanthrene carboxylic acids, including aristolochic acid I (AAI) and aristolochic acid II (AAIl) (Figure 5.1) [4]. Aristolochia herbs have been used in obstetrics and for the treatment of snake bites [6], as a therapy for arthritis, gout, rheumatism and for festering wounds [7]. Aristolochia species are also commonly used in Chinese traditional medicines. The dry fruits of Aristolochia contorta Bge. and Aristolochia debilis Seib.et Zucc., named Madouling in the Chinese Pharmacopoeia, are used to treat respiratory diseases, while the herb parts known as Tianxianteng are used as an anti-rheumatic agent [8].

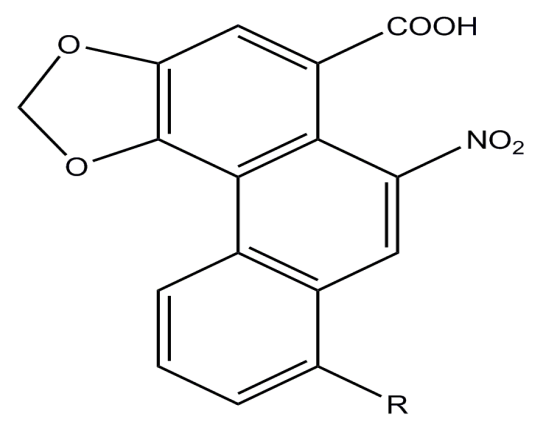

AAI : $\mathrm{R}=\mathrm{OCH}_{3}$

AAII : $\mathrm{R}=\mathrm{H}$

Fig. 5.1 Structural formula of aristolochic acids (AAs) 
Due to the anti-inflammatory properties of AAs, AA-containing preparations have been developed as pharmaceutical preparations in Germany [7] until studies proved that AAs were carcinogenic in rats [9]. Studies conducted over the years have associated AAs with Chinese Herb Nephropathy and Balkan Endemic Nephropathy, later known as Aristolochic Acid Nephropathy (AAN) [10]. In 1991, a unique form of nephropathy was reported in Belgium. Over 100 young women suffered from kidney damage leading to kidney transplantation [11], and with the lesions developing into renal and bladder cancer in several patients $[12,13]$. It was recognised that these adverse effects were the result of prolonged intake of a Chinese herb-based weight loss preparation which contained Aristolochia fangchi instead of Stephania tetranda because both plants are known under the same name, 'Fang Ji' in Chinese folk medicine [12].

After the occurrence of this dramatic episode, similar cases were reported in other European countries such as France, Spain, Germany, the UK, and also in the United States [14]. The responsible botanical preparations were marketed and sold in different forms: as dietary products in the form of pills or herbal infusions, for medicinal purposes such as reducing eczema, curing hepatitis B, arthritis and rheumatisms, and as pain relievers [14]. Subsequent to the Belgian incident, the European Agency for the Evaluation of Medicinal Products issued a position paper in October 2000 warning European Union Member States 'to take steps to ensure that the public is protected from exposure to aristolochic acids arising from the deliberate use of Aristolochia species or as a result of confusion with other botanical ingredients' [8]. Subsequently, most European Union Member States have restricted the use of Aristolochia species as well as of Stephania species in botanical products [8]. In the Netherlands, AAs became regulated as herbal preparations in the Commodities Act 'Herbal preparations'. Within this Act, the presence of AAs and their derivatives have been prohibited from being marketed since 2001 [15]. In 2001, the USFDA advised consumers to stop using products containing AAs [16]. The sale of AA-containing botanical products was also prohibited in several other countries such as Australia, Canada and New Zealand, and in many Asian countries (e.g., Japan) $[4,15,17]$. In spite of this, PFS and traditional medicines containing AAs appear to be still available in the markets $[15,18-21]$.

In the present study, the data on AA levels in PFS and other herbal products were collected from the literature and we provide an update on the presence and level of AAs in PFS purchased via online markets. The aim was to investigate whether after the Belgium incident and the subsequent regulatory awareness and measures taken, the risks associated with exposure to AAs via PFS and herbal products are indeed negligible. Based on the AA levels thus obtained estimated daily intakes Page | 156 
(EDIs) were established enabling risk assessment by the MOE approach to evaluate the risk from exposure to AAs from PFS purchased online from all over the world. Including the levels of AAs in PFS and other herbal products reported since 1990 was of interest given that the respective papers did not perform a risk assessment.

\subsection{MATERIALS AND METHODS}

\subsubsection{Literature search for food samples containing AAs}

Data from literature studies included in the present study were selected based on the following criteria: (1) the study reported on products that were collected from the early 1990s until 2016 and included analyses of AAs in herbal products, Chinese medicinal products or food supplements for oral use; and (2) the tested products represented commercially available products obtained from the local market, products ordered online or supplements taken by patients with AAN. Based on the collected data, the average percentage of samples that tested positive for the presence of AAI and/ or AAll was calculated for each study over the years.

\subsubsection{Collection of samples for analysis}

A total of 18 PFS from different brands were purchased from different online sources. A targeted sampling approach was applied collecting samples containing botanicals of concern. Product information and the respective botanical ingredients of concern as indicated on the label of each product are summarised in Table 5.1.

\subsubsection{Chemicals}

AAI and AAll were purchased from Sigma-Aldrich (Zwijndrecht, The Netherlands). Dimethyl sulfoxide (DMSO) (>99.9\%) was obtained from Acros Organics (Geel, Belgium). Methanol and acetonitrile (ULC/MS grade) were obtained from Biosolve (Valkenswaard, The Netherlands). Trifluoroacetic acid (TFA) (>99.8\%) was purchased from Merck (Darmstadt, Germany).

\subsubsection{Methanol extraction}

To quantify the AA content in the PFS samples, methanol extracts were prepared by adding $1 \mathrm{~g}$ of sample to $10 \mathrm{ml}$ of methanol followed by sonication for $20 \mathrm{~min}$ at RT. The methanol extracts were 
centrifuged for $5 \mathrm{~min}$ at 50,000 rpm and the supernatants were collected for ultra-performance liquid chromatography (UPLC) analysis of AA levels. The extraction efficiency was evaluated by spiking $1 \mathrm{~g}$ of samples S2 and S9 (Table 1) with different concentrations of AAI and AAll before starting the whole extraction procedure as described above. The average percentage of recovery was used to correct the levels of AAI and AAll in the PFS.

\subsubsection{UPLC analysis}

To quantify the presence of AAs, $3.5 \mu$ of undiluted samples were analysed by UPLC (Waters Acquity) equipped with a Waters BEH C18 $1.7 \mu \mathrm{m}$ column, 2.1 x $50 \mathrm{~mm}$ (Waters Ireland) as described previously [22] with minor modifications. In short, a gradient was made with ultra-pure water containing $0.1 \%(\mathrm{v} / \mathrm{v})$ TFA as solvent $A$ and acetonitrile as solvent $B$. The flow rate was set to $0.6 \mathrm{ml} /$ min. The starting condition was 80:20 (A:B), changing to $75: 25$ from 1 to $3 \mathrm{~min}$, then to 20:80 from 3 to $5 \mathrm{~min}$, and keeping the gradient at this condition for $1 \mathrm{~min}$. Then the gradient was modified to 0:100 from 6 to $7.3 \mathrm{~min}$ and retained for another $0.2 \mathrm{~min}$ after which the starting condition was reset from 7.5 to $8 \mathrm{~min}$ and kept at that level for another $1 \mathrm{~min}$ to equilibrate the column. Detection was carried out with a photodiode array detector (Waters, Milford, MA, USA) and chromatograms were analysed at $240 \mathrm{~nm}$.

\subsubsection{Estimated daily intakes (EDIs) of AAs resulting from the use of PFS and herbal products}

The exposure estimation of AAs from current PFS was based on the recommended daily intake of the PFS as indicated by the suppliers (Table 1). EDIs were estimated using a body weight of 70 $\mathrm{kg}$, the default value for adult body weight as proposed by EFSA [23]. Since the PFS samples that tested positive appeared to contain both AAI and AAll, a combined exposure assessment and risk assessment was performed. Based on the similarity in the mode of action and target organ toxicity for both AAs, the combined exposure by dose addition was calculated based on the direct addition for AAI and AAll by assuming an equal potency for both AAs. For PFS and other herbal products for which AA levels were reported in the literature, EDIs were calculated using the same approach assuming consumption of $0.25 \mathrm{~g}$ of AA-containing products, three times a day [12] and $70 \mathrm{~kg}$ bw. 


\subsubsection{Calculation of Margin of Exposure (MOE) values}

Considering the fact that AAs are genotoxic and carcinogenic, a harmonised approach called the margin of exposure (MOE) is recommended to judge if risk management actions are required [24]. The MOE is a dimensionless ratio between the $\mathrm{BMDL}_{10}$ (lower confidence bound of the benchmark dose giving $10 \%$ extra cancer incidence) and the EDI. The $\mathrm{BMDL}_{10}$ values were calculated from data on the induction of kidney tumours by AAs in rats [9] using all models for dichotomous data using the Environmental Protection Agency's (EPA) Benchmark Dose Software (BMDS) version 2.5. The doses and the duration of treatment were adjusted to the standard lifespan (104 weeks), as discussed by Paini et al. (2011) [25]. Only models that met the requirements for acceptance of the model fit were considered for the determination of $\mathrm{BMDL}_{10}$ values. The MOE-based risk assessment was performed for the PFS and herbal products containing AAs in the newly collected samples and the samples for which data were found in literature. 
Product description of the PFS analysed in the present study.

\begin{tabular}{|c|c|c|c|c|c|}
\hline Sample No & Product name & Product presentation & Dosage & Suspected botanical ingredient & $\begin{array}{l}\text { Country of } \\
\text { origin }\end{array}$ \\
\hline S1 & Slimonil men & Capsule & 1-2 capsules, 2 times per day & Aristolochia indica & India \\
\hline S2 & Marul Lupului-Antiinflamator & Plant leaf & 1 teaspoon per day & Aristolochia clematitis & Romania \\
\hline S3 & Zhu Po Hou Zao San & Globule & $0.45-0.6 \mathrm{~g}, 2-3$ times per day & Asarum heterotropoides & China \\
\hline S4 & Aristolochia clematitis C100 & Globule & 5-30 globules per day & Aristolochia clematitis & Germany \\
\hline S5 & Ba Zheng San & Capsule & $3-6$ capsules, 3 times per day & Aristolochia (Guan Mu Tong) & China \\
\hline S6 & Long Dan Xie Gan Wan & Globule & $0.5-1$ pack, 2 times per day & Aristolochia manshuriens & China \\
\hline S7 & Jingzhi Kesou Tanchuan Wan & Capsule & 1 capsule, 2 times per day & Aristolochia; xinxin & China \\
\hline S8 & Slimonil Women & Capsule & 1-2 capsules, 2 times per day & Aristolocia indica & India \\
\hline S9 & Lotiune Marul Lupului & Tincture & 1 teaspoon, 3 times per day & Aristolochia clematitis & Romania \\
\hline S10 & Fang Ji Huang Qi Tang & Capsule & $3-6$ capsules, 3 times per day & Stephania root (Han Fangji) & USA \\
\hline S11 & Varanadi Kwatham & Tablet & 3 tablets, 2 times per day & Aristolochia bracteolate & India \\
\hline S12 & Yangxue Qingnao Keli & Globule & 1 pack, 3 times per day & Xi Xin & China \\
\hline S13 & DaHuang & Plant stem & No information provided & Da Huang & China \\
\hline S14 & Zhengtian Wan & Globule & 1 pack, 2-3 times per day & Xi Xin & China \\
\hline S15 & Fangxieye & Plant leaf & 3-6 g per day & Folium Sennae & China \\
\hline S16 & Tong Cao & Plant stem & No information provided & Aristolochia; Xi Xin & China \\
\hline S17 & Akabea Moist Heat & Tablet & 3 tablets, 3-4 times per day & Akabea trifoliate caulis (Mu Tong) & USA \\
\hline S18 & Aristolochia clematitis D12 & Tablet & 1 tablet per day & Aristolochia clematitis & Germany \\
\hline
\end{tabular}




\subsection{RESULTS}

\subsubsection{Literature search for PFS and other herbal products containing}

\section{AAs}

Figure 5.2 presents an overview of published data on levels of AAs in botanical samples collected from 1990 to 2016 [13, 15, 20, 21, 26-39]. In total, 206 out of 573 (36.0\%) samples were positive for the presence of AAl, AAll or both AAs (supplementary data A). From 573 samples, 55 samples were purchased via online markets [20,21], of which 12 samples (22\%) tested positive for the presence of AAI and/or AAll. The other samples were purchased from local markets in different countries, including Belgium [13, 26], China and/or Japan, Korea and Taiwan [27, 28, 30-34, 36, 38], Australia [29], Hong Kong [35, 39], the Netherlands [15], and Switzerland [37]. Figure 5.2 presents an analysis of these data plotting the number (Figure 5.2a) and percentage (Figure 5.2b) of AA-containing samples against their time of collection. The results obtained show that there is no specific trend or a reduction in the percentage of positive samples over the years.

\subsubsection{Chemical analysis of AAs in recently collected PFS}

Figure 5.3 presents part of a UPLC chromatogram of a methanol extract from a PFS revealing the presence of both AAs, with AAI eluting at $4.3 \mathrm{~min}$ and AAll at $4.2 \mathrm{~min}$. The accuracy of the method was evaluated by calculating the recovery of AAs from spiked samples. The average recovery was 92\% for both AAI and AAll, and this was used to calculate the levels of AAI and AAll in the PFS samples using the calibration curves defined using commercially available reference compounds. Of the 18 PFS analysed, three samples (16.7\%) tested positive and contained both AAI and AAll at levels that ranged from 2.1 to 594.8 and from 0.6 to $235.3 \mu \mathrm{g} / \mathrm{g}$ respectively (Table 5.2). For all these PFS, the level of AAI was 2.5-3.5-fold higher than AAll supporting the fact that AAI is a major component in Aristolochia species [40, 41]. Among the three positive samples, S2 (plant leaf) had the highest AA levels followed by S9 (tincture) and S4 (globule). All samples that tested positive for AAs contain an ingredient called Aristolochia clematitis that is commonly known as Birthwort. 


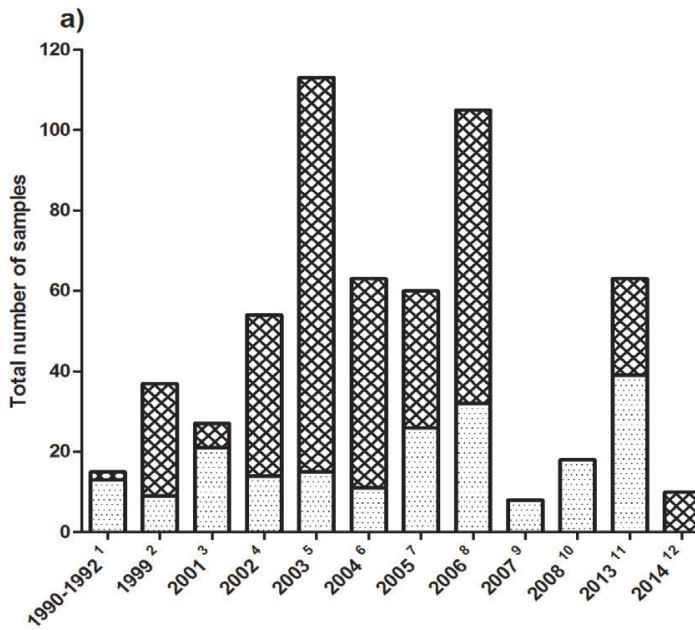

b)
Negative samples

Positive samples

${ }^{1}$ Bieler et al. 1997, Vanhaelen et al. 1994

2 Hashimoto et al. 1999

${ }^{3}$ Lee et al. 2002

${ }^{4}$ Wei et al. 2005, Martena et al. 2007

${ }^{5}$ Cheung et al. 2006, loset et al. 2003, Martena et. al 2007

${ }^{6}$ Schaneberg et al. 2004, Martena et al. 2007

${ }^{7}$ Huang et al. 2005, Koh er al. 2006, Martena et al. 2007

${ }^{8} \mathrm{Hsieh}$ et al. 2006, Zhou et al. 2006, Martena et al. 2007

${ }^{9}$ Kuo et al. 2010

${ }^{10}$ Zhao et al. 2008

${ }^{11}$ Xu et al. 2013, Vaclavik et al. 2014

${ }^{12}$ Wang and Chan 2014

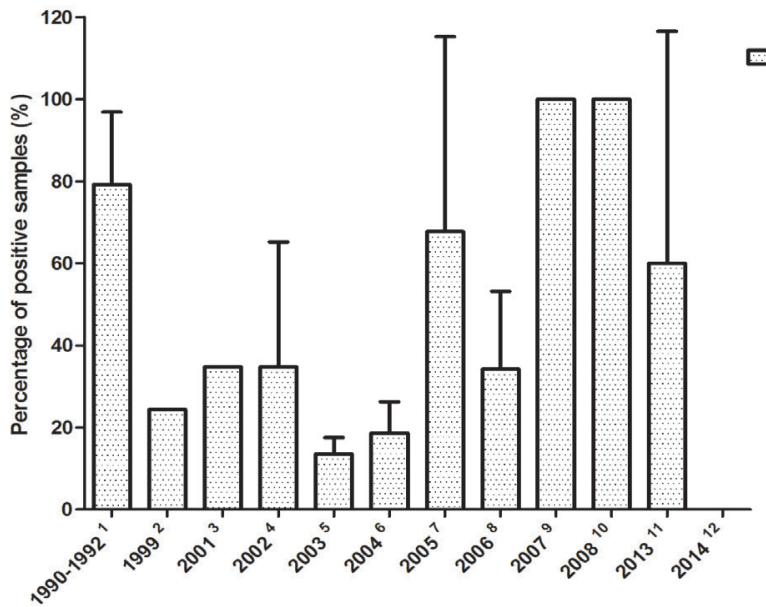

Fig. 5.2 Total number of plant food supplements and other herbal products containing AAs (a) and percentage of positive samples (mean values \pm SD) (b) over the years. The details of each study are presented in supplementary data A. 


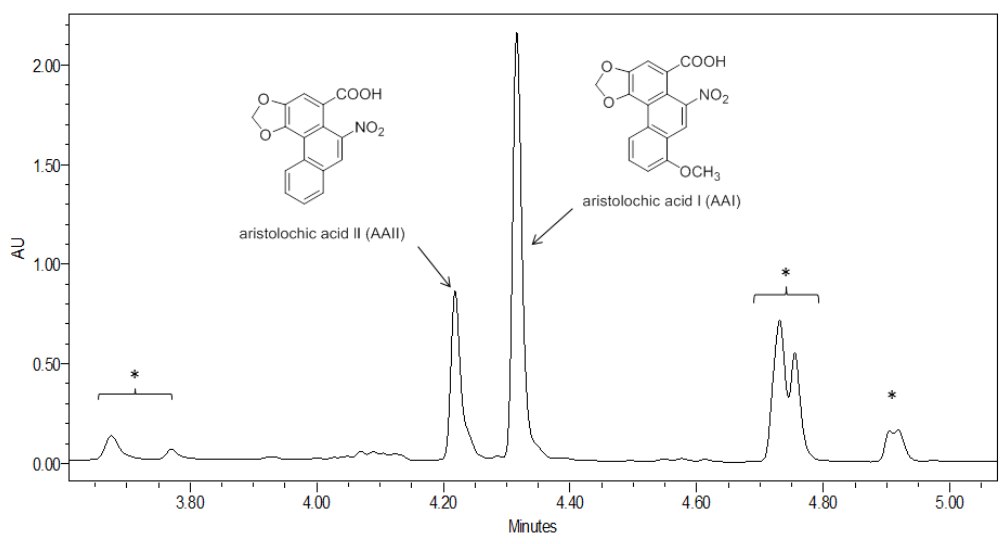

Fig. 5.3 UPLC chromatogram of the methanol extract of sample S2 (declared to contain Aristolochia clematitis). Peaks marked with an asterisk $\left.{ }^{*}\right)$ were not identified. The chromatogram was obtained at a wavelength of $240 \mathrm{~nm}$.

\section{Table 5.2}

Levels of aristolochic acid I (AAI) and aristolochic acid II (AAIl) in positive samples of PFS ( $n=3$ independent analyses).

\begin{tabular}{lll}
\hline Sample No. & \multicolumn{2}{c}{ Aristolochic acids $(\mu \mathrm{g} / \mathrm{g})$} \\
\cline { 2 - 3 } & AAI & AAll \\
\hline S2 & $594.8 \pm 126.7$ & $235.3 \pm 57.0$ \\
S4 & $2.1 \pm 0.4$ & $0.6 \pm 0.0$ \\
S9 & $14.4 \pm 0.8$ & $5.7 \pm 0.2$ \\
\hline
\end{tabular}

\subsubsection{EDI for combined exposure to AAs resulting from the consumption of PFS and herbal products}

A combined exposure to AAI and AAll was calculated based on adding the levels of both AAI and AAll as such. The EDIs of AAs resulting from consumption of PFS for a 70-kg person based on the recommended daily intake as indicated on the label of the respective supplement (Table 5.1) are presented in Table 5.3. The EDls amounted to $1.7 \times 10^{-3}-30 \mu \mathrm{g} / \mathrm{kg}$ bw/day.

From the 206 positive AA-containing PFS and other herbal products reported in 
the literature, for only 159 samples were the actual levels of AAs available for further analysis and calculation of an EDI. For these 159 samples, EDIs were calculated and presented in the supplementary data A.

\section{Table 5.3}

Estimated daily intakes (EDIs) of AAs.

\begin{tabular}{lll}
\hline Sample No. & $\begin{array}{l}\text { Recommended daily intake }(\mathrm{g}) \\
\text { of the PFS }\end{array}$ & $\mathrm{EDI}\left(\mu \mathrm{g} / \mathrm{kg} \mathrm{bw} /\right.$ day) ${ }^{\mathrm{a}}$ \\
\hline S2 & 2.5 & 30 \\
S4 & $0.04-0.25$ & $1.7-11 \times 10-3$ \\
S9 & 4.5 & 1.3 \\
\hline
\end{tabular}

${ }^{a} \mathrm{EDI}$ of $\mathrm{AAI}+\mathrm{EDI}$ of AAll

\subsubsection{Risk assessment of exposure to AAs from consumption of PFS and herbal products using the MOE approach}

In a next step the MOEs were calculated based on the EDIs and the lowest $\mathrm{BMDL}_{10}$ of $10 \mu \mathrm{gAAs} / \mathrm{kg}$ bw/day (Table 5.4) estimated from data reported for kidney tumour formation by a mixture of AAs (71\% of AAI and $21 \%$ of AAll) upon oral exposure [9] in rats. The MOE values thus obtained for S2, S4 and S9, presented in Table 5.5, were below 10,000, indicating a priority for risk management [24].

In addition, MOE values were also calculated for the collected literature data presented in supplementary data $A[13,15,19-21,26,27,29-35,39]$. Figure 5.4 shows the calculated MOEs based on the three samples analysed in the present study and the 159 samples reported in the literature for which actual levels of AAs were available enabling calculation of the respective EDIs. For $95.7 \%$ of these samples, the EDIs resulted in an MOE lower than 10,000, indicating a priority for risk management. It is interesting to note that of this $95.7 \%$, about $64.2 \%$ of these PFS result in EDIs that indicate an MOE value lower than 10, indicating that the dose to which humans will be exposed when using these PFS will be in the range of the dose levels that caused kidney tumour formation in rats.

Considering that the exposure to AAs will not be lifelong but may be limited to shorter time intervals, and applying Haber's rule [42] to calculate the risk for shorter-than-lifetime exposure, EDIs may be two to three orders of magnitude lower than assuming lifetime exposure. Since the labels of the respective products do not indicate a specific time period for use of the PFS, but rather Page | 164 
indicate taking the preparation as recommended by a physician, i.e., until the disease is cured, it was assumed that 2 weeks would be a realistic minimum estimate for the period of use for the PFS. Assuming 2 weeks' exposure, the MOE values would be 75 years $x 52$ weeks per year divided by 2 weeks $=1950$ times lower. Taking this shorter exposure period into account, about $51.8 \%$ of the positive samples would still give rise to MOE values lower than 10,000 (Figure 5.4). 
Results from a BMD analysis of the data for kidney tumour formation in rats [9] exposed to AAs using BMDS software version 2.5, a BMD of $10 \%$ and default settings based on assumption of equal potency of AAs.

\begin{tabular}{|c|c|c|c|c|c|c|c|}
\hline Model & Restriction & $\begin{array}{l}\text { No of } \\
\text { parameters }\end{array}$ & Log Likelihood & $p$-value & Accepted $^{a}$ & $\begin{array}{l}\mathrm{BMD}_{10}(\mu \mathrm{g} / \mathrm{kg} \\
\text { body wt/day })\end{array}$ & $\begin{array}{l}\mathrm{BMDL}_{10}(\mu \mathrm{g} / \mathrm{kg} \\
\text { body wt/day })\end{array}$ \\
\hline Reduced & & 1 & -22.2921 & - & - & - & - \\
\hline Full & & 4 & -15.5048 & - & - & - & - \\
\hline Gamma & none & 4 & -15.6056 & 0.9042 & No & 60 & 3 \\
\hline Logistic & n.a. ${ }^{b}$ & 2 & -16.3038 & 0.5144 & Yes & 150 & 100 \\
\hline LogLogistic & none & 2 & -15.5861 & 0.9528 & No & 50 & 4 \\
\hline LogProbit & none & 2 & -15.5422 & 0.9781 & No & 50 & 5 \\
\hline Multistage & none & 2 & -15.6008 & 0.9499 & Yes & 50 & 10 \\
\hline Probit & n.a. ${ }^{b}$ & 2 & -16.2417 & 0.9888 & Yes & 130 & 90 \\
\hline Weibull & none & 2 & -15.6055 & 0.5387 & No & 50 & 3 \\
\hline Quantal-Linear & n.a. ${ }^{b}$ & 1 & -15.6056 & 0.9409 & Yes & 50 & 30 \\
\hline
\end{tabular}

${ }^{a}$ Criteria for acceptance included $\mathrm{p}$-value $>0.05$ and the ratio between $\mathrm{BMD}_{10}$ and $\mathrm{BMDL}_{10}<10$

${ }^{\mathrm{b}}$ not applicable 
Table 5.5

MOE values of AAs resulting from the consumption of PFS.

\begin{tabular}{ll}
\hline Sample No. & MOE \\
\hline S2 & 0.3 \\
S4 & $900-5800$ \\
S9 & 8 \\
\hline
\end{tabular}

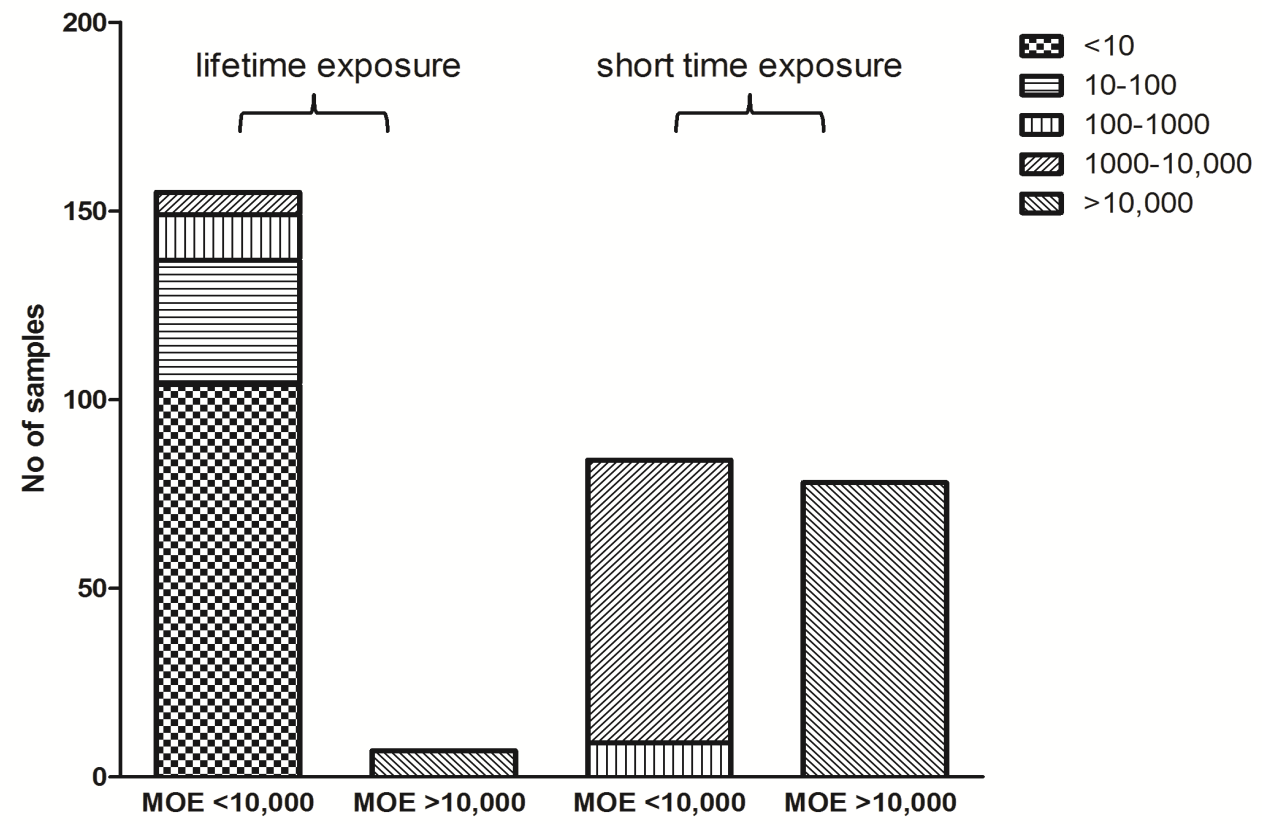

Fig. 5.4 Number of samples with respective MOE values assuming a lifetime or 2 weeks of exposure to AAs based on samples analysed in the present study and reported in the literature. The MOE was calculated by dividing the lowest $\mathrm{BMDL}_{10}$ of $\mathrm{AAs}$ of $10 \mu \mathrm{g} / \mathrm{kg}$ bw/day for kidney tumour formation by the EDI of AAs from the PFS and other herbal products. 
Chapter 5

Table 5.6

DNA adduct formation in the kidney of rats exposed to either AAI, AAll or a mixture of AAs obtained from the literature.

\begin{tabular}{|c|c|c|c|c|}
\hline AA & $\begin{array}{l}\text { Dose }(\mathrm{mg} / \mathrm{kg} \mathrm{bw} / \\
\text { day) }\end{array}$ & $\begin{array}{l}\text { Total no of } \\
\text { adducts/108 nts }{ }^{\text {b }}\end{array}$ & $\begin{array}{l}\text { Slope of the } \\
\text { curve for DNA } \\
\text { adduct formation } \\
\text { versus dose }^{c}\end{array}$ & Reference \\
\hline AAI & $0,2.5,15^{\mathrm{a}}$ & $0,0.09,0.4$ & 0.03 & Chan et al. (2008) [43] \\
\hline AAll & & $0,0.16,0.62$ & 0.04 & \\
\hline AAl & $0,0.04,0.4,4^{a}$ & $0,44.8,320,2588$ & 641.3 & Mei et al. (2006) [44] \\
\hline AAll & $0,0.056,0.56,5.6^{a}$ & 0, 49.1, 348.6, 2010 & 348.7 & \\
\hline AAl & 0,5 & 0,984 & 196.8 & Dong et al. (2006) [45] \\
\hline AAll & & 0,4180 & 836.0 & \\
\hline AAI & 0,10 & 0,42 & 4.2 & Pfau et al. (1990) [46] \\
\hline AAll & & 0,80 & 8.0 & \\
\hline
\end{tabular}

a adjusted dose $=$ dose $\mathrm{x}$ percentage of AAI or AAll

${ }^{\mathrm{b}}$ Total number of adducts presented was based on the total number of deoxyadenosine and deoxyguanosine adducts formed upon exposure to AAI or AAll

'Slope was calculated using the reported DNA adduct level at each tested dose level and assuming zero adduct formation at zero dose. 


\subsection{DISCUSSION}

In the present study, a risk assessment for AAs resulting from the intake of PFS and herbal products was performed using the MOE approach. An overview of the level of AAs present in PFS and other herbal products from 1990 to 2016 showed that 206 out of 573 (36.0\%) samples collected and analysed contained AAs. In order to determine the current exposure to AAs from the intake of PFS, 18 samples were purchased online and three of these 18 (16.7\%) samples were shown to contain AAI at levels up to $594.8 \mu \mathrm{g} / \mathrm{g}$ and AAll at levels up to $235.3 \mu \mathrm{g} / \mathrm{g}$. It is interesting to note that although Aristolochia sp. have been banned from being present in food including food supplements, AAs can still be found in some of the PFS. This conclusion is in line with what was found for other PFS samples and analysed after instalment of the ban in the Netherlands, the UK, the United States, Canada and Australia in 2001 [4, 15, 16], and in Taiwan in 2003 [47].

The results clearly confirmed that PFS containing AAs are still available on the market and easily accessible to the public despite the ban. The amount of AAs detected in the positive samples was comparable and within the range of what was reported based on an analysis of samples on the Dutch market 9 years ago [15] and also for samples collected in other countries including China, Australia, Japan, Korea, Taiwan and the United States [18-21, 27, 29]. The levels detected were also comparable with the levels of AAs found in the weight-loss regimen given to Belgian patients who developed AAN resulting in EDls of $7-31 \mu \mathrm{g} / \mathrm{kg}$ bw/day $[13,26]$. When analysing the number of positive samples over the years, there was no specific trend showing a reduction in the percentage of positive samples found to contain AAs. In fact, for the current PFS that were obtained via the online market, the percentage of positive samples (16.7\%) was in the same order of magnitude as the positive percentage found for the samples purchased online in 2004 (24.0\%) [20] and in $2013(20.0 \%)$ [21]. It is of interest to note that AA-containing supplements could be accessible via the internet in countries that have regulations when ordered from countries that did not take any measures. The two positive products ( 2 2, plant leaf and S9, tincture) were from Romania while the globule (S4) was from Germany where measures have been taken. All these three positive samples were prepared from Aristolochia Clematitis, a common plant in the wheat plantation in the Balkan region identified as the causative agent of Balkan Endemic Nephropathy [10]. EFSA has included this plant in the compendium of botanicals reported to contain toxic substances of concern [48] and all species of Aristolochia are prohibited to be present in food and PFS for sale in the Netherlands, the UK, the United States, Canada and Australia $[4,15,16]$. 
In the current study, the calculation of MOEs for kidney tumour formation was based on the $\mathrm{BMDL}_{10}$ derived from rat data [9]. This rat study tested a mixture of $\mathrm{AAs}$ ( $71 \%$ of $\mathrm{AAl}$ and $21 \%$ of AAll) upon oral exposure. However, the composition of AAs in PFS and herbal products varies and can be different. The results of the present study showed levels of AAI that were 2.5-3.5-fold higher than AAll, in line with the mixture tested in the rodent bioassay. The composition could be different depending on the species [34] and part of the plant used [39]. In the present study combined exposure was applied to estimate the EDI of AAs by simple dose addition. In theory, one could consider taking into account that the potency of AAI and AAll for DNA adduct formation and cancer induction may be different [43-46] and use a so-called toxic equivalency (TEQ) approach for the risk assessment. This TEQ approach would require the definition of toxic equivalency factors (TEFs). Table 5.6 shows an overview of the currently available data on relative potencies of AAI and AAll for relevant endpoints that could be of use in defining such TEFs. From this overview it can be concluded that data available for the definition of the TEFs are limited but seem to indicate that the difference in the relative potency of AAI and AAll would be small. This implies that when a combined AA exposure would be corrected using the TEQ approach, the overall MOE would be comparable when using the simple dose addition or a TEQ approach. Calculation of the MOEs for a lifetime exposure to AAs via PFS included in the present study resulted in MOEs that were below the default of 10,000 for $95.7 \%$ of all AA-containing samples. The default of 10,000 includes a factor 100 for interspecies differences and human variability in biokinetics and biodynamics, a factor of 10 for inter-individual uncertainties in cell cycle control and DNA repair, and another factor of 10 for the uncertainties arising from the fact that using the $\mathrm{BMDL}_{10}$ is not equivalent to no observed adverse effect level (NOAEL) and the effects can occur at a lower dose [24, 49]. For $64.2 \%$ of the samples MOEs were even below 10 indicating the dose to which humans will be exposed when using these PFS and herbal products will be in the range of the dose levels inducing kidney tumour formation in rats. The results obtained confirm the priority for risk management of AA-containing PFS. When considering that the MOE was calculated based on lifetime exposure while the use of these PFS may be limited to shorter periods of time, the EDIs might be two to three orders of magnitude lower, e.g., 1950 times lower upon 2 weeks of exposure. However, even in this situation MOEs would still be lower than 10,000 for more than $50 \%$ of the AA-containing PFS and other herbal products.

In conclusion, although the use of botanicals and botanical ingredients containing or suspected to contain plant species of the genus Aristolochia are no longer permitted in the market in many countries in the world, consumers are not yet fully protected from exposure to AA-containing Page $\mid 170$ 
PFS and other herbal products. Taken together, the present study indicates that exposure to AAs via PFS and other herbal products in the human populations even after several years of instalment of the legal restrictions is still of concern and a priority for further risk management, especially for people who frequently use the respective food supplements and herbal products.

\section{ACKNOWLEDGEMENTS}

This research was supported by the Ministry of Education of Malaysia (Project number- KPT (BS) 860828565598). 


\section{References}

1. Speijers, G., B. Bottex, B. Dusemund, A. Lugasi, J. Tóth, J. Amberg-Müller, C.L. Galli, V. Silano, and I.M.C.M Rietjens, Safety assessment of botanicals and botanical preparations used as ingredients in food supplements: Testing an European Food Safety Authority-tiered approach. Molecular Nutrition \& Food Research, 2010. 54(2): p. 175-185.

2. Schilter, B., C. Andersson, R. Anton, A. Constable, J. Kleiner, J. O'Brien, A. Renwick, O. Korver, F. Smit, and R. Walker, Guidance for the safety assessment of botanicals and botanical preparations for use in food and food supplements. Food and Chemical Toxicology, 2003. 41(12): p. 1625-1649.

3. Van Den Berg, S.J., P. Restani, M.G. Boersma, L. Delmulle, and I.M. Rietjens, Levels of genotoxic and carcinogenic compounds in plant food supplements and associated risk assessment. Food and Nutrition Sciences, 2011. 2(9): p. 989.

4. IARC, IARC Monographs on the Evaluation of Carcinogenic Risks to Humans. 2002, World Health Organization. p. 68-128.

5. Zhang, H., M. Cifone, H. Murli, G. Erexson, M. Mecchi, and T. Lawlor, Application of simplified in vitro screening tests to detect genotoxicity of aristolochic acid. Food and Chemical Toxicology, 2004. 42(12): p. 2021-2028.

6. Arlt, V.M., M. Stiborova, and H.H. Schmeiser, Aristolochic acid as a probable human cancer hazard in herbal remedies: a review. Mutagenesis, 2002. 17(4): p. 265-277.

7. Stiborová, M., E. Frei, V.M. Arlt, and H.H. Schmeiser, Metabolic activation of carcinogenic aristolochic acid, a risk factor for Balkan endemic nephropathy. Mutation Research, 2008. 658(1): $\mathrm{p}$. 55-67.

8. EMEA, The European agency for the evaluation of medicinal products, position paper on the risks associated with the use of herbal products containing Aristolochia species. 2000. p. 1-10.

9. Mengs, U., W. Lang, and J.-A. Poch, The carcinogenic action of aristolochic acid in rats. Archives of Toxicology, 1982. 51(2): p. 107-119.

10. Grollman, A.P., J. Scarborough, and B. Jelakovic, Aristolochic acid nephropathy: an environmental and iatrogenic disease. Advances in Molecular Toxicology, 2009. 3: p. 211-227.

11. Stiborová, M., E. Frei, V.M. Arlt, and H.H. Schmeiser, The role of biotransformation enzymes in the development of renal injury and urothelial cancer caused by aristolochic acid: urgent questions and difficult answers. Biomedical Papers of the Medical Faculty of the University Palacky Olomouc Czech Republic, 2009. 153(1): p. 5-11.

12. Vanherweghem, J.-L., C. Tielemans, D. Abramowicz, M. Depierreux, R. Vanhaelen-Fastre, M. Vanhaelen, M. Dratwa, C. Richard, D. Vandervelde, and D. Verbeelen, Rapidly progressive interstitial renal fibrosis in young women: association with slimming regimen including Chinese herbs. The lancet, 1993. 341(8842): p. 387-391.

13. Vanhaelen, M., R. Vanhaelen-Fastre, P. But, and J.-L. Vanherweghem, Identification of aristolochic acid in Chinese herbs. The lancet, 1994. 343(8890): p. 174.

14. Debelle, F.D., J.-L. Vanherweghem, and J.L. Nortier, Aristolochic acid nephropathy: a worldwide problem. Kidney international, 2008. 74(2): p. 158-169.

15. Martena, M.J., J.C. van der Wielen, L.F. van de Laak, E.J. Konings, H.N. de Groot, and I.M.C.M. Rietjens, Enforcement of the ban on aristolochic acids in Chinese traditional herbal preparations on the Dutch market. Analytical and bioanalytical chemistry, 2007. 389(1): p. 263-275.

16. FDA, Aristolochic Acid: FDA Warns Consumers to Discontinue Use of Botanical Products that Contain Aristolochic Acid. April 11, 2001.

17. Medsafe, Herbal, traditional and complementary medicines. New Zealand Medicines and Medical Devices Safety Authority. 2003.

18. Chan, W., K.C. Lee, N. Liu, and Z. Cai, A sensitivity enhanced high-performance liquid chromatography fluorescence method for the detection of nephrotoxic and carcinogenic aristolochic acid in herbal medicines. Journal of Chromatography A, 2007. 1164(1): p. 113-119.

19. Lee, T.-Y., M.-L. Wu, J.-F. Deng, and D.-F. Hwang, High-performance liquid chromatographic determination for aristolochic acid in medicinal plants and slimming products. Journal of Chromatography B, 2001. 766(1): p. 169-174. 
20. Schaneberg, B. and I. Khan, Analysis of products suspected of containing Aristolochia or Asarum species. Journal of Ethnopharmacology, 2004. 94(2): p. 245-249.

21. Vaclavik, L., A.J. Krynitsky, and J.I. Rader, Quantification of aristolochic acids I and II in herbal dietary supplements by ultra-high-performance liquid chromatography-multistage fragmentation mass spectrometry. Food Additives \& Contaminants: Part A, 2014. 31(5): p. 784-791.

22. Abdullah, R., W. Alhusainy, J. Woutersen, I.M.C.M. Rietjens, and A. Punt, Predicting points of departure for risk assessment based on in vitro cytotoxicity data and physiologically based kinetic (PBK) modeling: the case of kidney toxicity induced by aristolochic acid I. Food and Chemical Toxicology, 2016. 92: p. 104-116.

23. EFSA, Guidance on selected default values to be used by the EFSA Scientific Committee, Scientific Panels and Units in the absence of actual measured data. EFSA Journal, 2012. 10(3): p. 2579.

24. EFSA, European Food Safety Authority. Opinion of the scientific committee on a request from EFSA related to a harmonised approach for risk assessment of substances which are both genotoxic and carcinogenic. EFSA Journal, 2005. 282: p. 1-31.

25. Paini, A., G. Scholz, M. Marin-Kuan, B. Schilter, J. O'Brien, P.J. van Bladeren, and I.M.C.M. Rietjens, Quantitative comparison between in vivo DNA adduct formation from exposure to selected DNA-reactive carcinogens, natural background levels of DNA adduct formation and tumour incidence in rodent bioassays. Mutagenesis, 2011. 26(5): p. 605-618.

26. Bieler, C.A., M. Stiborova, M. Wiessler, J.-P. Cosyns, C.v.Y. de Strihou, and H.H. Schmeiser, ${ }^{32}$ P-post-labelling analysis of DNA adducts formed by aristolochic acid in tissues from patients with Chinese herbs nephropathy. Carcinogenesis, 1997. 18(5): p. 1063-1067.

27. Hashimoto, K., M. Higuchi, B. Makino, I. Sakakibara, M. Kubo, Y. Komatsu, M. Maruno, and M. Okada, Quantitative analysis of aristolochic acids, toxic compounds, contained in some medicinal plants. Journal of Ethnopharmacology, 1999. 64(2): p. 185-189.

28. Lee, T.-Y., M.-L. Wu, J.-F. Deng, and D.-F. Hwang, High-performance liquid chromatographic determination for aristolochic acid in medicinal plants and slimming products. Journal of Chromatography B, 2002. 766(1): p. 169-174.

29. Cheung, T.P., C. Xue, K. Leung, K. Chan, and C.G. Li, Aristolochic acids detected in some raw Chinese medicinal herbs and manufactured herbal products-a consequence of inappropriate nomenclature and imprecise labelling? Clinical Toxicology, 2006. 44(4): p. 371-378.

30. Huang, C.-Y., M.-C. Tseng, and J.-H. Lin, Analyzing aristolochic acids in Chinese herbal preparations using LC/MS/MS. Journal of Food and Drug Analysis, 2005. 13(2): p. 125-131.

31. Hsieh, S.-C., M.-F. Huang, B.-S. Lin, and H.-T. Chang, Determination of aristolochic acid in Chinese herbal medicine by capillary electrophoresis with laser-induced fluorescence detection. Journal of Chromatography A, 2006. 1105(1): p. 127-134.

32. Zhou, X., C. Zheng, J. Sun, and T. You, Analysis of nephroloxic and carcinogenic aristolochic acids in Aristolochia plants by capillary electrophoresis with electrochemical detection at a carbon fiber microdisk electrode. Journal of Chromatography A, 2006. 1109(2): p. 152-159.

33. Kuo, C.-H., C.-W. Lee, S.-C. Lin, I.-L. Tsai, S.-S. Lee, Y.J. Tseng, J.-J. Kang, F.-C. Peng, and L. WeiChu, Rapid determination of aristolochic acids I and II in herbal products and biological samples by ultrahigh-pressure liquid chromatography-tandem mass spectrometry. Talanta, 2010. 80(5): p. 1672-1680.

34. Xu, Y.-Q., X.-W. Li, G.-X. Liu, X. Wang, M.-Y. Shang, X.-M. Li, and S.-Q. Cai, Comparative study of the contents of analogues of aristolochic acid in two kinds of Aristolochiae Fructus by high-performance liquid chromatography. Journal of natural medicines, 2013.67(1): p. 113-122.

35. Wang, Y. and W. Chan, Determination of aristolochic acids by high-performance liquid chromatography with fluorescence detection. Journal of Agricultural and Food Chemistry, 2014. 62(25): p. 5859-5864.

36. Wei, F., X.L. Cheng, L.Y. Ma, W.T. Jin, B.T. Schaneberg, I.A. Khan, and R.C. Lin, Analysis of aristolochic acids and analogues in medicinal plants and their commercial products by HPLC-PAD-ESI/ MS. Phytochemical Analysis, 2005. 16(3): p. 222-230.

37. loset, J.-R., G. Raoelison, and K. Hostettmann, Detection of aristolochic acid in Chinese phytomedicines and dietary supplements used as slimming regimens. Food and Chemical Toxicology, 
2003. 41(1): p. 29-36.

38. Koh, H., H. Wang, S. Zhou, E. Chan, and S. Woo, Detection of aristolochic acid I, tetrandrine and fangchinoline in medicinal plants by high performance liquid chromatography and liquid chromatography/mass spectrometry. Journal of Pharmaceutical and Biomedical Analysis, 2006. 40(3): p. 653-661.

39. Zhao, Z.-Z., Z.-T. Liang, Z.-H. Jiang, K.S.-Y. Leung, C.-L. Chan, H.-Y. Chan, J. Sin, T.-O. Man, and K.-W. Law, Comparative study on the aristolochic acid I content of Herba Asari for safe use. Phytomedicine, 2008. 15(9): p. 741-748.

40. Schmeiser, H.H., C.A. Bieler, M. Wiessler, C.v.Y. de Strihou, and J.-P. Cosyns, Detection of DNA adducts formed by aristolochic acid in renal tissue from patients with Chinese herbs nephropathy. Cancer research, 1996. 56(9): p. 2025-2028.

41. Stiborová, M., E. Frei, B. Sopko, K. Sopková, V. Marková, M. Laňková, T. Kumstýřová, M. Wiessler, and H.H. Schmeiser, Human cytosolic enzymes involved in the metabolic activation of carcinogenic aristolochic acid: evidence for reductive activation by human NAD (P) H: quinone oxidoreductase. Carcinogenesis, 2003. 24(10): p. 1695-1703.

42. Felter, S.P., R.B. Conolly, J.P. Bercu, P.M. Bolger, A.R. Boobis, P.M. Bos, P. Carthew, N.G. Doerrer, J.I. Goodman, and W.A. Harrouk, A proposed framework for assessing risk from less-than-lifetime exposures to carcinogens. Critical Reviews in Toxicology, 2011. 41(6): p. 507-544.

43. Chan, W., H. Yue, W.T. Poon, Y.-W. Chan, O.J. Schmitz, D.W. Kwong, R.N. Wong, and Z. Cai, Quantification of aristolochic acid-derived DNA adducts in rat kidney and liver by using liquid chromatography-electrospray ionization mass spectrometry. Mutation Research/Fundamental and Molecular Mechanisms of Mutagenesis, 2008. 646(1): p. 17-24.

44. Mei, N., V.M. Arlt, D.H. Phillips, R.H. Heflich, and T. Chen, DNA adduct formation and mutation induction by aristolochic acid in rat kidney and liver. Mutation Research/Fundamental and Molecular Mechanisms of Mutagenesis, 2006. 602(1): p. 83-91.

45. Dong, H., N. Suzuki, M.C. Torres, R.R. Bonala, F. Johnson, A.P. Grollman, and S. Shibutani, Quantitative determination of aristolochic Acid-derived DNA adducts in rats using ${ }^{32} p$-postlabeling/ polyacrylamide gel electrophoresis analysis. Drug Metabolism and Disposition, 2006. 34(7): p. 11221127.

46. Pfau, W., H.H. Schmeiser, and M. Wiessler, ${ }^{32}$ P-postlabelling analysis of the DNA adducts formed by aristolochic acid I and II. Carcinogenesis, 1990. 11(9): p. 1627-1633.

47. Lai, M.-N., J.-N. Lai, P.-C. Chen, S.-C. Hsieh, F.-C. Hu, and J.-D. Wang, Risks of kidney failure associated with consumption of herbal products containing Mu Tong or Fangchi: a population-based case-control study. American Journal of Kidney Diseases, 2010. 55(3): p. 507-518.

48. EFSA, EFSA Compendium of botanicals that have been reported to contain toxic, addictive, psychotropic or other substances of concern. EFSA Journal, 2009. 7(9): p. 281.

49. Barlow, S., A. Renwick, J. Kleiner, J. Bridges, L. Busk, E. Dybing, L. Edler, G. Eisenbrand, J. Fink-Gremmels, and A. Knaap, Risk assessment of substances that are both genotoxic and carcinogenic: Report of an International Conference organized by EFSA and WHO with support of ILSI Europe. Food and Chemical Toxicology, 2006. 44(10): p. 1636-1650. 
Supplementary data $\mathrm{A}$

Estimated daily intakes of AAs and corresponding MOEs

\begin{tabular}{|c|c|c|c|c|c|c|c|c|}
\hline No & $\begin{array}{l}\text { AAI } \\
(\mu g / g)\end{array}$ & $\begin{array}{l}\text { AAll } \\
(\mu \mathrm{g} / \mathrm{g})\end{array}$ & $\begin{array}{l}\text { AAI + } \\
\text { AAll } \\
(\mu g / g)\end{array}$ & $\begin{array}{l}\text { EDI ( } \mu \mathrm{g} / \\
\text { kg bw/ } \\
\text { day) }\end{array}$ & $\begin{array}{l}\text { MOE for } \\
\text { kidney } \\
\text { tumour } \\
\text { formation }^{b}\end{array}$ & $\begin{array}{l}\text { No of } \\
\text { positive } \\
\text { samples/ } \\
\text { total } \\
\text { samples }\end{array}$ & $\begin{array}{l}\text { Collection } \\
\text { year }\end{array}$ & References \\
\hline 1 & 919 & 82 & 1001 & 10.7 & 0.9 & \multirow{9}{*}{$\begin{array}{l}25 / 190 \\
(5 / 38 \text { per } \\
\text { year })^{g}\end{array}$} & \multirow{9}{*}{$\begin{array}{l}2002- \\
2006\end{array}$} & \multirow[t]{9}{*}{ [15] } \\
\hline 2 & 1453 & 303 & 1756 & 18.8 & 0.5 & & & \\
\hline 3 & 1281 & 394 & 1675 & 17.9 & 0.6 & & & \\
\hline 4 & 936 & 212 & 1148 & 12.3 & 0.8 & & & \\
\hline 5 & 50 & 11 & 61 & 0.7 & 15.3 & & & \\
\hline 6 & 74 & 33 & 107 & 1.1 & 8.7 & & & \\
\hline 7 & 12 & NDd & 12 & 0.1 & 77.8 & & & \\
\hline 8 & 524 & 21 & 545 & 5.8 & 1.7 & & & \\
\hline 9 & 9 & ND & 9 & 0.1 & 103.7 & & & \\
\hline 10 & 456 & 144 & 600 & 6.4 & 1.6 & \multirow[t]{21}{*}{$21 / 27$} & \multirow[t]{21}{*}{2001} & \multirow[t]{21}{*}{ [19] } \\
\hline 11 & 547 & 188 & 735 & 7.9 & 1.3 & & & \\
\hline 12 & 668 & 198 & 866 & 9.3 & 1.1 & & & \\
\hline 13 & 451 & 257 & 708 & 7.6 & 1.3 & & & \\
\hline 14 & 437 & 414 & 851 & 9.1 & 1.1 & & & \\
\hline 15 & 548 & 412 & 960 & 10.3 & 1.0 & & & \\
\hline 16 & 83 & 115 & 198 & 2.1 & 4.7 & & & \\
\hline 17 & 42 & 99 & 141 & 1.5 & 6.6 & & & \\
\hline 18 & 60 & 101 & 161 & 1.7 & 5.8 & & & \\
\hline 19 & 24 & 93 & 117 & 1.3 & 8.0 & & & \\
\hline 20 & 39 & 124 & 163 & 1.7 & 5.7 & & & \\
\hline 21 & 28 & $<1$ & 28 & 0.3 & 33.3 & & & \\
\hline 22 & 26 & 79 & 105 & 1.1 & 8.9 & & & \\
\hline 23 & $<1$ & 94 & 94 & 1.0 & 9.9 & & & \\
\hline 24 & $<1$ & 76 & 76 & 0.8 & 12.3 & & & \\
\hline 25 & 23 & 78 & 101 & 1.1 & 9.2 & & & \\
\hline 26 & 24 & 95 & 119 & 1.3 & 7.8 & & & \\
\hline 27 & 22 & $<1$ & 22 & 0.2 & 42.4 & & & \\
\hline 28 & 22 & $<1$ & 22 & 0.2 & 42.4 & & & \\
\hline 29 & 30 & 148 & 178 & 1.9 & 5.2 & & & \\
\hline 30 & 598 & 94 & 692 & 7.4 & 1.3 & & & \\
\hline
\end{tabular}




\begin{tabular}{|c|c|c|c|c|c|c|c|c|}
\hline 31 & $0.07 c$ & ND & 0.07 & 1.0 & 10.0 & \multirow[t]{6}{*}{$6 / 25$} & \multirow[t]{6}{*}{2004} & \multirow[t]{6}{*}[20]{} \\
\hline 32 & $0.05 c$ & ND & 0.05 & 0.7 & 14.0 & & & \\
\hline 33 & $0.48 c$ & 0.4 & 0.88 & 12.6 & 0.8 & & & \\
\hline 34 & $0.4 \mathrm{c}$ & 0.35 & 0.75 & 10.7 & 0.9 & & & \\
\hline 35 & $0.16 c$ & 0.06 & 0.22 & 3.1 & 3.2 & & & \\
\hline 36 & $0.6 c$ & 0.32 & 0.96 & 13.7 & 0.7 & & & \\
\hline 37 & 1010 & 180 & 1190 & 12.8 & 0.8 & \multirow[t]{9}{*}{$9 / 37$} & \multirow[t]{9}{*}{1999} & \multirow[t]{9}{*}{ [27] } \\
\hline 38 & 1080 & 120 & 1200 & 12.9 & 0.8 & & & \\
\hline 39 & 790 & 80 & 870 & 9.3 & 1.1 & & & \\
\hline 40 & 3010 & 210 & 3220 & 34.5 & 0.3 & & & \\
\hline 41 & 1690 & 140 & 1830 & 19.6 & 0.5 & & & \\
\hline 42 & 8820 & 1000 & 9820 & 105.2 & 0.1 & & & \\
\hline 43 & 2220 & 220 & 2440 & 26.1 & 0.4 & & & \\
\hline 44 & 1430 & 60 & 1490 & 16.0 & 0.6 & & & \\
\hline 45 & 1030 & 40 & 1070 & 11.5 & 0.9 & & & \\
\hline 46 & 0.105 & 0.028 & 0.133 & $1.4 \times 10-3$ & 7017.5 & \multirow[t]{6}{*}{$6 / 30$} & \multirow[t]{6}{*}{2013} & \multirow[t]{6}{*}[21]{} \\
\hline 47 & 0.056 & ND & 0.056 & $6.0 \times 10-4$ & 16666.7 & & & \\
\hline 48 & 0.018 & ND & 0.018 & $1.9 \times 10-4$ & 51851.9 & & & \\
\hline 49 & 0.045 & ND & 0.045 & $4.8 \times 10-4$ & 20740.7 & & & \\
\hline 50 & 0.013 & ND & 0.013 & $1.4 \times 10-4$ & 71794.9 & & & \\
\hline 51 & 3.316 & 0.557 & 3.873 & $4.2 \times 10-2$ & 241.0 & & & \\
\hline 52 & 2000 & 200 & 2200 & 23.6 & 0.4 & $2 / 3$ & $\begin{array}{c}1990- \\
1992\end{array}$ & [26] \\
\hline 53 & $\mathrm{NAe}$ & NA & $650 \mathrm{f}$ & 7.0 & 1.4 & \multirow[t]{3}{*}{$11 / 12$} & \multirow{3}{*}{$\begin{array}{l}1990- \\
1992\end{array}$} & \multirow[t]{3}{*}{ [13] } \\
\hline 54 & NA & NA & $1800 \mathrm{f}$ & 19.3 & 0.5 & & & \\
\hline 55 & NA & NA & $2900 \mathrm{f}$ & 31.1 & 0.3 & & & \\
\hline 56 & 944.6 & 50.1 & 994.7 & 10.7 & 0.94 & \multirow[t]{8}{*}{$8 / 8$} & \multirow[t]{8}{*}{2007} & \multirow[t]{8}{*}{33} \\
\hline 57 & 802.6 & 148.7 & 951.3 & 10.2 & 0.98 & & & \\
\hline 58 & 511.5 & 29.4 & 540.9 & 5.8 & 1.73 & & & \\
\hline 59 & 7.6 & ND & 7.6 & 0.1 & 122.81 & & & \\
\hline 60 & 119.7 & 6.8 & 126.5 & 1.4 & 7.38 & & & \\
\hline 61 & 0.2 & ND & 0.2 & $2.1 \times 10-3$ & 4666.7 & & & \\
\hline 62 & 0.4 & ND & 0.4 & $4.3 \times 10-3$ & 2333.3 & & & \\
\hline 63 & 0.5 & ND & 0.5 & $5.4 \times 10-3$ & 1866.7 & & & \\
\hline 64 & 41 & ND & 41 & 0.4 & 22.8 & \multirow[t]{4}{*}{$6 / 34$} & \multirow[t]{4}{*}{2003} & \multirow[t]{4}{*}{29} \\
\hline 65 & 195 & 33 & 228 & 2.4 & 4.1 & & & \\
\hline 66 & 943 & 59 & 1002 & 10.7 & 0.9 & & & \\
\hline 67 & ND & 28 & 28 & 0.3 & 33.3 & & & \\
\hline
\end{tabular}

Page | 176 


\begin{tabular}{|c|c|c|c|c|c|c|c|c|}
\hline 68 & 8 & 8 & 16 & 0.2 & 58.3 & & & \\
\hline 69 & 40 & 210 & 250 & 2.7 & 3.7 & & & \\
\hline 70 & 11.1 & 5.4 & 16.5 & 0.2 & 56.6 & \multirow[t]{12}{*}{$12 / 12$} & \multirow[t]{12}{*}{2005} & \multirow[t]{12}{*}{ [30] } \\
\hline 71 & 27.4 & 24 & 51.4 & 0.6 & 18.2 & & & \\
\hline 72 & 201.9 & 54.3 & 256.2 & 2.7 & 3.6 & & & \\
\hline 73 & 101.1 & 34.1 & 135.2 & 1.4 & 6.9 & & & \\
\hline 74 & 2724.5 & 200.1 & 2924.6 & 31.3 & 0.3 & & & \\
\hline 75 & 66.5 & 34.7 & 101.2 & 1.1 & 9.2 & & & \\
\hline 76 & 3376 & 725.4 & 4101.4 & 43.9 & 0.2 & & & \\
\hline 77 & 101.8 & 37.7 & 139.5 & 1.5 & 6.7 & & & \\
\hline 78 & 297.9 & 43.5 & 341.4 & 3.7 & 2.7 & & & \\
\hline 79 & 79.8 & 31.5 & 111.3 & 1.2 & 8.4 & & & \\
\hline 80 & 41 & 25.8 & 66.8 & 0.7 & 14.0 & & & \\
\hline 81 & 26.1 & 8.8 & 34.9 & 0.4 & 26.7 & & & \\
\hline 82 & 5 & 16 & 21 & 0.2 & 44.4 & \multirow[t]{24}{*}{$24 / 62$} & \multirow[t]{24}{*}{2006} & \multirow[t]{24}{*}{ [31] } \\
\hline 83 & 8 & ND & 8 & 0.1 & 116.7 & & & \\
\hline 84 & 40 & 2 & 42 & 0.5 & 22.2 & & & \\
\hline 85 & ND & 3 & 3 & 0.0 & 311.1 & & & \\
\hline 86 & 120 & 10 & 130 & 1.4 & 7.2 & & & \\
\hline 87 & 10 & 1 & 11 & 0.1 & 84.8 & & & \\
\hline 88 & 40 & 3 & 43 & 0.5 & 21.7 & & & \\
\hline 89 & 15 & 2 & 17 & 0.2 & 54.9 & & & \\
\hline 90 & 20 & ND & 20 & 0.2 & 46.7 & & & \\
\hline 91 & 8 & ND & 8 & 0.1 & 116.7 & & & \\
\hline 92 & 20 & ND & 20 & 0.2 & 46.7 & & & \\
\hline 93 & 50 & ND & 50 & 0.5 & 18.7 & & & \\
\hline 94 & 65 & 8 & 73 & 0.8 & 12.8 & & & \\
\hline 95 & 85 & 10 & 95 & 1.0 & 9.8 & & & \\
\hline 96 & 5 & 15 & 20 & 0.2 & 46.7 & & & \\
\hline 97 & 150 & 12 & 162 & 1.7 & 5.8 & & & \\
\hline 98 & 45 & 5 & 50 & 0.5 & 18.7 & & & \\
\hline 99 & 5 & ND & 5 & 0.1 & 186.7 & & & \\
\hline 100 & 5 & 3 & 8 & 0.1 & 116.7 & & & \\
\hline 101 & 32 & 4 & 36 & 0.4 & 25.9 & & & \\
\hline 102 & 10 & 0 & 10 & 0.1 & 93.3 & & & \\
\hline 103 & ND & 8 & 8 & 0.1 & 116.7 & & & \\
\hline 104 & 40 & ND & 40 & 0.4 & 23.3 & & & \\
\hline 105 & 100 & 10 & 110 & 1.2 & 8.5 & & & \\
\hline
\end{tabular}


Chapter 5

\begin{tabular}{|c|c|c|c|c|c|c|c|c|}
\hline 106 & 980 & 350 & 1330 & 14.3 & 0.7 & \multirow[t]{3}{*}{$3 / 6$} & \multirow[t]{3}{*}{2006} & \multirow[t]{3}{*}[32]{} \\
\hline 107 & 270 & 46 & 316 & 3.4 & 3.0 & & & \\
\hline 108 & 230 & 53 & 283 & 3.0 & 3.3 & & & \\
\hline 109 & 0.19 & NA & 0.19 & $2.0 \times 10-3$ & 4912.3 & \multirow[t]{18}{*}{$18 / 18$} & \multirow[t]{18}{*}{2008} & \multirow[t]{18}{*}{ [39] } \\
\hline 110 & 2.16 & NA & 2.16 & $2.3 \times 10-2$ & 432.1 & & & \\
\hline 111 & 11.91 & NA & 11.91 & 0.1 & 78.4 & & & \\
\hline 112 & 5.3 & NA & 5.3 & 0.1 & 176.1 & & & \\
\hline 113 & 0.93 & NA & 0.93 & $1.0 \times 10-3$ & 1003.6 & & & \\
\hline 114 & 6.14 & NA & 6.14 & 0.1 & 152.0 & & & \\
\hline 115 & 2.21 & NA & 2.21 & $2.4 \times 10-2$ & 422.3 & & & \\
\hline 116 & 220.96 & NA & 220.96 & 2.4 & 4.2 & & & \\
\hline 117 & 254.04 & NA & 254.04 & 2.7 & 3.7 & & & \\
\hline 118 & 201.65 & NA & 201.65 & 2.2 & 4.6 & & & \\
\hline 119 & 440.61 & NA & 440.61 & 4.7 & 2.1 & & & \\
\hline 120 & 1903.31 & NA & 1903.31 & 20.4 & 0.5 & & & \\
\hline 121 & 36.42 & NA & 36.42 & 0.4 & 25.6 & & & \\
\hline 122 & 535.4 & NA & 535.4 & 5.7 & 1.7 & & & \\
\hline 123 & 544.41 & NA & 544.41 & 5.8 & 1.7 & & & \\
\hline 124 & 0.04 & NA & 0.04 & $4.3 \times 10-4$ & 23333.3 & & & \\
\hline 125 & 0.03 & NA & 0.03 & $3.2 \times 10-4$ & 31111.1 & & & \\
\hline 126 & 0.03 & NA & 0.03 & $3.2 \times 10-4$ & 31111.1 & & & \\
\hline 127 & 597 & 57 & 654 & 7.0 & 1.4 & \multirow[t]{17}{*}{$33 / 33$} & \multirow[t]{17}{*}{2013} & \multirow[t]{17}{*}[34]{} \\
\hline 128 & 713 & 65 & 778 & 8.3 & 1.2 & & & \\
\hline 129 & 257 & 19 & 276 & 3.0 & 3.4 & & & \\
\hline 130 & 981 & 59 & 1040 & 11.1 & 0.9 & & & \\
\hline 131 & 770 & 41 & 811 & 8.7 & 1.2 & & & \\
\hline 132 & 636 & 66 & 702 & 7.5 & 1.3 & & & \\
\hline 133 & 928 & 55 & 983 & 10.5 & 0.9 & & & \\
\hline 134 & 642 & 53 & 695 & 7.4 & 1.3 & & & \\
\hline 135 & 755 & 66 & 821 & 8.8 & 1.1 & & & \\
\hline 136 & 898 & 82 & 980 & 10.5 & 1.0 & & & \\
\hline 137 & 336 & 30 & 366 & 3.9 & 2.6 & & & \\
\hline 138 & 343 & 34 & 377 & 4.0 & 2.5 & & & \\
\hline 139 & 337 & 23 & 360 & 3.9 & 2.6 & & & \\
\hline 140 & 283 & ND & 283 & 3.0 & 3.3 & & & \\
\hline 141 & 653 & 44 & 697 & 7.5 & 1.3 & & & \\
\hline 142 & 808 & 34 & 842 & 9.0 & 1.1 & & & \\
\hline 143 & 606 & 38 & 644 & 6.9 & 1.4 & & & \\
\hline
\end{tabular}

Page | 178 


\begin{tabular}{|c|c|c|c|c|c|c|c|c|}
\hline 144 & 450 & 62 & 512 & 5.5 & 1.8 & & & \\
\hline 145 & 814 & 25 & 839 & 9.0 & 1.1 & & & \\
\hline 146 & 519 & 15 & 534 & 5.7 & 1.7 & & & \\
\hline 147 & 343 & 31 & 374 & 4.0 & 2.5 & & & \\
\hline 148 & 296 & 27 & 323 & 3.5 & 2.9 & & & \\
\hline 149 & 338 & 32 & 370 & 4.0 & 2.5 & & & \\
\hline 150 & 330 & 30 & 360 & 3.9 & 2.6 & & & \\
\hline 151 & 252 & 23 & 275 & 2.9 & 3.4 & & & \\
\hline 152 & 566 & 39 & 605 & 6.5 & 1.5 & & & \\
\hline 153 & 668 & 56 & 724 & 7.8 & 1.3 & & & \\
\hline 154 & 730 & 62 & 792 & 8.5 & 1.2 & & & \\
\hline 155 & 510 & 35 & 545 & 5.8 & 1.7 & & & \\
\hline 156 & 283 & 13 & 296 & 3.2 & 3.2 & & & \\
\hline 157 & 778 & 101 & 879 & 9.4 & 1.1 & & & \\
\hline 158 & 679 & 49 & 728 & 7.8 & 1.3 & & & \\
\hline 159 & 331 & 24 & 355 & 3.8 & 2.6 & & & \\
\hline 160 & ND & ND & & & & $0 / 10$ & 2014 & [35] \\
\hline
\end{tabular}

${ }^{a} \mathrm{EDI}$ is estimated based on consumption of $0.25 \mathrm{~g}$ of $\mathrm{AA}, 3$ times a day and $70 \mathrm{~kg}$ bw

${ }^{b}$ The lowest BMDL10 value for AA-induced kidney tumour formation, $10 \mu \mathrm{g} A \mathrm{As} / \mathrm{kg}$ bw/day

${ }^{\mathrm{C}}$ Calculated in $\mathrm{mg} /$ day

${ }^{d}$ ND non-detected

e NA non-available

${ }^{f}$ Calculated based on assuming that the supplement only contained AAI

${ }^{g}$ Number of positives samples/ total samples per year is averaged for five years 



\section{CHAPTER}

\section{6}

General discussion and future perspectives 


\subsection{DISCUSSION OF THE RESULTS}

This thesis aimed to provide additional evidence for an alternative testing strategy that can be used in quantitative risk assessment contributing to the 3Rs (Replacement, Reduction and Refinement) of animal studies. The novel method is based on extrapolation of in vitro concentration-response curves obtained with cell line models to in vivo dose-response curves using physiologically based kinetic (PBK) modeling-based reverse dosimetry. From the predicted in vivo dose-response curves, points of departure (PODs) for risk assessment like a benchmark dose (BMD) or lower confidence limit of the BMD (BMDL) can be derived. So far, the approach has been shown to be able to predict in vivo developmental toxicity [1-3]. This thesis focused on testing the novel approach for a different target organ and toxicological endpoint, aiming to predict kidney toxicity and kidney DNA adduct formation by the nephrotoxic, genotoxic and carcinogenic aristolochic acids (AA) as the model compounds.

In Chapter 2, the in vitro cytotoxicity of aristolochic acid I (AAI) was determined in two different kidney cell lines derived from pig kidney (LLC-PK1) and madin-darby canine kidney (MDCK). Then, PBK models were developed that describe the absorption, distribution, metabolism and excretion (ADME) of AAl in rat, mouse and human. The kinetic parameters were collected by performing in vitro incubations using relevant rat, mouse and human tissue fractions. This revealed that overall catalytic efficiency (scaled to a whole liver) for metabolic conversion of AAI to a less toxic metabolite, AAla by rat and human was comparable between the different species, being only 2-fold higher in rat than human. The defined PBK models were used to translate the in vitro concentration-response curves for cytotoxicity to in vivo dose-response curves for nephrotoxicity of $A A I$. The $B M D L_{10}$ values that were derived from the predicted in vivo dose-response curves reveal that the predicted PODs generally fall within the range of PODs derived from in vivo literature data on kidney toxicity of AAI. The combined in vitro-PBK modeling approach provided PODs for risk assessment with a similar level of uncertainty as observed in the experimental animal studies, supporting the future possibilities of this approach in risk assessment replacing or reducing animal based testing.

The same PBK models were subsequently used in Chapter 3 to translate in vitro concentration-response curves for AAI-DNA adduct formation to in vivo dose-response curves for AAI-DNA adduct levels in the kidney. The predicted in vivo AAI-DNA adduct levels in the rat, mouse and human kidney were within an order of magnitude compared to the values reported in the 
literature, the latter showing large inter-study variations. In addition, based on the predictive model obtained it could be estimated that at the $\mathrm{BMD}_{10}$ value for AAl-induced tumor formation in the rat kidney, the AAI-DNA adduct levels in the rat kidney would amount to 4-11 adducts in $10^{8}$ nts. The human model predicted that to obtain this level of DNA adduct formation in human kidney, human exposure levels of 0.04 to $0.11 \mathrm{mg} / \mathrm{kg}$ bw/day would be required, which are similar to dose levels estimated for the exposure of Belgian patients exposed to AAs that developed cancer in the urinary tract.

Given that exposure to AAl is often accompanied by the presence of AAll [4-6], the objective of Chapter $\mathbf{4}$ was to investigate the DNA adduct formation of AAI and AAll in kidney cells and to translate the in vitro data to the in vivo situation using PBK modeling-based reverse dosimetry. In addition, the relative levels of AAI- and AAll-DNA adducts were determined. The predicted in vivo AAI- and AAll-DNA adduct formation in the rat kidney fell within the wide range of DNA adduct levels reported in in vivo studies. Furthermore, the results obtained showed a remarkable difference in relative level of DNA adduct formation of AAI and AAll in the in vitro model that appeared not to be reflected in vivo where similar levels of DNA adduct formation are observed. Converting the in vitro data to in vivo dose-response curves by PBK modeling-based reverse dosimetry reveals that the discrepancy between the in vitro and in vivo data can only in part be explained by the differences in the ADME characteristics of the two AAs as described in the PBK model. The difference between DNA adduct formation of AAI and AAll in the in vitro and the in vivo situation remains an unresolved issue that needs further investigation.

The accidental exposure to AAs via consumption of slimming pills in Belgium, which caused kidney toxicity and kidney cancer with detectable levels of DNA adducts in the kidney of patients $[7,8]$ resulted in the banning of AA-containing food and food supplements from the market [9-11]. In spite of the ban, plant food supplements (PFS) and herbal products containing AAs are still available on the market [4, 5, 12-15], but the levels of AAs reported in literature so far are without an accompanying risk assessment. In Chapter $\mathbf{5}$ of the thesis, the current state-of-the-art was investigated by analysing an additional series of PFS also performing a risk assessment on use of these PFS based on the margin of exposure (MOE) approach. The results obtained revealed that even 15 years after the ban, which was installed in the Netherlands, United Kingdom, USA, Canada and Australia in 2001 [4, 9, 10], AA-containing PFS and herbal products are still available on the market especially via Internet. The results obtained revealed that three out of the 18 analyzed PFS contained AAs. The estimated MOEs that would result from daily use of these and the previously 
analyzed 159 AA-containing PFS and herbal products were generally below 10,000 indicating a concern if the PFS or herbal products would be consumed on a daily basis over longer periods of time. When considering that the use of these samples may be limited to shorter periods of time, for example 2 weeks, the MOE values would increase but for more than $50 \%$ of the positive samples they would still be below 10,000. These results also revealed that in spite of the ban installed more than 15 years ago, consumers can still be exposed to AA-containing PFS and herbal products, and AA-containing products still raise concern especially for people who frequently use the products.

\subsection{GENERAL DISCUSSION AND FUTURE PERSPECTIVES}

The present thesis demonstrated the potential of the combined in vitro and PBK modeling-based reverse dosimetry approach to derive in vivo dose-response curves for kidney toxicity and DNA adduct formation of AAs. The results of the present thesis can be discussed in a wider perspective especially taking into account the possibilities and limitations of the novel approach, together with some important considerations for future studies. The topics to be considered when discussing the present results include;

2o The in vitro system selected for studying kidney toxicity.

a Critical analysis on the current novel PBK modeling-based reverse dosimetry approach.

๙ Use of DNA adduct formation in cancer risk assessment.

¿ Implementation of the combined in vitro PBK modeling-based reverse dosimetry approach in risk assessment.

¿o Future perspectives.

\subsubsection{The in vitro system selected for studying kidney toxicity}

In vitro models have been used widely in toxicology studies. Selection of the appropriate cell model is one of the most important issues especially when performing in vitro studies to elucidate the mechanism of action of chemicals and when the in vitro data are to be used for translation to the human situation. The LLC-PK1 cell line derived from the kidney of a juvenile male Hampshire pig is routinely used to study nephrotoxic effects of chemicals in humans because the cells exhibit many of the enzymatic and transport properties of the human proximal tubule cells $[16,17]$ which are the cells that represent the direct target of AAI [18]. The LLC-PK1 cell line has also been proven to be sensitive to AAI exposure [19]. However, when extrapolating the results from LLC-PK1 cells to Page | 184 
humans, one needs to be cautious about the interspecies differences in dynamics. Theoretically, one could argue that the approach could be further optimized by using human cell-based kidney model to generate in vitro data that better predicts the human situation.

However, comparison of the cytotoxicity of AAI in the LLC-PK1 cells to the AAl-induced cytotoxicity in primary renal human cells and even to the cytotoxicity in other cell types from other species described in the literature [19] reveals that the in vitro concentration-response curve for LLC-PK1 do not only match those for primary human kidney cells but also those for primary rat cells, primary porcine kidney cells and cells from the MDCK cell line, the kidney cells derived from canine (see figure 6.1, based on Chapter 2, Figure 2.4b). These results reveal that species differences in dynamics of AAI toxicity may be limited, and that in this case the LLC-PK1 cells provide an adequate model to predict in vivo kidney toxicity in humans.

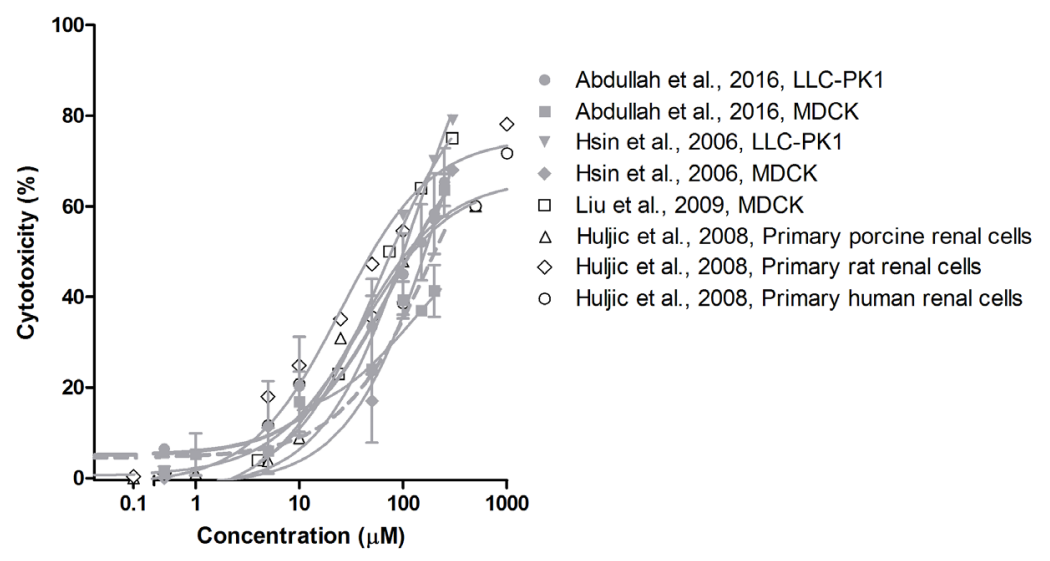

Figure 6.1 (Based on Figure 2.4b). Concentration response-curves for the cytotoxicity of AAI $(\mu \mathrm{M})$ towards the LLC-PK1 and MDCK cell line upon 24 hours exposure (mean values \pm SD) compared to data on concentration response-curves reported in literature for other cell models including primary human renal cells. For further details and references see Chapter 2 [20].

Another aspect that needs to be considered with respect to the selection of an in vitro system for studying kidney toxicity is that many chemicals may be transported to the kidney by active transporters expressed in the epithelium of proximal tubule cells. Organic anion transporters (OATs) were shown to be involved in the transport of AAI to the kidney [21]. However, AAI can also enter the cells through transport mechanisms other than transport via OATs, for example by simple 
diffusion [21]. In order to investigate the impact of transporters in the kidney in the uptake and excretion of AAs in kidney cells, transfected cells such as madin-canine kidney II (MDCK II), Chinese hamster ovary (CHO), human embryonic kidney (HEK 293) and HeLa [22] cell lines could be used because they may express the kidney transporter proteins of interest. The in vitro transporter kinetic studies may also include studies on individual transporter(s). However, the scaling of the expression and the activity of kidney transporter in an in vitro model to the in vivo situation needs to be defined to a further extent before such data will proof to be of value.

For a better understanding of kidney function using in vitro models, a recent development on 'next-generation' in vitro models of the kidney can be considered. Such models may incorporate more physiologically representative in vitro systems for studying kidney function, for example using the co-culture of multiple cell types, 3D cell culture systems and/or the use of so-called 'kidney-ona-chip' devices using microfluidic culturing techniques [22]. Such devices that enhance the in vivolike complexity and functionality [23], may provide even better predictive in vitro models to study a complex organ such as the kidney.

\subsubsection{Critical analysis on the current novel PBK modeling-based reverse dosimetry approach}

In Chapter 2, the predictions of in vivo PODs were made by extrapolation from in vitro concentrationresponse curves to in vivo dose-response curves using PBK modeling-based reverse dosimetry. In this reverse dosimetry approach, the applied in vitro concentration and the maximum concentration $\left(C_{\max }\right)$ of AAl in the kidney as input in the PBK model were assumed to be equal. In this chapter, the LLC-PK1 and MDCK cells were exposed to AAI in medium with $10 \%$ of fetal calf serum (FCS). It is well established that serum in culture medium may significantly decrease the unbound fraction of a chemical in an in vitro systems [24]. It is important to take this protein binding into account in the PBK model because only the fraction that is freely available in the target organ is assumed to cause an effect. Figure 6.2 shows the level of AAI-DNA adduct formation when the cells were exposed to AAI in medium with and without the presence of $10 \% \mathrm{FCS}$. These results confirm that protein binding significantly decreases the DNA adduct formation and should thus be taken into account in the combined in vitro-PBK modeling approach. Therefore, prior to extrapolation to the in vivo situation, the correction for protein binding needs to be incorporated by multiplying the in vitro concentration with a correction factor based on the difference between the fraction of unbound 
AAI in cell culture medium and the fraction of unbound AAI in plasma (Chapters 3 and 4). Both when exposing cells with or without FCS such a correction for protein binding in plasma is required since the in vitro protein conditions whether with or without FCS never fully match the in vivo situation.

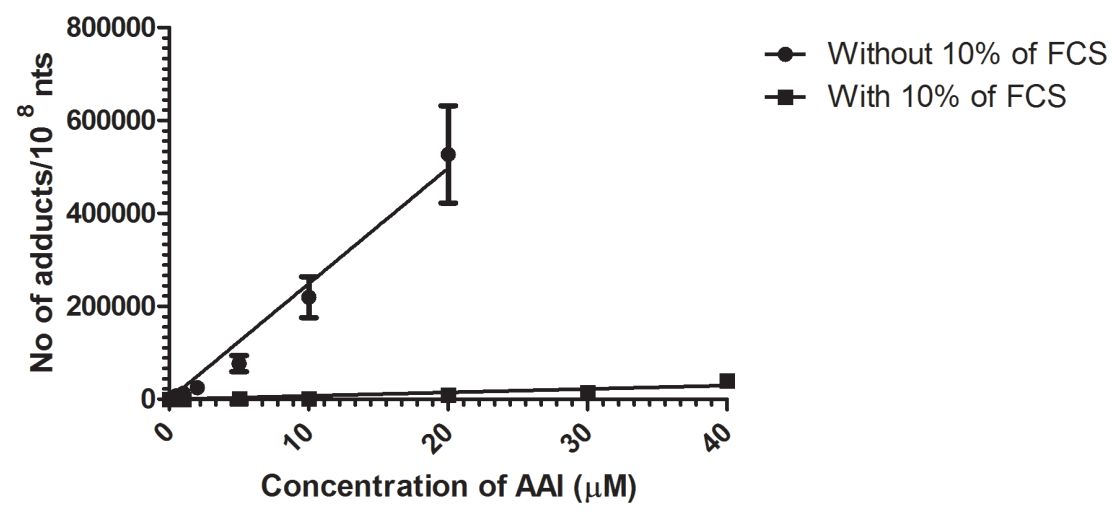

Figure 6.2 Comparison between concentration response-curves for dA-AAl adduct formation in LLC-PK1 cells exposed for 24 hours to AAl in medium without FCS (filled circles) and in medium with FCS (filled squares).

An applied concentration of chemicals in vitro may also be different from the concentration at the target site and/or in the cells [24] due to non-specific binding to the plastic of well plates, evaporation or degradation of chemicals over time during the experimental exposure [25]. The cell density is also an important factor to take into account because studies showed that cell density may influence the free fraction of chemicals $[26,27]$. Higher density of cells has been shown to lower the observed toxicity due to a decrease in number of chemical molecule per cell to cause the toxicity. To overcome these challenges, application of a non-binding material of well plates to reduce the binding to plastic, use of plate sealers to minimize the evaporation and use of fixed number of cells for all experiments may be essential, depending on the compound under study [25]. In addition, the in vitro free concentration can be modeled using physicochemical properties of the compounds for in vitro-in vivo extrapolation as suggested by Gülden and Siebert (2003) [28] and Kramer at al. (2015) [29]. In the present study, differences in the free fraction in vitro and in vivo were taken into account by applying a correction factor for differences in protein concentrations as presented in Chapter 3 and 4.

Another important issue when translating the in vitro concentration-response curves 
to in vivo dose-response curves is to choose the relevant dose metric for the extrapolation. The predictions can be made based on two approaches. The first approach is by translating the in vitro concentration-response curve to an in vivo dose-response curve by setting an in vitro concentration equal to the $C_{\max }$ in the kidney or blood as presented in Chapter 2 of this thesis. The second approach relates the in vitro concentration to the area under the kidney or blood concentrationtime curve (AUC) by multiplying the applied concentration with the assay time [30] assuming that the concentration of the chemical is constant in the incubations over time as done in Chapter 2-4. The dose metric that is commonly used for in vitro-in vivo extrapolation is dependent on the type of reactions and interactions expected to be relevant for the compound under investigation. For reversible reactions, the $C_{\max }$ may present a suitable dose metric while for irreversible reactions, the AUC might be preferable [25].

In order to derive the POD for risk assessment, BMD modeling is applied to the defined dose-response curves. There are two options in order to derive the POD; the first option is to translate the whole in vitro curve and then perform the BMD modeling while in the second option the BMD modeling is performed on the in vitro concentration-response curve providing a benchmark concentration $(\mathrm{BMC})$ value that is subsequently translated to a corresponding $B M D$ value. When the kinetics are linear with the dose, the outcome of these two approaches will be similar, but when the kinetics are not linear with the dose, the first approach that translates the whole in vitro curve to an in vivo dose response curve before the BMD modeling is applied, is the preferred option. This is the approach applied in the present thesis (Chapter 2-4).

An effort to study in vitro nephrotoxicity to mimic the in vivo situation for defining PODs for risk assessment is an important challenge. In the present thesis, cytotoxicity of AAs was studied using the MTT assay which is a common method to detect cell viability. However, toxic effects in vivo may not be related to cell death but to cell dysfunction that subsequently leads to specific effects in the respective tissue. In spite of this, the predicted in vivo PODs in this thesis were within an order of magnitude from in vivo studies (Chapter 2) that used classical approaches for the detection of acute kidney toxicity by measuring the blood urea nitrogen (BUN) and creatinine concentration. Use of omics approaches, such as transcriptomics (global mRNA changes), proteomics (global protein changes) and metabolomics (global metabolites changes) may provide promising future approaches to model more specific and sensitive endpoints. The measurement of molecular markers of specific proteins in in vitro systems may include for example proteins involved in stress response (such as nuclear factor (erythroid-derived 2)-like 2 (Nrf2) and heme oxygenase 1 (HO-1)) or markers related Page | 188 
to kidney injury (such as kidney injury marker 1 (KIM-1)) and use of concentration-response curves based on these biomarkers may further improve the accuracy of the predictions [23]. Important to keep in mind in such an approach is that the selected biomarker should be considered as a reflection of an adverse effect.

\subsubsection{Use of DNA adduct formation in cancer risk assessment}

The quantification of DNA adduct formation is considered a biomarker of exposure rather than a biomarker of effect [31] although a significant association of increased DNA adduct formation with increased tumor formation has been frequently observed $[32,33]$. However, the correlations are not necessarily linear [34]. The level of DNA adducts in the body is determined by processes such as absorption, distribution, metabolic activation, detoxification, reactivity of the compound and its reactive metabolite(s), and by DNA repair.

The development of the current PBK models to predict the DNA adduct formation in vivo is one step closer to the ultimate adverse effect to predict the tumor formation than predicting the formation of the ultimate DNA reactive metabolite as such. Prediction of the DNA adduct formation should preferably include a description of the stability and repair of the DNA adducts. When including an equation that describes the DNA adduct formation in a relevant in vitro cell model these parameters of formation and stability of the DNA adducts are implicitly included in the PBK model. However, the present study only assessed the DNA adduct levels upon a 24-hour exposure. Studying the DNA adduct levels at earlier and later time points may provide more information on the stability of the AA-induced DNA adducts. A next endpoint to consider would be the mutagenicity of the DNA adducts formed and/or the possible use of gene expression that has been related to genotoxicity and/or tumor formation as biomarkers of effect. Another important factor that needs to be included in this tumor formation model is to incorporate the repeated dose exposure that might lead to accumulation and persistence of DNA adducts over time in a specific organ.

\subsubsection{Implementation of the combined in vitro PBK model-based reverse dosimetry approach in risk assessment}

Figure 6.3 shows the general framework of the combined in vitro PBK modeling-based reverse dosimetry approach to predict in vivo dose-response curves that can be used in risk assessment. The results of the present thesis show that the prediction of PODs for kidney toxicity and kidney 
DNA adduct formation obtained by integrating in vitro toxicity data with in silico PBK modelbased reverse dosimetry do not deviate more from in vivo studies than the variations observed between PODs and DNA adduct formation derived from different in vivo studies. Thus, this thesis concludes that this approach is not better, but provides a suitable alternative, with a similar level of uncertainty as observed in experimental animal data. Therefore this method provides an alternative that would contribute significantly to the $3 \mathrm{Rs}$ of animal use and the relevance of in vitro data for safety evaluation in humans.
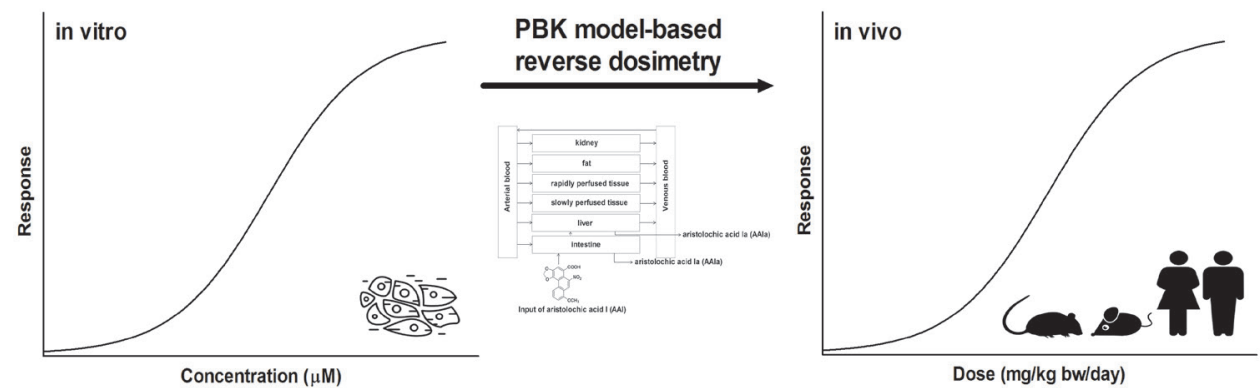

Figure 6.3 General framework for applying in vitro concentration-response curves with PBK modeling-based reverse dosimetry for the prediction of in vivo dose-response curves to set PODs for risk assessment (adapted from [1, 3, 35]).

In principle, the derived PODs for nephrotoxicity could be used to set a safe exposure level (ADI or TDI). For the specific case of AAI the POD for nephrotoxicity could be used to estimate the risk on nephrotoxicity at given levels of exposure (the ratio of the POD and the estimated daily intake should be >100) but not to define a TDI given that the compound is also a genotoxic carcinogen for which no TDI can be defined. The in vitro-in silico approach could also be used to define a $\mathrm{BMDL}_{10}$ for a genotoxicity/carcinogenicity endpoint and support a risk assessment for the carcinogenicity of AAs based on the so called Margin of Exposure approach as recommended by the European Food Safety Authority [36]. However, for setting the PODs for carcinogenic chemicals, further efforts are required for additional or other endpoints for the in vitro assays that can be accepted as biomarkers for this in vivo effect. Alternatively the PBK models may be used to facilitate read-across from a chemical for which in vivo carcinogenicity data and a related $\mathrm{BMDL}_{10}$ are available to a chemical that Page | 190 
is bioactivated by the same pathway and acts by the same mode of action on a similar target organ but for which no tumor data are available. In this way PBK modeling was used to estimate a BMDL for elemicin by read-across from data on the related alkenylbenzenes estragole and methyleugenol [37], and for apiole and myristicin from data on safrole [38, 39].

An attempt to correlate the DNA adduct levels with the doses that cause tumor formation could be undertaken by using the PBK model to predict the number of DNA adducts formed at the $\mathrm{BMD}_{10}$ values based on actual tumor formation data in animal experiments as done in the study presented in Chapter 3. The present thesis also revealed that the public is still exposed to AAcontaining PFS and herbal products from the market above the dose levels that can be considered as safe (Chapter 5). The human PBK model developed in the present thesis might be used to predict the expected number of DNA adducts to be formed upon intake of AAs from these PFS and herbal products. Figure 6.4 presents the predicted DNA adduct levels based on estimated daily intake (EDI) of AAs from PFS and herbal products as compared to the DNA adduct levels reported for the Belgian patients with Aristolochic Acid Nephropathy (AAN) and urothelial carcinoma in some patients [7, 40]. This outcome reveals that exposure to AAs from some PFS and herbal products are at the same range of AAs to which Belgian patients were exposed.

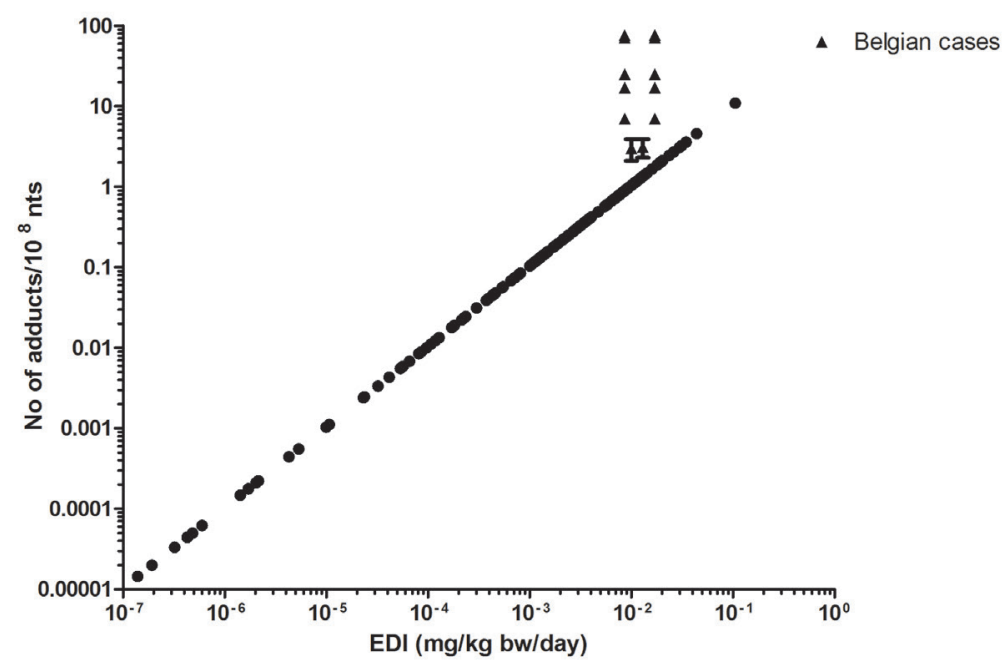

Figure 6.4 Comparison of PBK modeling-based reverse dosimetry predicted DNA adduct formation based on the estimated daily intake ( $\mathrm{mg} / \mathrm{kg}$ bw/day) of AAs from PFS and herbal products from this thesis and obtained from literature (Chapter 5) (filled circles) and detected in the kidneys of Belgian patients with Aristolochic Acid Nephropathy (filled triangles). 
It is also important to note that for risk assessment purpose reliable in vivo data are required. However, in this present study, it was shown that the in vivo data for especially DNA adduct formation by AAs deviate by more than 3 orders of magnitude at similar AA exposure levels. The factors that may contribute to these large differences may be due to the different methods used for analysis (32P-postlabeling vs LC-MS), the use of AAI and AAll in mixtures vs pure AAI or AAll, the exposure duration and variability in AA-adduct quantification and definition of calibration curves given the fact that the respective DNA adducts have to be chemically synthesized by a method with only limited yields [41]. In spite of all these uncertainties for the in vivo dose-response data predicted using in vitro-PBK modeling based reverse dosimetry, the uncertainty level was shown to be smaller than differences emerging from the comparison of different in vivo studies, which further supports that the in vitro-PBK model based approach may provide a reliable method to be used in risk assessment practice.

\subsubsection{Future perspectives.}

The ultimate goal of the development of in vitro PBK modeling-based reverse dosimetry is to replace animal testing in risk assessment in the near future.

One factor that needs future consideration before this in vitro PBK modeling-based reverse dosimetry approach for predicting PODs can be applied in the risk assessment relates to the question of whether use of the approach would need extra uncertainty factors. An additional uncertainty factor may be needed depending on the in vitro toxicity assay selected for studying the toxicity. In current risk assessment practice, an uncertainty factor of 10 is used to account for interspecies differences. This factor consists of a factor of 4.0 for species differences in kinetics and 2.5 for species differences in dynamics [42]. When using a human PBK model for making the in vitro-PBK model based reverse dosimetry predictions the factor of 4 for interspecies differences in kinetics could be eliminated. When using an adequate human in vitro model also the interspecies factor of 2.5 for differences in toxicodynamics may be redundant. This would leave the uncertainty factor of 10 for interindividual differences and leave room for introduction of perhaps an additional uncertainty factor to take into account the uncertainties of the combined in vitro-PBK modeling approach. To actually provide the basis for such a definition of default uncertainty factors generation of far more proofs of principle for different endpoints and target organs might be essential to define the in vitro-PBK model approach related uncertainties to a further extent. 
Another factor that needs further future investigation is the difference in toxic potency between AAI and AAll which turned out to be different in vitro as compared to the in vivo situation (Chapter 4). Also the possible difference in the stability and mutagenic potency of the different DNA adducts is of interest.

A next question that is of interest is how many years it might take to implement this in vitro-PBK model based method to replace animal testing in risk assessment? This is a difficult question to answer because at present, in vivo data are still considered as the 'gold standard' for the identification of toxicity. In order to apply the outcome from the in vitro PBK modeling-based reverse dosimetry approach in (regulatory) decision-making, more data from diverse chemicals and toxicity endpoints should be gathered and evaluated. When doing so especially development of an adequate in vitro assay to detect non-genotoxic carcinogenicity will be required as well, which presents a huge challenge in itself.

\subsection{CONCLUSIONS}

This thesis presents an alternative approach for defining dose-response curves in risk assessment without the use of in vivo animal testing. Combining in vitro toxicity data with kinetic processes described in a PBK model is a promising approach to contribute to alternatives for animal testing in toxicity assessment. This thesis has demonstrated that the combined in vitro PBK modeling-based reverse dosimetry approach adequately predicted the in vivo nephrotoxicity and can also predict the in vivo kidney DNA adduct formation of AAs as model compounds. The results obtained revealed the possibility of this combined in vitro-in silico approach to determine a POD for a chemical and solving the problem of how to use in vitro data for risk assessment. In addition, this thesis illustrated that AAs are still present in PFS and herbal products available in the market even after several years of the installment of legal restrictions, and that AAs can even be present at levels that indicate a priority for risk management actions especially for people who frequently use the respective PFS and herbal products. Altogether, this thesis provided further support for the use of in vitro-in silico based alternative tools for risk assessment practice studying effects on the kidney as a novel endpoint and using model compounds not included in the approach so far. 


\section{References}

1. Louisse, J., E. de Jong, J.J. van de Sandt, B.J. Blaauboer, R.A. Woutersen, A.H. Piersma, I.M.C.M. Rietjens, and M. Verwei, The use of in vitro toxicity data and physiologically based kinetic modeling to predict dose-response curves for in vivo developmental toxicity of glycol ethers in rat and man. Toxicological Sciences, 2010. 118(2): p. 470-484.

2. Louisse, J., S. Bosgra, B.J. Blaauboer, I.M.C.M. Rietjens, and M. Verwei, Prediction of in vivo developmental toxicity of all-trans-retinoic acid based on in vitro toxicity data and in silico physiologically based kinetic modeling. Archives of Toxicology, 2015. 89(7): p. 1135-1148.

3. Strikwold, M., B. Spenkelink, R.A. Woutersen, I.M.C.M. Rietjens, and A. Punt, Combining in vitro embryotoxicity data with physiologically based kinetic (PBK) modelling to define in vivo doseresponse curves for developmental toxicity of phenol in rat and human. Archives of Toxicology, 2013. 87(9): p. 1709-1723.

4. Martena, M.J., J.C. van der Wielen, L.F. van de Laak, E.J. Konings, H.N. de Groot, and I.M.C.M. Rietjens, Enforcement of the ban on aristolochic acids in Chinese traditional herbal preparations on the Dutch market. Analytical and bioanalytical chemistry, 2007. 389(1): p. 263-275.

5. Lee, T.-Y., M.-L. Wu, J.-F. Deng, and D.-F. Hwang, High-performance liquid chromatographic determination for aristolochic acid in medicinal plants and slimming products. Journal of Chromatography B, 2001. 766(1): p. 169-174.

6. Xu, Y.-Q., X.-W. Li, G.-X. Liu, X. Wang, M.-Y. Shang, X.-M. Li, and S.-Q. Cai, Comparative study of the contents of analogues of aristolochic acid in two kinds of Aristolochiae Fructus by high-performance liquid chromatography. Journal of natural medicines, 2013. 67(1): p. 113-122.

7. Bieler, C.A., M. Stiborova, M. Wiessler, J.-P. Cosyns, C.v.Y. de Strihou, and H.H. Schmeiser, ${ }^{32}$ P-post-labelling analysis of DNA adducts formed by aristolochic acid in tissues from patients with Chinese herbs nephropathy. Carcinogenesis, 1997. 18(5): p. 1063-1067.

8. $\quad$ Arlt, V.M., M. Stiborová, J. vom Brocke, M.L. Simoes, G.M. Lord, J.L. Nortier, M. Hollstein, D.H. Phillips, and H.H. Schmeiser, Aristolochic acid mutagenesis: molecular clues to the aetiology of Balkan endemic nephropathy-associated urothelial cancer. Carcinogenesis, 2007. 28(11): p. 2253-2261.

9. FDA, Aristolochic Acid: FDA Warns Consumers to Discontinue Use of Botanical Products that Contain Aristolochic Acid. 2001.

10. IARC, IARC Monographs on the Evaluation of Carcinogenic Risks to Humans. 2002, World Health Organization. p. 68-128.

11. EMEA, The European agency for the evaluation of medicinal products, position paper on the risks associated with the use of herbal products containing Aristolochia species. 2000. p. 1-10.

12. Chan, W., K.C. Lee, N. Liu, and Z. Cai, A sensitivity enhanced high-performance liquid chromatography fluorescence method for the detection of nephrotoxic and carcinogenic aristolochic acid in herbal medicines. Journal of Chromatography A, 2007. 1164(1): p. 113-119.

13. Hashimoto, K., M. Higuchi, B. Makino, I. Sakakibara, M. Kubo, Y. Komatsu, M. Maruno, and M. Okada, Quantitative analysis of aristolochic acids, toxic compounds, contained in some medicinal plants. Journal of Ethnopharmacology, 1999. 64(2): p. 185-189.

14. Schaneberg, B. and I. Khan, Analysis of products suspected of containing Aristolochia or Asarum species. Journal of Ethnopharmacology, 2004. 94(2): p. 245-249.

15. Vaclavik, L., A.J. Krynitsky, and J.I. Rader, Quantification of aristolochic acids I and II in herbal dietary supplements by ultra-high-performance liquid chromatography-multistage fragmentation mass spectrometry. Food Additives \& Contaminants: Part A, 2014. 31(5): p. 784-791.

16. Hull, R., W. Cherry, and G. Weaver, The origin and characteristics of a pig kidney cell strain, LLC-PK1. In vitro, 1976. 12(10): p. 670-677.

17. Gstraunthaler, G., W. Pfaller, and P. Kotanko, Biochemical characterization of renal epithelial cell cultures (LLC-PK1 and MDCK). American Journal of Physiology: Renal Pgysiology, 1985. 248(4): $p$. F536-F544.

18. Lebeau, C., F.D. Debelle, V.M. Arlt, A. Pozdzik, E.G. De Prez, D.H. Phillips, M.M. DeschodtLanckman, J.-L. Vanherweghem, and J.L. Nortier, Early proximal tubule injury in experimental aristolochic acid nephropathy: functional and histological studies. Nephrology Dialysis Transplantation, 
2005. 20(11): p. 2321-2332.

19. Huljic, S., E.I. Bruske, N. Pfitzenmaier, E. O'Brien, and D.R. Dietrich, Species-specific toxicity of aristolochic acid (AA) in vitro. Toxicology in Vitro, 2008. 22(5): p. 1213-1221.

20. Abdullah, R., W. Alhusainy, J. Woutersen, I.M.C.M. Rietjens, and A. Punt, Predicting points of departure for risk assessment based on in vitro cytotoxicity data and physiologically based kinetic (PBK) modeling: the case of kidney toxicity induced by aristolochic acid I. Food and Chemical Toxicology, 2016. 92: p. 104-116.

21. Dickman, K.G., D.H. Sweet, R. Bonala, T. Ray, and A. Wu, Physiological and molecular characterization of aristolochic acid transport by the kidney. Journal of Pharmacology and Experimental Therapeutics, 2011. 338(2): p. 588-597.

22. Scotcher, D., C. Jones, M. Posada, A. Rostami-Hodjegan, and A. Galetin, Key to Opening Kidney for In Vitro-In Vivo Extrapolation Entrance in Health and Disease: Part I: In Vitro Systems and Physiological Data. The AAPS Journal, 2016. 18(5): p. 1067-1081.

23. Wilmer, M.J., C.P. Ng, H.L. Lanz, P. Vulto, L. Suter-Dick, and R. Masereeuw, Kidney-on-a-chip technology for drug-induced nephrotoxicity screening. Trends in Biotechnology, 2016. 34(2): p. 156170.

24. Kramer, N.I., M. Krismartina, A.n. Rico-Rico, B.J. Blaauboer, and J.L. Hermens, Quantifying processes determining the free concentration of phenanthrene in basal cytotoxicity assays. Chemical Research in Toxicology, 2012. 25(2): p. 436-445.

25. Groothuis, F.A., M.B. Heringa, B. Nicol, J.L. Hermens, B.J. Blaauboer, and N.I. Kramer, Dose metric considerations in in vitro assays to improve quantitative in vitro-in vivo dose extrapolations. Toxicology, 2015. 332: p. 30-40.

26. Gülden, M., S. Mörchel, and H. Seibert, Factors influencing nominal effective concentrations of chemical compounds in vitro: cell concentration. Toxicology in Vitro, 2001. 15(3): p. 233-243.

27. Gülden, M., A. Jess, J. Kammann, E. Maser, and H. Seibert, Cytotoxic potency of $\mathrm{H}_{2} \mathrm{O}_{2}$ in cell cultures: impact of cell concentration and exposure time. Free Radical Biology and Medicine, 2010. 49(8): p. 1298-1305.

28. Gülden, M. and H. Seibert, In vitro-in vivo extrapolation: estimation of human serum concentrations of chemicals equivalent to cytotoxic concentrations in vitro. Toxicology, 2003. 189(3): $p$. 211-222.

29. Kramer, N.I., E. Di Consiglio, B.J. Blaauboer, and E. Testai, Biokinetics in repeated-dosing in vitro drug toxicity studies. Toxicology in Vitro, 2015. 30(1): p. 217-224.

30. Daston, G.P., R.E. Chapin, A.R. Scialli, A.H. Piersma, E.W. Carney, J.M. Rogers, and J.M. Friedman, A different approach to validating screening assays for developmental toxicity. Birth Defects Research Part B: Developmental and Reproductive Toxicology, 2010. 89(6): p. 526-530.

31. Neumann, H.-G., The role of DNA damage in chemical carcinogenesis of aromatic amines. Journal of Cancer Research and Clinical Oncology, 1986. 112(2): p. 100-106.

32. Eaton, D.L. and E.P. Gallagher, Mechanisms of aflatoxin carcinogenesis. Annual Review of Pharmacology and Toxicology, 1994. 34(1): p. 135-172.

33. Straif, K., R. Baan, Y. Grosse, B. Secretan, F. El Ghissassi, and V. Cogliano, Carcinogenicity of polycyclic aromatic hydrocarbons. The Lancet Oncology, 2005. 6(12): p. 931-932.

34. Poirier, M.C. and F.A. Beland, DNA adduct measurements and tumor incidence during chronic carcinogen exposure in animal models: implications for DNA adduct-based human cancer risk assessment. Chemical Research in Toxicology, 1992. 5(6): p. 749-755.

35. Rietjens, I.M.C.M., J. Louisse, and A. Punt, Tutorial on physiologically based kinetic modeling in molecular nutrition and food research. Molecular Nutrition \& Food Research, 2011. 55(6): p. 941956.

36. EFSA, European Food Safety Authority. Opinion of the scientific committee on a request from EFSA related to a harmonised approach for risk assessment of substances which are both genotoxic and carcinogenic. EFSA Journal, 2005. 282: p. 1-31.

37. van den Berg, S.J., A. Punt, A.E. Soffers, J. Vervoort, S. Ngeleja, B. Spenkelink, and I.M.C.M Rietjens, Physiologically based kinetic models for the alkenylbenzene elemicin in rat and human and 
possible implications for risk assessment. Chemical Research in Toxicology, 2012. 25(11): p. 2352-2367. 38. Al-Malahmeh, A.J., A. Al-Ajlouni, S. Wesseling, A.E. Soffers, R. Kiwamoto, J. Vervoort, and I.M.C.M. Rietjens, Physiologically based kinetic modeling of the bioactivation of myristicin. Archives of Toxicology, 2016: p. 1-22.

39. Alajlouni, A.M., A.J. Al-Malahmeh, R. Kiwamoto, S. Wesseling, A.E. Soffers, A.A. Al-Subeihi, J. Vervoort, and I.M.C.M. Rietjens, Mode of action based risk assessment of the botanical food-borne alkenylbenzene apiol from parsley using physiologically based kinetic (PBK) modelling and read-across from safrole. Food and Chemical Toxicology, 2016. 89: p. 138-150.

40. Nortier, J.L., M.-C.M. Martinez, H.H. Schmeiser, V.M. Arlt, C.A. Bieler, M. Petein, M.F. Depierreux, L. De Pauw, D. Abramowicz, P. Vereerstraeten, and J.-L. Vanherweghem, Urothelial carcinoma associated with the use of a Chinese herb (Aristolochia fangchi). The New England Journal of Medicine, 2000. 342(23): p. 1686-1692.

41. Yun, B.H., T.A. Rosenquist, V. Sidorenko, C.R. Iden, C.-H. Chen, Y.-S. Pu, R. Bonala, F. Johnson, K.G. Dickman, and A.P. Grollman, Biomonitoring of aristolactam-DNA adducts in human tissues using ultra-performance liquid chromatography/ion-trap mass spectrometry. Chemical Research in Toxicology, 2012. 25(5): p. 1119-1131.

42. Renwick, A., Data-derived safety factors for the evaluation of food additives and environmental contaminants. Food additives \& contaminants, 1993. 10(3): p. 275-305. 


\section{CHAPTER}

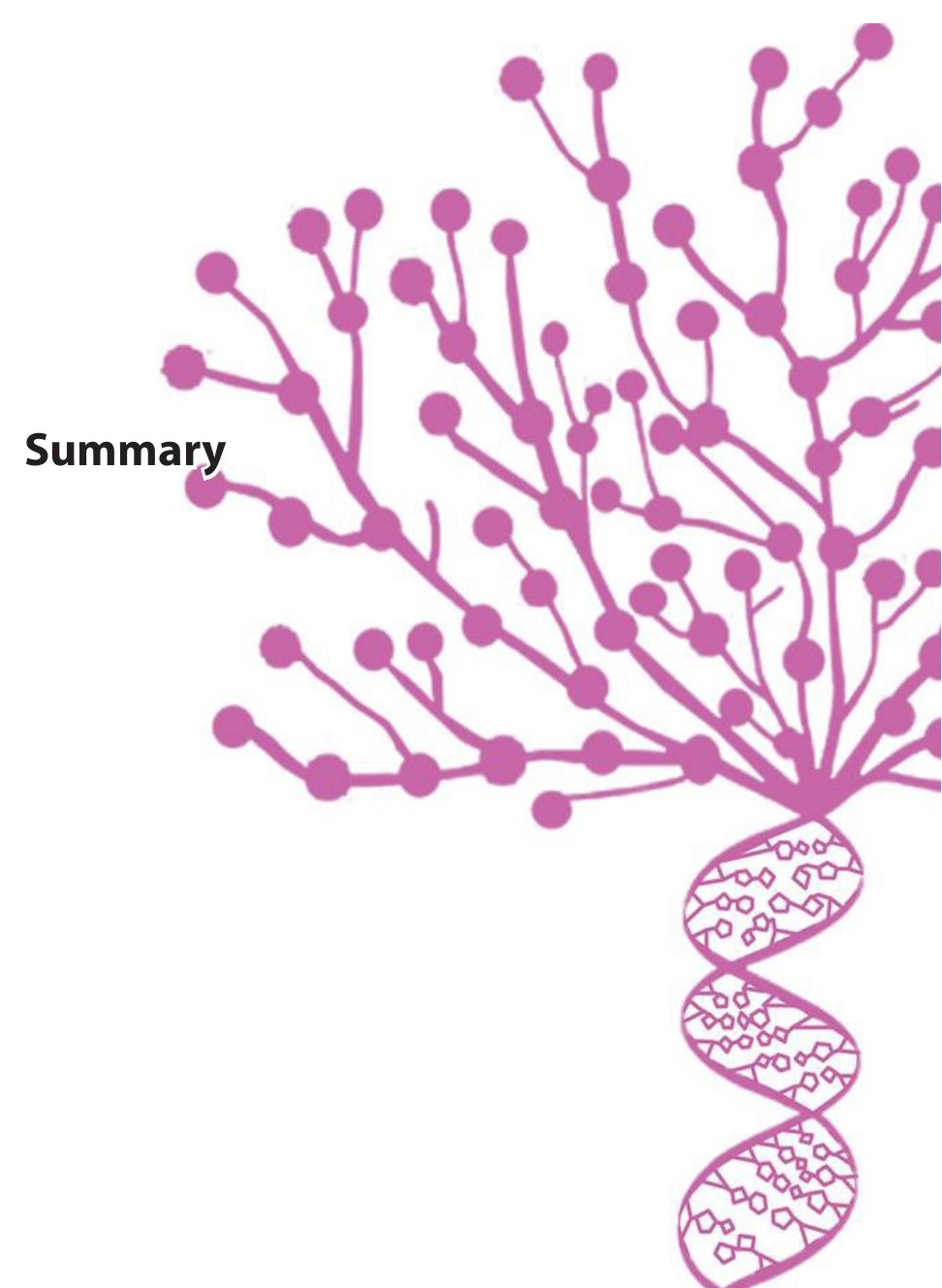




\section{SUMMARY}

This $\mathrm{PhD}$ thesis aimed to provide additional evidence to demonstrate the potential of an integrated testing strategy using in vitro assays with physiologically based kinetic (PBK) modeling basedreverse dosimetry to predict in vivo toxicity without animal testing. Kidney toxicity was chosen as the toxicity endpoint and aristolochic acids (AAs) were selected as model chemicals. AAs are natural nephrotoxic, genotoxic and carcinogenic chemicals present in Aristolochia species. PBK models for rat, mouse and human were developed for aristolochic acid I (AAI) based on kinetic parameter values derived from in vitro incubations using relevant tissue fractions. Then, in vitro concentrationresponse curves for cytotoxicity of AAI were obtained in kidney cell lines and translated to in vivo dose-response curves for kidney toxicity using PBK modeling-based reverse dosimetry. The points of departure (PODs) obtained from these predicted in vivo dose-response curves generally fell within the range of PODs derived from in vivo literature data on kidney toxicity of AAI. The same PBK models were subsequently used to translate the in vitro concentration-response curves for AAI-DNA adduct formation to in vivo dose-response curves for kidney AAI-DNA adduct formation. The predicted in vivo AAI-DNA adduct formation in the rat, mouse and human kidney varied within an order of magnitude compared to the in vivo values reported in the literature. The PBK models were also used to predict the dose level that would be required in humans to obtain the level of DNA adducts in rats at the $\mathrm{BMD}_{10}$ (the benchmark dose causing a $10 \%$ extra risk above background level) value for AAl-induced tumor formation in the rat kidney. This analysis revealed that the dose level required to induce the level of DNA adduct formation that equals the DNA adduct level at the $B_{10}$ were similar to AA doses estimated to be taken in Belgian patients that developed urinary tract cancer. Given that the exposure to AAl is often accompanied by the presence of AAll, in a next study the relative formation of DNA adducts by these two major AA congeners was investigated. The results revealed that the relative higher formation of AAI-DNA adducts as compared to AAll-DNA adducts observed in vitro was not reflected in vivo where the levels formed upon exposure to equal dose levels were relatively similar. PBK model based translation of the in vitro data to the in vivo situation revealed that PBK model based prediction of in vivo DNA adduct formation is feasible. However, predicted AAI-DNA adduct levels were higher than predicted AAll-DNA adduct levels, indicating that the difference between the in vitro and in vivo AAI-/AAll-DNA adduct ratios could only in part be explained by differences in in vivo kinetics of AAI compared to AAll. The discrepancy between the difference in DNA adduct formation of AAI and AAll in the in vitro and the in vivo situation is an 
issue that needs further investigation to also adequately predict the relative differences between the two AAs. In a final chapter this thesis aimed to investigate the possible risks associated with exposure to AAs based on AA levels measured in plant food supplements (PFS) and herbal products. This is of interest given the restrictions on the presence of AAs in food, installed in various countries including The Netherlands, after the incidences with induction of Aristolochic Acid Nephropathy upon use of herbal weight loss preparations that accidentally contained AAs. The risk assessment of PFS and herbal products containing AAs purchased via online markets revealed that consumers can still be exposed to AA-containing PFS and herbal products and that the corresponding levels of exposure raise concern especially for people who frequently use the products. Altogether, this thesis presented further support for the use of combined in vitro-PBK modeling based alternative tools for risk assessment and revealed the continued risks posed by AAs present in PFS and herbal products. 



\section{Appendices}
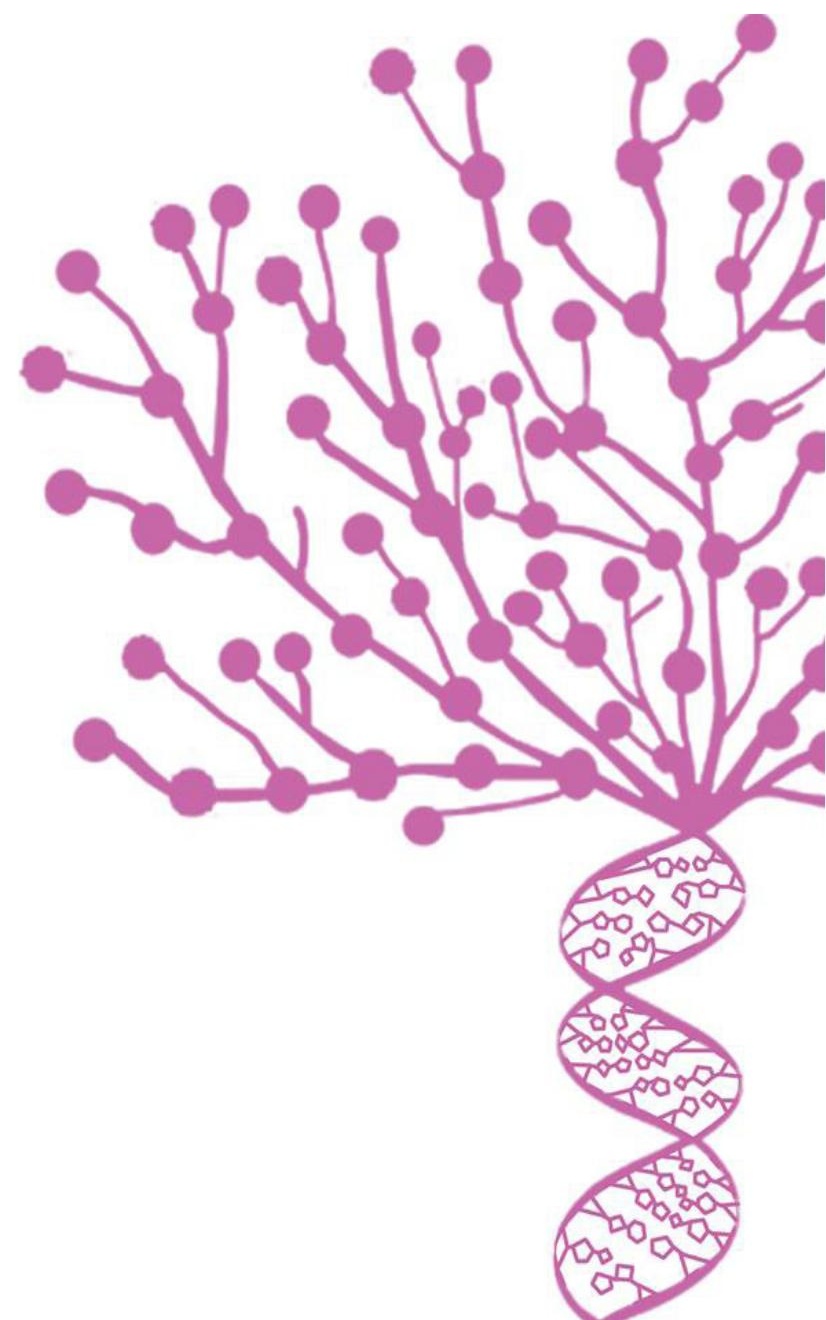


\section{Ackowledgements}

It is never easy to make a successful completion of PhD. There are many people to whom I am most grateful for their kindness in helping and inspiring me throughout my $\mathrm{PhD}$ journey.

Firstly, I would like to acknowledge my efficient promotor, Ivonne Rietjens, whom I admire a lot. I still remember, in 2012, when I started to find the place for my doctoral study and I approached you based on my interest in Food Toxicology. Without knowing who I am, my attitude and how I work, you accepted me to be one of your students. Then, my journey started in this wonderful department. Ivonne, you knew that the last stretch of PhD was the most difficult part in my PhD journey. Thank you for passing by my office, advising me to keep calm and be away from panic attack due to limited time left. Lessons learnt for myself in these years are to make decisions by myself, be more critical on the finding of my research and the most important message is:'A good teacher is not the one who teaches you how to think like him/her but a good teacher is teaching you how to think without him/her'; so I am doing my best to be an independent researcher and a good teacher. I cannot thank you enough for your continued support, training and guidance over the past four years.

I would like to express special gratitude to Wasma Alhusainy (post-doc) and Ans Punt (copromotor). Wasma, I am indebted with you, for all your knowledge and guidance during my first few months in this department. Also my thanks go to Ans for her knowledge in computer modeling and also her patience in correcting my scientific manuscripts. Without the help from two gentlemen in the department; Bert Spenkelink and Sebas Wesseling (later appointed to be my co-promotor), I don't think I would have been able to finish my experiments on time. I will always remember our 'good' time especially before my progress meetings and the smile with the 'give-me-five' hands after the meeting, I am so thankful to have both of you in my project. You cheered up my life! My special thanks go to Jochem Louisse for being part of my supervisory committee and helping me during the final stage of my journey. Thank you so much for not giving up with my project although it was quite a challenge. To Lidy, Irene, and Gre, thank you for helping me out with the administrative things that ease my life in here. Also thanks to Laura, Hans, Nico, Letty and Ans Soffers for the technical support and great talks that we've had together.

I would like to sincerely thank my dear friends in Tox family. Rung, thank you for being an incredibly understanding friend and my best partner-in-crime. Thank you for lending me your ears 
when I needed it and always being honest with me. We shared many things together especially in photography and enjoying the Korean series. Dear big brother, Nacho. The journey to your dreams always starts from within! You know well your Achilles' heel (you know mine too!) and let's work smart for that! Stop overthinking of everything, get up and finish what you started! To my dear Sudanese sister; Aziza, I would like to thank you for teaching me the wisdom of life, we support each other no matter what, joining us to run even though you do not enjoy it that much and thank you so much for all the laugh that we had together. I am going to miss your cream caramel! From the bottom of my heart, I love you guys! To all my colleagues in Toxicology; Abdul, Amir, Arif, Arthem, Ashraf, Barae, Diana, Diego, Eryana, Georgia, Hequn, Jia, Jonathan, Justine, Karsten, Lenny, Lu, Marcia, Marta, Mebra, Mengying, Myrthe, Myrto, Reiko, Samantha, Shuo, Suparmi; thank you for all the good time when doing science together, during sports day, lab trip, PhD trip, Walibi trip, skydiving trip in Texel and all the fun activities together, I am so blessed to have all of you during my PhD days. With the good atmosphere in our 'cute' department, I am able to work and enjoy this journey. It's not only about lab, it's about fraternity! I would like to thanks my MSc students for their interest and contributions to my project; Ester, Stefania, Jasper, Chioma, Lu, Chunyang, Nyle, Ixchel, Vincent, Fang and Yanit.

To my dear prof-to-be friends; K.Huda, K.Salma, K.Nia, K.Husna, K.Yati, K.Hana, K.Aina, K.Ein, K.Fatin, K.Niza, Shira and Nor that started their PhD journey about the same time with me at different parts of the world, I am thankful to have all of you. WhatsApps connected us; we encourage each other, sharing things especially to overcome our feeling from being apart from our family, sharing jokes and motivate each other. Not to forget, my dear Sarz, my (another) best partner-incrime during traveling, it was a pleasure to travel around the world with you and make my life more exciting! Our mission continues in Malaysia okay!

To my dearest Malaysian friends in Wageningen, especially K.huda and K.su; you are always close to my heart. Thanks for the heart-talk sessions and for being a real friend that I can trust. My dearest warge-wage, K.Yani, Due, Naim, K.Fatimah, Razak, K.Nozie, K.Izan, Ameen, K.Tihah, Aidil, K.Nuyu, Hafeez, K.Huda R, K.Shikin, Sharul, Azie, Shak, Siew Ling, Loo Wee, Zul, Lini, Nazri, Pao, Shol, K.Shifa, ZulW, K.Farhana, Mus, K.Yati, and Hafiz, thank you for the help, the foods and sweet memories together. I also would like to thank the Malaysian Students' Association in The Netherlands (MAS-NL) for giving me the opportunity to be one of the executive committee member in this association. Special thanks go to Sharil, Adib, Yon and Syahir for all the efforts and brainstorming sessions. I hope that the establishment of this association, will give a platform to all Malaysian students' in the 
Netherlands to gather, to move forward and to serve as a support group to Malaysian living abroad. The most important persons throughout my PhD years, Mak and Abah, thank you for all your constant supports, endless love and du'a. Without your believe in me, I don't think I would have been able to achieve this success. This degree is for both of you. I want to thank you for raising me for who I am today. To all my siblings, Along, Helmi, Shikin, Nizam, Nurul and Athira, thanks for all your support and for always being there with our parents. To all my nieces and nephews, Wafiy, Zara, Zharif, Hasya, Chempaka and Arjuna, I always miss you! I will always remember when Wafiy screamed loudly; Cik Nyah, don't cry ok! at the airport when sending me back to The Netherlands. Cik Nyah is always strong, don't worry!

Last but not least, to the Ministry of Education of Malaysia and Universiti Putra Malaysia, thanks for all the financial support for all these years. I will be back to Malaysia, serve the country and be a great contributor for my nation. Head-up Malaysian!

'Verily, with the hardship, there is relief' (Qur'an 94:6). I am blessed!

Rozaini binti Abdullah

March 2017, Wageningen 


\section{Curriculum Vitae}

Rozaini Abdullah was born in Kuala Lumpur, Malaysia on August $28^{\text {th }}, 1986$. She attended pre-university education in Melaka, Malaysia. In 2009, she received a Bachelor in Environmental Health with Honours from The National University of Malaysia, Kuala Lumpur. She published her first scientific paper on evaluation of mutagenic and anti-mutagenic activities of Mytragyna Speciosa Korth during her final year of undergraduate. She developed a specific interest in toxicology, which led her to undertake for

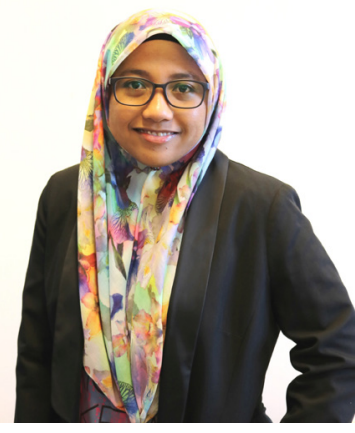
Master in the same university. Her research explores on assessment of shrimp paste dietary intake and its association with toxicological genetic profile and supervised by three dedicated mentors, Dr A.R Ghazali, Dr N.F Rajab and Prof. Dr S. Shahar. While doing her master's study, she already secure a position as a tutor at Universiti Putra Malaysia. After successfully completing her Master's degree in 2012, she is funded by Ministry of Education, Malaysia to continue her doctoral study in Toxicology under supervision of Prof. Dr Ivonne M.C.M Rietjens. When not pursuit of her academic path, Rozaini actively participated in Malaysian Students Association and she has been appointed as the Vice President of the association from 2014 to 2015. Alongside of her PhD research, she followed a highly ambitious postgraduate training and education in toxicology that enabled her to register as a European Toxicologist. After completing her doctoral study, she will return to her homeland of Malaysia for an academic position in the Department of Environmental and Occupational Health, Faculty of Medicine and Health Sciences at Universiti Putra Malaysia. 


\section{List of Publications}

\section{Peer reviewed publications}

Abdullah, R., Alhusainy, W., Woutersen, J., Rietjens, I.M.C.M., Punt, A., 2016. Predicting points of departure for risk assessment based on in vitro cytotoxicity data and physiologically based kinetic (PBK) modeling: the case of kidney toxicity induced by aristolochic acid I. Food and Chemical Toxicology 92: 104-116.

Abdullah, R., Diaz, L.N., Wesseling, S., Rietjens, I.M.C.M., 2017. Risk assessment of plant food supplements and other herbal products containing aristolochic acids using Margin of Exposure (MOE) approach. Food Additives and Contaminants: Part A 34(2): 135-144.

Abdullah, R., Wesseling, S., Spenkelink, B., Louisse, J., Punt, A., Rietjens, I.M.C.M., Defining in vivo dose-response curves for kidney DNA adduct formation of aristolochic acid I in rat, mouse and human by an in vitro and physiologically based kinetic modeling approach. Submitted.

Abdullah, R., Wesseling, S., Spenkelink, B., Rietjens, I.M.C.M., Louisse, J. Prediction of in vivo DNA adduct formation upon exposure to aristolochic acid I and II using a combined in vitro-physiologically based kinetic modeling approach. In preparation.

\section{Abstracts/conference proceedings}

Abdullah, R., Alhusainy, W., Rietjens, I.M.C.M., Punt, A., 2015. Prediction of in vivo nephrotoxicity using an in vitro-in silico approach: the case of aristolochic acid I. Toxicology Letters 238: S94.

Abdullah, R.,Wesseling, S., Spenkelink, B., Louisse, J., Punt, A., Rietjens, I.M.C.M., 2016. Prediction of kidney DNA binding using an in vitro-in silico approach: the case of aristolochic acid I. In: Annual meeting of the Dutch Society of Toxicology (NVT).

Abdullah, R..Wesseling, S., Spenkelink, B., Louisse, J. Rietjens, I.M.C.M., 2017. Combining in vitro data and physiologically based kinetic (PBK) modelling to obtain insights in the discrepancy between the relative levels of in vitro and in vivo kidney DNA adduct formation by aristolochic acid I and II. In: The Society of Toxicology $56^{\text {th }}$ Annual Meeting. 


\section{Overview of Completed Training Activities}

\section{Discipline specific courses}

Pathobiology, Postdoctoral Education of Toxicology (PET) (2014)

Occupational Toxicology, PET (2014)

Organ Toxicology, PET (2014)

Laboratory Animal Science, PET (2014)

Ecotoxicology, PET (2014)

Mutagenesis and Carcinogenesis, PET (2015)

Molecular Toxicology, PET (2015)

Legal and Regulatory Toxicology, PET (2016)

\section{Meetings}

$51^{\text {st }}$ Congress of the European Society of Toxicology (EUROTOX), Porto, Portugal (2015) (poster presentation)

Dutch Society of Toxicology (NVT) annual meeting, Zeist, The Netherlands (2016) (oral presentation) The Society of Toxicology $56^{\text {th }}$ Annual Meeting and ToxExpo, Baltimore, Maryland, USA (2017) (poster presentation)

\section{General courses}

Technique for Writing and Presenting a Scientific Paper, Wageningen Graduate Schools (WGS) (2013)

Data Management, WGS (2013)

VLAG PhD week, VLAG (2014)

Philosophy and ethics of food science and technology, VLAG (2014)

Reviewing a Scientific Paper, WGS (2014)

Peer PhD Consultation- as support in academic skills development, VLAG (2014)

Lecturing, University Teaching Qualification (2015)

Brain training, WGS (2015)

\section{Optional}

Preparation Research Proposal

Attending scientific presentations, Division of Toxicology Wageningen University (2013-2017)

PhD excursion to United Kingdom, Division of Toxicology Wageningen University (2013)

Food Toxicology (MSc course), Wageningen University (2014)

Food Safety Risk Assessment (MSc course), Wageningen University (2014)

\section{Approved by Graduate School VLAG}


The research described in this thesis was financially supported by the Ministry of Education of Malaysia (Project number- KPT (BS) 860828565598).

Financial support from Wageningen University \& Research for printing the thesis is gratefully acknowledged.

Cover \& layout design: Azrol Kassim \& Rozaini Abdullah

Printed by: Digiforce, Vianen | www.proefschriftmaken.nl 